\section{Mensaje de Bienvenida}

\author{
QFB. Elizabeth Guzmán Vázquez
}

Miembros de las Asociación, Colegas Congresistas y Compañeros de las Casas Comerciales y Miembros de la Mesa Directiva:

Bienvenidos a este XVIII Congreso de la Asociación Mexicana de Medicina Transfusional A.C.

Es para mí un honor reiniciar las actividades de nuestros congresos; en esta ocasión vía virtual, dadas las condiciones actuales en nuestro país, derivadas de la epidemia de COVID-19 y con la finalidad de preservar la seguridad de todos en estos momentos.

Ha sido un año muy difícil desde que asumí la presidencia de la asociación, lleno de muchos retos: el principal fue aceptar las pérdidas de personas muy queridas y allegadas a la asociación, compañeros nuestros con los que compartimos momentos increíbles en diferentes momentos laborales o de convivencia en nuestras reuniones anuales. Los extrañaremos por siempre.

También ha sido un gran reto modificar nuestra forma tradicional de comunicación, ahora a través de vía remota y aprender a usar estos nuevos recursos, logrando así continuar con el Diplomado de Medicina Transfusional en línea con la participación de 50 alumnos, y ahora llegar a este día de la inauguración de nuestro congreso con un programa muy parecido a nuestro formato tradicional, esto ha significado un trabajo arduo de todo mi equipo de trabajo: preparar un congreso que reúne múltiples tópicos de actualidad de la Medicina Transfusional; destacar la continuidad de los Talleres en Línea, además de la participación de la investigación en modo cartel y oral.

Los temas en nuestro Congreso serán muy variados y esperamos que los mismos sean de su interés. Entre los nuevos tópicos relacionados con COVID-19, destacan el uso hemático del paciente, el manejo transfusional en los extremos de la vida (Pediatría-Geriatría), así como donación altruista, hemovigilancia, gestión de calidad, inmunohematología y los avances internacionales en el campo de la transfusión en Latinoamérica.

Confluyen profesionales de varios campos de la medicina transfusional de América Latina, Europa, Estados Unidos y Canadá. Profesionales a los cuales agradecemos profundamente su apoyo y tiempo para este evento.

Asimismo, como en años anteriores, la Sociedad Internacional de Transfusión Sanguínea (ISBT) ha otorgado el aval a nuestro Congreso, ya que ha considerado que reúne los requisitos académicos adecuados, lo cual nos hace sentirnos orgullosos.

Sin más, deseo nuevamente que este Congreso cumpla con sus expectativas y que sea una nueva experiencia que nos deje conocimiento y enriquezca nuestro trabajo cotidiano.

Agradecemos nuevamente la cooperación de nuestros profesores invitados, el apoyo de las Casas Comerciales que han creído en nosotros en este proyecto, ya que sabemos que también han sido tiempos difíciles para ellos y que esta manera virtual no es tan rentable como un evento presencial y, sobre todo, a ustedes Congresistas por estar con nosotros en este nuevo proyecto.

Miércoles 29 de septiembre de 2021.

Correspondencia:

QFB. Elizabeth Guzmán Vázquez

Presidenta de la Asociación Mexicana

de Medicina Transfusional A.C.

Gestión 2020-2022

E-mail: lizguzvaz@yahoo.com.mx 


\section{Resúmenes de Trabajos Libres del XVIII Congreso, 2021, de la Asociación Mexicana de Medicina Transfusional, A.C.}

C1. Plasmaféresis en pacientes hospitalizados en el Occidente de México. Etiología, seguridad y resultado clínico

Gutiérrez Alatorre Aldo Fernando Adrián,* De la Mora López Patricia A, ${ }^{\ddagger}$ Bea Zúñiga Alejandra, $\$$ Martínez Pinedo Alba Yesenia, ${ }^{\S}$ Baltazar Martínez Angela Yanet $^{\S}$

* Médico Hematólogo, Coordinación de Capacitación y Enseñanza. Centro Estatal de la Transfusión Sanguínea Jalisco. ₹ Directora del Centro Estatal de la Transfusión Sanguínea J alisco. ${ }^{\S}$ Enfermera encargada de Sangrado y Procesos Terapéuticos. Centro Estatal de la Transfusión Sanguínea Jalisco.

Introducción: Desde que la aféresis terapéutica se instauró en la década de los 70 hasta el día de hoy, se han beneficiado una gran cantidad de pacientes que sin esta intervención probablemente estarían muertos. ${ }^{1}$ Debido al beneficio teórico de la aféresis en múltiples enfermedades con un componente inmune y/o metabólico, se debió establecer categorías e indicaciones precisas para este método basados en la efectividad documentada en dichas enfermedades. ${ }^{2}$ Actualmente, se necesita continuar con el estudio de la efectividad de la aféresis terapéutica en un contexto de nuevas terapias que pueden reforzar o relevar el uso de ésta y reevaluar constantemente qué enfermedades continúan siendo subsidiarias de este procedimiento, cuáles no y en cuáles la nueva instauración puede mejorar el desenlace de la misma. Objetivo: Describir de la totalidad de las plasmaféresis terapéuticas realizadas de 2016 al 2021 efectuadas por el CETS Jalisco, los datos demográficos de la población, tratamiento coadyuvante, reacciones adversas y desenlace clínico del paciente. Material y métodos: Se realizó un análisis retrospectivo de los registros de plasmaféresis del CETS Jalisco del $01 / 01 / 2016$ al 01/01/2021 y los expedientes clínicos de los pacientes sometidos a la misma; se usaron medidas de tendencia central como media, mediana y moda, además de la mortalidad derivada de las patologías tratadas. Resultados: De enero de 2016 a enero de 2021 se realizaron 103 recambios plasmáticos a un total de 27 pacientes, la edad promedio fue de 31.3 años, con rango de tres a 70 años, se realizaron en promedio 3.8 recambios plasmáticos por paciente con rangos de 1 a 8, los diagnósticos en orden de frecuencia fueron: púrpura trombocito- pénica trombótica (PTT) con siete pacientes; nefritis lúpica cinco pacientes; síndrome de Guillain-Barré tres pacientes; anemia hemolítica microangiopática (sin considerarla PTT por falta de ADAMTS-13) tres pacientes; rechazo postrenal humoral y celular dos pacientes; esclerosis múltiple, enfermedad de Graves, enfermedad de Wilson, glomerulonefritis rápidamente progresiva, granulomatosis de Wegener, miastenia gravis y síndrome de anticuerpos antifosfolípido (SAAF) catastrófico: un paciente cada una, respectivamente (Figura C1.1). Se presentaron nueve reacciones adversas a la plasmaféresis de tipo vasovagal (uno por cada 11 procedimientos), todas ellas revirtiendo con la administración de carbonato de calcio vía oral, disfunción de catéter en tres pacientes (uno de ellos con sangrado del lumen, el cual requirió cambio del mismo), sin mortalidad asociada al procedimiento. Entre los medicamentos administrados más utilizados se encontró el esteroide en $48.3 \%$ de los pacientes registrados y rituximab en $25.9 \%$ (siete pacientes) (Figura C1.2). La mejoría clínica documentada se presentó en $66 \%$ de los pacientes (cuatro de 27 expedientes no estaban completos) y en el seguimiento $100 \%$ de los pacientes vivos habían mantenido respuesta al mes de inicio del tratamiento. Tres pacientes murieron por complicaciones derivadas de la enfermedad, ninguna de ellas fue imputable a

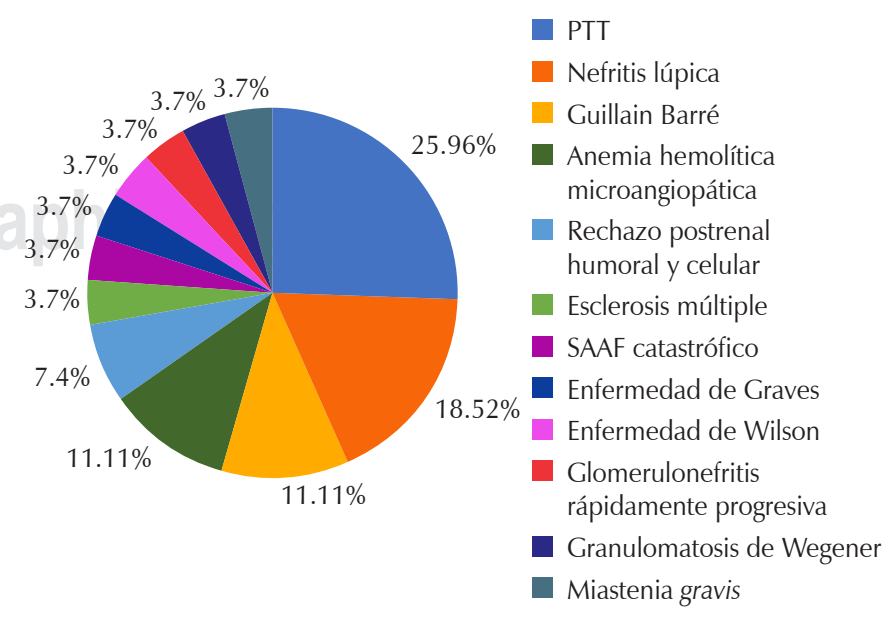

Figura C1.1: Distribución por diagnóstico. 


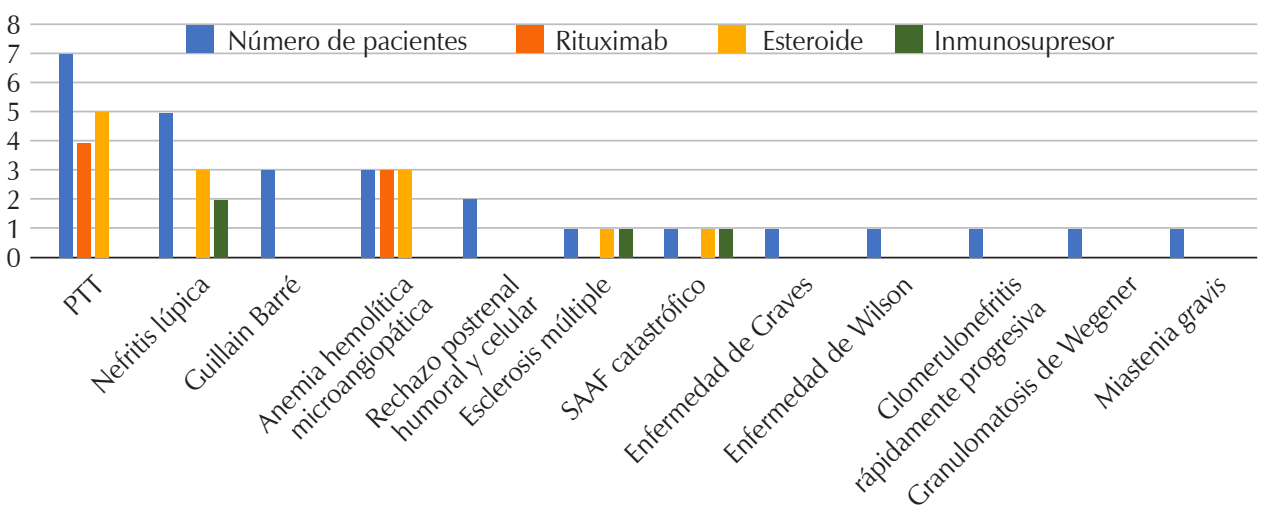

Figura C1.2:

Tratamiento coadyuvante. la plasmaféresis. Análisis: En este estudio retrospectivo se encontró que las etiologías más frecuentes subsidiarias de plasmaféresis fueron la PTT, nefritis lúpica y el síndrome de Guillain-Barré, este último sobre todo en pacientes sin recurso para el inicio de inmunoglobulina IV. Llamó la atención que no hubo diferencia en el número de recambios plasmáticos entre pacientes con uso de rituximab y sin él (el rituximab no disminuyó la cantidad de recambios); sin embargo, la valoración de más casos podría cambiar esto. Conclusiones: La plasmaféresis terapéutica es un procedimiento seguro, con un alto porcentaje de mejoría clínica que debe ser instaurado lo antes posible en sospecha de patologías beneficiadas del procedimiento. En el presente estudio no encontramos diferencia entre el número de recambios plasmáticos y el uso del rituximab, aunque la población estudiada fue pequeña. Se requiere de estudios prospectivos para analizar la efectividad en patologías en donde este procedimiento aún no se usa con universalidad, con lo cual podría mejorar la indicación de ella.

\section{Referencias}

1. Ocharan-Corcuera J. Aféresis terapéutica. Diálisis y Trasplante. 2006; 27 (2): 59-60.

2. Padmanabhan A, Connelly-Smith L, Aqui N, Balogun RA, Klingel $\mathrm{R}$, Meyer $\mathrm{E}$ et al. Guidelines on The Use Of Therapeutic Apheresis In Clinical Practice - Evidence-Based Approach From The Writing Committee Of the American Society for Apheresis: the eighth special issue. J Clin Apher. 2019; 34 (3): 171-354.

C2. Disminución en el recuento de plaquetas después de la donación de aféresis plaquetaria en el separador celular Amicus

Villalobos González Mireya Carolina,* Álvarez González Graciela, ${ }^{\ddagger}$ Moreno Ramírez Lilia Nayeli ${ }^{\ddagger}$

* Químico Farmacobióloga. Banco de Sangre Proquimed (Proquimed de León, S.C.). ‡ Técnico Laboratorista Químico. Banco de Sangre Proquimed (Proquimed de León, S.C.).

I ntroducción: Los donantes de plaquetas por aféresis pueden donar con más frecuencia que un donante de sangre total, por lo que se debe reunir los mismos criterios de donación de sangre. Sin embargo, es importante el recuento plaquetario antes de efectuar el procedimiento de plaquetaféresis sin excepción, previniendo una disminución mayor a 100,000 $\mu \mathrm{L}$ de recuento plaquetario postdonación y de esta forma no afectar al donador de plaquetas, la cuenta plaquetaria predonación debe ser mayor o igual a $150,000 / \mu \mathrm{L}$ estipulado por la NOM-253. La aféresis de plaquetas requiere que el donador esté conectado en la máquina por un lapso de 60 a 90 minutos, durante el cual de 4,000 a 5,000 litros de sangre del donador son procesados por el separador celular. La cantidad de plaquetas obtenidas depende del tipo de separador y de las características del donador (peso, número de plaquetas, etc.), por lo tanto, también en esto se basará la disminución de plaquetas en el donador. Objetivo: Demostrar la importancia del recuento plaquetario previo a la donación y saber la cantidad aproximada de disminución de plaquetas en el donador para cumplir con lo estandarizado y no afectar al donador con un recuento plaquetario menor a 100,000/ $\mu \mathrm{L}$. Material y métodos: Estudio observacional, descriptivo y cuantitativo sobre la disminución del conteo plaquetario después de una donación de aféresis en el separador celular Amicus. Resultados: Se estudió una población de 40 donadores de aféresis plaquetaria, 33 donadores masculinos y siete donadores femeninos con características de peso entre los 70 y $90 \mathrm{~kg}$, de edades entre los 22 y 40 años, todos con un conteo de plaquetas previo al procedimiento mayor a 150,000 plaquetas $/ \mu \mathrm{L}$, con una media de conteo de 283,000 plaquetas/ $\mu \mathrm{L}$ de los donadores (Tabla C2.1). Se observa una disminución de plaquetas posterior a la donación que va de las 106,000 a las 165,000 plaquetas/ $\mu$ L, con un promedio de disminución de 133,000 plaquetas/ $\mu \mathrm{L}$ (Figura C2.1), todos los donadores se programaron en el separador celular Amicus (Figura C2.2) con un rendimiento de 6.6 de obtención equivalente a 11 concentrados plaquetarios aproximadamente. Se observa que no hay diferencia en la disminución del conteo plaquetario debido al sexo femenino y masculino, ni a la edad, pero sí al conteo previo de plaquetas, es decir, que a mayor presencia de plaquetas previas a la donación, más secuestro plaquetario se presenta durante el procedimiento. Conclusión: De acuerdo con la población de donantes estudiados se llega a la 
deducción de que el criterio para la selección de un donante de plaquetaféresis en el Banco de Sangre Proquimed deberá presentar un conteo plaquetario mayor a $250,000 / \mu \mathrm{L}$ para no afectar al donador con un conteo menor a las $100,000 / \mu \mathrm{L}$ plaquetas, sabiendo que la disminución del conteo plaquetario es de $133,000 / \mu \mathrm{L}$, por lo cual con un donador que tenga conteo de plaquetas menor a lo sugerido, probablemente tendrá un conteo menor a lo estandarizado.

\section{Referencias}

1. Walter Torres O. Manual técnico. 17a ed. Buenos Aires: Asociación Argentina de Hemoterapia e Inmunohematología; 2012.

2. NORMA Oficial Mexicana NOM-253-SSA1-2012, Para la disposición de sangre humana y sus componentes con fines terapéuticos.

Tabla C2.1: Disminución en el centro de plaquetas postdonación de aféresis.

\begin{tabular}{|c|c|c|c|c|c|c|}
\hline Fecha & Sexo paciente & ID donador & $\begin{array}{c}\text { Plaquetas } \\
\text { predonación } \times \\
10^{3} / \mu \mathrm{L}\end{array}$ & $\begin{array}{l}\text { Plaquetas } \\
\text { postdonación } \\
\times 10^{3} / \mu \mathrm{L}\end{array}$ & $\begin{array}{l}\text { Disminución de } \\
\text { plaquetas }\end{array}$ & $\begin{array}{c}\text { Promedio } \\
\text { de plaquetas } \\
\text { disminuidas }\end{array}$ \\
\hline 11/01/2020 08:26:11 & M & 109735 & 244 & 106 & 138 & \\
\hline 11/01/2020 08:16:43 & M & 109734 & 319 & 179 & 140 & \\
\hline 14/01/2020 18:58:30 & $M$ & 109752 & 305 & 167 & 138 & \\
\hline 18/01/2020 16:27:56 & M & 109785 & 360 & 200 & 160 & \\
\hline 15/01/2020 09:25:14 & $\mathrm{F}$ & 109762 & 267 & 118 & 149 & \\
\hline 13/02/2020 09:04:57 & M & 109906 & 401 & 236 & 165 & \\
\hline 14/02/2020 12:11:51 & $\mathrm{F}$ & 109921 & 407 & 302 & 105 & \\
\hline 17/02/2020 09:56:31 & M & 109943 & 226 & 107 & 119 & \\
\hline 20/02/2020 16:43:52 & M & 109968 & 239 & 132 & 107 & \\
\hline 24/02/2020 19:04:42 & M & 109972 & 250 & 120 & 130 & \\
\hline 26/02/2020 07:52:34 & M & 109980 & 345 & 181 & 164 & \\
\hline 10/03/2020 09:20:02 & $\mathrm{F}$ & 110031 & 242 & 104 & 138 & \\
\hline 10/03/2020 12:51:35 & M & 110038 & 324 & 161 & 163 & \\
\hline 11/03/2020 08:23:46 & M & 110042 & 308 & 186 & 122 & \\
\hline 11/03/2020 09:29:00 & $M$ & 110045 & 343 & 201 & 142 & \\
\hline 11/03/2020 09:35:20 & $M$ & 110047 & 223 & 104 & 119 & \\
\hline 12/03/2020 13:35:06 & $M$ & 110063 & 275 & 120 & 155 & \\
\hline 13/03/2020 12:45:29 & M & 110072 & 200 & 95 & 105 & \\
\hline 14/03/2020 08:09:37 & M & 110075 & 258 & 109 & 149 & \\
\hline 14/03/2020 08:18:43 & $\mathrm{F}$ & 110076 & 248 & 105 & 143 & \\
\hline 03/04/2020 13:13:08 & $M$ & 110188 & 235 & 131 & 104 & \\
\hline 11/04/2020 09:50:29 & $\mathrm{F}$ & 110217 & 265 & 153 & 112 & \\
\hline 17/04/2020 10:37:03 & M & 110254 & 222 & 116 & 106 & \\
\hline 09/01/2020 13:23:51 & $M$ & 109723 & 379 & 237 & 142 & \\
\hline 09/01/2020 13:29:06 & $M$ & 109724 & 215 & 110 & 105 & \\
\hline 11/01/2020 09:00:00 & $M$ & 109738 & 293 & 150 & 143 & \\
\hline 14/01/2020 13:28:02 & $M$ & 109750 & 247 & 92 & 155 & \\
\hline Promedio & & & 283 & 150 & 133 & \\
\hline
\end{tabular}


Figura C2.1:

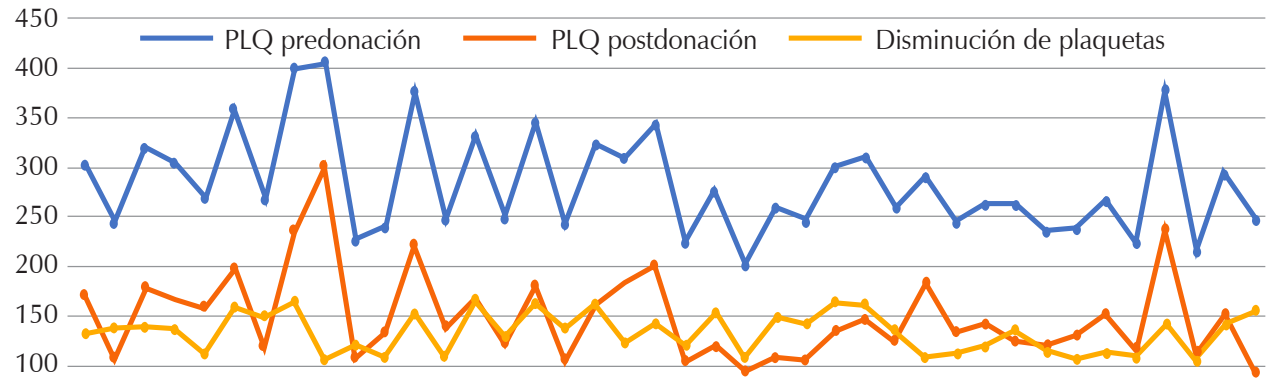

50

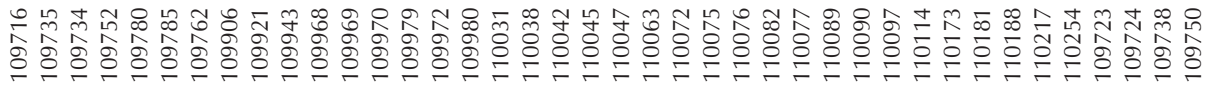

Disminución de plaquetas postdonación de aféresis.

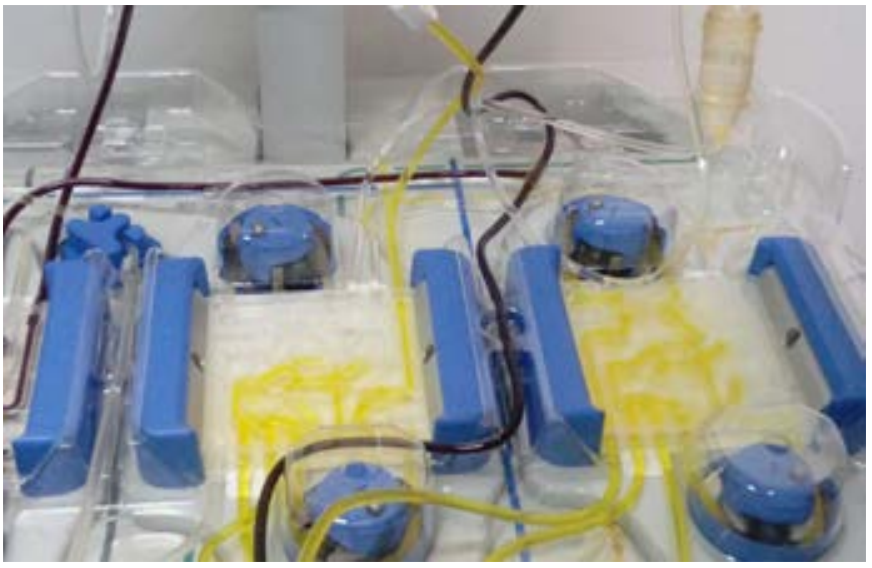

Figura C2.2.

C3. Prevalencia de agentes infecciosos en donadores de sangre del Hospital Materno Perinatal « Mónica Pretelini Sáenz» de 2018 a 2020 Arias Loaiza Mariana,* Vergara Cuadros Adrián Gerardo, ${ }^{\ddagger}$ Cuervo Araque Claudia María, ${ }^{\S}$ Ávila Arzate Karen Adriana"

* Bacterióloga y Laboratorista Clínica de la Institución Universitaria Colegio Mayor de Antioquia, Medellín, CoIombia. ‡ Médico Especialista en Salud Pública. Jefe de Medicina Transfusional del Hospital Materno Perinatal «Mónica Pretelini Sáenz». Toluca, México. § Bacterióloga y Laboratorista Clínica, Magíster en Epidemiología. Grupo de Investigación Biociencias de la Institución Universitaria Colegio Mayor de Antioquia, Medellín, Colombia. " Química Farmacobióloga, Especialista en Salud Pública. Adscrita al Hospital Materno Perinatal «Mónica Pretelini Sáenz». Toluca, México.

Introducción: La terapia transfusional es considerada una importante alternativa terapéutica en caso de accidentes, traumatismos, complicaciones en embarazos, pacientes con enfermedades oncohematológicas, entre otras situaciones que generan pérdida excesiva de la sangre, pero a pesar de los múltiples avances en medicina transfusional, no se dispone de una fuente diferente a la humana para obtener hemocomponentes que suplan las necesidades de los pacientes. ${ }^{1}$ Esta fuente puede presentar riesgos de infección al receptor en el momento de la transfusión. La infección transmitida por transfusión (ITT) es producida por la transmisión directa de un agente infeccioso específico (virus, parásito o bacteria) desde la unidad de sangre al receptor susceptible. ${ }^{2}$ Objetivo: Establecer la prevalencia de los agentes infecciosos transmisibles por transfusión en donadores de sangre del Hospital Materno Perinatal «Mónica Pretelini Sáenz» durante el periodo 2018 a 2020. Material y métodos: Tipo de estudio: descriptivo transversal. Población: 466 donadores que fueron atendidos en el Banco de Sangre entre 2018 y 2020, con positividad en las pruebas tamiz. Criterios de inclusión: se seleccionaron todos los donadores con pruebas de tamizaje serológico positivas (virus de la hepatitis $\mathrm{B}$ y $\mathrm{C}$ [VHB y VHC], virus de la inmunodeficiencia humana [VIH], Chagas, sífilis o Brucella), que, además, tuvieran el resultado de la prueba confirmatoria y los datos de ocho variables: sexo, edad, estado civil, escolaridad, ocupación, zona geográfica, grupo sanguíneo y tipo de donación. Los resultados de las pruebas tamiz y confirmatorias se obtuvieron desde los archivos físicos de registro y las variables desde el sistema operativo BBCore. Criterios de exclusión: no se tomaron en cuenta aquellos pacientes que, a pesar de tener el resultado de las pruebas tamiz, no contaban con el resultado de la prueba confirmatoria. Análisis estadístico: los resultados de las pruebas y las variables fueron consolidados en una base de datos y para el procesamiento de los datos se empleó el programa estadístico informático SPSS versión 25.0, para realizar los cruces de las pruebas tamiz, confirmatoria y las variables asociadas, obteniendo las distribuciones de frecuencia, prevalencia y valor predictivo positivo entre las pruebas. Resultados: Análisis: las prevalencias para los tres años de estudio fueron: VHB $(0.00 \%)$, VIH $(0.10 \%)$, Chagas $(0.16 \%)$, VHC $(0.17 \%)$, sífilis $(0.17 \%)$ y Brucella $(0.36 \%)$ para una población de 18,108 donantes (Figura C3.1). El marcador infeccioso con mayor prevalencia es la Brucella y la principal población afectada son los campesinos (29\%) y el sexo masculino ( $51 \%$ ). De los valores predictivos positivos (VPP) entre los agentes se obtuvo $22 \%$ para VHC, Io que indica que por cada 100 pruebas tamiz que son 


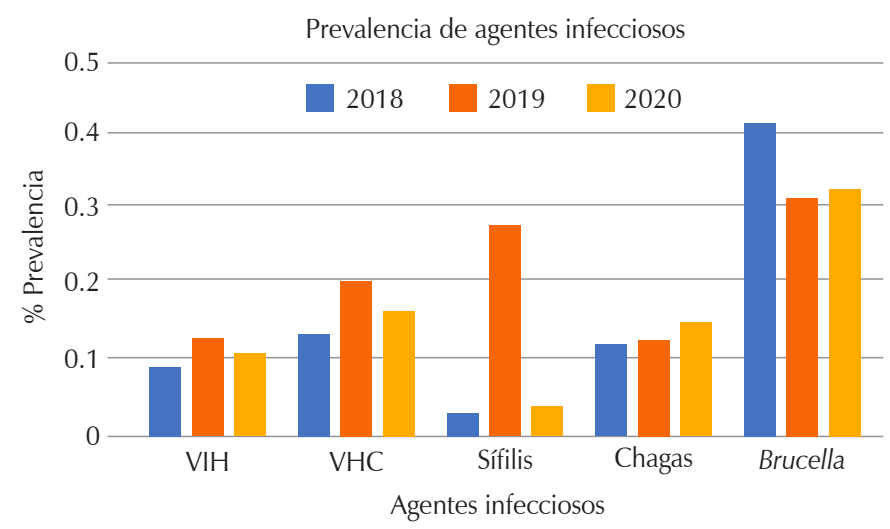

Figura C3.1: Prevalencia de marcadores infecciosos 2018-2020.

positivas para VHC, sólo 22 pruebas son realmente positivas. Asimismo, se obtuvo un VPP de $0 \%, 24 \%$, $27 \%$ y $50 \%$ para los agentes VHB, VIH, Chagas y sífilis, respectivamente. Conclusiones: La prevalencia de infecciones transmisibles por vía transfusional es baja frente a estudios previos, pero significativa. La prevalencia de la hepatitis B como marcador de infección para los tres años en estudio fue de $0 \%$, esto puede explicarse por un bajo riesgo residual de infección a VHB por transfusión en México, que es cercano o menor de un caso por 400,000 transfusiones, o porque el virus sea indetectable por las pruebas tamiz. La mayor prevalencia fue de Brucella $(0.36 \%)$, se considera que es importante que el Sector Salud tenga presente el número de casos reportados y tomar acciones preventivas para disminuir el padecimiento de esta enfermedad.

\section{Referencias}

1. Ruiz Mendoza L, Villegas Gracia R, Cardona Arias J. Prevalencia de agentes transmisibles por transfusión y factores asociados en un banco de sangre de Córdoba-Colombia 2014-2016. Rev Udcaactual Divulg Cient. 2018; 21 (2): 297-308.

2. Rodríguez MH. Enfermedades infecciosas por transfusión en México. Rev Mex Med Tran. 2011; 4 (2): 78-90.

C4. Prevalencia de seropositividad de Treponema pallidum en donadores de sangre del Hospital Regional No. 12 «Lic. Benito Juárez» del IMSS Yucatán

Canché Mena Karina Alejandra,* Martínez Fernández Alma Estrella ${ }^{\ddagger}$

* Médico Patólogo Clínico adscrito al Centro de Colecta del Hospital Regional No. 12 «Lic. Benito Juárez» del I MSS Yucatán. ${ }^{\ddagger}$ Médico Patólogo Clínico adscrito al Servicio de Transfusión del Hospital Regional No. 12 «Lic. Benito J uárez» del IMSS Yucatán.

I ntroducción: El Treponema pallidum, causante de la sífilis, continúa siendo un problema de salud pública. La Organización Mundial de la Salud reportó en 2016 cerca de dos millones de nuevos casos en la región de las Américas. Un segundo grupo de riesgo son los hombres que tienen sexo con otros hombres ( $\mathrm{HSH})$, cuya cifra ha despuntado en las últimas décadas. En tanto que la sífilis se considera una infección transmisible por transfusión (ITT), el cribado de la patología se ha institucionalizado en todos los bancos de sangre de México, aunque hasta el momento no se ha reportado sífilis adquirida por hemocomponentes en nuestro país, el riesgo es latente. El Boletín de Vigilancia Epidemiológica de la semana 53 del año 2020, reportó 71 hombres y 41 mujeres con sífilis para Yucatán, lo que representa $2.2 \%$ del total de los casos en México. Los últimos datos en donadores del sureste mexicano, para la seroprevalencia de sífilis son del año 2006, siendo de $0.29 \%$ y en 2013 el Centro Estatal reportó una incidencia de $0.89 \%$. Objetivos: Describir la prevalencia de seropositividad de anticuerpos contra Treponema pallidum en los donadores de sangre del Hospital Regional No. 12. «Lic. Benito J uárez» del I MSS Yucatán de 2016 a 2020. Material y métodos: Estudio descriptivo, retrospectivo, trasversal realizado con información del registro de donantes del sistema informático E-Delphi de 2017 a 2020, así como bitácoras de registro de serología reactiva del año 2016. Por la naturaleza retrospectiva y anónima de la información extraída no se requiere de consentimiento informado. Resultados: Del año 2016 al 2020 se recibieron 15,263 donadores, de los cuales se identificaron 171 casos reactivos correspondiendo a 144 hombres y 27 mujeres ( 1.2 y $0.8 \%$, respectivamente), la edad promedio fue de 39.8 años con un rango de 21 y 65 años. La edad media en los hombres fue de 40.2 años y en mujeres fue de 38 años. La prevalencia reportada fue de $1.12 \%$. El año de mayor prevalencia fue 2016 con 21 casos por 1,000 donadores, y el año de menor prevalencia fue 2019 con siete por 1,000 donadores (Figura C4.1). Se identificaron a siete pacientes con coinfección con serología reactiva para VIH y uno con coinfección con Chagas. El 28\% de los donadores eran de procedencia rural. Conclusión: Yucatán es uno de los estados en donde se ha visto un incremento de casos de sífilis con el paso de los años. La prevalencia reportada en este periodo fue de $1.12 \%$, lo que correspondería a 3.8 veces más que lo reportado en 2006, y 1.25 veces más a lo reportado en 2013 por el CETS. Por lo tanto, al ser una entidad reemergente es indispensable contar con un buen interrogatorio por parte del médico valorador, así como la exploración física aunado de las pruebas

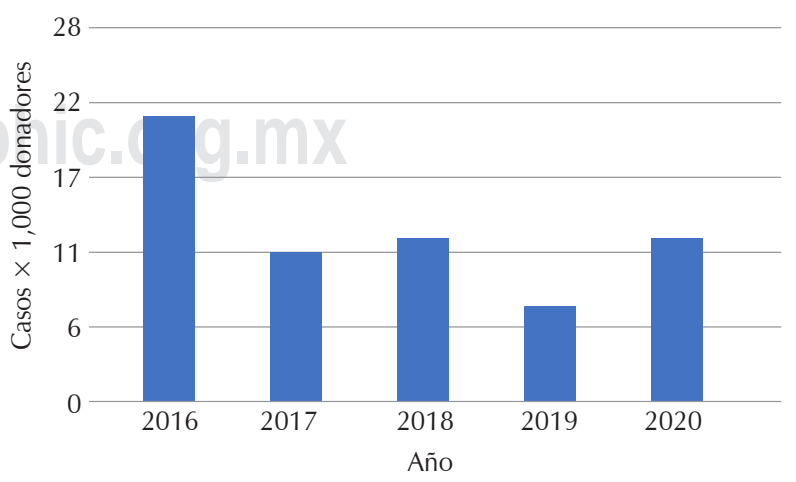

Figura C4.1: Prevalencia de seropositividad de sífilis en donadores del Hospital General Regional No. 12 IMSS Yucatán. 
serológicas cuyas metodologías actualmente tienen una mayor sensibilidad y especificidad.

\section{Referencias}

1. Peeling RW, Mabey D, Kamb ML, Chen XS, Radolf JD, Benzaken AS. Syphilis. Nat Rev Dis Primers. 2017; 3: 17073. doi: 10.1038/nrdp.2017.73.

2. NORMA Oficial Mexicana NOM-253-SSA1-2012, Para la disposición de sangre humana y sus componentes con fines terapéuticos. Diario Oficial de la Federación, 25 de noviembre de 2016.

3. Boletín Epidemiológico. Vigilancia epidemiológica semana 53, 2020. Dirección General de Epidemiología, Secretaría de Salud. Disponible en: https://www.gob.mx/cms/uploads/attachment/file/614743/sem53. pdf

4. García-Montalvo BM. Seropositividad de VIH, VHB, VHC y Treponema pallidum en donadores de sangre en el Sureste de México. Rev Invest Clin. 2006; 58 (6): 567-572.

C5. Serodetección y seroprevalencia de virus del dengue en donadores sanguíneos en la ciudad de Xalapa, Veracruz

Valerio Morales Laura Cecilia,* López Martínez Alondra, ${ }^{\ddagger}$ García Ramírez David, ${ }^{\S}$ Valerio García Alfredo," Valerio Morales Ignacio Alfredo," Castañeda Morales Juan Manuel**

* Médico Patólogo Clínico, responsable sanitario del Banco de Sangre Integral. ₹ Médico Infectólogo adscrito al Hospital General de Zona No. 11 I MSS Xalapa. ${ }^{\S}$ Médico seleccionador. Banco de Sangre Integral. "Químico Fármaco Biólogo. Director General. Banco de Sangre Integral. " Médico Internista. Director Médico. Banco de Sangre Integral. ** QFB de Servicio Social. Banco de Sangre Integral.

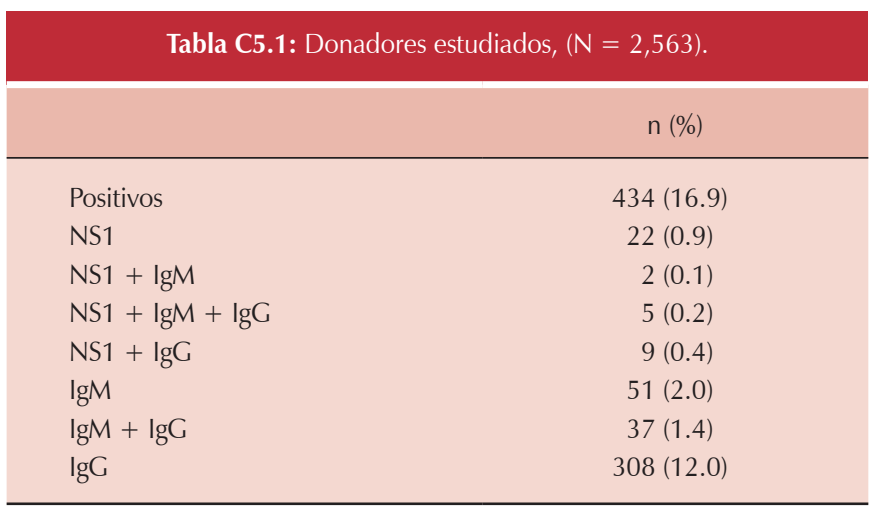

Introducción: Derivado del brote de infección por virus del dengue presentado en el año 2019, el Centro Nacional de la Transfusión Sanguínea realizó un comunicado sobre las recomendaciones para la selección y el diferimiento de donantes para los servicios de sangre frente a la prevalencia del dengue y otras infecciones transmitidas por mosquito Aedes aegypti, dentro de las recomendaciones para zonas endémicas estaba realizar tamizaje del virus por pruebas de anticuerpos (IgG, IgM o ambos). El estado de Veracruz ha presentado un importante número de casos de dengue en los últimos 10 años, en 2019 el Sistema Nacional de Vigilancia Epidemiológica (SINAVE) reportó un total de 10,902 casos confirmados con una tasa de incidencia de 131.74 y 1,525 casos confirmados en el año 2020. Objetivo: Determinar la serodetección y seroprevalencia del virus del dengue en donadores en un banco del sector privado de la ciudad de Xalapa, Veracruz. Material y métodos: Se trata de un estudio retrospectivo, observacional, realizado a través de la revisión de las determinaciones obtenidas en donadores durante el periodo comprendido de diciembre de 2019 al 15 de julio de 2021 mediante el método de inmunoensayo cromatográfico cualitativo para la detección del antígeno NS1, anticuerpos IgG e IgM para el virus del dengue en el Banco de Sangre Integral. Los resultados de las determinaciones y los datos demográficos fueron analizados en Excel. Resultados: Se estudiaron a 2,563 candidatos a donar, encontrando 434 candidatos (16.9\%) positivos como se pude observar en la Tabla C5.1. Las características demográficas en donadores fueron: 1,918 (74.8\%) del sexo masculino, los grupos de edad con mayor frecuencia fueron de 18 a 28 años: $916(35.7 \%)$ y 29 a 39: $781(30.5 \%)$. En cuanto a los meses con mayor número de marcadores de infección reciente, podemos observar en la Figura C5.1 el pico máximo de IgM en el mes de agosto de 2020. Discusión: Detectamos 126 candidatos diferidos por marcadores de infección reciente (NS1, IgM) correspondiendo a $4.9 \%$ del total de los candidatos analizados, comparada con otras determinaciones serológicas de infecciones transmisibles por transfusión se encuentra en alta frecuencia. Los donadores cursaban asintomáticos, por lo cual el haber omitido esta determinación pudo causar la infección de dengue transmitido por transfusión en los receptores,

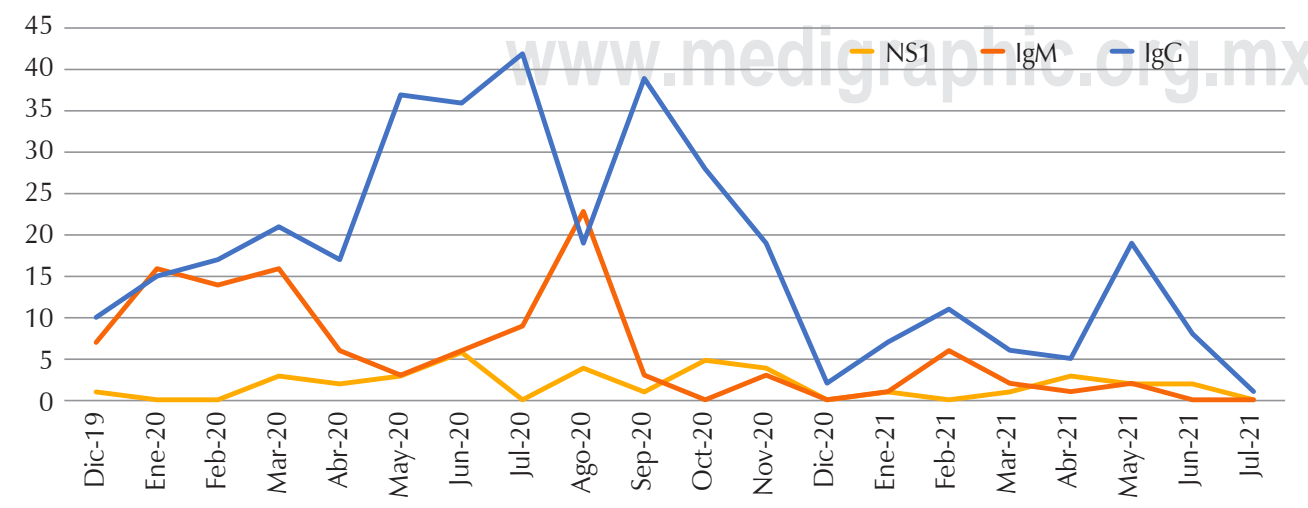

Figura C5.1:

Frecuencias por mes de pruebas positivas. 
la cual ha sido reportada por la literatura. Conclusión: En escenarios ideales la prueba por PCR o técnicas moleculares presentan un mejor desempeño; sin embargo, los costos son elevados. La detección de NS1 e I gM puede ser una estrategia costo-efectiva adecuada para el tamizaje de donadores en zonas endémicas.

\section{Referencias}

1. Arredondo-García JL, Aguilar-López ECG, Aguilar Lugo-Gerez JJ, Osnaya-Romero N, Pérez-Guillé G, Medina-Cortina H. Panorama epidemiológico de dengue en México 2000-2019. Rev Latin Infect Pediatr. 2020; 33 (2): 78-83. doi: 10.35366/94418.

2. Ashshi AM. Serodetection of dengue virus and its antibodies among blood donors in the western region of Saudi Arabia: a preliminary study. Blood Transfus. 2015; 13 (1): 135-138. doi: 10.2450/2014.0134-14

3. Sabino EC, Loureiro P, Lopes ME, Capuani L, McClure C, Chowdhury D et al. Transfusion-transmitted dengue and associated clinical symptoms during the 2012 epidemic in Brazil. J Infect Dis. 2016; 213 (5): 694-702. doi: 10.1093/infdis/jiv326.

4. Perera L, De Zoysa N, Jayarajah U, Senanayake N, De Zoysa I, Seneviratne SL. Transfusion-transmissible dengue infections. Trans R Soc Trop Med Hyg. 2020; 114 (11): 866-882. doi: 10.1093/trstmh/traa075.

\section{C6. Factores de riesgo relacionados al anti-core en} donantes de sangre en un hospital de Cañete, Perú Iturrizaga Blas Rubén Clever,*,‡ Sánchez Jacinto Billy J oel*,s

* Tecnólogo Médico. ₹ Hospital Rezola de Cañete. ${ }^{\S}$ Universidad Peruana Cayetano Heredia.

I ntroducción: La hepatitis B es una enfermedad crónica y es un problema de salud pública. Un informe de la OMS en el año 2019 reportó que 296 millones de personas presentaban infección crónica por el virus de la hepatitis B. Actualmente existen dos marcadores para determinar la infección por hepatitis B que son el antígeno de superficie (HBsAg) y el anticore total (anti-core). En nuestro país la seroprevalencia de hepatitis $B$ realizado durante el año 2020 reportó que $0.4 \%$ fue positivo para HBsAg, mientras, para el anticore total fue de $10.1 \%$. Recientemente, en los últimos años existe un interés enfocado

\section{Tabla C6.1: Características demográficas, ( $N=202)$}

\begin{tabular}{lc}
\hline Características & $\mathrm{n}(\%)$ \\
\hline Género & \\
$\quad$ Femenino & $44(21.78)$ \\
Masculino & $158(78.22)$ \\
Grupos de edad (años) & \\
$\leq 40$ & $143(70.79)$ \\
$>40$ & $59(29.21)$ \\
Estado civil & \\
Soltero & $61(30.20)$ \\
Casado & $32(15.84)$ \\
Divorciado & $2(0.99)$ \\
Conviviente & $107(52.97)$ \\
Tatuajes & $15(7.43)$ \\
Sí & $187(92.57)$ \\
No &
\end{tabular}

\begin{tabular}{|c|c|c|c|}
\hline \multirow[b]{2}{*}{ Características } & \multicolumn{2}{|c|}{ Anticuerpo anticore } & \multirow[b]{2}{*}{$\mathrm{p}$} \\
\hline & No & Sí & \\
\hline Género & & & $0.052^{*}$ \\
\hline Femenino & $42(95.45)$ & $2(4.55)$ & \\
\hline Masculino & $133(84.14)$ & $25(15.82)$ & \\
\hline Grupos de edad (años) & & & $0.020^{* *}$ \\
\hline$\leq 40$ & $129(90.21)$ & 14 (9.79) & \\
\hline$>40$ & $46(77.97)$ & $13(22.03)$ & \\
\hline Estado civil & & & $0.015^{\Phi *}$ \\
\hline Soltero & 59 (96.76) & $2(3.28)$ & \\
\hline Casado & $28(87.50)$ & $4(12.50)$ & \\
\hline Divorciado & $2(100.00)$ & $0(0)$ & \\
\hline Conviviente & $86(80.37)$ & $21(19.63)$ & \\
\hline Tatuajes & & & $0.430^{\Phi *}$ \\
\hline No & $163(87.17)$ & $24(12.83)$ & \\
\hline Sí & $12(80.00)$ & $3(20.00)$ & \\
\hline
\end{tabular}

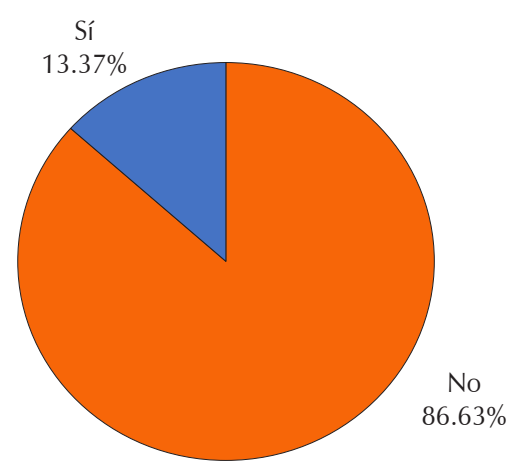

Figura C6.1: Frecuencia de anticore.

en pacientes positivos para anti-HBc y negativo para HBsAg, este patrón se denomina «anti-HBc aislado» y esto puede incluir un resultado falso positivo, infección resuelta o infección por cepas variantes de VHB. Por lo tanto, es de mayor importancia conocer la frecuencia de anti-core y los posibles factores relacionados. Objetivo: Determinar la asociación entre los factores de riesgo y el anticuerpo anti-core en el Hospital Rezola de Cañete durante el año 2019. Material y métodos: Es un estudio descriptivo, transversal. Población: las fichas de los donantes de sangre del Hospital Rezola de Cañete durante el año 2019. Tamaño de muestra: el cálculo se basó en proporción, fue un total de 186 fichas. El cálculo se realizó en el programa Open Epi v3.01. Análisis estadístico: se realizó un análisis univariado y pruebas bivariadas. Se consideró una $\mathrm{p}$ significativa $<0.05$. El software utilizado fue el Stata v 14. Resultados: Los resultados se muestran en las Tablas C6.1 y C6.2, y en la Figura C6.1. Conclusiones: La prevalencia del anticore es relativamente baja. EI RP en varones fue 3.48 más que mujeres. Se encontró relación entre el grupo etario, estado civil y el anti-core. 
C7. Incidencia de rechazo de donadores por Brucella en Banco de Sangre de la UMAE No. 2, Sonora

Nafarrate-Cota Rosa Isela,* Núñez-Encinas Veronika,* Verduzco-Moreno Abel,* Rodríguez-Ortega Guadalupe* * UMAE del Hospital de Especialidades No. 2. Centro Médico Nacional del Noroeste.

I ntroducción: De acuerdo con la región geográfica en la que se encuentra este banco de sangre, por la normativa NOM-253-2012-SSA, se incluye en las pruebas adicionales la detección de Brucella, la cual se debe ajustar al mismo protocolo que el resto de las pruebas de detección de agentes infecciosos transmisibles por transfusión, en donde al primer resultado de pruebas de tamizaje reactivo o dudoso se le debe dar destino final a la unidad implicada. Al ser una región ganadera, normativamente se debe realizar el tamizaje a todo donante. Objetivo: Determinar la incidencia de donadores rechazados por Brucella en el Banco de Sangre de la UMAE No. 2, Sonora. Material y métodos: Estudio observacional, descriptivo, retrospectivo, transversal. Se estudió durante el último semestre comprendido de diciembre de 2020 a mayo de 2021, mediante prueba de tamizaje, la cantidad de pruebas de aglutinación en placa con antígeno teñido con rosa de bengala, y de éstas cuáles fueron reactivas, en los donadores estudiados en el semestre referido. Resultados: De los 2,767 donantes, seis $(0.21 \%)$ fueron rechazados por tener pruebas

\begin{tabular}{cccc} 
& \multicolumn{2}{c}{ Tabla C7.1: Características de donantes reactivos. } \\
Sexo & Edad & Ocupación & Mes \\
\hline M & 30 & Empleado & Enero \\
F & 19 & Estudiante & Febrero \\
F & 21 & Estudiante & Marzo \\
M & 24 & Empleado & Abril \\
M & 23 & Empleado & Mayo \\
M & 32 & Empleado & Mayo \\
\hline
\end{tabular}

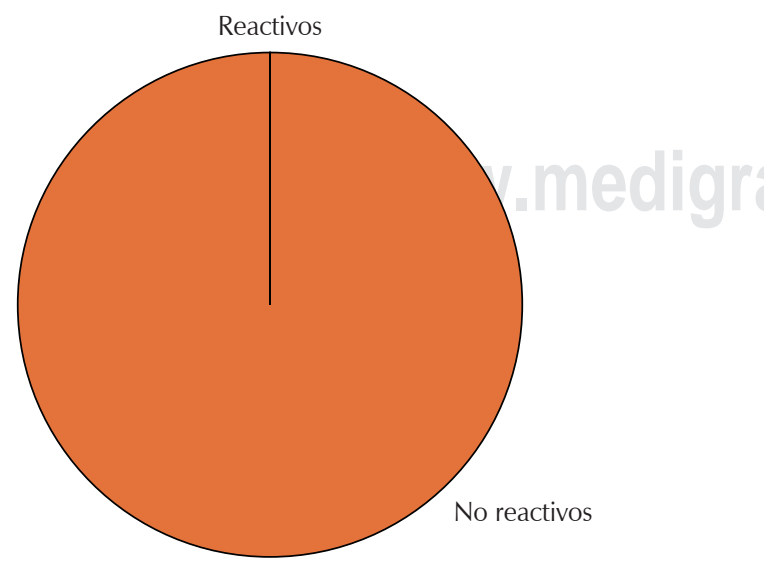

Figura C7.1: Reactividad a Brucella. reactivas de rosa de bengala (Figura C7.1). Siendo en su mayoría en el rango etario de 18-24 años (Tabla C7.1) $(66.6 \%)$, seguido de 25 a 44 años $(33.4 \%)$, con una media de 24.8 años de edad, cuatro $(66.6 \%)$ hombres y dos (33.4\%) mujeres. Las dos (33.4\%) mujeres eran estudiantes, no se captó la licenciatura que cursaban, y los hombres $(66.6 \%)$ se capturaron sus datos como empleados, tampoco se tiene la empresa para la cual trabajaban, uno de ellos, ingeniero. Análisis: Al ser considerada una región de riesgo para la transmisión de Brucella vía sanguínea, se sigue haciendo su estudio por medio de tamizaje; sin embargo, no hay consenso entre los distintos bancos del estado para cotejar la prevalencia a nivel estatal. Conclusiones: Se debe consensar entre los distintos bancos de la región sus estadísticas y porcentajes de reactividad en este tipo de pruebas. Realizar un seguimiento epidemiológico de estos candidatos a donar, ya que la NOM-253-2012-SSA nos marca que deben diferirse tres años después de la recuperación completa de haber padecido brucelosis.

C8. I mpacto del control microbiológico en la recolección de células progenitoras hematopoyéticas y hemocomponentes

Chávez-Estrada Yair Omar,* Alvarado-Navarro Dalila Marisol, $\neq$ Hernández-Navarro Ana Karen,* VázquezHernández Karina Elizabeth,* Salazar-Riojas Rosario, ${ }^{\$}$ Gómez-Almaguer David"

* Químico, Medicina Transfusional. Servicio de Hematología del Hospital Universitario «Dr. José Eleuterio González» UANL, Monterrey, México. ₹ Médico responsable, Medicina Transfusional. Servicio de Hematología del Hospital Universitario «Dr. J osé Eleuterio González» UANL, Monterrey, México. ${ }^{\S}$ Jefa del Laboratorio de Hematología del Hospital Universitario «Dr. J osé Eleuterio González» UANL, Monterrey, México. "J efe del Servicio de Hematología del Hospital Universitario «Dr. José Eleuterio González» UANL, Monterrey, México.

I ntroducción: Uno de los riesgos presentes en pacientes que reciben transfusiones de hemocomponentes, células progenitoras hematopoyéticas $(\mathrm{CPH})$ o terapias celulares es la administración de un producto con contaminación bacteriana, incrementando la posibilidad de que se presente un evento adverso relacionado a la transfusión. Algunos factores de riesgo para la contaminación de estos productos son: tiempo de duración prolongada de los sistemas de recolección, variaciones en los protocolos de limpieza y la experiencia en la manipulación del analista clínico de las unidades de aféresis. Con la finalidad de disminuir el riesgo de contaminación de los productos de $\mathrm{CPH}$ y los componentes sanguíneos recolectados para uso terapéutico, se deben reunir ciertos requisitos de calidad necesarios para que resulten inocuos o no patogénicos, funcionales y viables. Por lo cual es importante detectar los cultivos microbiológicos (CM) positivos y estimar su origen de contaminación para así evaluar un lineamiento estricto del control de calidad de $\mathrm{CM}$ de $\mathrm{CPH}$ y hemocomponentes. Ob- 
jetivo: Evaluar la susceptibilidad a la contaminación microbiana en las recolecciones de $\mathrm{CPH}$ y hemocomponentes, además de evaluar el impacto de la contaminación, estableciéndose la importancia de la susceptibilidad y resistencia de los microorganismos presentes en las recolecciones. Material y métodos: Estudio retrospectivo, descriptivo; realizado en el Hospital Universitario «Dr. José Eleuterio González» de la UANL en Servicio de Hematología, se analizaron los hemocultivos de 1,744 procedimientos de enero de 2013 a diciembre de 2020 de recolecciones de $\mathrm{CPH}$ de SPM y MO; y hemocomponentes (plaquetas, eritrocitos y plasma) obtenidos por aféresis mediante los separadores celulares: Amicus ${ }^{\mathrm{TM}}$ Fenwal $^{\circledR}$, Spectra Optia Terumo ${ }^{\circledR}$ y COBE Spectra Terumo ${ }^{\circledR}$. Se empleó el equipo BD BACTEC FX40 para los frascos de hemocultivos BD BACTEC ${ }^{\mathrm{TM}}$ Peds Plus ${ }^{\mathrm{TM}} / \mathrm{F}$ Culture Vials-Becton Dickinson. Se tomaron las muestras en campana de bioseguridad con guantes estériles y técnica aséptica. Cada determinación se efectuó por triplicado y por cada botella positiva se realizó una tinción directa al
Gram y se sembró en medio microbiológico rutinario para corroborar el estatus positivo previamente detectado por el BD BACTEC FX40. Se utilizó la técnica de Kirby-Bauer para medir la sensibilidad en disco a los antibióticos. Resultados: De los 1,744 procedimientos revisados, se observó positividad para cultivo microbiológico en 27 casos, de los cuales cuatro fueron en productos de recolección de células hematopoyéticas, dos en productos plaquetarios, uno en concentrado eritrocitario, 20 en manipulación in vitro (terapia celular) y no se observaron cultivos positivos en recolecciones de plasma. Se identificaron 24 especies de microorganismos entre ellos: Streptococcus spp., Staphylococcus spp., Acinetobacter spp., Clostridium spp., Micrococcus spp., Bacillus spp., Chryseobacterium sp., Corynebacterium spp., Peptoniphilus sp., Propionibacterium spp. y Salmonella spp. De los cuales el predomino de $45.8 \%(n=$ 11) fue el género de Staphylococcus spp.; $8.3 \%(n=$ 2) fue Acinetobacter spp.; $8.3 \%(n=2)$ Micrococcus spp; $8.3 \%(n=2)$ Corynebacterium spp. entre cada

Tabla C8.1: Identificación de microrganismos aislados en recolección de células progenitoras hematopoyéticas y hemocomponentes.

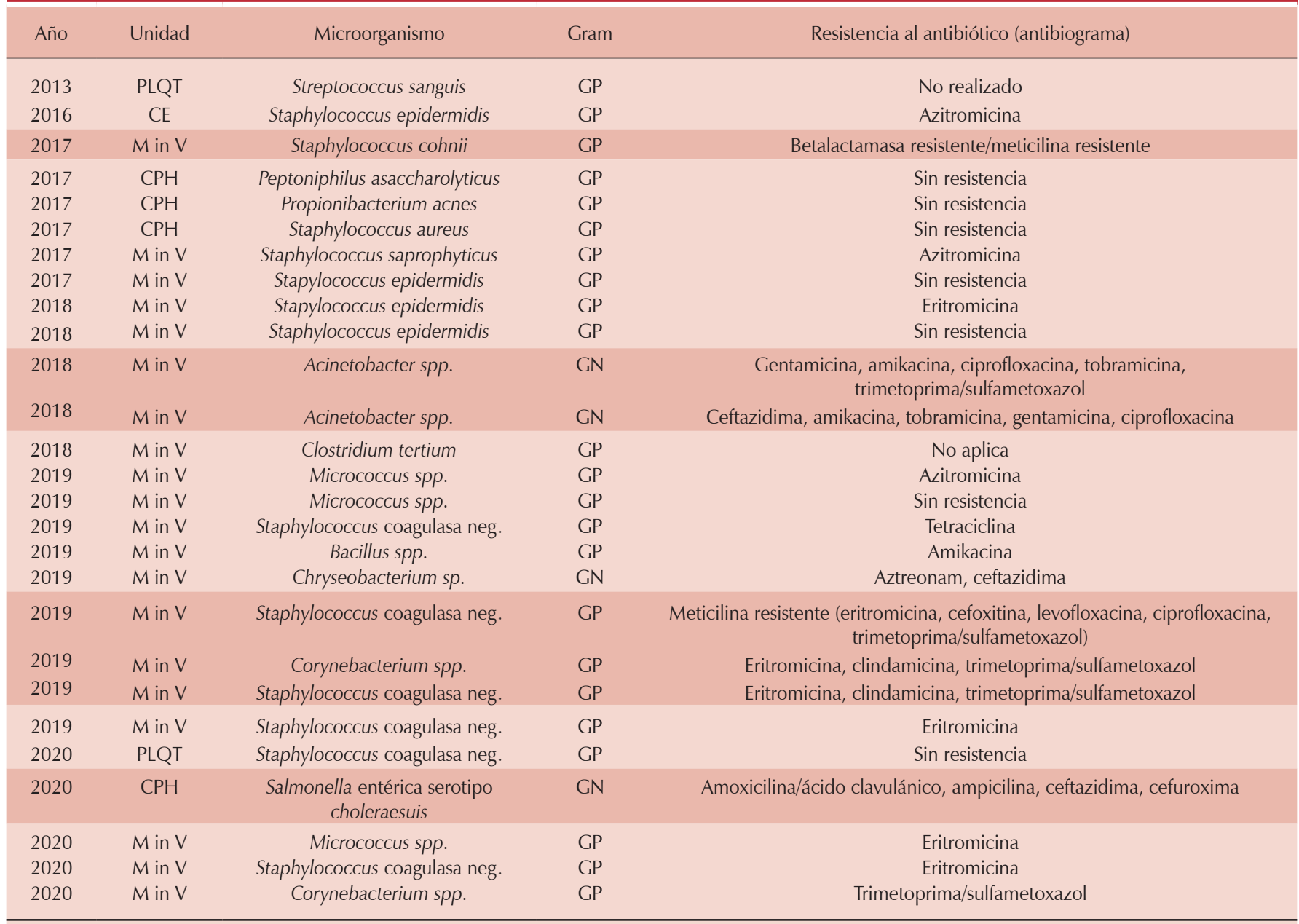

$\mathrm{PLQT}=$ concentrado plaquetario; $\mathrm{CE}=$ concentrado eritrocitario; $\mathrm{CPH}=$ células progenitoras hematopoyéticas; $\mathrm{M}$ in V: manipulación in vitro (fraccionamiento, criopreservación, descongelación y terapia celular); $\mathrm{GP}=\mathrm{Gram}$ positivos; $\mathrm{GN}=\mathrm{Gram}$ negativo; $\quad \mathrm{MDR}=$ microorganismos multidrogo resistentes. 


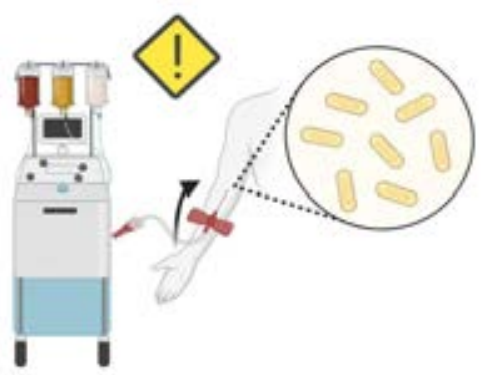

1. Conexión del paciente a la unidad recolectora mediante aféresis
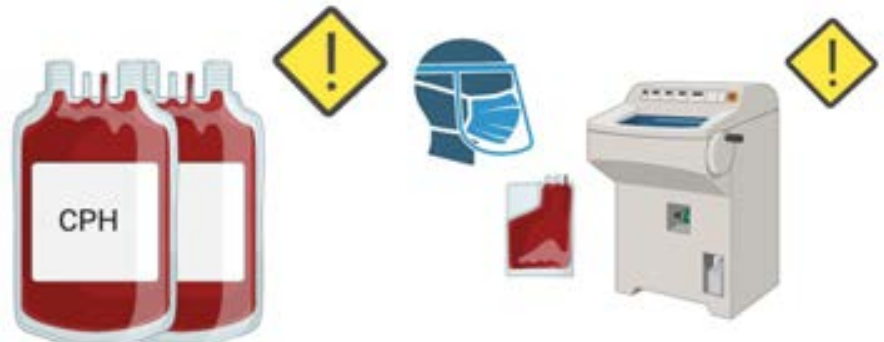

4. Fraccionamiento de la unidad recolectora

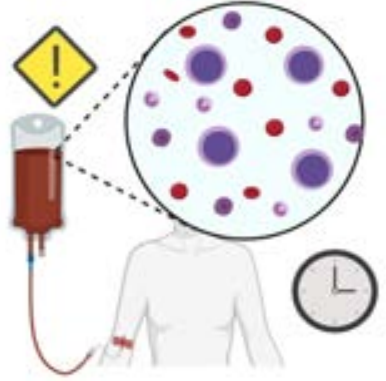

2. Recolección de células

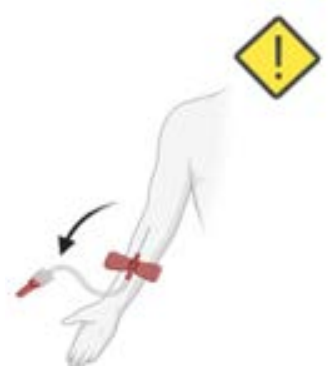

3. Desconexión del paciente y resguardo de la unidad de $\mathrm{CPH}$

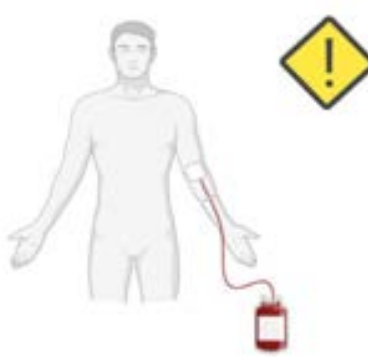

6. Infusión de las $\mathrm{CPH}$ al paciente (trasplante)
Figura C8.1:

Puntos críticos del control microbiológico en la recolección de células progenitoras hematopoyéticas (PCCM-CPH). uno de los demás microorganismos $1 \%(n=1)$. En la determinación de la resistencia se evaluaron un total de 20 antibióticos, entre ellos de los grupos macrólidos, betalactámicos, aminoglucósidos, fluoroquinolonas, sulfonamidas, cefalosporina de segunda/ tercera generación y lincosamidas respectivamente para cada tipo de microorganismo (Tabla C8.1), siete de ellos mostraron una mayor prevalencia en cuanto a las resistentes a eritromicina, y tres a azitromicina, además de observarse que siete de las 23 bacterias eran resistentes al menos a tres familias de diferentes antibacterianos. Conclusión: Ningún paciente presentó reacciones adversas después de la transfusión. S. epidermidis fue el microorganismo de mayor frecuencia perteneciente a microbiota de la piel. La presencia de ciertas bacterias hace un llamado de emergencia en el seguimiento y reevaluación de la susceptibilidad a la contaminación microbiana en área de proceso clínicas sumamente limpias (Figura C8.1). La resistencia en el transcurso de los años se vio aumentada, permitiéndonos reflexionar sobre el uso de antibióticos, incorporando nuevas delimitantes y protocolos a la profilaxis postrasplante para un mejor manejo de las unidades y procesamientos realizados.

\section{Referencias}

1. Hirji Z, Saragosa R, Dedier H, Crump M, Franke N, Burrows L et al. Contamination of bone marrow products with an actinomycete resembling Microbacterium species and reinfusion into autologous stem cell and bone marrow transplant recipients. Clin Infect Dis. 2003; 36 (10): e115-e121.

2. Jacobs MR, Good CE, Fox RM, Roman KP, Lazarus HM. Microbial contamination of hematopoietic progenitor and other regenerative cells used in transplantation and regenerative medicine. Transfusion. 2013; 53 (11): 2690-2696.

3. Klein MA, Kadidlo D, McCullough J, McKenna DH, Burns LJ. Microbial contamination of hematopoietic stem cell products: incidence and clinical sequelae. Biol Blood Marrow Transplant. 2006; 12 (11): 1142-1149.

C9. Comparación de dos métodos de medición de hemoglobina en el tamizaje de donadores de sangre en el Hospital Universitario de la UANL y determinación de variables influyentes en un método no invasivo

San Miguel Garay Erik Alejandro,* Ayala de la Cruz Sergio, ${ }^{\ddagger}$ Díaz Chuc Erik Alejandro, ${ }^{\S}$ Luna Falcón Claudio Fabrizio,* González Herver Luis Ernesto,* Silva Diez Mariana*

* Residentes de la Especialidad de Patología Clínica. Hospital Universitario «Dr. J osé Eleuterio González». Universidad Autónoma de Nuevo León. ₹ Profesor de la Especialidad de Patología Clínica. Hospital Universitario «Dr. J osé Eleuterio González». ` J efe del Banco de Sangre. Profesor de la Especialidad de Patología Clínica. Hospital Universitario «Dr. José Eleuterio González».

Introducción: El tamizaje del donador de sangre incluye, entre otros criterios, la medición de la hemoglobina $(\mathrm{Hb})$ en sangre total y sus valores mínimos de concentración se establecen en la NOM253-SSA1-2012, de acuerdo con la altura sobre el nivel del mar; ${ }^{1}$ si bien, dentro de la mayoría de los bancos de sangre se utiliza de manera rutinaria un citómetro automatizado para el análisis de las mues- 
tras provenientes de los donadores, en circunstancias especiales es requerido algún otro método para dicho propósito, un ejemplo son las campañas de donación que se realizan fuera del ámbito hospitalario. Una buena herramienta para ello son los equipos de medición point-of-care, los cuales tienen la ventaja de ser portátiles, fáciles de usar y rápidos; sin embargo, el desempeño de estos equipos llevados a la práctica ha arrojado resultados discordantes ${ }^{2,3}$ y pocos estudios se han llevado a cabo evaluando una población como la nuestra. Objetivo: Comparar los resultados de los valores de hemoglobina por un método no invasivo del tipo point-of-care contra los resultados de un método espectrofotométrico automatizado en el tamizaje de donadores de sangre y determinar las variables que influyen en la capacidad predictiva del método no invasivo. Material y métodos: Se obtuvieron las mediciones de hemoglobina de individuos que calificaron como predonadores aptos mediante una evaluación clínica. Los individuos fueron registrados y atendidos en el Banco de Sangre del Hospital Universitario «Dr. J osé Eleuterio González» de la Universidad Autónoma de Nuevo León (UANL, Monterrey, México). Se utilizó el equipo NBM-200 (OrSense, Estados Unidos), el cual es un portátil de tipo point-of-care, que utiliza espectroscopia de oclusión como método de lectura de la cifra de hemoglobina, haciendo pasar a través de la porción proximal del dedo pulgar un haz de luz que llega a un detector, al mismo tiempo que realiza una oclusión momentánea e intermitente de la circulación de la zona. Una vez que se realiza la medición, la señal se traduce en un número que indica la cifra de hemoglobina del sujeto. Como método de comparación se utilizó el equipo Cell-Dyn Emerald
(Abbott, Estados Unidos), citómetro automatizado, llevando a cabo una reacción química con laurilsulfato de sodio para la detección de hemoglobina a través de espectrofotometría. Se recabaron datos de peso, estatura, edad, índice de masa corporal (IMC) y sexo de los participantes, junto con los valores de $\mathrm{Hb}$ de ambos equipos para su análisis descriptivo. Se realizó un análisis inferencial mediante modelaje de regresión lineal simple, múltiple y no paramétrica, utilizando los valores del método no invasivo pointof-care como variable dependiente y hemoglobina por citometría hemática automatizada, sexo, edad e IMC como variables independientes. También se realizó un análisis de Bland-Altman con diferencia de hemoglobina NBM-200-Emerald. Se utilizó para todos los cálculos el software RStudio (The R Foundation for Statistical Study) versión 4.0.3. Resultados: Se hizo la medición por el NBM-200 a 100 individuos pudiendo obtener datos completos de un total de 97 donadores; los sujetos incluidos para el análisis y las causas de exclusión se detallan en la Figura C9.1. La estadística descriptiva se resume en la Tabla C9.1. Dentro de los diferentes modelos de regresión lineal que se probaron, el que resultó más sencillo fue el siguiente: $\mathrm{Hb}$ NBM-200 $=5.8+(0.65 \times \mathrm{Hb}$ Emerald) $\left(r^{2}=0.42 ; p<0.001\right)$ (Figura C9.2A). El modelo que mejor se ajustaba fue: Hb NBM-200 = $9.5+(0.33 \times \mathrm{Hb}$ Emerald $)+1.38$ ( $\mathrm{si}$ es sexo masculino) ( $r^{2}=0.56 ; p<0.001$ en las tres variables) mostrando una distribución normal en los residuos y sin multicolinealidad importante (Figura C9.2B). En el análisis de Bland-Altman para comparación de métodos se encontró una diferencia media entre ambos equipos (NBM-200-Emerald) de 0.68 (inter-

\begin{tabular}{|c|c|c|c|c|c|c|}
\hline & n $(\%)$ & Edad (años)* & 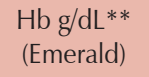 & $\begin{array}{l}\mathrm{Hb} \mathrm{g/dL**} \\
(\mathrm{NBM}-200)\end{array}$ & IMC kg/m²* & $\begin{array}{c}\text { Diferencia de Hb } \\
\text { (NBM-200- Emerald)** }^{*}\end{array}$ \\
\hline Mujeres & $24(26.1)$ & $38.5(26.5-49.2)$ & $13.4(0.93)$ & $14.0(0.96)$ & $30.5(4.55)$ & $0.66(1.05)$ \\
\hline Hombres & 68 (73.9) & $38(28.8-45.2)$ & $15.2(0.98)$ & $15.8(1.23)$ & $29.6(5.48)$ & $0.52(1.46)$ \\
\hline
\end{tabular}

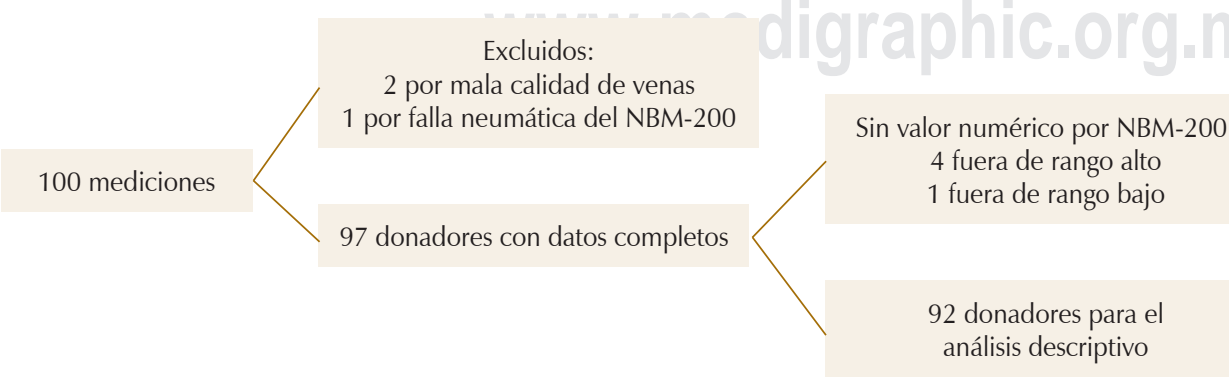

Figura C9.1: Diagrama del manejo de datos.
Excluidos: 4 por valores atípicos de la diferencia entre métodos

88 donadores para los modelos de regresión 
A

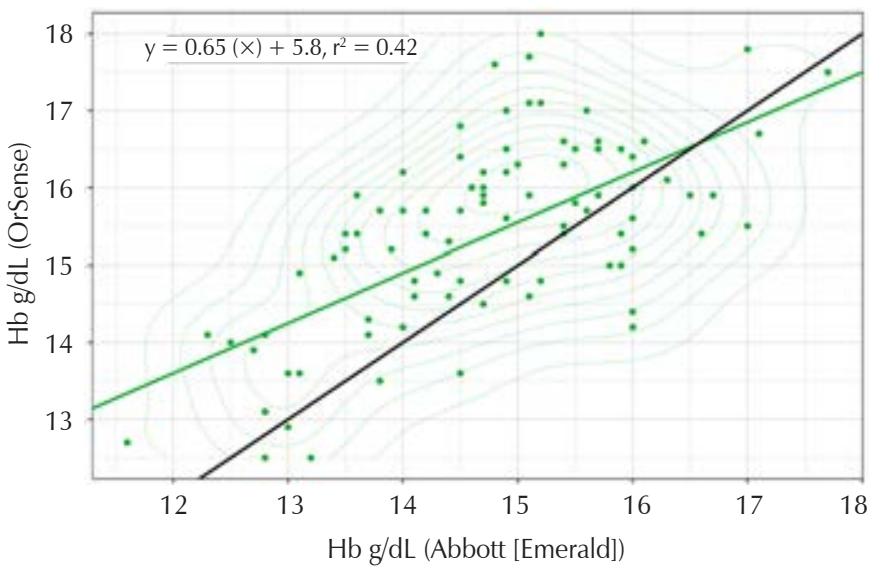

B
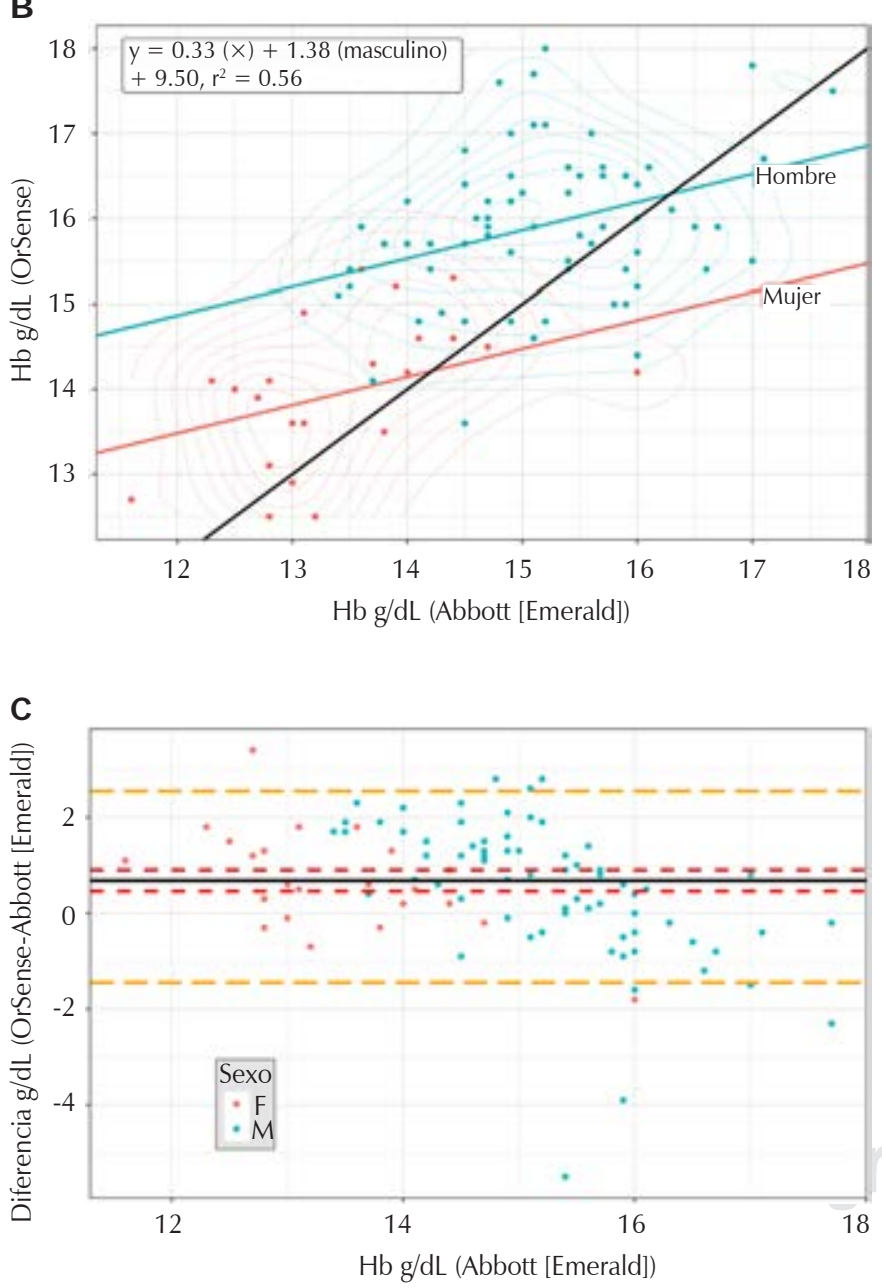

Figura C9.2: A) Gráfico del modelo de regresión más sencillo; la línea verde representa la regresión de los datos obtenidos. B) Gráfico del mejor modelo de regresión obtenido separado para cada sexo. C) Gráfico de Bland-Altman para la comparación de ambos métodos; la línea negra representa la media de la diferencia, las líneas rojas punteadas el intervalo de confianza al 95\% de la media, las líneas naranja punteadas representan el rango intercuartil al 95\%. valo de confianza [IC] 95\% de 0.46-0.90, prueba t de Student de una muestra), excluyendo del mismo modo los valores atípicos (outliers) en dicho análisis (Figura C9.2C). Análisis: En cuanto a la comparación de ambos métodos de medición de la hemoglobina, se encontró un sesgo positivo a favor del método no invasivo (NBM-200) de $0.68 \mathrm{~g} / \mathrm{dL}$. Tomando en cuenta el mejor modelo de regresión obtenido, las variables sexo y el propio intercepto son independientes de la cifra de hemoglobina obtenida y ambas cuentan con significancia estadística; sin embargo, la proporción de variación de los resultados que puede explicarse por dicho modelo es poca. Las variables estatura, peso, IMC, edad y diferencia de los métodos no fueron estadísticamente significativas en ninguno de los modelos de regresión. Conclusión: Se encontró una diferencia marcada de las cifras de hemoglobina entre ambos sexos, aunque la disparidad de éstos en nuestra población de estudio, así como la cantidad de datos analizados, puede llevar a interpretaciones erróneas precipitadas. Si bien, el mejor modelo de regresión obtenido se ajusta a nuestros objetivos, éste no posee las características ideales ni la calidad para poder emplear el método no invasivo del NBM-200 como tamizaje de donadores de sangre, considerando que la capacidad explicativa de dicho modelo no posee las características ideales para el uso de este método como tamizaje de donadores de sangre.

\section{Referencias}

1. Norma Oficial Mexicana NOM-253-SSA1-2012. Para la disposición de sangre humana y sus componentes con fines terapéuticos. Diario Oficial (tercera sección). Poder Ejecutivo. Secretaría de Salud. México, D.F. 26 de octubre de 2012.

2. Kim MJ, Park Q, Kim MH, Shin JW, Kim HO. Comparison of the accuracy of noninvasive hemoglobin sensor (NBM-200) and portable hemoglobinometer (HemoCue) with an automated hematology analyzer (LH500) in blood donor screening. Ann Lab Med. 2013; 33: 261-267.

3. Belardinelli A, Benni M, Tazzari P L, Pagliaro P. Noninvasive methods for haemoglobin screening in prospective blood donors. Vox Sanguinis. 2013; 105: 116-120.

C10. Características demográficas de los donadores en Banco de Sangre de la UMAE No. 2 Sonora Nafarrate-Cota Rosa Isela,* Galindo-Alvarado María Leticia,* Cervera-Bustamante J osé Enrique G,* McGregorMeza Phillip Alexander,* Michaelis-Topete J orge Alberto,* Sánchez-Medina Fernando*

* UMAE del Hospital de Especialidades No. 2, Centro Médico Nacional del Noroeste.

I ntroducción: El objetivo del proceso de selección de los candidatos a donar es determinar si la persona se encuentra en condiciones adecuadas para realizar la donación, dentro de estas características debe cumplir con ser mayor de edad y por NOM253-SSA-2012 no mayor a 65 años según el punto 6.10.4.2. Objetivo: Analizar las características demográficas de los donadores en Banco de Sangre de la UMAE No. 2 Sonora. Material y métodos: 
Estudio observacional, descriptivo, retrospectivo, transversal. Se estudió durante el último semestre comprendido de diciembre 2020 a mayo de 2021, las características demográficas de los donadores en Banco de Sangre de Cd. Obregón, Sonora, IMSS. Resultados: De los 2,767 donadores efectivos que se tuvieron en el semestre referido, el mayor porcentaje fue el sexo masculino en el rango etario de 25 a 44 años de edad (Tabla C10.1) en $43.5 \%$ (n $=1,206)$, seguido del rango etario de 18-24 años $32.1 \%(n=890)$, y en tercer lugar el sexo femenino en su rango etario de 25-44 años de edad en un $7.9 \%(n=220)$. La población donante de edades comprendidas entre los 45 a 65 años de edad comprende un $10.8 \%$ entre ambos sexos. En relación con las unidades sanguíneas donadas de acuerdo a su tipo $A B O$ y $R h$ (D) fueron (Figura C10.1): en un $57 \%(n=1,572)$ el tipo $0+$, seguido de $A+26 \%$ ( $n$ $=723)$, y $B+7.5 \%(n=209)$, los donadores de menor afluencia fue $A B$ - en un $0.1 \%(n=6)$. Análisis: Nuestro Banco de Sangre atiende a donadores en un rango de 18 a 65 años, siendo el sexo femenino el que menos acude al Ilamado. La prevalencia de grupos sanguíneos de los donantes es concordante con lo reportado en México, siendo el primer lugar en grupos sanguíneos el 0 positivo en un $60-70 \%$. Conclusiones: Es importante que se tenga la información de la población donante que más acude

\section{Tabla C10.1: Sexo y edad de los donadores.}

\begin{tabular}{lrrrrrrr} 
& \multicolumn{3}{c}{ Femenino } & & \multicolumn{3}{c}{ Masculino } \\
\cline { 2 - 3 } \cline { 7 - 8 } Mes & $18-24$ & $25-44$ & $45-66$ & & $18-24$ & $25-44$ & $45-66$ \\
\hline Diciembre & 20 & 39 & 7 & & 128 & 180 & 29 \\
Enero & 23 & 30 & 11 & & 187 & 113 & 29 \\
Febrero & 34 & 48 & 12 & & 128 & 201 & 33 \\
Marzo & 23 & 39 & 8 & & 136 & 224 & 41 \\
Abril & 17 & 35 & 9 & & 148 & 218 & 57 \\
Mayo & 33 & 29 & 7 & & 163 & 270 & 58 \\
Total & 150 & 220 & 54 & & 890 & 1,206 & 247 \\
\hline
\end{tabular}

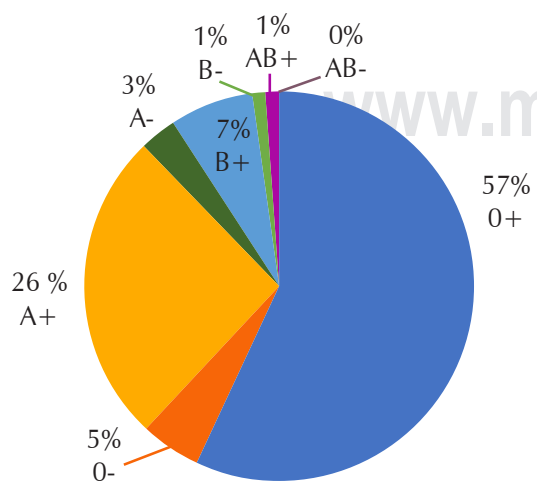

Figura C10.1: Grupos sanguíneos de donantes. con nosotros a practicar este acto de generosidad de donación sanguínea, y promover y actuar en la donación altruista en todos los grupos.

C11. Efecto de inactivación de patógenos sobre la concentración de anticuerpos SARS-CoV-2 en plasma convaleciente

Fernández-Sánchez E,*,‡ Sierra Madero Juan G,\$ Bermúdez-Ferro KE,* Barrientos-Galeana E,* MontesBarragán S,* Robles-Hernández SG,* López-Martínez $\mathrm{H}^{*}$ * Departamento de Hematología y Banco de Sangre, Instituto Nacional de Cancerología, México. ₹ Centro Nacional de la Transfusión Sanguínea. México. ${ }^{\S}$ Departamento de Infectología, Instituto Nacional de Ciencias Médicas y Nutrición Salvador Zubirán, México.

Introducción: La actual pandemia de coronavirus SARS-CoV- 2 ha impulsado diversas líneas de investigación entre las que se encuentra el uso de plasma convaleciente como auxiliar en el tratamiento de la enfermedad. Diversos estudios en el ámbito internacional han utilizado tecnología de reducción de patógenos ${ }^{1,2}$ con el propósito de aumentar la seguridad transfusional debido al riesgo de contacto reciente con el virus, infección latente o asintomática del donador, así como el desconocimiento exacto del tiempo de incubación y mecanismos de transmisión del virus. Diversos estudios han evidenciado que el uso de dichas tecnologías genera cambios en proteínas, disminuyendo el efecto terapéutico de productos sanguíneos. ${ }^{3,4}$ Objetivo: Evaluar el efecto de riboflavina y luz UVB como método de inactivación de patógenos sobre la concentración de anticuerpos anti SARS-CoV-2 en plasma convaleciente. Material y métodos: Alícuotas almacenadas a $-70{ }^{\circ} \mathrm{C}$ hasta su procesamiento. Inmunoensayo por quimioluminiscencia IgG antiglicoproteína espicular para subunidades 1 y 2 (Liason XL, Diasorin). Análisis estadístico con $t$ de Student (Figura C11.1). Resultados: Los resultados obtenidos se muestran en la Figura C11.2A y B. Conclusión: El uso de tecnologías de inactivación no presenta cambios en la concentración IgG anti SARSCoV-2; por lo que el uso de inactivación no debe ser considerado como factor que altere la integridad del producto o tenga un impacto negativo sobre el posible efecto terapéutico en el uso como tratamiento para la infección por SARS-CoV-2.

\section{Referencias}

Keil SD, Ragan I, Yonemura S, Hartson L, Dart NK, Bowen R. Inactivation of severe acute respiratory syndrome coronavirus 2 in plasma and platelet products using a riboflavin and ultraviolet light-based photochemical treatment. Vox Sang. 2020; 115 (6): 495-501.

2. Marquez FG, Riviello-Goya S, Vargas Ruiz AG, Ortíz Brizuela E, Gil López F, Gutierrez Marín A et al. Low rate of thrombosis in Mexican patients with COVID-19 infection. a Benefit of higher doses anticoagulants or a sub diagnosis? Blood. 2020; 136: 29-30.

3. Estcourt LJ, Malouf R, Hopewell S, Trivella M, Doree C, Stanworth SJ et al. Pathogen-reduced platelets for the prevention of bleeding. Cochrane Database Syst Rev. 2017; 7 (7): CD009072.

4. Jimenez-Marco T, Quetglas-Oliver M. Alternative methods of platelet storage and pathogen reduction. ISBT Science Series. 2021; 1-7. 


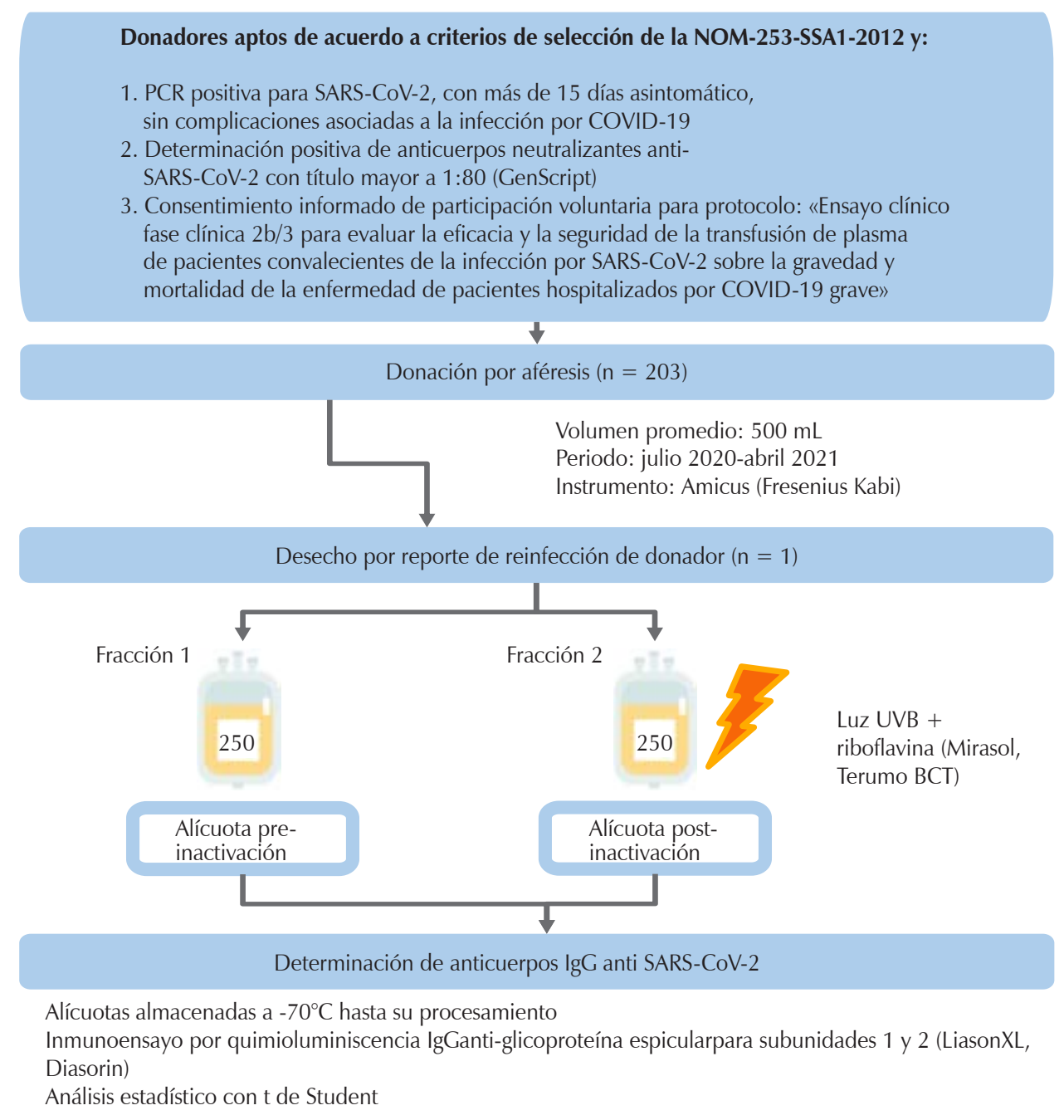

A

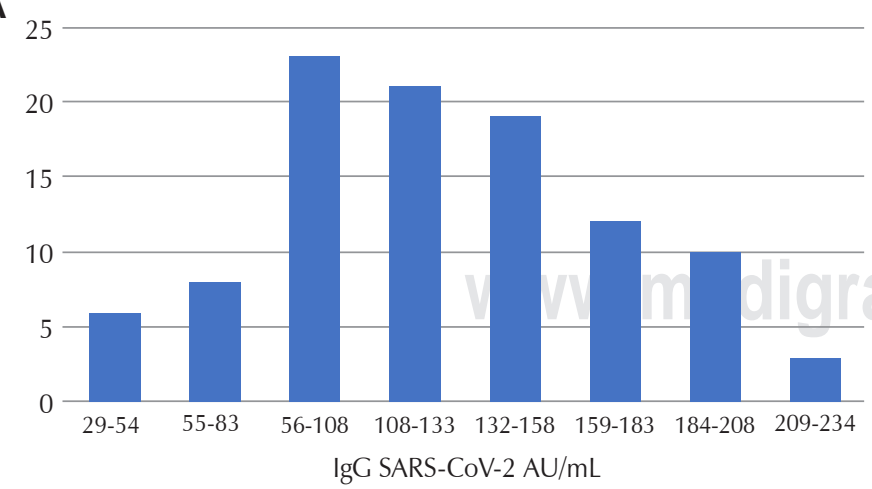

B

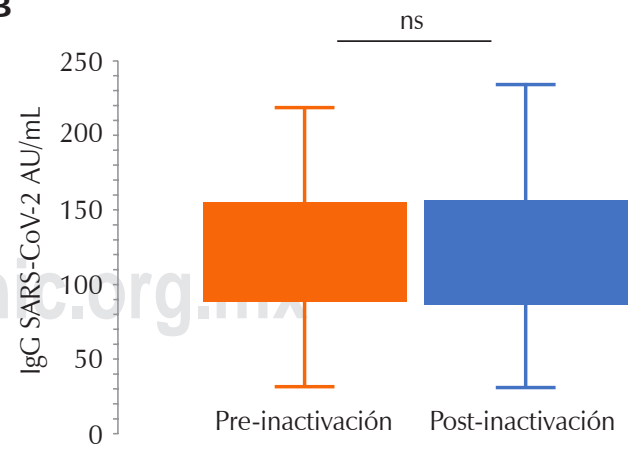

Figura C11.2: Efecto de riboflavina y luz UVB como método de inactivación de patógenos sobre la concentración de anticuerpos anti SARS-CoV-2. A) Distribución de anticuerpos IgG SARS-CoV-2 en donadores de plasma convaleciente. B) Efecto en la concentración de anticuerpos IgG pre y postratamiento de inactivación con riboflavina y luz UV (Mirasol). ns $=$ sin diferencia estadística, p $>0.05$. 
C12. Efectividad de irradiación y riboflavina/luz ultravioleta B sobre la actividad de linfocitos T residuales en concentrados plaquetarios

Bermúdez-Ferro KE,* Schcolnik-Cabrera $A, \neq$ ChávezBlanco A, ${ }^{\S}$ Barrientos-Galeana E,* Montes-Barragán S,* Fernández-Sánchez $\mathrm{E}^{*}, \uparrow$

* Departamento de Hematología y Banco de Sangre, Instituto Nacional de Cancerología, México. ₹ Département de Biochimie et Médicine Moléculaire, Université de Montréal. Montréal, QC, Canada. § División de Investigación Básica, Instituto Nacional de Cancerología, México. " Centro Nacional de la Transfusión Sanguínea, México.

I ntroducción: La transfusión de componentes sanguíneos conlleva el riesgo de desarrollar reacciones adver-
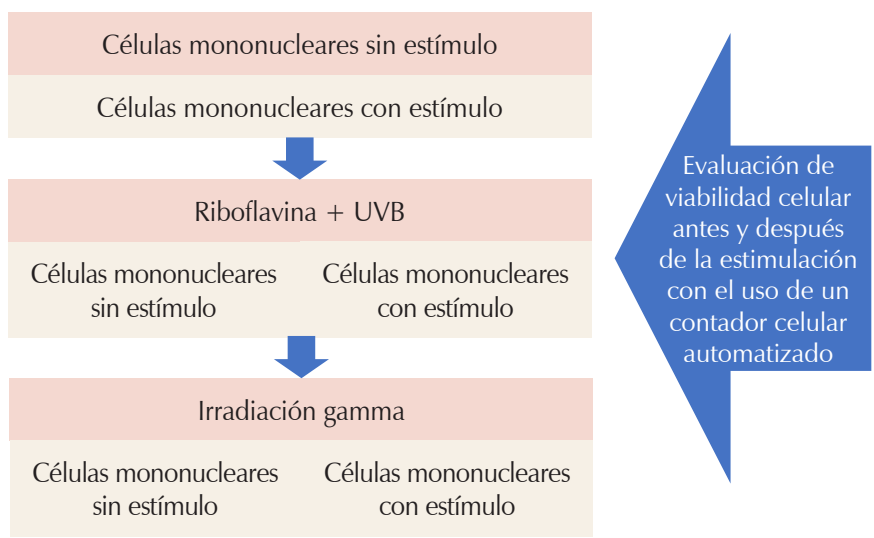

Al final del tiempo de estimulación se recuperó el botón celular y se congeló a $-80^{\circ} \mathrm{C}$ para el análisis posterior de IL-2

Se cuantificó IL-2 con el kit ELISA Max Deluxe Set Human IL-2

(BioLegend), en el sobrenadante de células con o sin estimulación

Figura C12.1. sas mediadas por la activación de la respuesta inmune, como la enfermedad de injerto contra huésped asociada con la transfusión (EICH-AT). ${ }^{1}$ Los componentes pueden ser inactivados o irradiados con el propósito de limitar la capacidad de replicación y respuesta de linfocitos $T$ residuales; ${ }^{2}$ sin embargo, se requieren estudios que permitan evaluar y comparar la efectividad de dichos métodos. 3,4 Objetivo: Comparar la eficacia de irradiación y el uso de riboflavina y luz ultravioleta $B(R+U V)$ como métodos de inactivación de linfocitos $T$ residuales en concentrados plaquetarios. Material y métodos: Estudio experimental, controlado, no aleatorizado. Las muestras de estudio fueron concentrados plaquetarios obtenidas por fraccionamiento de sangre total de donadores. Las unidades fueron expuestas a inactivación (Mirasol, Terumo BCT) o irradiados (25 Gy). Los análisis estadísticos realizados fueron análisis de varianza (ANOVA) de una vía con corrección de Dunnett para la comparación de viabilidad, y t de Student no pareada de dos colas para la comparación de la concentración de IL-2. Un valor de $\mathrm{p}<0.05$ se consideró estadísticamente significativo (Figura C12.1). Resultados: Los resultados obtenidos se muestran en la Figura C12.2A y B. Conclusión: EI tratamiento de concentrados plaquetarios con R + UV muestra una mayor efectividad sobre la irradiación en linfocitos $T$ residuales, al presentar éstas menor viabilidad celular de base, y menor capacidad de respuesta ante el estímulo para su replicación y producción de IL-2.

\section{Referencias}

1. Marschner S, Fast LD, Baldwin WM 3rd, Slichter SJ, Goodrich RP. White blood cell inactivation after treatment with riboflavin and ultraviolet light. Transfusion. 2010; 50 (11): 2489-2498.

2. Fast LD, DiLeone G, Marschner S. Inactivation of human white blood cells in platelet products after pathogen reduction technology treatment in comparison to gamma irradiation. Transfusion. 2011; 51 (7): 1397-1404

3. Loren D. Fast, et al. Inactivation of Human White Blood Cells in Red Blood Cell Products Using Mirasol Pathogen Reduction Technology (PRT). Transfusion 2013:53:373-381.
A

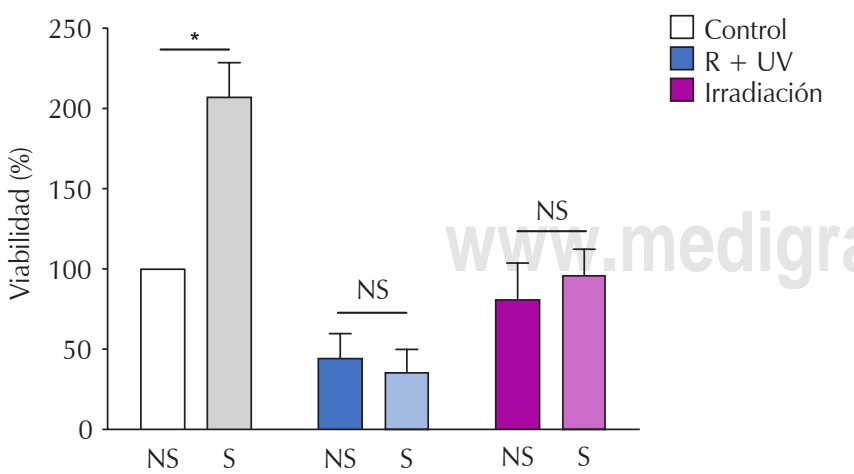

B

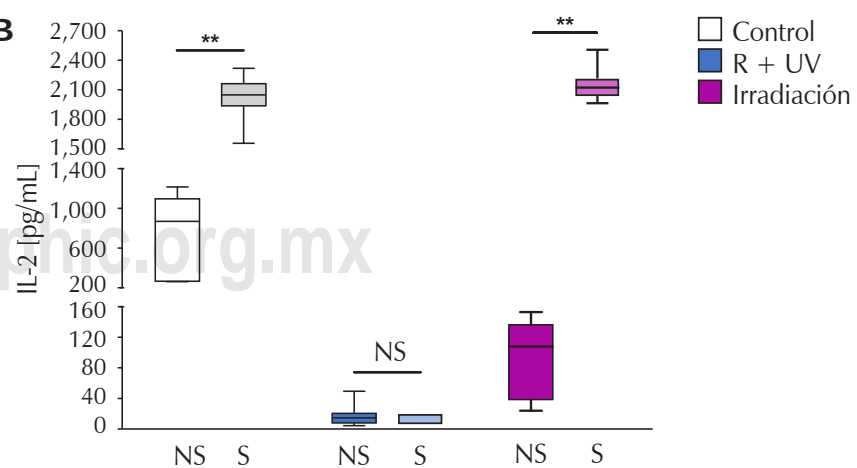

Figura C12.2: Eficacia de irradiación y riboflavina + luz ultravioleta $(R+U V)$ como métodos de inactivación sobre linfocitos T residuales en concentrados plaquetarios. A) Efecto de I+ PMA sobre viabilidad celular. B) Concentración de IL-2 en células residuales de concentrados plaquetarios sometidas a estímulo. Para ambos experimentos se consideraron ensayos control que no fueron sometidos a ningún tipo de tratamiento; se realizaron tres replicados biológicos independientes con tres replicados técnicos internos. I+ PMA $=$ ionomicina, forbol, miristato y acetato; $N S=$ sin estimulación; $S=$ estimulación; $n s=$ sin diferencia estadística. ${ }^{*} \mathrm{p} \leq 0.001 ;{ }^{* *} \mathrm{p} \leq 0.0001$. 
4. Kopolovic I, Ostro J, Tsubota H, Lin Y, Cserti-Gazdewich CM, Messner $\mathrm{HA}$ et al. A systematic review of transfusion-associated graft-versushost disease. Blood. 2015; 126 (3): 406-414.

C13. Obtención de valores de referencia hematológicos de la población de donadores del Banco de Sangre del Instituto Nacional de Pediatría SSA

Jaloma Avendaño Roberto Enrique,* Monreal Olmedo Adriana, ${ }^{\ddagger}$ Maldonado Silva Karla ${ }^{\S}$

* Jefe del Laboratorio de Banco de Sangre del Instituto Nacional de Pediatría. ₹ Químico adscrito del Banco de Sangre del Instituto Nacional de Pediatría. ${ }^{\S}$ Médico J efa del Departamento de Banco de Sangre del Instituto Nacional de Pediatría.

I ntroducción: Un problema prioritario para la Organización Mundial de la Salud (OMS) y la Organización Panamericana de la Salud (OPS), ha sido el acceso universal a la sangre segura y la autosuficiencia en todos los bancos de sangre para disminuir los índices de diferimiento de los países de América; México siguiendo los lineamientos establecidos por la OMS y OPS generó una serie de directrices que se manifiestan en la NOM-253-SSA1-2012 Para la disposición de sangre humana y sus componentes con fines terapéuticos, dentro las cuales consideraron, entre otras cosas, los criterios hematológicos para la aceptación o rechazo de candidatos a donación; sin embargo, únicamente se establecieron valores mínimos de hemoglobina, hematocrito y plaquetas, quedando a la deriva los valores máximos permitidos, además de los valores de leucocitos totales indispensables en la valoración clínica de los candidatos a donación. Objetivo: Obtener los valores de referencia hematológicos de los analitos hemoglobina, hematocrito, leucocitos totales y plaquetas; por medio del análisis retrospectivo de la población mexicana atendida en el Banco de Sangre del INP, comparar el resultado con los estipulados en NOM-253-SSA1-2012 y generar valores que no se encuentran descritos. Material y métodos: Con el fin de poder generar valores apegados a la población mexicana, estadísticamente se buscó generar rangos de referencia a través de los lineamientos de las guías de la CLSI (protocolo EP28 A3C); llevando a cabo el análisis retrospectivo de 41,927 donadores de 29 estados del país, en un periodo comprendido del 1 de enero de 2015 al 30 de junio de 2021; obteniendo los valores de percentil 3 y percentil 97 para cada analito y así calcular los valores de referencia específicos. Resultados: Los resultados obtenidos se muestran en las Tablas C13.1 y C13.2. Conclusiones: Utilizando los valores hematológicos obtenidos de la población mexicana atendida en el Banco de Sangre del INP de enero 2015 a junio 2021 (41,927 donadores), se lograron obtener los rangos de referencia por medios estadísticos y al compararlos con los estipulados en la Norma-253-SSA1-2012 son muy similares, además de obtener los valores de los leucocitos totales y los valores altos, los cuales no se encuentran mencionados en la Norma y que son de vital importancia para poder aceptar o rechazar a los candidatos a donación. Conocer los valores de referencia de la población mexicana (donadores de 29 estados del país) es una herramienta en pro de la seguridad transfusional, al reforzar el pilar de la selección del donador y con ello garantizar la disminución de los índices de diferimiento al conocer los valores en los que fluctúan nuestra población, incrementando la autosuficiencia de los servicios de sangre.

\section{Referencias}

1. NORMA Oficial Mexicana NOM-253-SSA1-2012, Para la disposición de sangre humana y sus componentes con fines terapéuticos.

2. Clinical and Laboratory Standards Institute (CLSI). Defining, establishing, and verifying reference intervals in the clinical laboratory. 3rd ed. Pennsylvania, USA: CLSI; 2008.

3. Suministro de sangre para transfusiones en los países del Caribe y Latinoamérica en 2005: Datos Basales para el Plan Regional de Acción para Seguridad Transfusional 2006-2010.

\begin{tabular}{lcc}
\hline \multicolumn{3}{c}{ Tabla C13.2: Rangos de referencia. } \\
& Mujeres & Hombres \\
\hline Hematocrito $(\%)$ & $32.8-48.0$ & $42.5-58.7$ \\
Hemoglobina $(\mathrm{g} / \mathrm{dL})$ & $12.6-17.5$ & $14.5-20.0$ \\
Leucocitos totales $\left(\times 10^{3} / \mu \mathrm{L}\right)$ & $4.2-11.8$ & $4.1-11.5$ \\
Plaquetas $\left(\times 10^{3} / \mu\right)$ & $157-474$ & $152-480$ \\
\hline
\end{tabular}

Tabla C13.1: Valores promedio por rangos de edad.

\begin{tabular}{|c|c|c|c|c|c|c|c|c|}
\hline Total de datos & 3,779 & 8,704 & 2,172 & 14,655 & 6,271 & 16,744 & 4,257 & 27,272 \\
\hline Edad & 20.9 & 33.5 & 50.9 & 32.8 & 21.1 & 33.6 & 50.6 & 33.4 \\
\hline Hematocrito (\%) & 43.3 & 43.4 & 43.6 & 43.4 & 49.7 & 50.1 & 49.8 & 50 \\
\hline Hemoglobina $(\mathrm{g} / \mathrm{dL})$ & 14.8 & 14.9 & 14.9 & 14.9 & 17 & 17 & 16.9 & 17 \\
\hline
\end{tabular}


C14. Correlación de grupo sanguíneo con linfopenia en la susceptibilidad a contagio de SARS-CoV-2, presente en los candidatos a donar del Instituto Nacional de Pediatría de abril a junio de 2021 Monreal Olmedo Adriana,* Maldonado Silva Karla, ${ }^{\prime}$ Jaloma Avendaño Roberto $\mathrm{E}^{\S}$

* Químico adscrito del Banco de Sangre del Instituto Nacional de Pediatría. * Médico adscrito y Jefa del Departamento de Banco de Sangre del Instituto Nacional de Pediatría. § Químico adscrito y Jefe del Laboratorio de Banco de Sangre del Instituto Nacional de Pediatría.

Introducción: En la población nacional mexicana existen muchos factores de riesgo para adquirir SARSCoV-2, entre estos factores se encuentran la edad, género y enfermedades de predisposición a comorbilidad; debido a estos riesgos, se han tenido que actualizar las recomendaciones para el diferimiento de donantes. Conforme señalan los estudios de Yang y Cheng, la linfopenia no sólo se perfila como un biomarcador que podría tener una gran utilidad para predecir de forma rápida la evolución de casos críticos donde $85 \%$ de los pacientes con SARS-CoV-2 grave tienen linfopenia, esto motiva un interés por conocer si los antígenos del sistema $A B O$ juegan un papel de susceptibilidad a infección por SARS-CoV-2. Objetivo: Analizar si existe una posible asociación entre el grupo sanguíneo $A B O$ en la susceptibilidad a contagio de SARS-CoV- 2 de los candidatos a donar, a través de linfopenia como respuesta adaptativa, en el Instituto Nacional de Pediatría en el periodo de abril a junio del 2021. Material y métodos: Se realizó un estudio retrospectivo de los resultados de la biometría hemática realizadas a los candidatos a donar así de como su grupo sanguíneo ABO de abril a junio del 2021, se tomaron los grupos sanguíneos de aquéllos que se difirieron por linfopenia (linfocitos $<1.5$ ) y se llevó a cabo la correlación (Figura C14.1). Resultados: De 1,757 candidatos a donar comprendidos en ese periodo, 118 tuvieron linfocitos por debajo de 1,500 células/ $\mu \mathrm{L}$ en la biometría hemática (por lo que se difirieron), resultaron 72 del grupo $0(61 \%), 37$ del grupo A $(31 \%)$, siete del grupo $B(6 \%)$ y dos del grupo AB (1.7\%). Conclusiones: De los resultados obtenidos se concluye que, con nuestros datos, no es posible confirmar una correlación de susceptibilidad a contagio por SARS-CoV-2 debido al grupo sanguíneo, como se menciona en los artículos citados en la referencia, ${ }^{1-3}$ porque ningún individuo fue caso confirmado al no existir en protocolos del Instituto Nacional de Pediatría previos análisis de PCR al referir atención especial a menores. Se requieren estudios adicionales antes de aceptar con nuestros datos que el grupo sanguíneo es un determinante de predisposición a contagio a SARS-CoV-2, a pesar de que la linfopenia se perfila como biomarcador. Se observó que los candidatos a donar que resultaron linfopénicos la mayoría fue grupo $O$, seguidos de grupo $A$, en la suposición que la linfopenia debiera señalar una infección por SARS-CoV-2, los resultados pertenecen a la prevalencia normal de grupo ABO en México. Todo lo contrario de lo reportado en la literatura, ${ }^{1-3}$ donde

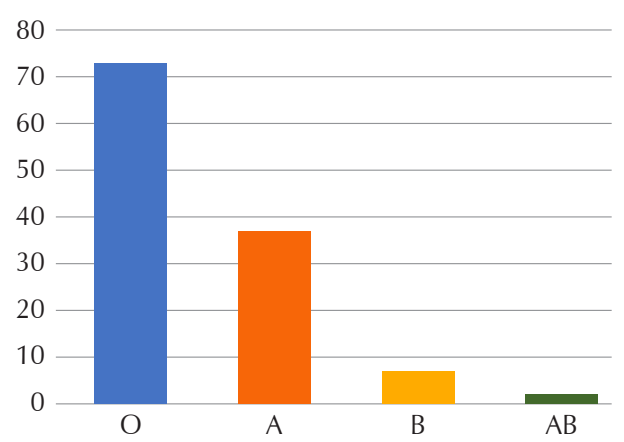

Figura C14.1: Linfopenia por grupo ABO.

se menciona que la mayor susceptibilidad de contagio se encuentra en el grupo A y B.

\section{Referencias}

1. Zalba Marcos S, Antelo ML, Galbete A, Etayo M, Ongay E, García-Erce JA. Infección y trombosis asociada a la COVID-19, posible papel del grupo sanguíneo ABO. Med Clin (Barc). 2020; 155 (8): 340-343.

2. Tamayo-Velasco A, Jiménez García MT, Sánchez Rodríguez A, Hijas Villaizan M, Carretero Gómez J, Miramontes-González JP. Asociación del grupo sanguíneo A con mayor comorbilidad hospitalaria en pacientes infectados por SARS-CoV-2. Med Clin (Barc). 2021.

3. Torres-Alarcón CG, García-Ruíz A, Cañete-Ibáñez CR, Morales-Pogoda II, Muñoz-Arce CM, Cid-Domínguez BE et al. Antígenos del sistema sanguíneo $\mathrm{ABO}$ como factor de riesgo para la gravedad de la infección por SARS-CoV-2. Gac Méd Méx. 2021; 157 (2): 181-187.

C15. I ncidencia de reacciones adversas en los donadores de Banco de Sangre UMAE No. 2

Nafarrate-Cota RI,* García-Verdugo LE,* León-Valenzuela MA,* Placencia-Velázquez VG,* Galindo-Alvarado ML* * Hospital de Especialidades No. 2, Centro Médico Nacional del Noroeste.

I ntroducción: Debemos cumplir con la normativa de tener procedimientos de prevención, tratamiento y registro de las reacciones o efectos adversos que puedan ocurrir en los donantes; así como contar con instrucciones del actuar en cada caso. Lo anterior lo debe registrar el personal que lleva a cabo la extracción con el respaldo del médico evaluador o el médico designado para evaluar las reacciones asociadas a la donación. Objetivo: Determinar la incidencia de reacciones adversas en los donadores de Banco de Sangre UMAE No. 2. Material y métodos: Estudio observacional, descriptivo, retrospectivo, transversal. Se estudió durante el último semestre, comprendido de diciembre 2020 a mayo del 2021, la cantidad de reacciones adversas en los donadores de Banco de Sangre UMAE $\mathrm{N}^{\circ} 2$, tomado de la bitácora de registro del personal encargado de la extracción sanguínea. Resultados: De las 2,767 donaciones efectuadas durante el último semestre (Figura C15.1), se tuvieron 218 reacciones $(8 \%)$, siendo el primer lugar (Figura C15.2) las reacciones vasovagales (Tabla C15.1) 76.10\% $(n=166)$, seguido de sangrado tardío en $9.6 \%(n=$ $21)$, convulsiones $6.4 \%(n=14)$, náuseas/vómito $5.5 \%$ $(n=12)$, síncope $1.8 \%(n=4)$ y hematoma $0.45 \%(n$ 


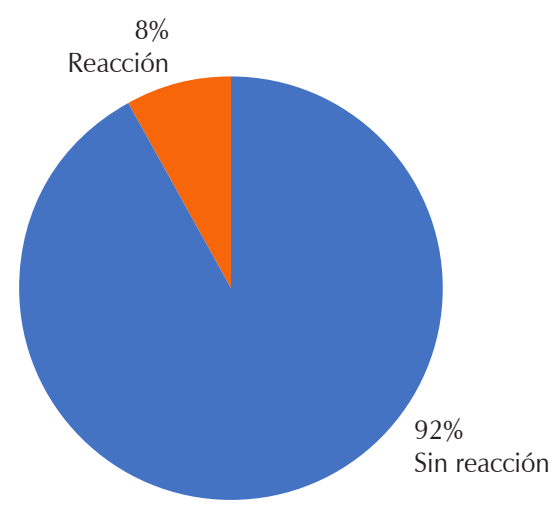

Figura C15.1: Porcentaje de reacciones.

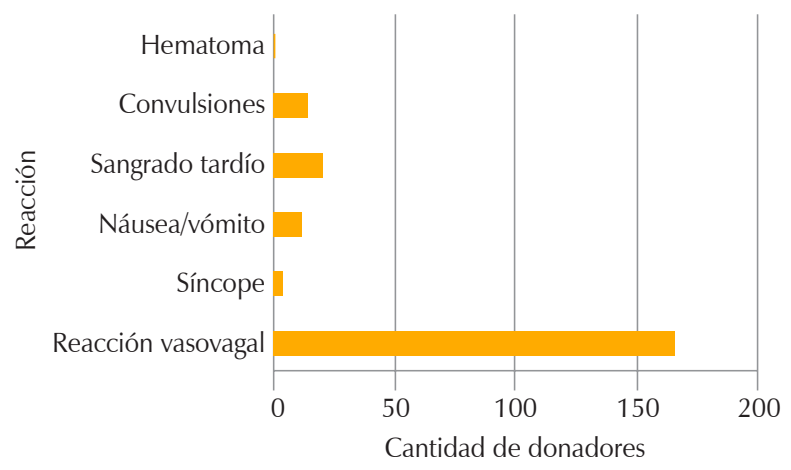

Figura C15.2: Tipos de reacciones.

\begin{tabular}{lcccc}
\hline \multicolumn{5}{c}{ Tabla C15.1: Distribución por sexo y edades. } \\
\hline \multicolumn{5}{c}{ Reacción vasovagal } \\
\hline Edad & $18-24$ & $25-39$ & $40-65$ & Total \\
Femenino & 13 & 11 & 4 & 28 \\
Masculino & 62 & 59 & 17 & 138 \\
Total & 75 & 70 & 21 & 166 \\
\hline
\end{tabular}

=1). Análisis: El primer lugar está ocupado por las reacciones vasovagales, lo cual, en la región árida en la que nos encontramos, ha llegado a temperaturas de más de 45 oC con humedad de hasta $70 \%$, lo que nos hace propensos a este tipo de reacciones, ya que el calor, asociado a las horas de ayuno, son factores propicios para tenerlas. Conclusión: Hay que reforzar el manual de reacciones adversas en el proceso de donación que llevan en conjunto al personal de extracción y la parte médica en el actuar de este tipo de reacciones. Debemos trabajar en la reducción de ese $8 \%$ de reacciones asociadas a la donación sanguínea que se ha venido presentando en el último semestre.

C16. Predicción del evento adverso a la donación mediante inteligencia artificial basada en neural Network
Hernández Olicón AP,*,‡ Baptista González HA, ${ }^{\ddagger, \S}$ Hernández J iménez $R,{ }^{\ddagger}$ Carreño Durán LR*

* Laboratorio de Diagnóstico Molecular. Departamento de Bioquímica. Escuela Nacional de Ciencias Biológicas. IPN. ‡ Banco de Sangre y Medicina Transfusional. Hospital Médica Sur. § Hematología-Perinatal. I nstituto Nacional de Perinatología.

Introducción: El principio de la seguridad en el donante está orientado a la prevención y reducción de la ocurrencia del evento adverso a la donación (EAD) que inevitablemente genera una experiencia desagradable que disminuye el interés y disposición de las personas, propiciando una falla en la etapa de donación segura. Se debe a reacciones vasovagales por el estrés psicológico de la situación o a factores neurológicos. Los Bancos de Sangre tienen la responsabilidad de establecer estrategias para prevenir y detectar tempranamente la presencia de reacciones adversas. Los EAD no previsibles por la dificultad para su detección y atención, son un factor importante a tener en cuenta en cualquier Servicio de Banco de Sangre, al tener una causa multifactorial, la preservación de la salud del donante de sangre que presenta una EAD en gran medida está determinada por la experiencia que tiene el personal en la identificación y atención rápida y adecuada de ésta. Los algoritmos de inteligencia artificial como los Neural Networks (NN) de aprendizaje supervisado, se encargan de encontrar patrones de un gran número de datos, por esta naturaleza les es posible aprender examinando los registros individuales, generando una predicción para cada registro y realizando ajustes a las ponderaciones cuando realiza una predicción incorrecta. Este proceso se repite muchas veces (entrenamiento), mejorando sus predicciones hasta haber alcanzado uno o varios criterios de parada, es decir, hasta alcanzar un entrenamiento suficiente que siga prediciendo confiablemente. A medida que progresa el entrenamiento, el NN se va haciendo cada vez más preciso en la replicación de resultados conocidos. Una vez entrenada, la red se puede aplicar a casos futuros en los que se desconoce el resultado. Objetivo: Diseñar un algoritmo que prediga la no ocurrencia del EAD asociado a la donación mediante un Neural Network. Material y métodos: Se diseñaron cinco arquitecturas de NN a partir del lenguaje de programación $\mathrm{R}$, empleando Rstudio ${ }^{\circledR}$, utilizando 1,000 datos de donantes obtenidos en el Banco de Sangre y Medicina Transfusional del Hospital Médica Sur, considerando 14 variables independientes que pueden influenciar el EAD. Los datos fueron repartidos aleatoriamente en un subconjunto de entrenamiento y otro de validación, en una proporción de 75/25, respectivamente. Resultados: La arquitectura del NN con mayor eficiencia en la predicción del EAD se configuró con una capa de entrada, cuatro capas ocultas con seis perceptrones y una capa de salida, empleando el algoritmo R prop+y un factor de activación logístico realizando 50 repeticiones. Las variables que se consideraron son las que evalúa el clínico en el Banco de Sangre para calificar 
A

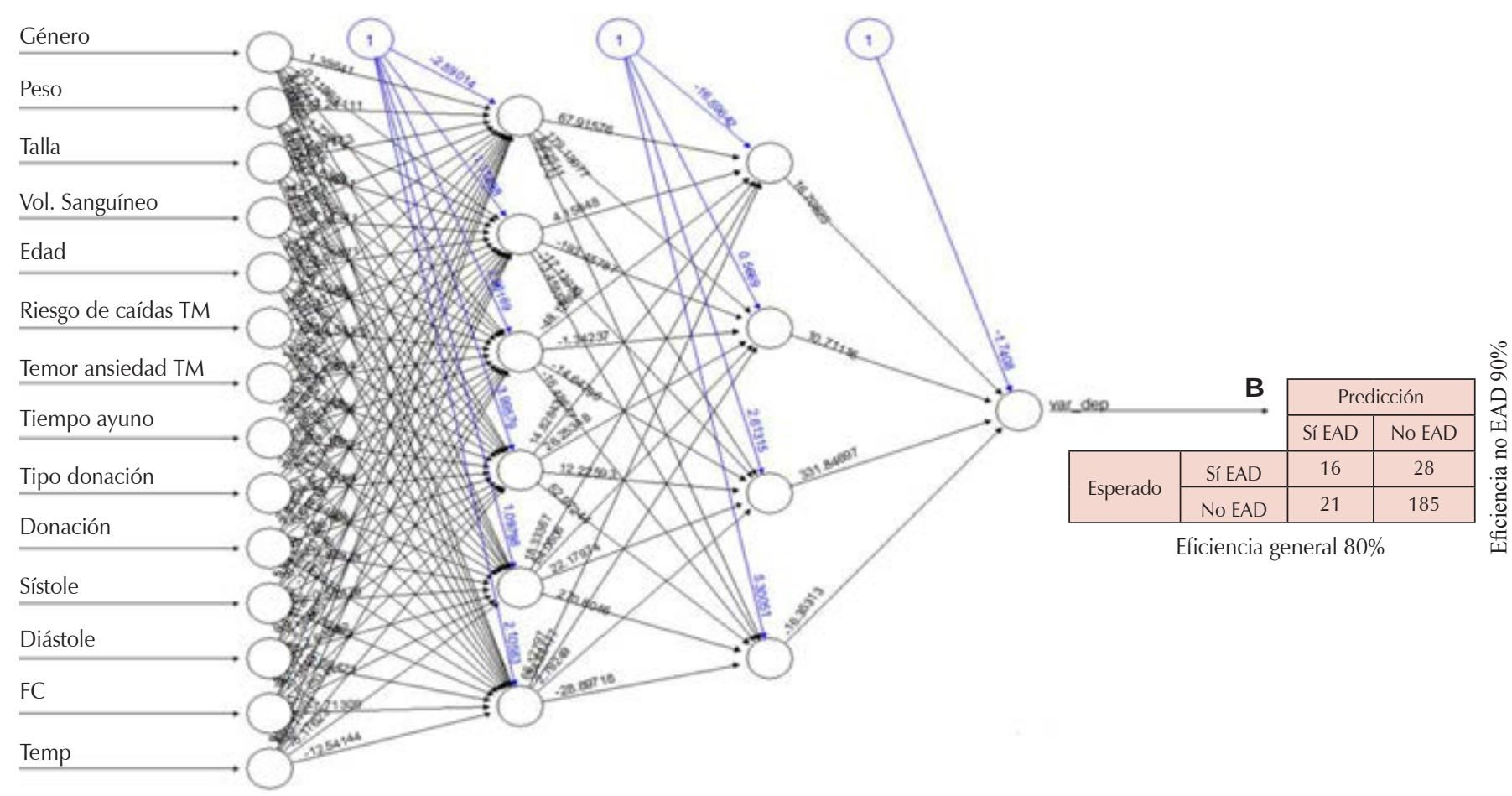

Figura C16.1: Algoritmo de predicción del EAD. A). Neural Network diseñado. B) Cuadro de contingencia para cálculo de la eficiencia.

el riesgo de ocurrencia del EAD: género, peso, talla, volumen sanguíneo, edad, riesgo de caídas, temor y ansiedad, tiempo de ayuno, si es su primera vez de donación, el tipo de componente, sístole, diástole, frecuencia cardiaca y temperatura. Partiendo de una base de datos de 1,000 donantes, se empleó $75 \%$ de esta base para generar el entrenamiento, el restante $25 \%$ corresponde a 250 donantes particionados al azar, de éstos, 204 no presentaron evento adverso y se clasificaron apropiadamente 173 , obteniendo $85 \%$ de confiabilidad. La eficiencia general del algoritmo es de $74 \%$ para predecir confiablemente la ocurrencia o no de un EAD. En un segundo entrenamiento del algoritmo diseñado, la prueba de validación arrojó que: de los 250 donantes estudiados, 206 no presentaron EAD y se identificaron correctamente 185 , lo que dio una eficiencia del $90 \%$ para predecir un No EAD. La eficiencia del algoritmo para predecir correctamente si un donante presentará o no alguna reacción asociada la donación fue de 80\% (Figura C16.1). Conclusión: La predicción del EAD de forma rutinaria en el Banco de Sangre representa un gran reto por la complejidad de las variables inherentes al donador, incluso para el profesional más experimentado, por lo que la inclusión de metodologías de inteligencia artificial innovadoras como el algoritmo de Neural Network diseñado para la predicción del evento adverso a la donación, brinda $80 \%$ de seguridad adicional en la selección del candidato a donación; este modelo puede replicarse en otros sitios de colecta, considerando sus propias variables, tanto cuantitativas como cualitativas, contribuyendo en una práctica más segura, disminuyendo el riesgo de complicaciones al donante.

C17. Incidencia de anticuerpos irregulares el Centro Estatal de la Transfusión Sanguínea de Jalisco. Registro de 3 años

García Reyes B,* De la Mora López PA, ${ }^{\ddagger}$ Jiménez López $Y_{,}{ }^{\S}$ Ortega Pérez MI , ${ }^{\S}$ Huerta Enríquez EA, ${ }^{\S}$ Robles Aldaz $L M,{ }^{\S}$ Juárez Aguilar $R,{ }^{\S}$ Galván Huerta $U,{ }^{\S}$ Martín del Campo Godínez TE, $\$$ Navarrete Castañeda I, $\$$ Ruelas Montaño AK§

* Médico Hematóloga, Coordinación de Inmunohematología. Centro Estatal de la Transfusión Sanguínea Jalisco. ₹ Directora del Centro Estatal de la Transfusión Sanguínea Jalisco. § Químicos adscritos al Área de Inmunohematología. Centro Estatal de la Transfusión Sanguínea Jalisco.

Antecedentes: La detección e identificación de anticuerpos irregulares, así como la evaluación de su significado clínico en pacientes que requieren una transfusión sanguínea, es fundamental, debido a que nos ayuda a seleccionar unidades de sangre compatibles $y$, con ello, prevenir el riesgo de reacciones adversas asociadas a transfusión. Por tal motivo, es crucial conocer la incidencia general de aloinmunización en la población jalisciense registrada en el Centro Estatal de la Transfusión Sanguínea (CETS) Jalisco, institución que funge como laboratorio de referencia 
Incidencia de anticuerpos irregulares
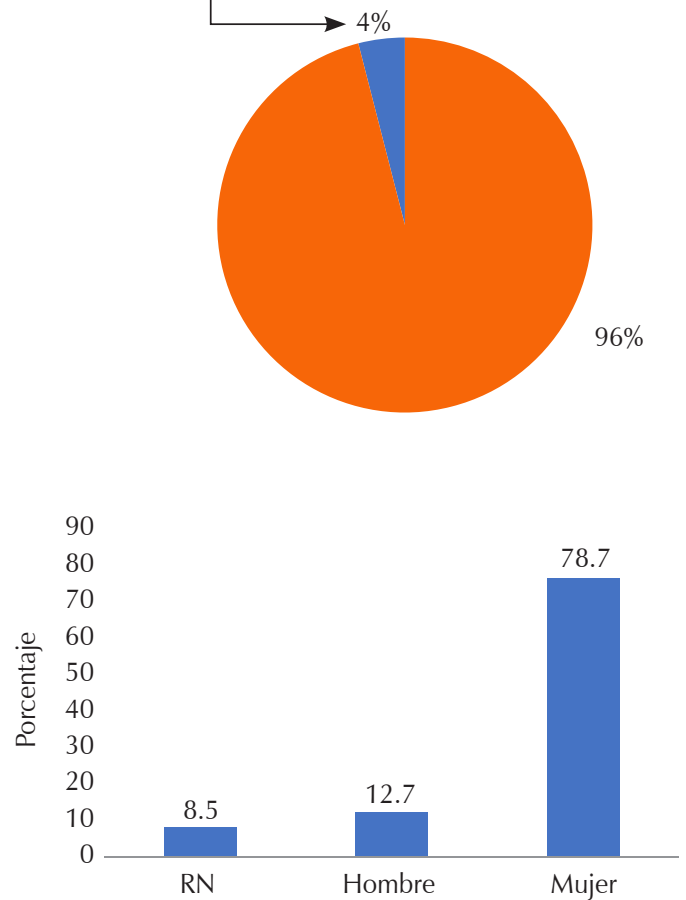

Figura C17.1: Incidencia por género/RN.

a nivel estatal en problemas inmunohematológicos. Objetivo: Determinar la incidencia de anticuerpos irregulares en pacientes del CETS Jalisco registrados entre el 01 de enero de 2018 y el 31 de diciembre de 2020. Material y métodos: Estudio retrospectivo. Se analizó la base de datos del sistema Hematix y se incluyeron pacientes con presencia de anticuerpos irregulares registrados en el periodo comprendido entre el 01 de enero de 2018 al 31 de diciembre de 2020. Se excluyeron los casos con diagnóstico de anemia hemolítica autoinmune. Resultados: Se registraron 5,241 pacientes con requerimiento transfusional, de los cuales 235 presentaron aloanticuerpos, equivalente a una incidencia de $4.4 \%$. Del total de casos, $78.7 \%$ fueron registrados en mujeres, $12.7 \%$ en hombres y $8.5 \%$ en recién nacidos, siendo estos últimos anticuerpos pasivos de origen materno. En $85.9 \%$ de los casos sólo se identificó un anticuerpo; $10.2 \%$ presentó dos anticuerpos y $3.7 \%$ mezcla de tres o más anticuerpos. Se identificó un total de 276 aloanticuerpos, siendo los más frecuentes el anti-E, anti-K, anti-D, anti-Le y anti-c, en una proporción de 21.3, 15.2, 15.2, 13 y $7.2 \%$ (Figura C17.1), respectivamente. Por género, los anticuerpos identificados con mayor frecuencia en mujeres fueron anti-E (23\%), anti-K (16.3\%) y anti-Le $(13.5 \%)$ y en hombres fueron anti-E $(32.5 \%)$, anti-K $(16.2 \%)$ y anti-D $(13.9 \%)$. En recién nacidos (15), el anticuerpo pasivo más frecuente fue el anti-D en $61.9 \%$, seguido de anti-Le ${ }^{a}$ en $19 \%$. Conclusiones: La incidencia general de anticuerpos irregulares en la población jalisciense es similar o incluso ligeramente superior a lo reportado en la literatura nacional, siendo
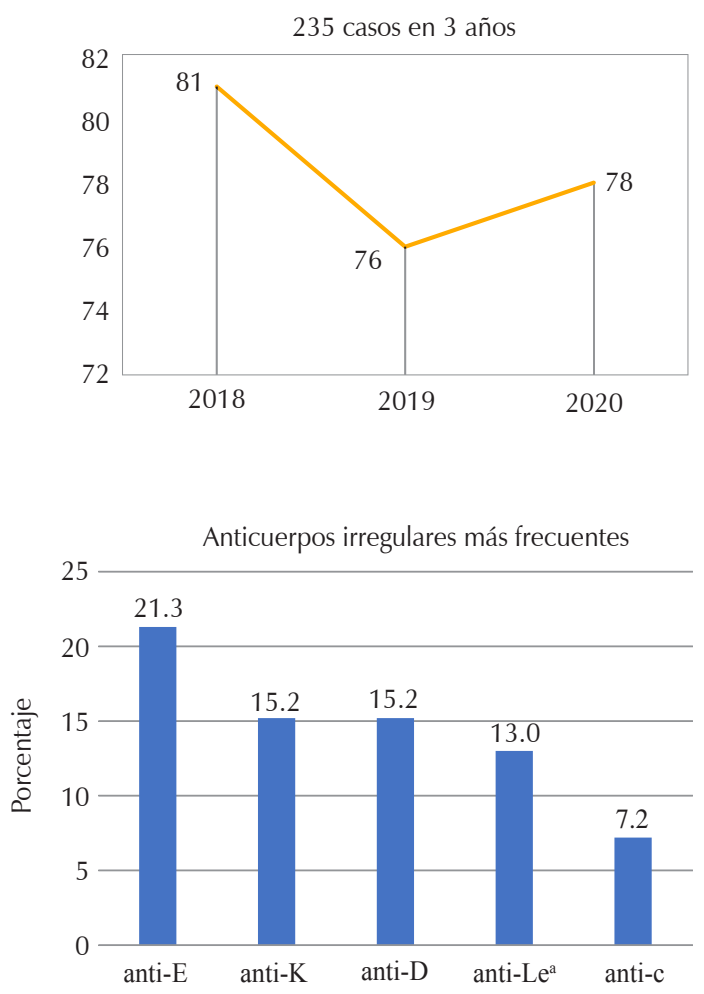

mayor en el sexo femenino hasta seis veces más que los hombres. La casuística de los aloanticuerpos reportados con mayor frecuencia coincide fuertemente con lo descrito en otras series latinoamericanas.

\section{Referencias}

1. Luna-González J. Anticuerpos irregulares, su importancia en medicina transfusional. Rev Med Inst Mex Seguro Soc. 2005; 43 (Suppl 1): 17-20.

2. Torres-Padilla JC. Prevalencia de anticuerpos antieritrocitos en pacientes con cáncer. Rev Mex Patol Clin. 2008; 55 (Suppl 1): 7.

3. Rendón-Romero S. Frecuencia de anticuerpos irregulares en donadoras con dos o más embarazos y donadores Rh negativos. Rev Mex Med Tran. 2014; 7 (1): 33-34.

\section{C18. I mportancia de la Prueba directa de Coombs} en el tamiz neonatal

Rosenfeld Mann $\mathrm{F}$,* Baptista González $\mathrm{H}$,*, Rodríguez Alvarado AG,* Bouchán Valencia $\mathrm{P}$,* Coeto Barona G,* Gudiño Santos EF§

* Hematología Perinatal. ₹ Fundación Clínica Médica Sur. Ciudad de México. ${ }^{\S}$ J efe del Laboratorio Central. Instituto Nacional de Perinatología.

Introducción: Es amplia la variabilidad a nivel mundial en las prácticas para la prueba directa de Coombs (PDC) en recién nacidos (RN), desde tamizaje universal, neonatos en riesgo y diagnóstico en los casos de enfermedad hemolítica neonatal. En México, aunque es una práctica obligada por la autoridad sanitaria, no hay un reporte sobre su ocurrencia e impacto clínico. Objetivo: Presentar los resultados del tamizaje PDC en una cohorte de binomios ma- 
Tabla C18.1: Variables perinatales significativas.

\begin{tabular}{|c|c|c|c|}
\hline \multirow[b]{2}{*}{ Variable } & \multicolumn{2}{|c|}{ Prueba directa de Coombs } & \multirow[b]{2}{*}{ Significancia (OR) } \\
\hline & $\begin{array}{c}\text { Positivo, n (\%) } \\
(240 / 2.7)\end{array}$ & $\begin{array}{c}\text { Negativo, n (\%) } \\
(8,501 / 97.3)\end{array}$ & \\
\hline Cesárea $(5,939 / 67.9)$ & 209 (3.5) & $5730(96.5)$ & 3.21 (2.20 a 4.69$)$ \\
\hline Madre O $(6,173 / 70.60)$ & $225(3.6)$ & $5948(96.4)$ & $5.96(3.29$ a 10.81$)$ \\
\hline Masculino $(4,402 / 50.4)$ & $138(3.1)$ & 4,264 (96.9) & $1.34(1.03$ a 1.73$)$ \\
\hline Prematuro $(776 / 8.9)$ & $79(10.2)$ & 697 (89.8) & $5.53(4.14$ a 7.40$)$ \\
\hline 2,500 g y menos $(2,253 / 25.8)$ & $107(4.7)$ & $2,146(95.3)$ & 1.95 (1.21 a 3.12) \\
\hline A $(1,874 / 21.4)$ & $149(8.0)$ & $1,725(92.0)$ & 15.73 (10.77 a 22.96$)$ \\
\hline B $(652 / 7.5)$ & $57(8.7)$ & 595 (91.3) & $17.53(11.35$ a 27.06$)$ \\
\hline$\geq$ Ocho días hospital $(1,206 / 13.8)$ & $85(7.0)$ & $1,121(93.0)$ & $3.16(2.75$ a 4.74$)$ \\
\hline Fototerapia $(1964 / 11.2)$ & $220(11.2)$ & $1,744(88.8)$ & $41.66(26.41$ a 65.71$)$ \\
\hline
\end{tabular}

dre y sus RN. Material y métodos: Se incluyeron todos los RN vivos del 2017 al 2020. A todo RN vivo se efectúa la toma de muestra de sangre de cordón umbilical (CU) para la determinación de grupo sanguíneo $A B O / R h D$ y PDC. Se reportan los resultados en la cohorte sobre resultados de la PDC y el título. Se registraron las variables demográficas, clínicas maternas y neonatales, hiperbilirrubinemia-Hiper$\mathrm{BrT}$ - (bilirrubina total- $\mathrm{BrT}$ - $\geq 12.8 \mathrm{mg} / \mathrm{dL}$ ) o ingreso a fototerapia. Se definió la incompatibilidad a RhD, en caso de madre RhD negativo e hijo RhD positivo. Resultados: Se incluyeron 8,741 binomios para su análisis; 240 RN (2.7\%) fueron reactivos a la PDC. Se identificaron variables maternas con asociación con la PDC positiva (Tabla C18. 1): nacimiento por cesárea (OR IC 95\% 3.21; 2.20 a 4.69), madre grupo $O(5.96 ; 3.29$ a 10.81$)$, madre RhD negativo (1.90; 1.07 a 3.64$)$, neonato grupo A (15.73; 10.77 a 22.96), neonato grupo $B(17.53 ; 11.35$ a 27.06$)$. Con IABO y EHFRN potencial (40.08; 28.40 a 56.57), incompatibilidad RhD $(2.47 ; 1.45$ a 4.21$)$, estancia hospitalaria $\geq$ ocho días $(3.16 ; 2.75$ a 4.74$)$ e ingreso a fototerapia $(41.66 ; 26.41$ a 65.71$)$. La frecuencia de $\mathrm{PDC}+$ en binomio $\mathrm{O} / \mathrm{A}, \mathrm{O} / \mathrm{B}, \mathrm{O} / \mathrm{A}, \mathrm{B}$ e isogrupo fue de $10.1,5.9,0$ y $1.6 \%$, respectivamente. Conclusión: En este estudio de cohorte la frecuencia de Coombs directo neonatal es de $2.7 \%$, similar al observado anteriormente en nuestro país. Las variables asociadas coincidieron con los RN de mayor riesgo para el desarrollo de hiperbilirrubinemia neonatal, teniendo mayor impacto en el ingreso a fototerapia y en días de estancia hospitalaria. La PDC cumple los requisitos de prueba tamiz y debe ser valorada en los diferentes contextos de la población en nuestro entorno para incorporarse como tamizaje neonatal.
C19. Un riesgo perinatal persistente: la aloinmunización materna por antígenos eritrocitarios

Rosenfeld Mann F,* Baptista González $\mathrm{H}, *, \neq$ Roque Álvarez $\mathrm{E},{ }^{\ddagger}$ Martínez Reyes $\mathrm{C}^{\ddagger}$

* Hematología Perinatal. Instituto Nacional de Perinatología. * Medicina transfusional y Banco de Sangre, Ciudad de México.

Introducción: La enfermedad hemolítica del feto y recién nacido (EHFRN) por la aloinmunización materna con anticuerpos antieritrocitarios ha dejado de ubicarse dentro de las primeras causas de mortalidad en la etapa neonatal. Sin embargo, persiste con carga de la enfermedad significativa en el primer año de vida. Objetivo: Presentar la frecuencia de aloinmunización materna reportada en México, basada en los reportes de rastreo de anticuerpos irregulares antieritrocitarios (RAI) en México. Material y métodos: Se compiló información de los reportes de casos obtenidos en México, publicados en revistas científicas o de la literatura gris de los congresos relacionados de Medicina Transfusional, Hematología, Patología Clínica, Obstetricia o Pediatría. Se almacenó la información en una base de datos para su posterior análisis. Se formaron dos grupos: grupo 1, pacientes obstétricas evaluadas en las pruebas cruzadas o bajo estudio de EHFRN. Grupo 2, hombres y mujeres adultos, evaluados en las pruebas pretransfusionales de compatibilidad. Se excluyeron pacientes pediátricos y adultos oncohematológicos y de cirugía cardiaca, con anemia hemolítica autoinmune, Coombs directo positivo y aquellos anticuerpos irregulares positivos no identificados. Para fines de este reporte no se compararon las diferentes metodologías empleadas en cada centro. Resultados: Se identificaron siete reportes que incluyeron al 
grupo 1 con 5,810 pacientes y al grupo 2 con 87,167 sujetos. Tuvieron RAI reactivos 452 mujeres (7.7\%) y 669 adultos (1.2\%), para cada grupo. Mezcla de anticuerpos $1.9 \%(0.2$ a $6.6 \%)$ El orden de los anticuerpos maternos más frecuentemente identificados fueron: anti-D 316 mujeres (69.9\%) y 234 adultos (34.9\%) . Anti-E, 25 (5.5\%) y 133 casos (19.8). Anti-c, $19(4.2 \%)$ y 19 casos (2.8\%). Anti-C, 11 casos $(2.4 \%)$ y 35 adultos, $(5.2 \%)$. Anti-Fya cuatro casos $(0.9 \%)$ y 22 adultos (3.3\%). Anti-J ka, cuatro casos $(0.9 \%)$ y 24 adultos (3.6\%). Anti-Kell, 3 casos $(0.6 \%)$ y 76 adultos $(11.3 \%)$. Anti-Dia, dos casos $(0.4 \%)$ y 38 casos $(5.8 \%)$. Anti-J kb, un caso $(0.2 \%)$ y cuatro casos, $(0.6 \%)$, para los grupos 1 y 2 , respectivamente. Conclusión: Aunque el anti-D y anti-E son los anticuerpos más frecuentes tanto en la población obstétrica como en adultos en estudio de pruebas de compatibilidad. En orden subsecuente es distinto para cada población. En pacientes obstétricas es anti- $\mathrm{D}>$ anti-E $>$ anti- $c>$ antiC>anti-Fya>anti-J ka>anti-Kell>anti-Dia>anti-J kb y en adultos es anti-D>anti- $\mathrm{E}>$ anti-Kell $>$ anti-Dia>antiC>anti-Jka>anti-Fya>anti-c>anti-Jkb.

\section{C20. I ncompatibilidad ABO. Reporte de casos}

Rodríguez Alvarado AG,* Baptista González $\mathrm{H}, \neq, \S$ Rosenfeld Mann F, Bouchán Valencia P, ${ }^{\ddagger}$ Coeto Barona $\mathrm{G}$, Coronado Zarco A,* Gudiño Santos EF"

* Subdirección de Neonatología. ₹ Hematología Perinatal. Instituto Nacional de Perinatología. § Fundación Clínica. Médica Sur. Ciudad de México. " Laboratorio Central.

Tabla C20.1: Resultados de acuerdo con Coombs directo e incompatibilidad a grupo ABO.

\begin{tabular}{|c|c|c|c|c|c|c|}
\hline \multirow{2}{*}{$\begin{array}{l}\text { Incompatibilidad } \\
\text { ABO }\end{array}$} & \multicolumn{3}{|c|}{ Positivo (188/78.3) } & \multicolumn{3}{|c|}{ Negativo $(3,068 / 36.0)$} \\
\hline & $\mathrm{Hb}(188)$ & Retis (186) & $\mathrm{BrT}(188)$ & $\mathrm{Hb}(3,102)$ & Retis $(3,102)$ & $\operatorname{BrT}(3,068)$ \\
\hline Presente (562) & $16.0(7.6$ a 20.5$)$ & $5.8(1.8$ a 15.9$)$ & 9.8 (3.3 a 23.5) & 17.0 (10.2 a 23.5$)$ & 5.3 (0.6 a 17.9) & $9.4(0.3$ a 22.1$)$ \\
\hline
\end{tabular}

Tabla C20.2: Resultado de la PDC y casos con hiperbilirrubinemia de acuerdo con el tipo de incompatibilidad materno neonatal al grupo ABO.

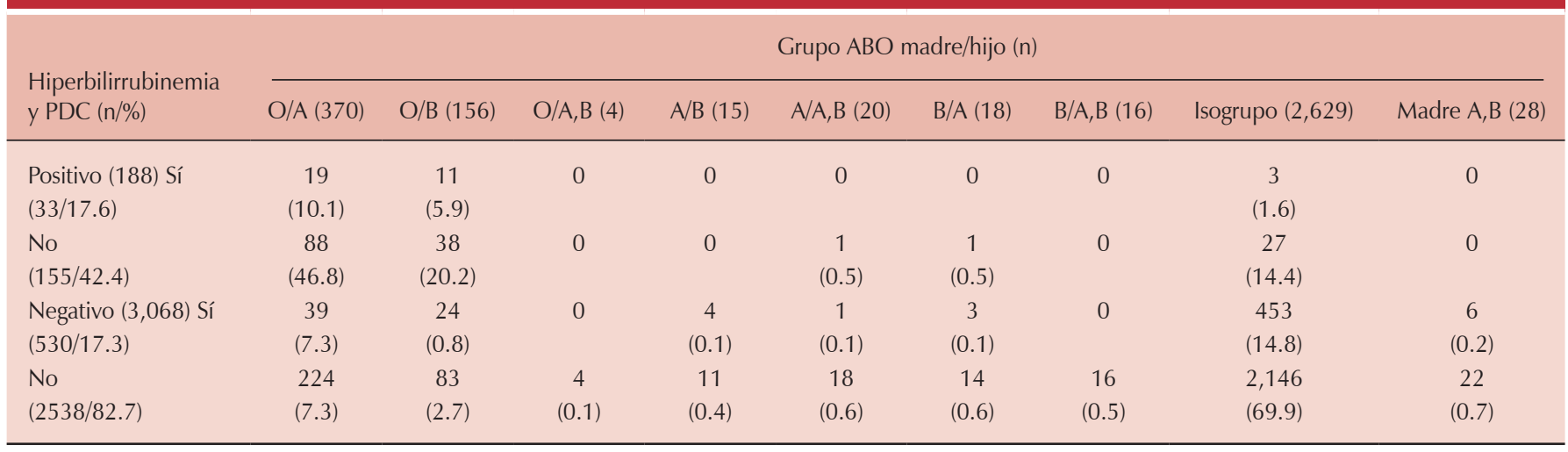

Tabla C20.3: Resultados en las titulaciones de la prueba directa de Coombs por incompatibilidad ABO y RhD.

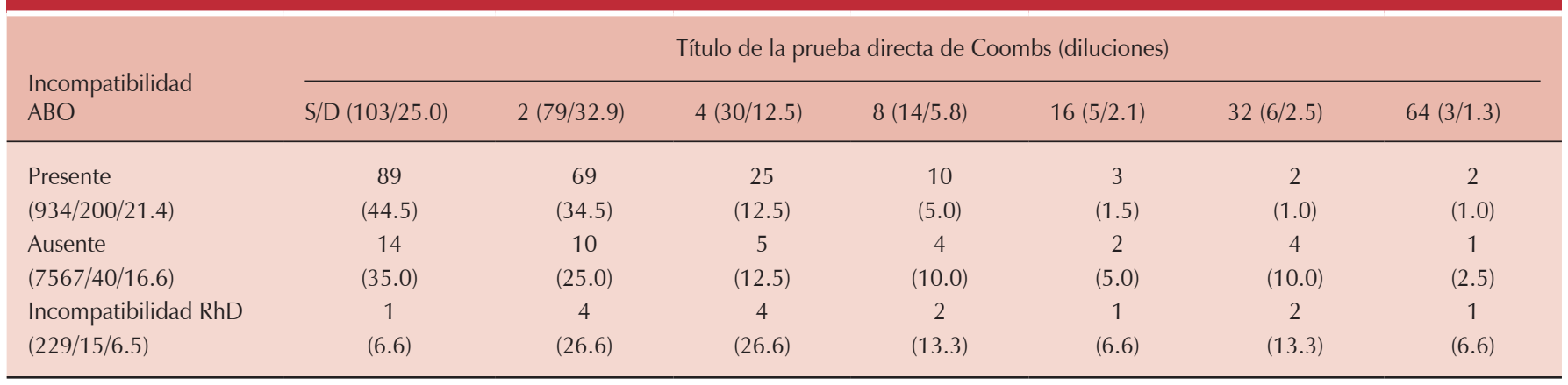


Introducción: La incompatibilidad $\mathrm{ABO}(\mathrm{I} A B O)$ es una de las etiologías más comunes de hiperbilirrubinemia neonatal. Hay variabilidad en las prácticas del tamizaje universal al nacimiento del grupo $A B O /$ RhD y prueba directa de Coombs (PDC) a nivel mundial. Aunque en México es una práctica obligada por la autoridad sanitaria, no hay un reporte sobre su detección e impacto. Objetivo: Presentar los resultados del tamizaje ABO/RhD y PDC en una cohorte de binomios: madre y su recién nacido (RN). Material y métodos: Se incluyeron todos los RN vivos entre 2017 y 2020, con la política institucional de recolectar muestra de sangre de cordón umbilical (CU) para la determinación de grupo sanguíneo ABO/RhD y PDC. Se registraron las variables demográficas, clínicas maternas, neonatales, presencia de hiperbilirrubinemia ( $\geq 12.8 \mathrm{mg} / \mathrm{dL}$ ) e ingreso a fototerapia. Se definió la IABO con riesgo potencial de enfermedad hemolítica (EHFRN), en los casos de madre/hijo: O/A, O/B, O/A,B; A/B, B/A. Como ausencia de riesgo de EHFRN por IABO en los casos de binomio a isogrupo o madres grupo AB. Resultados: Se incluyeron 8,741 binomios. En 240 RN (2.7\%) fueron PDC positivo. No hubo asociación entre la presencia de PDC e IABO con las variables de hemoglobina, reticulocitos o valores de bilirrubinas totales (Tablas C20.1 a C20.3). Conclusión: La incompatibilidad ABO con EHFRN potencial más común es binomio O/A y O/B, hacia $13 \%$ de los casos y la frecuencia de PDC positiva de $2.7 \%$ es similar a la observada en otros centros. Esta información apoya la política de incluir el tamizaje $\mathrm{ABO} / \mathrm{RhD}$ y PDC al nacimiento.

\section{C21. La aloinmunización materna por antígenos eritrocitarios resultados de la compilación en México}

Baptista González HA,*, Rosenfeld Mann F,* Lira Plasencia J,§ Roque Álvarez $\mathrm{E}^{\S}$

* Coordinación de Hematología Perinatal. ₹ Ginecología Y Obstetricia. Instituto Nacional de Perinatología. § Medicina Transfusional y Banco de Sangre. Médica Sur.

Introducción: La enfermedad hemolítica del feto y recién nacido (EHFRN) por la aloinmunización materna con anticuerpos antieritrocitarios persiste con carga de la enfermedad significativa en el primer año de vida. No existe un registro nacional en mujeres de edad reproductiva y de sus hijos sobre la incidencia de aloinmunización, EHFRN, las secuelas en neurodesarrollo e impacto en el sistema de salud. Objetivo: Presentar la compilación de los reportes en México sobre la frecuencia de aloinmunización materna y anticuerpos antieritrocitarios (RAI) involucrados. Material y métodos: Compilación. Reportes de población mexicana, publicados en revistas científicas o de la literatura gris que incluyeron resultados de RAI positivo. Se integraron cuatro grupos: Grupo 1: mujeres RhD negativo. Grupo 2. Pacientes en estudio de EHFRN o prueba cruzada incompatible. Grupo 3. Pruebas pretransfusionales en pacientes obstétricas. Grupo 4. Hombres y mujeres adultos sometidos a pruebas de compatibilidad sanguínea. (Tablas C21.1 a C21.4). Discusión: El anti-D sigue siendo el más común en México ( $>45 \%$ ). Pero otros anticuerpos están aumentando en su frecuencia como es el anti-E y el anti-Kell, entre otros más, que también tienen relevancia clínica. Es importante establecer un registro nacional de mujeres en edad reproductiva y aloanticuerpos eritrocitarios.

Tabla C21.2: Ocurrencia más común de anticuerpos con significancia clínica en presentación aislada o en mezcla de anticuerpos.

\begin{tabular}{|c|c|c|c|c|}
\hline Anticuerpos & $\begin{array}{c}\text { Grupo } 1 \\
\text { (E-2) }\end{array}$ & $\begin{array}{c}\text { Grupo } 2 \\
\text { (E-2) }\end{array}$ & $\begin{array}{c}\text { Grupo } 3 \\
\text { (E-3) }\end{array}$ & $\begin{array}{c}\text { Grupo } 4 \\
\text { (E-10) }\end{array}$ \\
\hline $\begin{array}{l}\text { Población } \\
\text { incluida }\end{array}$ & 196 & 147 & 109 & 669 \\
\hline $\begin{array}{l}\text { Anti-D (n/\%) } \\
\text { Amplitud (\%) }\end{array}$ & $\begin{array}{c}139 / 49.8 \\
(25 \text { a } 74.6)\end{array}$ & $\begin{array}{l}107 / \mathbf{5 8 . 0} \\
(50 \text { a } 66)\end{array}$ & $\begin{array}{c}70 / \mathbf{4 7 . 1} \\
(0 \text { a } 83.3)\end{array}$ & $\begin{array}{l}234 / \mathbf{3 4 . 9} \\
(0 \text { a } 83.3)\end{array}$ \\
\hline $\begin{array}{l}\text { Anti-E (n/\%) } \\
\text { Amplitud (\%) }\end{array}$ & $\begin{array}{c}3 / 2.4 \\
(0.4 \text { a } 6.3)\end{array}$ & $\begin{array}{c}12 / 8.1 \\
(6.1 \text { a } 10)\end{array}$ & $\begin{array}{c}10 / \mathbf{1 9 . 1} \\
(7.2 \text { a } 33.3)\end{array}$ & $133 / \mathbf{1 9 . 8}$ \\
\hline $\begin{array}{l}\text { Anti-Kell (n/\%) } \\
\text { Amplitud (\%) }\end{array}$ & $1 / 0.9$ & $\begin{array}{c}2 / \mathbf{3 . 9}(2.7 \\
\text { a } 5.0)\end{array}$ & & 76/11.3 \\
\hline $\begin{array}{l}\text { Anti-c (n/\%) } \\
\text { Amplitud (\%) }\end{array}$ & $\begin{array}{l}3 / \mathbf{0 . 7} \\
(0-0.7)\end{array}$ & $\begin{array}{c}9 / 6.2 \\
(4.8 \text { a } 7.5)\end{array}$ & $\begin{array}{c}7 / 2.1 \\
(0 \text { a } 6.3)\end{array}$ & $19 / \mathbf{2 . 8}$ \\
\hline $\begin{array}{l}\text { Anti-Fya (n/\%) } \\
\text { Amplitud (\%) }\end{array}$ & $\begin{array}{c}1 / \mathbf{1 . 6} \\
(0 \text { a } 3.1)\end{array}$ & $\begin{array}{c}3 / \mathbf{1 . 0} \\
(0 \text { a } 2.0)\end{array}$ & 0 & $22 / 3.3$ \\
\hline
\end{tabular}

Tabla C21.1: Ocurrencia de aloinmunización en los grupos de estudio.

92,977 pacientes, 17 estudios

\begin{tabular}{|c|c|c|c|c|}
\hline Variable & & $\begin{array}{c}\text { Grupo } 2 \\
(\mathrm{E}-2)\end{array}$ & & \\
\hline Población incluida & 2,825 & 172 & 2,813 & 87,167 \\
\hline Casos con RAI reactivo (n/\%) & 268/12.4 & $172 / \mathbf{1 0 0}$ & 121/3.2 & $901 / \mathbf{1 . 9}$ \\
\hline Amplitud (\%) & (9.0 a 15.8$)$ & (100) & (1.9 a 4.7$)$ & (0.2 a 6.6$)$ \\
\hline Anticuerpos clínicamente significativos & 196/7.2 & 147/83.2 & 109/3.3 & 669/1.2 \\
\hline
\end{tabular}


Tabla C21.3: Ocurrencia menos común de anticuerpos con significancia clínica en presentación aislada o en mezcla de anticuerpos.

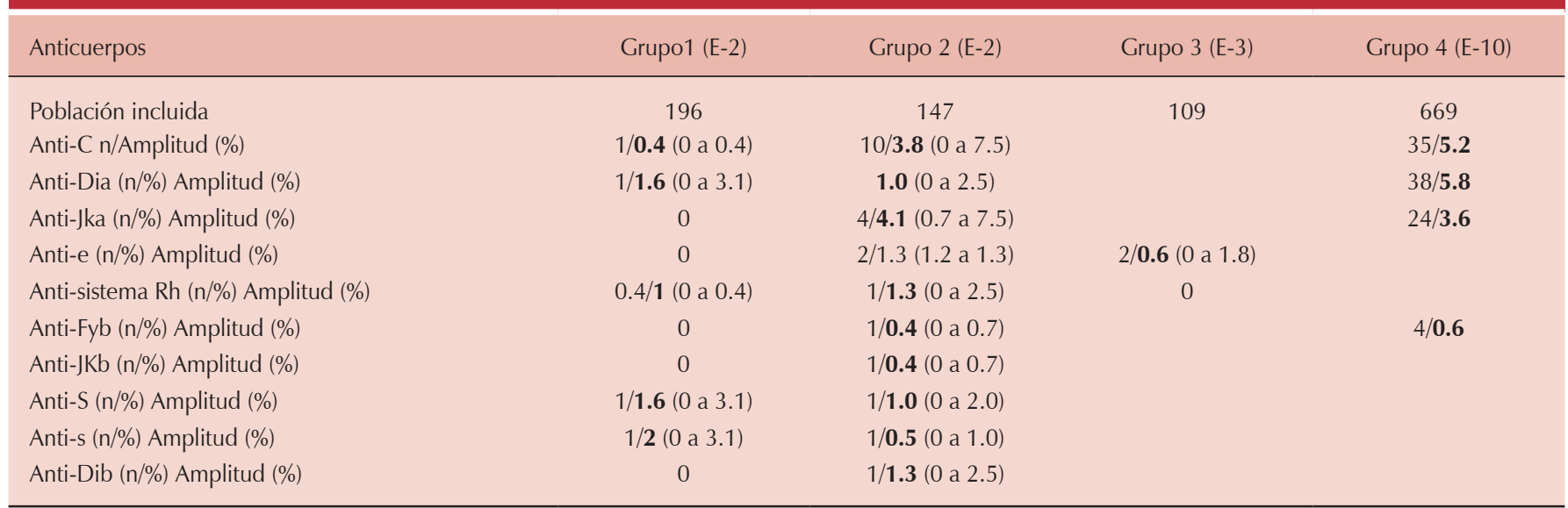

Tabla C21.4: Secuencia en la frecuencia de anticuerpos por grupo de estudio

\begin{tabular}{|c|c|c|c|c|c|c|c|c|c|c|}
\hline Grupo 1 & Anti-D> & Anti-E> & Anti-s> & Anti-Fya $=$ & Anti-Dia $=$ & Anti-S> & Anti-SRh> & Anti-Kell> & Anti-c> & Anti-C \\
\hline Mujeres $\mathrm{RhD}$ negativo & 49.8 & 2.4 & 2.0 & 1.6 & 1.6 & 1.6 & 1.0 & 0.9 & 0.7 & 0.4 \\
\hline $\begin{array}{l}\text { Pacientes en estudio } \\
\text { de EHFRN o PCl }\end{array}$ & 58.0 & 8.1 & 6.2 & 4.1 & 3.9 & 3.8 & 1.3 & 1.3 & 1.3 & 1.0 \\
\hline Grupo 3 & Anti-D> & Anti-E> & Anti-c $=$ & Anti-Kell> & Anti-e & & & & & \\
\hline Grupo 4 & Anti-D> & Anti-E> & Anti-Kell> & Anti-Dia > & Anti-C> & Anti-Jka > & Anti-Fya > & Anti-c> & Anti-Jkb & \\
\hline Adultos con PC & 34.9 & 19.8 & 11.3 & 5.8 & 5.2 & 3.6 & 3.3 & 2.8 & 0.6 & \\
\hline
\end{tabular}

\section{C22. Estrategia para la identificación del antígeno Kell en donantes de sangre}

Roque $\mathrm{AE}$,* Villanueva $\mathrm{EE}$,* López $\mathrm{ME}$,* Rufino $\mathrm{CN}$,* Reyes $\mathrm{CV}$,* Muñoz CM,* Baptista GH*

* Medicina Transfusional y Banco de Sangre. Hospital Médica Sur.

Introducción: El antígeno Kell (K) es el prototipo para estimar la antigénica de los grupos. El anti- $K$ es de origen aloinmune, se encuentra dentro de los primeros tres anticuerpos más frecuentes en adultos bajo estudio de compatibilidad sanguínea. Existen diferentes estrategias para identificar el antígeno Kell en los donantes y unidades de eritrocitos. Objetivo: Presentar los resultados de la estrategia en la identificación del $\mathrm{K}$ en donantes $\mathrm{RhD}$ positivo y RhD negativo. Material y métodos: Desde diciembre del 2020, se inició la estrategia de identificar el $\mathrm{K}$ en todos los donantes RhD negativo y a los donantes recurrentes o de repetición RhD positivo. El $\mathrm{K}$ se identificó en técnica de aglutinación en tubo con antisuero monoclonal (Gamma-clone Immucor anti-K). Se reportan frecuencias alélicas para cada donante RhD positivo y negativo, así como para grupo ABO. Resultados: Se estudiaron 1,626 donantes. 205 donantes RhD negativo

\begin{tabular}{|c|c|c|}
\hline \multicolumn{3}{|c|}{$\begin{array}{l}\text { Tabla C22.1: Frecuencia de Ag. Kell en } \\
\text { donadores Rh(D) Positivos y Negativos. }\end{array}$} \\
\hline $\operatorname{RhD}(\mathrm{N})$ & K Neg n (\%) & K Pos n (\%) \\
\hline Negativo (205) & 201 (98.1) & $4(1.9)$ \\
\hline Positivo $(1,421)$ & $1,374(96.7)$ & $47(3.3)$ \\
\hline
\end{tabular}

y $1,421 \mathrm{RhD}$ positivo. La frecuencia del $\mathrm{K}$ fue de $1.9 \mathrm{y}$ $3.3 \%$ en los sujetos RhD negativo y RhD positivo, respectivamente. La frecuencia de $K$ en sujetos $R h D$ negativo por grupo $A B O$ fue de $2.5,0,0$ y $2.1 \%$ para grupos $A, A B, B$ y $O$, respectivamente. La condición $R h D$ positivo fue del $4.4,0,2.3$ y $3.1 \%$ para los grupos $A$, $A B$, $B$ y $O$, respectivamente. Cuando se agrupan por grupo $A B O$, independiente del RhD, la frecuencia del $K$ es del $4.07,0,1,93$ y $3.12 \%$, para los grupos $A, A B$, B y O. La asociación del $\mathrm{K}$ con las proteínas RhC, Rhc, RhE y Rhe fue del 3.4, 2.7. 2.9 y 3.14, respectivamente. Finalmente, la distribución de los Grupos $A B O$ fue del $39.5,2.4,10.7$ y $47.3 \%$ para los grupos $A, A B, B$ y $O$, para los RhD negativo y de $27.2,1.6,9.4$ y $61.9 \%$ para el mismo orden de grupos $A B$ en sujetos $R h D$ 
Tabla C22.2. Frecuencia de Ag. Kell por Grupo ABO y Rh(D).

\begin{tabular}{ccc} 
Grupo ABO & \% Rh Neg K Pos & \% Rh Pos K Pos \\
\hline A & 2.5 & 4.4 \\
AB & 0.0 & 0.0 \\
B & 0.0 & 2.3 \\
0 & 2.1 & 3.1 \\
\hline
\end{tabular}

Tabla C22.3. Frecuencia de

Ag. Kell por Grupo ABO.

\begin{tabular}{cl} 
Grupo ABO & $\%$ K PosGeneral \\
\hline A & 4.07 \\
AB & 0.0 \\
B & 1.9 \\
0 & 3.13 \\
\hline
\end{tabular}

Tabla C22.4. Frecuencia de Ag. Kell por Proteinas del Rh (CcEe).

\begin{tabular}{cc} 
RhCE & $\%$ K PosGeneral \\
\hline RhC & 3.4 \\
RhC & 2.7 \\
RhE & 2.9 \\
Rhe & 3.14 \\
\hline
\end{tabular}
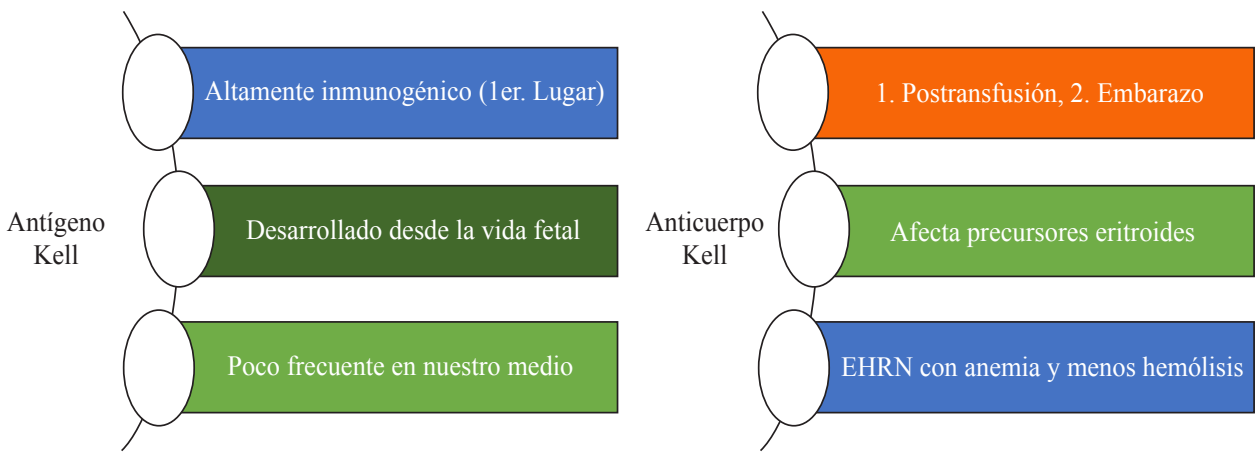

Figura C22.1.

Caracteristicas del Antígeno y Anticuerpo Kell. positivo. (Tablas C22.1 a C22.4 y Figura C22.1). Discusión: La frecuencia del alelo Kell no ocurre con mayor frecuencia en los sujetos RhD negativo, comparado con donantes recurrentes o de repetición $\mathrm{RhD}$ positivo ( 1.9 vs $3.3 \%$ ), inclusive es mayor la frecuencia en estos últimos. Con estos resultados, no es de esperarse que exista mayor incidencia de aloinmunización por donantes RhD negativo y con antígeno Kell que su contraparte RhD positivo. Esta observación deberá afirmarse mediante el seguimiento en receptores y el efecto de la selección del antígeno Kell.

\section{C23. Control de calidad como predictor de dosis plaquetaria}

De La Rosa López A,* Llaca Díaz JM, ₹ Díaz Chuc EA, ${ }^{\$}$ Ayala De La Cruz Vף

* Médico Residente de Patología Clínica. * Maestro en Salud Pública, Jefe del Departamento de Patología Clínica. § Médico Patólogo Clínico, Jefe de Banco de Sangre. " Médico Patólogo Clínico, profesor del Departamento de Patología Clínica. Hospital Universitario «Dr. José E González».

Introducción: En servicios de Banco de Sangre los concentrados plaquetarios (CP) son un recurso altamente variable en su disposición, por lo que es importante implementar estrategias que permitan un mejor aprovechamiento de los CP. Previamente se ha comparado la eficacia de la transfusión profiláctica de $\mathrm{CP}$ a dosis baja (1.5-2.9 $\left.\times 10^{11}\right)$ y estándar (3.0-6.0 $\times$ $10^{11}$ ) sin encontrar diferencias significativas en eficacia para prevención de hemorragia, por lo que administrar una dosis plaquetaria baja es igual de segura para el paciente sin sangrado. Objetivo: Determinar la probabilidad de obtener una dosis plaquetaria baja y

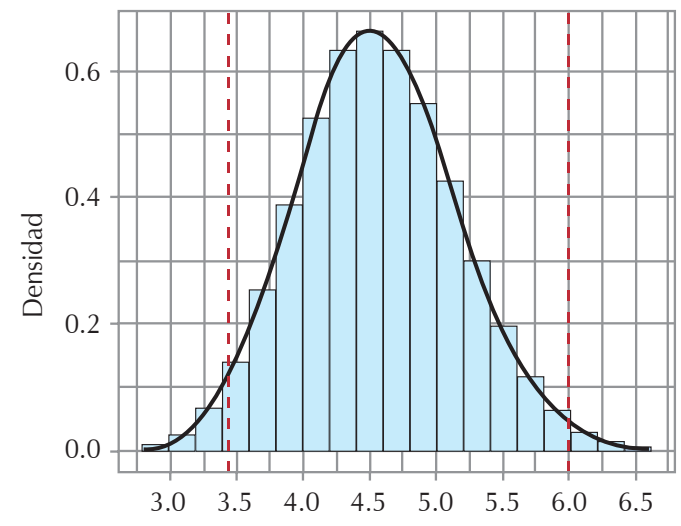

Figura C23.1: Histograma de dosis plaquetaria para simulación con 4 CP (Línea roja punteada $=$ percentiles 2.5 y $97.5 \%$ ).

estándar a partir de un número determinado de concentrados plaquetarios. Metodología: Se incluyeron concentrados plaquetarios contenidos en el registro de control de calidad de los que se obtuvo el conteo plaquetario, se realizó una simulación de Montecarlo para 2, 3, 4, 5, 6, 7 y 8 CP (Figura C23.1); posteriormente, se calculó la probabilidad de obtener una dosis plaquetaria total baja y estándar. Se elaboró una simulación de Montecarlo con un millón de iteraciones utilizando un muestreo aleatorio sin reemplazo de 3, 4, 5, 6 y $8 \mathrm{CP}$; luego en cada iteración, se sumó el resultado de los concentrados plaquetarios muestreados. Se determinó la probabilidad de obtener una transfusión con una dosis total que cumpla con valores de dosis baja y estándar para cada muestreo de CP. Se utilizó el método de cuantiles de Hyndman-Fan para muestras continuas para calcular los percentiles ( 2.5 y $97.5 \%$ ) 


\begin{tabular}{|c|c|c|c|c|}
\hline n CP & $\begin{array}{l}\text { Probabilidac } \\
\text { plaquetaria } \\
\text { y estándar ( }\end{array}$ & $\begin{array}{l}\text { ner dosis } \\
\left..5 \times 10^{11}\right) \\
\left.{ }^{11}\right)(\%)\end{array}$ & $\begin{array}{l}\text { Dosis pla } \\
\text { según pe } \\
97.5 \%\end{array}$ & $\begin{array}{l}\times 10^{11} \\
2.4 y\end{array}$ \\
\hline 2 & 50.89 & 0 & 8.92 & 2.26 \\
\hline 3 & 97.47 & 5.35 & 1.49 & 3.34 \\
\hline 4 & 99.99 & 51.81 & 2.13 & 4.05 \\
\hline 5 & 100 & 93.36 & 2.78 & 5.13 \\
\hline 6 & 100 & 99.8 & 3.44 & 5.99 \\
\hline 7 & 100 & 99.99 & 4.12 & 6.61 \\
\hline 8 & 100 & 100 & 4.79 & 7.45 \\
\hline
\end{tabular}

$\mathrm{CP}=$ Concentrados plaquetarios. de las dosis totales administradas para los diferentes números de $\mathrm{CP}$ analizados en las simulaciones. Los datos estadísticos fueron analizados en el programa $\mathrm{R}$ Studio versión 1.4.1106. Resultados: Se analizaron 99 concentrados plaquetarios, se obtuvo una media de conteo plaquetario por CP $0.76 \times 10^{11}$ con una desviación estándar de $0.25 \times 10^{11}$ con coeficiente de variación de $32.98 \%$. La probabilidad de administrar una dosis plaquetaria $\geq 1.5 \times 10^{11}$ plaquetas con 3 CP fue de $97.47 \%$. A partir de 4 CP la probabilidad de administrar una dosis plaquetaria baja y segura al paciente es prácticamente de $100 \%$. Los resultados de probabilidad de obtener dosis plaquetaria baja y estándar se encuentran resumidos en la Tabla C23.1. Conclusiones: Tradicionalmente al solicitar una transfusión plaquetaria profiláctica se calcula la dosis plaquetaria a transfundir asumiendo que los concentrados plaquetarios tienen en promedio $0.6 \times 10^{11}$ plaquetas, asumiendo que tienen una distribución normal y una distribución estándar estrecha. Sin embargo, en nuestro estudio observamos que si bien el promedio de plaquetas/CP fue de $0.76 \times 10^{11}$, el coeficiente de variación fue de $32.98 \%$, significativamente mayor que la variabilidad biológica interindividuo de $12.3 \%$, por lo que administrar un estimado número de $\mathrm{CP}$ basado en el promedio resulta inadecuado, debido a la alta variabilidad biológica y otros factores que influyen en el proceso de la obtención de CP (fuerza centrífuga, etcétera).

\section{Referencia}

1. Heddle N, Cook R, Tinmouth A, Kouroukis C, Hervig T, Klapper E et al. A randomized controlled trial comparing standard- and lowdose strategies for transfusion of platelets (STOP) to patients with thrombocytopenia. Blood. 2009; 113 (7): 1564-1573.

C24. Niveles de anticuerpos IgG contra SARSCoV-2 en un grupo de donadores de plasma convaleciente

Chávez-Estrada YO,* Alvarado-Navarro DM, ${ }^{\ddagger}$ HernándezNavarro AK,* Moncada-Saucedo NK, $\$$ Salazar-Riojas R, $"$ Gómez-Almaguer D"I
* Químicos Medicina transfusional. Servicio de Hematología. ₹ Médico responsable Medicina transfusional. Servicio de Hematología. § Doctora responsable de Medicina Molecular. Servicio de Hematología. "J efa del laboratorio del Hematología. "J efe del Servicio de Hematología. Hospital Universitario «Dr. José Eleuterio González» UANL, Monterrey, México.

I ntroducción: Desde finales del 2019 se hizo un llamado de atención a la salud pública mundial debido a los primeros reportes sobre Coronavirus (COVID-19) causada por el virus SARS-CoV-2, dicha enfermedad logró diseminarse rápidamente alrededor del mundo, catalogándose como la pandemia del siglo XXI. Debido a la gravedad de la enfermedad y sin un tratamiento eficaz aprobado, se implementaron rápidamente estrategias para contrarrestar la infección grave con transfusiones de plasma convaleciente (PC) con presencia de anticuerpos contra SARS-CoV-2 de personas sanas recuperadas. Actualmente, son pocos los casos informados sobre la utilidad de los niveles de anticuerpos contra el virus del SARS-CoV- 2 en el PC. No obstante, la cuantificación de los anticuerpos IgG específicos determina la durabilidad de la inmunidad en personas ya recuperadas de la naturaleza del virus. Objetivo: Determinar la asociación entre los niveles de anticuerpos IgG SARS-CoV-2 con variables

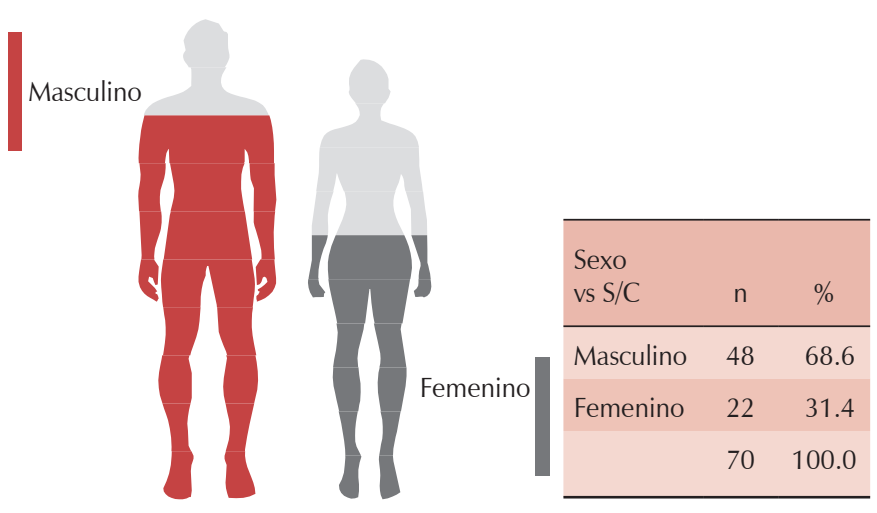

Figura C24.1: Índice S/C con relación al género masculino vs femenino.

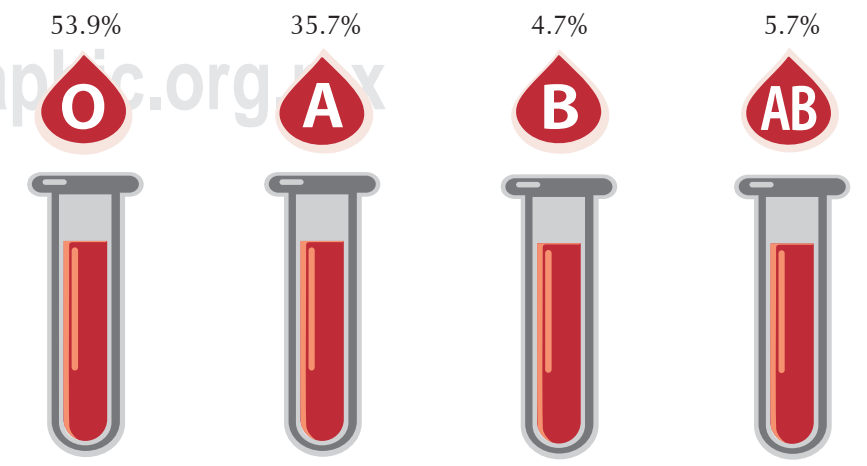

Figura C24.2: Porcentaje de índice S/C por grupo sanguíneo. 
sociodemográficas del paciente y parámetros de la biometría hemática. Material y métodos: Estudio retrospectivo, descriptivo y observacional, realizado en el Servicio de Hematología del Hospital Universitario «Dr. José Eleuterio González». Se analizaron las muestras de donaciones de plasma convaleciente realizadas durante el periodo de abril del 2020 a enero de 2021. La detección semicuantitativa de anticuerpos IgG frente al virus SARS-CoV-2 en plasma humano se realizó por medio de la técnica de inmunoanálisis quimioluminiscente de micropartículas (CMIA), por medio del equipo ARCHITECT i1000 System, y se calculó el índice S/C. Resultados: Se incluyeron 70 muestras de donaciones de plasma convaleciente. La mediana de índice muestra/punto de corte SARSCoV-2 IgG (S/C) fue de 5.70. Para determinar el grado de asociación entre el índice S/C, se realizó un análisis por medio del coeficiente de correlación de Spearman. Se encontró un nivel de correlación bajo entre el índice S/C y la edad del paciente ( rho = $0.269, p=0.024$ ) y con el hematocrito ( $r$ o $=0.202$, $\mathrm{p}=0.073$ ), moderado con el peso ( $r$ ho $=0.485, \mathrm{p}$ $<0.001$ ) y nulo con el recuento plaquetario (rho $=$ $0.003, p=0.979$ ). Además, se encontró un índice $\mathrm{S} / \mathrm{C}$ mayor en pacientes masculinos que en mujeres $(6.62$ [4.88-7.46] vs 4.88 [3.04-6.51], respectivamente; $p$ $=0.003$ ) (Figura C24.1). A pesar de que encontramos una diferencia estadísticamente significativa entre el índice S/C por grupo sanguíneo (grupo 0: 6.01 [3.98-6.79]; grupo A: 6.65 [4.94-7.44]; grupo B: 4.58 [2.96-4.86]; grupo AB: 7.33 [6.62-7.55]; $p=$ $0.040)$, después de realizar un análisis post hoc, no se encontraron diferencias entre parejas. Conclusión: El género masculino presentó una mayor producción de anticuerpos y el grupo sanguíneo $B$ parece tender a una menor producción (Figura C24.2). Además, la producción se correlaciona moderadamente con el peso del paciente. Se sugiere el aumento en el número de muestras para estudios posterior sobre el virus y su naturaleza.

\section{Referencias}

1. Boscato LM, Stuart MC. Heterophilic antibodies: a problem for all immunoassays. Clin Chem. 1988; 34 (1): 27-33.

2. Xiao AT, Gao C, Zhang S. Profile of specific antibodies to SARS-CoV-2: the first report. J Infect. 2020; 81 (1): 147-178. doi: 10.1016/j.jinf.2020.03.012.

3. Zhao J, Yuan $\mathrm{Q}$, Wang $\mathrm{H}$, et al. Antibody responses to SARS-CoV-2 in patients of novel coronavirus disease 2019. Clin Infect Dis. 2020; 71 (16): 2027-2034. doi: 10.1093/cid/ciaa344.

C25. I ncremento en el recuento plaquetario posttransfusión de aféresis plaquetaria, recolectada con el separador celular Amicus

Villalobos González MC,* Álvarez González G, ${ }^{\ddagger}$ Moreno Ramírez $\mathrm{LN}^{\ddagger}$

* Químico Farmacobióloga. ₹ Técnico Laboratorista Químico. Banco de Sangre Proquimed (Proquimed de León, S.C.).

I ntroducción: El rendimiento de la aféresis plaquetaria se mide por el incremento de la cifra de plaquetas circulantes post-transfusión. Existen diversas fórmulas, siendo una de las más utilizadas el incremento de conteo corregido.

Cuenta incremental $=$ cuenta plaquetaria post-transfusión Cuenta plaquetaria pre-transfusión

Incremento corregido del recuento plaquetario (IRC) $=$ Cuenta incremental $(\mathrm{CI}) \times$ Superficie corporal/dosis infundida

El incremento esperado en pacientes con transfusión profiláctica, con dosificación correcta de plaquetas y AB0 compatibles es de 10-20.000 Pla/ $\mu \mathrm{L}$. En casos de obtener un rendimiento $<7.500$ plaquetas en más de dos transfusiones seguidas con la calidad comprobada, se considera que existe refractariedad plaquetaria, de causa inmune o no inmune, procediéndose al estudio de ésta. Objetivo: Dar trazabilidad a la calidad de las aféresis plaquetarias obtenidas en Banco de Sangre Proquimed, comprobando el incremento mínimo necesario en el conteo plaquetario post-transfusión. Material y métodos: Se estudiaron las unidades de plaquetas obtenidas por aféresis en el separador celular Amicus y se realizó conteo pre-transfusión y post-transfusión para evaluar el incremento plaquetario que nuestras unidades de aféresis proporcionan al receptor. Resultados: En el estudio realizado a 48 unidades de aféresis plaquetarias obtenidas con el separador celular Amicus, todas con un rendimiento de 6.6 , se observa que en $81 \%$ de las unidades transfundidas se obtiene un IRC (incremento corregido del recuento plaquetario) mayor al 7.500, dando como resultado una transfusión exitosa y el 19\% restante está asociado a un evento del receptor (sepsis o reacción a la transfusión), por lo cual no se obtiene el IRC deseado, también se observa que el incremento plaquetario va desde las 20.000 plaquetas infundidas como mínimo para obtener un IRC satisfactorio hasta las 155.98 plaquetas infundas como máximo en Banco de Sangre Proquimed. (Tabla C25.1, Figuras C25.1 y C25.2). Conclusión: Basado en la bibliografía del manual técnico AABB donde se estipula que un ICR mayor a 7.500 plaquetas, se considera una transfusión exitosa, y $81 \%$ de las unidades estudiadas obtuvieron un ICR igual o mayor a éste, se considera que las unidades de aféresis plaquetarias obtenidas en Banco de Sangre Proquimed tienen una buena viabilidad y calidad comprobada. Las unidades que no cumplen con IRC estipulado están asociadas a un evento adverso que presentó el receptor.

\section{Referencias}

1. Manual técnico: traducción al español de la $17^{\mathrm{a}}$ edición de la American Asocciation of Blood Banks / dirigido por Osear Walter Torres. - 17 $7^{\text {ed. }}$ - Buenos Aires: Asociación Argentina de Hemoterapia e Inmunohematología, 2012. 1208 p. ; 23x16 cm. ISBN 978-987-964974-9 I. Bancos de Sangre. 2. Hemoterapia. I. Torres, Osear Walter, dir. COD616.15

2. Lee GA. (s.f.). Goldman-Cecil. Tratado de Medicina Interna. Barcelona España: Elsevier. 
Tabla C25.1: Incremento en el recuento plaquetario post-transfusión de aféresis plaquetaria con equipo Amicus.

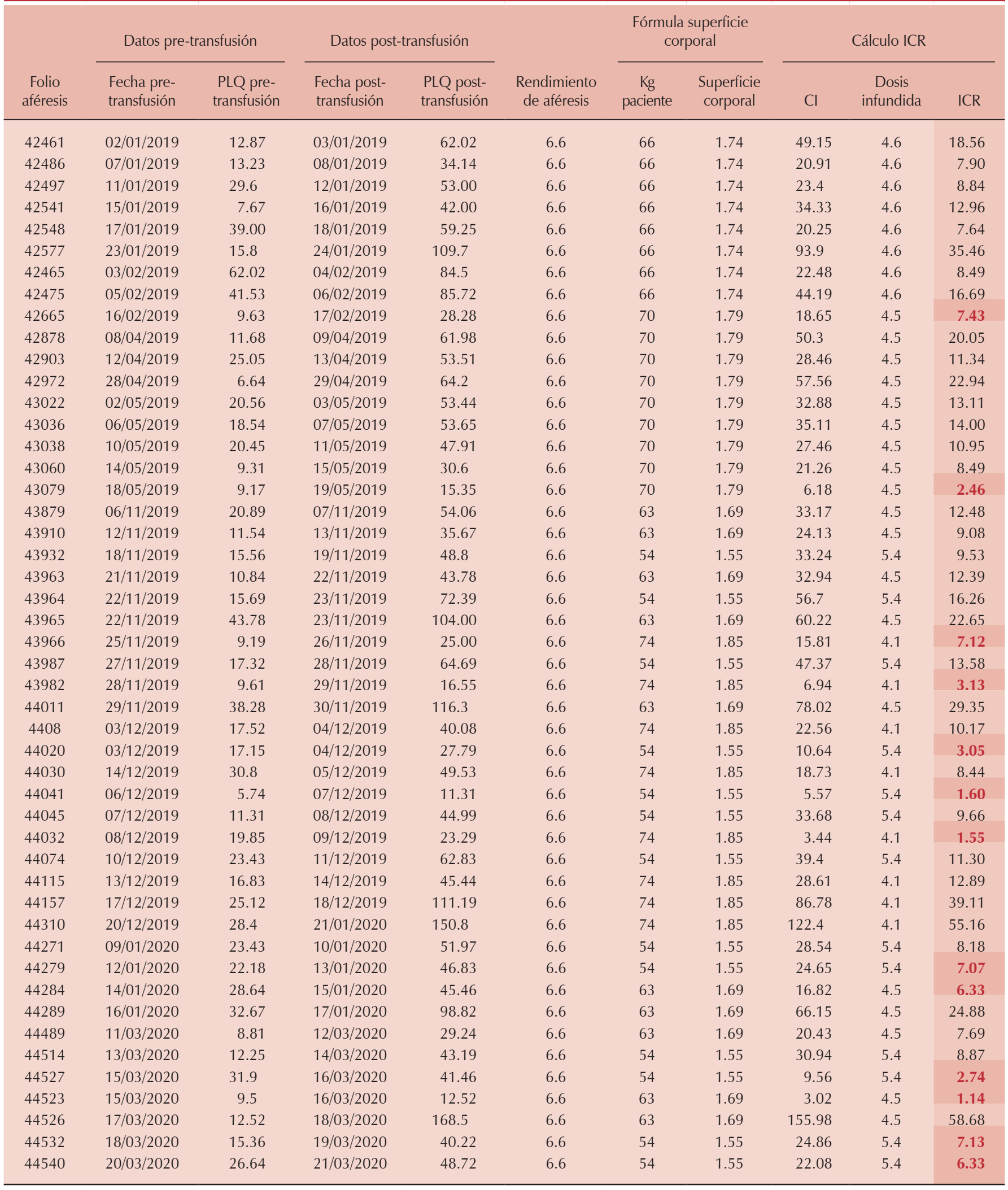

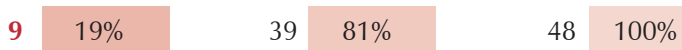




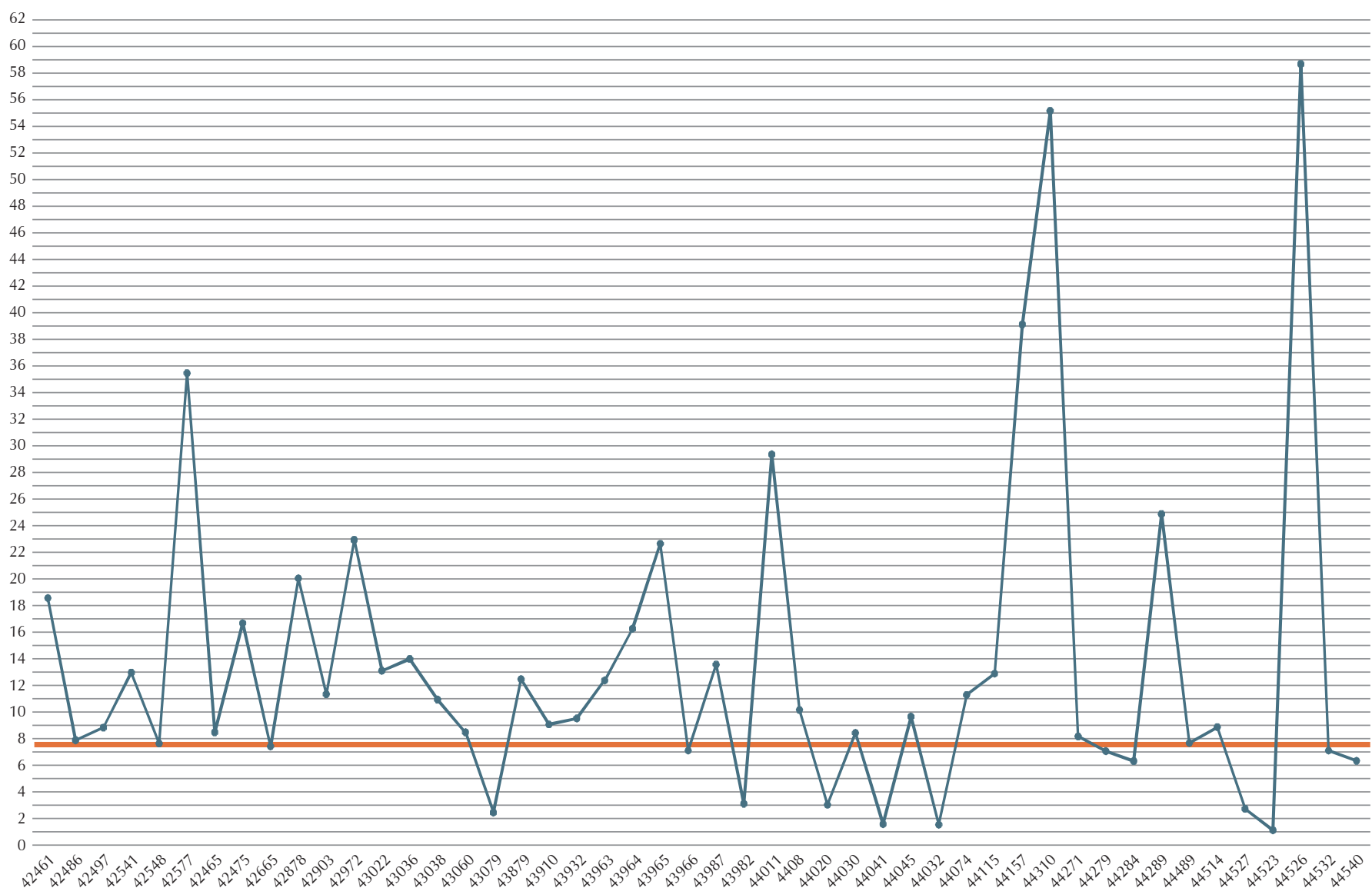

Figura C25.1: Incremento corregido del recuento plaquetario.

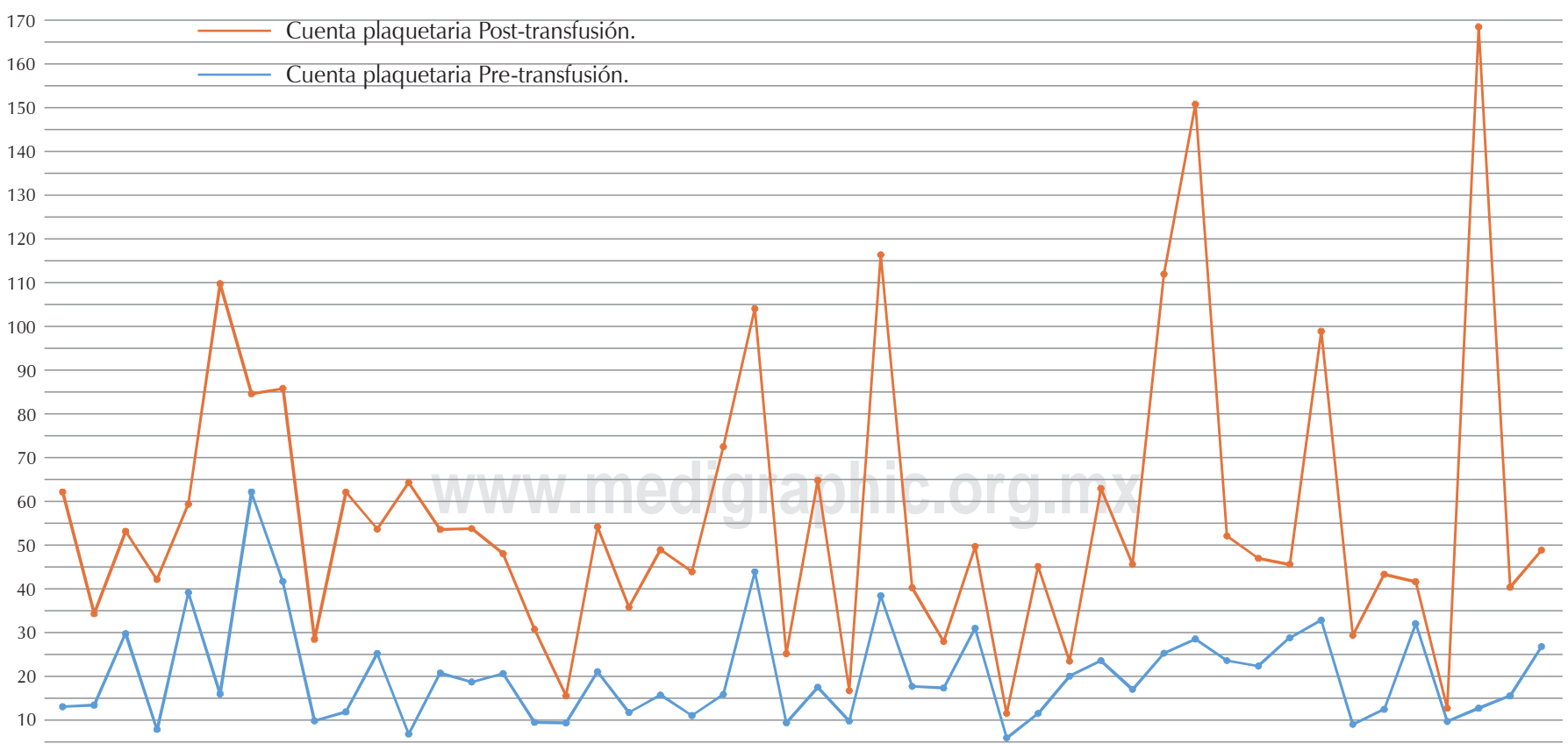

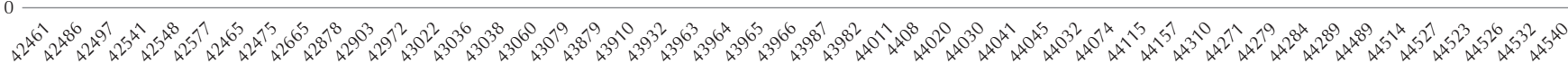

Figura C25.2: Diferencia de plaquetas pre-transfusión y post-transfusión. 
C26. Aféresis de alto volumen para recolección autóloga de hematoprogenitores en hospital universitario «Dr. J osé Eleuterio González»

Alvarado-Navarro DM,* Salazar-Riojas MR, ${ }^{*}$ HernándezNavarro AK, ${ }^{\S}$ Chávez Estrada YO, ${ }^{\S}$ Jaime-Pérez JC," Gómez-Almaguer D॥

* Coordinador de Medicina transfusional de Servicio de Hematología. ${ }^{\ddagger}$ J efe de Laboratorio de Servicio de Hema-

Tabla C26.1: Datos generales de paciente y procedimiento. $\mathrm{N}=175$.

\begin{tabular}{|c|c|}
\hline Datos de pacientes & n (\%) \\
\hline \multicolumn{2}{|l|}{ Género } \\
\hline Masculino & $98(56)$ \\
\hline Femenino & $77(44)$ \\
\hline Edad (años) & $53(7-77)$ \\
\hline \multicolumn{2}{|l|}{ Diagnóstico } \\
\hline Mieloma múltiple & $96(54.9)$ \\
\hline Linfoma de Hodgkin & $34(19.4)$ \\
\hline Linfoma no Hodgkin & $45(24.7)$ \\
\hline \multicolumn{2}{|l|}{ Estimulación } \\
\hline G-CSF & $94(53.7)$ \\
\hline \multicolumn{2}{|l|}{ G-CSF + plerixafor } \\
\hline $0.12 \mathrm{mg} / \mathrm{kg}$ & $37(21.4)$ \\
\hline $0.24 \mathrm{mg} / \mathrm{kg}$ & $32(18.0)$ \\
\hline G-CSF + ciclofosfamida & $11(6.3)$ \\
\hline G-CSF + plerixafor + ciclofosfamida & $1(0.6)$ \\
\hline \multicolumn{2}{|l|}{ Aféresis } \\
\hline Volumen procesado $(\mathrm{mL})$ & $20.409(6.900-35.737)$ \\
\hline Volemia procesada & $5(2.5-6.0)$ \\
\hline \multicolumn{2}{|l|}{ Tipo de aféresis } \\
\hline AVE & $20(11.4)$ \\
\hline AAV & $155(88.6)$ \\
\hline $\mathrm{CD} 34+\mathrm{x} 10^{6} / \mathrm{kg}$ & $4.4(0.1-24.6)$ \\
\hline \multicolumn{2}{|l|}{ Eventos adversos } \\
\hline Relacionado al acceso & $9(5.1)$ \\
\hline Náuseas y vómito & $12(6.9)$ \\
\hline Parestesias & $21(12.0)$ \\
\hline Cefalea & $3(1.7)$ \\
\hline
\end{tabular}

$\mathrm{G}-\mathrm{CSF}=$ factor estimulante de colonia de granulocitos, $\mathrm{AVE}=$ aféresis de volumen estándar, $\mathrm{AAV}=$ aféresis de alto volumen. tología. § Químico analista de Servicio de Hematología. " J efe de Enseñanza de Postgrado de Hematología. "J efe de Departamento de Servicio de Hematología. Universidad Autónoma de Nuevo León, Hospital Universitario «Dr. José Eleuterio González», Servicio de Hematología.

Introducción: La cantidad mínima de células hematoprogenitoras $(\mathrm{CD} 34+)$ en un autotrasplante para garantizar la recuperación hematológica es de $2 \times$ $10^{6} / \mathrm{kg}$. Sin embargo; hasta $30 \%$ de pacientes con hemopatías malignas no logran movilizar y recolectar dicha cantidad. El procedimiento de aféresis se puede llevar a cabo procesando un volumen estándar (AVE), es decir, dos a tres veces el volumen sanguíneo total; y la aféresis de alto volumen (AAV) involucra procesar 4 a 6 volemias. Este último método es utilizado para optimizar la eficiencia de la colección, con el objetivo de disminuir el número de procedimientos y alcanzar la cantidad mínima de células CD34+. Objetivo: Evaluar el rendimiento y seguridad de AAV en colectas autólogas de células hematoprogenitoras. Material y métodos: Estudio retrospectivo y observacional, realizado en el Servicio de Hematología del Hospital Universitario «Dr. J osé Eleuterio González». Se incluyeron todas las colectas autólogas de células hematoprogenitoras durante el periodo 2013-2021. Se incluyeron pacientes con enfermedades hematológicas malignas. Los procedimientos de aféresis se realizaron en los siguientes separadores celulares: COBE Spectra, Spectra Optia y Amicus. Resultados: Se evaluaron 175 procedimientos, de los cuales, 56\% fueron masculinos y la mediana de edad 53 años. El 54.9\% tenía diagnóstico de mieloma múltiple, $19.4 \%$ linfoma de Hodgkin y $24.7 \%$ linfoma no Hodgkin. El $53.7 \%$ recibió estimulación con G-CSF, 39.4\% de G-CSF con plerixafor, G-CSF con ciclofosfamida y sólo $0.6 \%$ combinación de los tres fármacos (Tabla C26.1). De los pacientes que recibieron plerixafor, $21.7 \%$ recibió dosis baja $(0.12 \mathrm{mg} / \mathrm{kg})$ y $18.3 \%$ dosis completa $(0.24 \mathrm{mg} / \mathrm{kg})$. La mediana de volumen procesado fue $20,406 \mathrm{~mL}$ y la mediana de volemias procesadas fue de 5. En $11.4 \%$ de los pacientes se procesó un volumen estándar y $88.6 \%$ se procesó alto volumen. De los pacientes del grupo AVE, la mediana de CD34+X10\% $\mathrm{kg}$ fue 3.78, a diferencia de AAV fue 4.55 (valor $\mathrm{p}=$

Tabla C26.2: Análisis por tipo de estimulación. N = 175

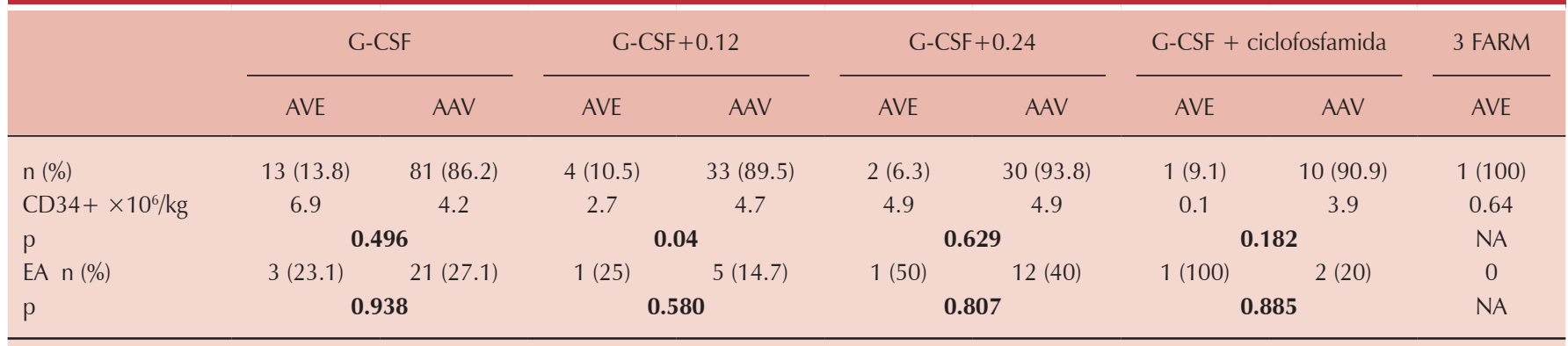

$\mathrm{G}-\mathrm{CSF}=$ factor estimulante de colonia de granulocitos, $\mathrm{AVE}=$ aféresis de volumen estándar, $\mathrm{AAV}=$ aféresis de alto volumen; 0.12: 0.12 mg/kg de Plerixafor; 0.24: 0.24 mg/kg de Plerixafor; 3 FARM = G-CSF, ciclofosfamida y plerixafor; $E A=$ eventos adversos. 
$0.884)$. La frecuencia de eventos adversos en AVE fue $25 \%$ y en AAV fue $26.5 \%$ (valor $p=0.815$ ). Al analizar la muestra por grupos de estimulación, tampoco se observó una diferencia estadísticamente significativa de los pacientes en los que se procesó AVE y AAV (Tabla C26.2). Conclusión: En el análisis global, el rendimiento de células CD34+ de $\operatorname{AVE}(3.78 \times 10 \%)$ $\mathrm{kg})$ fue menor en comparación $\operatorname{AAV}\left(4.55 \times 10^{6} / \mathrm{kg}\right)$, sin embargo, esta diferencia no fue estadísticamente significativa. La frecuencia de eventos adversos de AVE fue $25 \%$ y AAV $26.5 \%$ sin diferencia significativa. Por lo tanto, la práctica de AAV es recomendable solamente para circunstancias en las que se deba obtener dosis de CD34+ extremadamente alta.

\section{Referencias}

1. Giralt S, Costa L, Schriber J et al. Optimizing autologous stem cell mobilization strategies to improve patient outcomes: consensus guidelines and recommendations. Biol Blood Marrow Transplant. 2014; 20: 295-308.

2. Lopez F, Manresa P, Díaz V et al. Comparison and cost analysis of three protocols for mobilization and apheresis of hematopoietic progenitor cells. J Clin Apher. 2019; 34: (461-467.

\section{C27. Descripción y análisis del programa donador padrino en el Hospital I nfantil del Estado de Sonora (HIES)}

Gámez Sánchez FR,* López Miranda A,* García Rivera MA,* I barra Córdova MG,* Vidal López EM,* Flores Tapia FJ,* Fierro Monrreal MD,* Sau Escovar AS*

* Banco de Sangre del Hospital Infantil del Estado de Sonora.

Introducción: La Organización Mundial de la Salud (OMS) y la Organización Panamericana de la Salud (OPS) establecen que para abastecer de sangre segura a la población se debe fomentar el trabajo en equipo, obtener la sangre y componentes sanguíneos de donantes voluntarios y altruistas, no remunerados y regulares, asegurándose que reciban una atención de calidad. La donación voluntaria no remunerada y regular han permitido que en las últimas dos décadas hubiera una reducción importante del riesgo de transmisión transfusional de agentes infecciosos. En el año 2015, dentro del HIES, iniciamos con el programa «donador padrino», por la necesidad de contar con hemocomponentes para la población más vulnerable que por alguna razón no podía realizar la donación; en un principio, los donadores de reposición eran los que se convertían en donador padrino, pero gracias a la promoción del programa dentro del estado y a la realización de campañas en las universidades, se ha ido paulatinamente incrementando el número de donadores altruistas que pertenecen al programa donador padrino. Un donador padrino es aquella persona que, como el nombre lo dice, adopta a uno o varios pacientes como su ahijado y le regala vida a través de su donación de sangre o plaquetas. Para convertir a un donador dirigido o de reposición en donador padrino, debemos actuar con buena actitud de servicio desde recepción hasta el último eslabón de la cadena del proceso de donación, es muy importante darle un trato digno desde que lle-

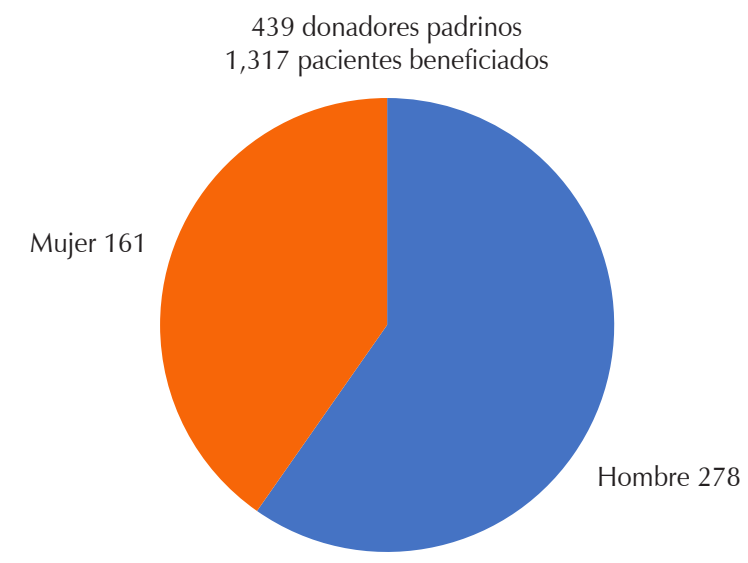

Figura C27.1.

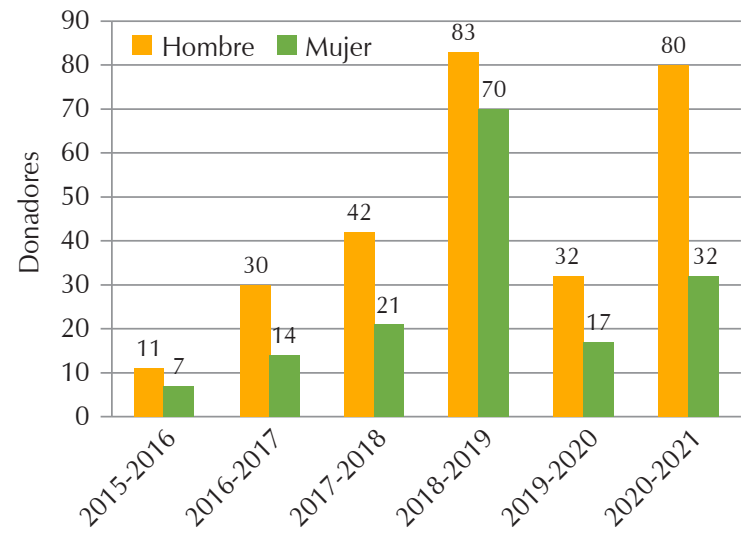

Figura C27.2: Donadores padrinos.

ga hasta que se va para que éste tenga la intención de volver a donar varias veces durante el año (fidelización), explicarle que hay pacientes que requieren sangre y plaquetas cada 12 horas y es imposible en la mayoría de los casos la donación por parte del familiar, ya que es de escasos recursos económicos, que no gozan de buena salud y alimentación, es decir, sensibilizarlos a que ellos pueden hacer la diferencia al convertirse en un donador altruista, en un donador padrino. Objetivo: Dar a conocer la implementación del programa y el análisis de los resultados obtenidos a partir del inicio de este programa. Material y métodos: Es un estudio retrospectivo en el cual se tomó la información recabada y archivada en nuestro sistema digital de Banco de Sangre para obtener las cifras del crecimiento exponencial por año de donadores padrinos. Resultados: Se observa que el crecimiento exponencial de la captación de donadores padrinos es la siguiente por año. Donaciones efectivas: periodo del 01/01/2015 al 01/01/2016 fueron 11 hombres y siete mujeres. Periodo del 01/01/2016 al $01 / 01 / 2017$ fueron 30 hombres y 14 mujeres. Periodo del 01/01/2017 al 01/01/2018 fueron 42 hombres y 21 mujeres. Periodo del 01/01/2018 al 01/01/2019 fueron 83 hombres y 70 mujeres. Periodo del 01/01/2019 al 01/01/2020 fueron 32 hombres y 17 mujeres. Periodo 
del 01/01/2020 al 01/01/2021 fueron 80 hombres y 32 mujeres. Siendo beneficiados 1,317 pacientes con los diferentes hemocomponentes obtenidos. (Figuras C27.1 y C27.2). Conclusiones: Se observa que, gracias a la implementación de este programa de sensibilización a la población mediante pláticas personalizadas, campañas de donaciones en escuelas y empresas, hay un crecimiento en la donación altruista exponencial por año y nuestro grupo de donadores padrinos va creciendo y al mismo tiempo se va educando a la sociedad sobre la importancia de la donación de sangre y plaquetas.
C28. Protocolo para determinar la exactitud de medida en los termómetros infrarrojos utilizados en el Banco de Sangre del I nstituto Nacional de Pediatría I barra $\mathrm{BI}$,* Barona CC, ${ }^{\ddagger}$ Maldonado SK, Rodríguez HV, Jarquín NJCll

* Encargada de gestión de equipos y mantenimientos. Banco de Sangre. ₹ Coordinador de Calidad. Banco de Sangre. ${ }^{\S}$ J efa de Departamento de Banco de Sangre. " Jefa de Servicio de Electromedicina. "Técnico en Instalaciones y mantenimiento electrónico del Servicio de Electromedicina. Instituto Nacional de Pediatría.

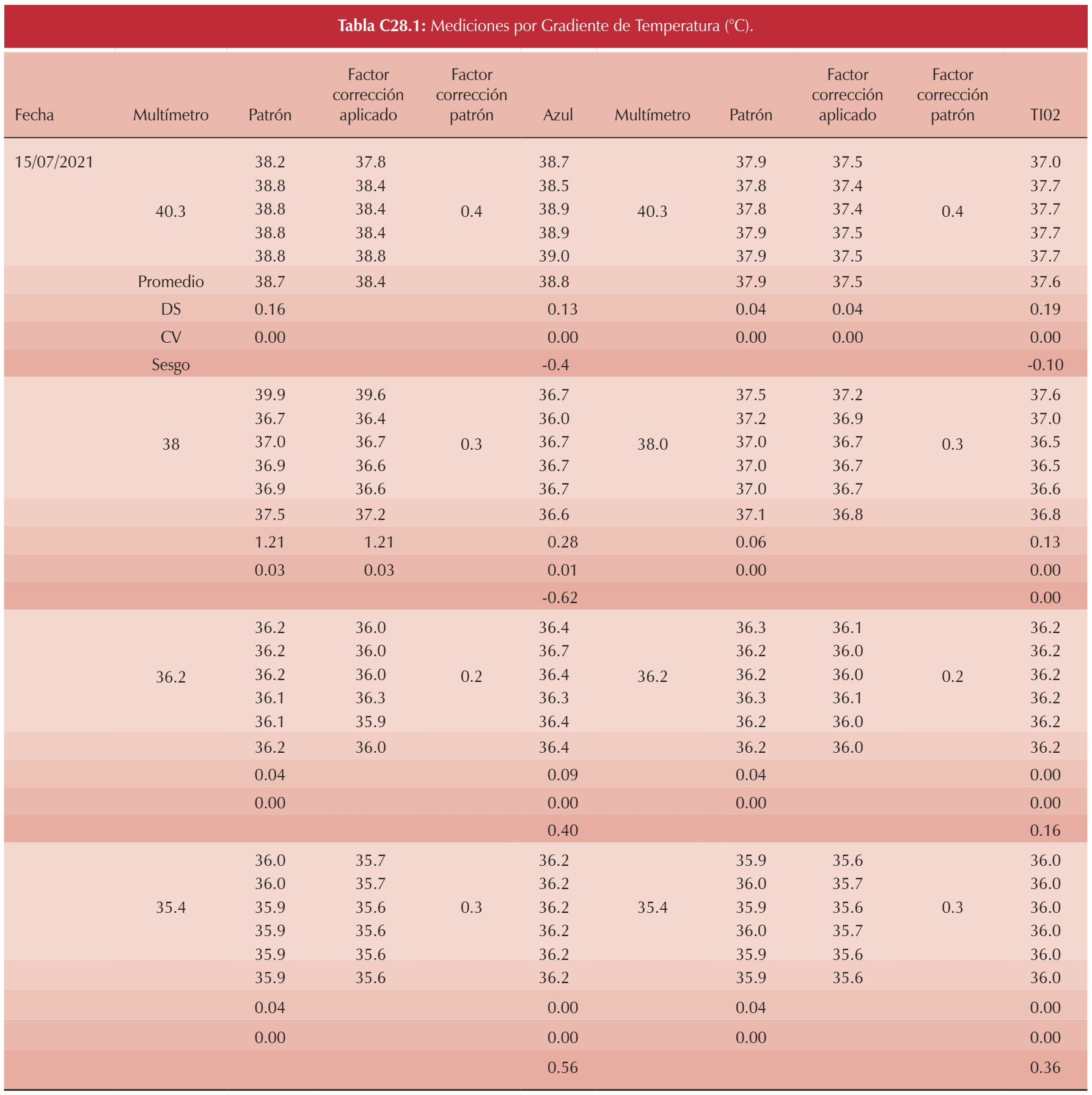


Tabla C28.2: Mediciones por Gradiente de Temperatura $\left({ }^{\circ} \mathrm{C}\right)$.

\begin{tabular}{|c|c|c|c|c|c|}
\hline Fecha & Multímetro & Patrón & $\begin{array}{l}\text { Factor corrección } \\
\text { aplicado }\end{array}$ & $\begin{array}{l}\text { Factor corrección } \\
\text { patrón }\end{array}$ & TI01 \\
\hline \multirow[t]{23}{*}{$16 / 07 / 2021$} & & 40.2 & 39.8 & & 41.6 \\
\hline & 42.1 & 40.9 & 40.5 & 0.4 & 41.7 \\
\hline & & 41.0 & 40.6 & & 41.0 \\
\hline & DS & 0.4 & & & 0.31 \\
\hline & $\mathrm{CV}$ & 0.0 & & & 0.01 \\
\hline & Sesgo & & & & 1.34 \\
\hline & & 38.4 & 38.0 & & 38.7 \\
\hline & & 38.4 & 38.0 & & 38.9 \\
\hline & & 38.4 & 38.0 & & 38.6 \\
\hline & & 0.19 & & & 0.29 \\
\hline & & 0.00 & & & 0.01 \\
\hline & & & & & 0.66 \\
\hline & & 36.9 & 36.7 & & 37.7 \\
\hline & & 36.9 & 36.7 & & 36.7 \\
\hline & 36.9 & 36.9 & 36.7 & 0.2 & 36.7 \\
\hline & & 36.9 & 36.7 & & 36.7 \\
\hline & & 36.9 & 36.7 & & 36.7 \\
\hline & & 36.9 & 36.7 & & 36.9 \\
\hline & & 36.0 & 35.7 & & 36.2 \\
\hline & & 36.1 & 35.8 & & 36.3 \\
\hline & & 0.04 & & & 0.04 \\
\hline & & 0.00 & & & 0.00 \\
\hline & & & & & 0.49 \\
\hline
\end{tabular}

I ntroducción: La selección de donadores es un área crítica en el Banco de Sangre, ya que es el primer contacto con el donante en el cual se determina si es apto o no para realizar el proceso de donación de forma satisfactoria. Uno de los procesos que forma parte de esta área es la toma de signos vitales, somatometría y valoración de accesos venosos, en donde se comienza la evaluación de las condiciones físicas en las que se presenta el candidato a donante para comenzar el proceso de donación. Dentro de los parámetros que se miden en este proceso, es importante la temperatura corporal para la detección de algún proceso infeccioso. Como medida emergente durante la pandemia por SARS-CoV-2 utilizamos termómetros infrarrojos para medir la temperatura al ingreso al Banco de Sangre y en somatometría, aplicando las acciones preventivas emitidas por la Secretaría de Salud para evitar contagios. Los termómetros infrarrojos de grado médico, aunque no miden como tal la temperatura corporal, éstos dan un buen acercamiento a dicha temperatura, midiendo la temperatura de la superficie a la que se apunta, tomando en cuenta la distancia a la que se realizan las mediciones, pues a mayor distancia del cuerpo por medir, hay menor exactitud y mayor número de interferencias. En el presente trabajo, llevamos a cabo 

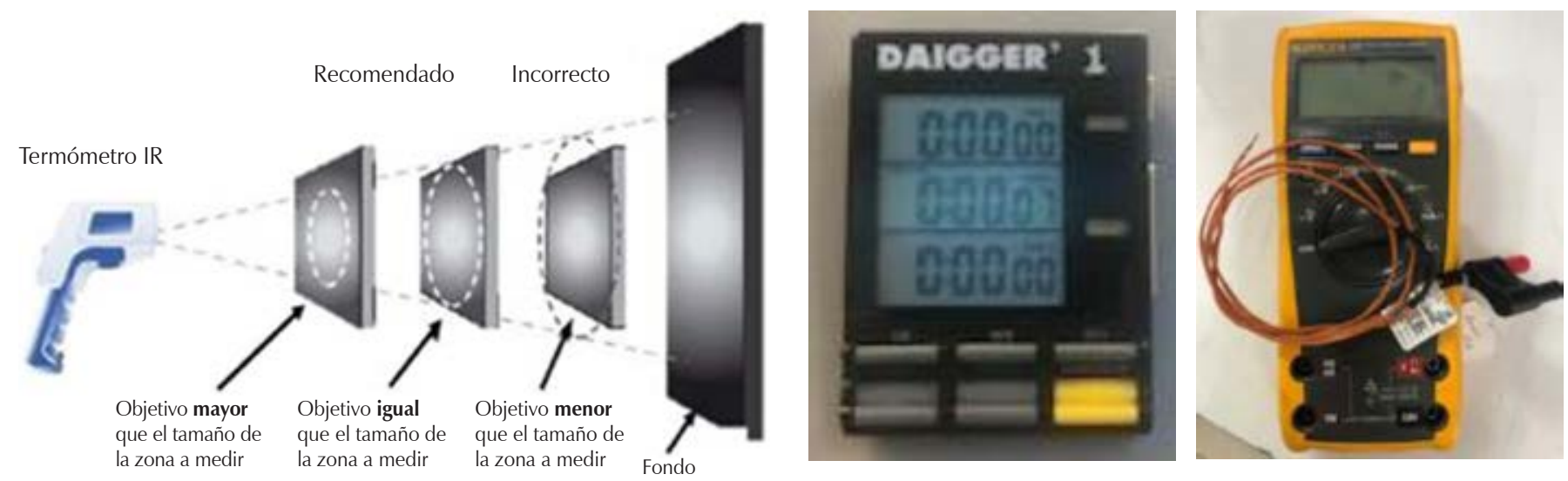

Tomado de: Meneses Gómez C. Calibración de termómetros IR y cámaras termográficas: asegurando la medición correcta. Webinars seminarios online gratuitos. Intronica Ltda. Santiago, Chile.
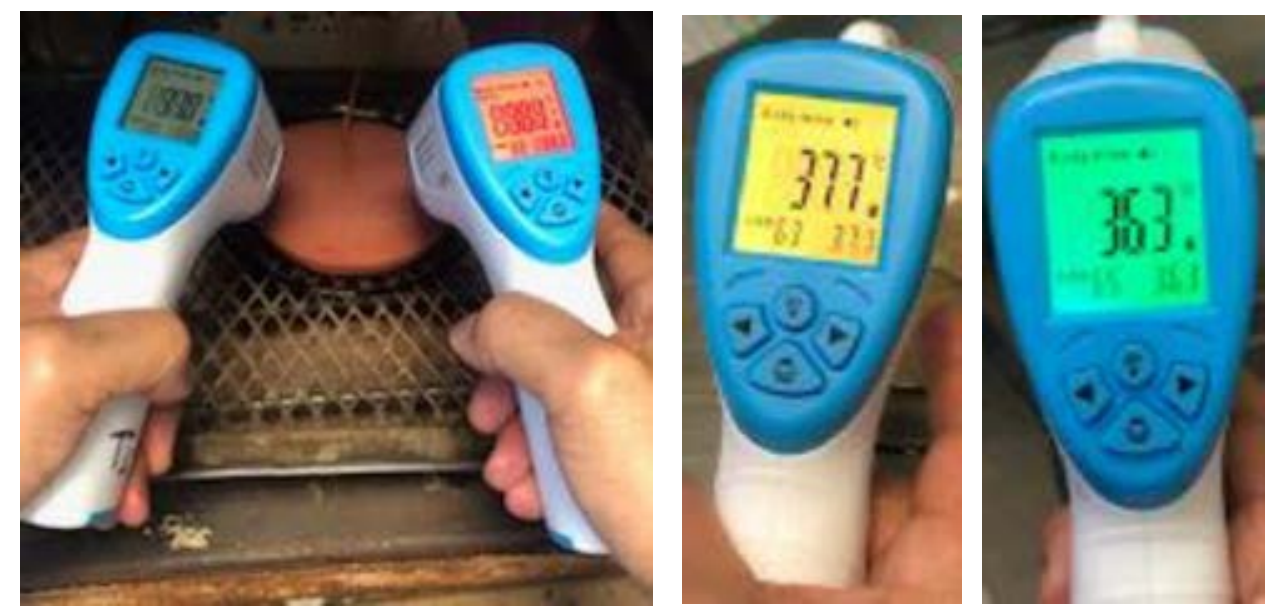

Figura C28.1:

Área de medición de termómetro, ubicación recomendada e incorrecta.

el diseño de un protocolo para determinar la exactitud de medida y desempeño de los equipos infrarrojos para medición de temperatura, en conjunto con el Servicio de Electromedicina, tomando en cuenta que el Instituto no cuenta con los recursos suficientes para el envío de estos equipos a compañías externas para su calibración periódica. Objetivo: Identificar la exactitud de medida de los equipos utilizados para mediciones de temperatura entre 35.5 y $40{ }^{\circ} \mathrm{C}$, tomando como referencia al inserto del equipo. Material y métodos: Los materiales utilizados fueron: un termómetro infrarrojo modelo BZ-R6, calibrado por un proveedor externo (Certificado de Calibración No. IAM-TIR-10187), identificado como «patrón». Tres termómetros infrarrojos modelo BZ-R6, identificados como TI01, TI02 y «azul». Equipo de secado por radiación para material de vidrio. Placas de vidrio. Seis piezas de embutido de cerdo de $1 \mathrm{~cm}$ de grosor. Cronómetro para laboratorio DAIGGER. Multímetro modelo 179 con sonda tipo k con certificado de calibración No. IAM-C45468/20 (multímetro) y No. IAM-TEMP-10145 (sonda). El método fue un protocolo de medida por comparación, utilizando un termómetro infrarrojo previamente calibrado por compañía externa, con el cual se tomaron medidas de temperatura a diferentes grados, comenzando de la más alta $\left(42^{\circ} \mathrm{C}\right)$ a la más baja $\left(35.5^{\circ} \mathrm{C}\right)$, en donde se realizaron las mediciones conforme la temperatura descendía hasta el valor aproximado en el que se llevarían a cabo las determinaciones. El precalentamiento del equipo de secado fue realizado con ayuda del multímetro, hasta llegar a una temperatura interior $\approx 42{ }^{\circ} \mathrm{C}$, colocando el embutido sobre placa de vidrio e introduciendo la punta de la sonda a un ángulo $\approx 30^{\circ} \mathrm{C}$ en el embutido; los termómetros cuentan con una alarma audible y visual para identificar temperaturas normales (verde), medias (amarillo) y altas (rojo). Las cinco mediciones realizadas con el patrón y equipos en comparación (con una repetición cada cinco minutos) registrando temperatura de referencia del multímetro y la temperatura registrada por los termómetros. Resultados: En las Tablas C28.1, C28.2 y en la Figura C28.1 se muestran los resultados obtenidos. Conclusiones: De acuerdo con los resultados obtenidos, identificamos una diferencia de medidas de \pm 0.2-0.4 ${ }^{\circ} \mathrm{C}$ para cada equipo, que concuerda con lo especificado por el fabricante; esta diferencia será aplicada al realizar las mediciones correspondientes por cada equipo. La diferencia mayor detectada fue en mediciones reali- 
zadas a temperaturas superiores a $40{ }^{\circ} \mathrm{C}$ para el equipo identificado como TI01. La aplicación de la exactitud de medida en mediciones somatométricas es un punto crítico para la evaluación de candidatos a donante, cumpliendo criterios de la NOM-253-SSA1-2012, así como es un auxiliar en la detección oportuna de sintomatología asociada a infecciones bacterianas o virales, como el SARS-CoV-2.

\section{Referencias}

1. www.mbmetrologia.com. Termómetros infrarrojos. Guía de selección, uso y recomendaciones. 2020.

2. Lenhardt R, Sessler DI. Estimation of mean-body temperature from mean-skin and core temperature. Anesthesiology. 2006; 105: 1117-1121.

3. Cárdenas GD. Guía técnica sobre trazabilidad e incertidumbre en la calibración de termómetros de radiación. CENAM, México. 2018; Recuperado de: http://www.cenam.mx 


\section{RESÚMENES PLÁTICAS}

\author{
Criterios de transfusión en el paciente geriátrico \\ Rodríguez Peña Adriana* \\ * Médico Adscrito de Geriatría en el Hospital General \\ de Zona No. 53 Instituto Mexicano del Seguro Social.
}

La Organización Mundial de la Salud (OMS) considera como adulta mayor a toda persona mayor de 60 años. ${ }^{1}$ Entre 2015 y 2050, el porcentaje de los habitantes del planeta mayores de 60 años casi se duplicará, pasando de 12 a $22 \%$, es por eso que debemos garantizar un sistema sanitario y social preparado para afrontar ese cambio demográfico ${ }^{2}$ estandarizando las políticas de salud pública que promuevan la igualdad y revisando la política transfusional en adultos mayores, según las guías nacionales e internacionales.

Acerca de la estadística de la donación y la transfusión de sangre en función del envejecimiento: la composición de los grupos de edades de la población muestra disminución de $5 \%$ en el número de habitantes de 0 a 19 años junto a un incremento del doble de ese valor en los adultos mayores. Las donaciones decrecen en cerca de $8 \%$, mientras que el número de pacientes transfundidos aumentan $33 \%$, por lo que vemos que los requerimientos de sangre son mayores, de la misma forma ${ }^{3}$ la prevalencia de anemia incrementa con la edad; con valores entre 5 y $10 \%$ en pacientes de 65 a 70 años que llega hasta $15.25 \%$ en mayores de 80 , en pacientes con criterios de fragilidad y mayores de 65 años puede oscilar entre 48 y $60 \%$, según el National Geriatrics Research Consortium y del Beverly Healthcare Data Warehouse, considerando que la prevalencia de anemia menor de $10 \mathrm{~g} / \mathrm{dL}$ es relativamente baja (13\%); este estado, a pesar de ser frecuente no es normal y aumenta la morbimortalidad, dependencia, caídas, deterioro cognitivo y riesgo cardiovascular, ${ }^{4}$ por eso la importancia de saber en qué momento debemos corregirla. Los criterios de transfusión descritos para la población adulta joven evitan el uso innecesario de hemoderivados y permiten la seguridad de la transfusión restrictiva; en el adulto mayor hay pocos estudios con validez externa, por lo que nos basamos en lo ya escrito; sin embargo, la evidencia científica empieza a dilucidar algunos puntos. La Asociación de Anestesiología de Inglaterra dice que no hay aumento de mortalidad con $\mathrm{Hb}$ (hemoglobina) de $8 \mathrm{~g} / \mathrm{dL}$, incluso en pacientes adultos mayores. Según la Sociedad Española de Transfusión Sanguínea los pacientes mayores de 70 años requieren generalmente valores mayores de $7 \mathrm{~g} /$ dL postoperatorios; y de acuerdo a la Sociedad Navarra de Salud en mayores de 70 años está justificada la transfusión perioperatoria para aumentar la $\mathrm{Hb}>$ 8-9 g/dL; el margen terapéutico es estrecho, aunque los triggers restrictivos parecen menos aconsejables conforme aumenta la edad. Las indicaciones para la estrategia restrictiva incluyen a la mayoría de los pacientes hospitalizados hemodinámicamente estables por motivos médicos y quirúrgicos, incluidos los que están en la unidad de cuidados intensivos o con choque séptico (grado 1B). Excepto en los siguientes casos:
- Síntomas: con hemoglobina $<10 \mathrm{~g} / \mathrm{dL}$.

- SCA/IM: cuando la hemoglobina es $\leq 8 \mathrm{~g} / \mathrm{dL}$; se considera cuando la hemoglobina está entre 8 y 10 $\mathrm{g} / \mathrm{dL}$; y mantenemos la hemoglobina $\geq 10 \mathrm{~g} / \mathrm{dL}$ en el paciente con síntomas, inestabilidad hemodinámica o isquemia en curso.

- Transfusión masiva: a menudo no pueden tratarse con los umbrales de hemoglobina, sino con la evolución del estado clínico. ${ }^{5}$

En general las diferentes guías recomiendan una transfusión restrictiva en niveles de 7-8g/dL, por ejemplo, la American Association of Blood Banks (AABB) de 2016 incluye recomendaciones para pacientes sin sangrado activo y hemodinámicamente estables:

- Hemoglobina $<6 \mathrm{~g} / \mathrm{dL}$ : se recomienda transfusión salvo en circunstancias excepcionales.

- Hemoglobina de 6 a 7 g/dL: en general está indicada la transfusión.

- Hemoglobina de 7 a $8 \mathrm{~g} / \mathrm{dL}$ : apropiada en pacientes sometidos a cirugía ortopédica o cardiaca y en aquéllos con enfermedad cardiovascular estable después de evaluar el estado clínico.

- Hemoglobina de 8 a $10 \mathrm{~g} / \mathrm{dL}$ : la transfusión generalmente no está indicada, pero debe considerarse para algunas poblaciones (anemia sintomática, hemorragia continua, síndrome coronario agudo con isquemia).

- Hemoglobina $>10 \mathrm{~g} / \mathrm{dL}$ : no está indicada, pero puede haber excepciones.

Estos valores también se adaptan al tipo de paciente y patología, dentro de este grupo etario es importante mencionar las peculiaridades de los pacientes con síndrome isquémico coronario agudo, fractura de cadera, paciente frágil, oncológico y en la etapa final de la vida (enfermedad terminal y cuidados paliativos). ${ }^{6}$

En pacientes con fractura de cadera hay beneficio con la transfusión cuando además de hematocrito bajo ocurre una pérdida mayor de $500 \mathrm{~cm}^{3}$; según el metaanálisis de Wu (2001) hay mayor mortalidad en el grupo restrictivo cuando se compara $\mathrm{Hb}$ de 8 y $10 \mathrm{~g} / \mathrm{dL}$; además estos pacientes transfundidos con triggers iguales o mayores a $10 \mathrm{~g} / \mathrm{dL}$ presentan recuperación funcional significativa. En la fractura de cadera los principales factores asociados a requerimientos de hemoderivados son: edad avanzada, tipo de fractura (con inestabilidad), $\mathrm{Hb}$ al ingreso, y uso de antiagregantes plaquetarios, por lo que monitorear las concentraciones de $\mathrm{Hb}$ durante el periodo perioperatorio es importante para corregir la anemia severa de manera oportuna y evitar exacerbar enfermedades subyacentes e inducir complicaciones graves; ${ }^{7}$ se recomienda optimizar la $\mathrm{Hb}$ preoperatoriamente, evaluando el riesgo/beneficio de forma individual.

En otro contexto como la cirugía no cardiaca, una revisión retrospectiva de la base de datos de 310,311 veteranos > 65 años, donde se evaluó la asociación de anemia preoperatoria con mortalidad o eventos cardiacos, las probabilidades ajustadas de muerte o eventos cardiacos se correlacionaron inversamente con el hematocrito 
preoperatorio. Incluso la anemia leve (hematocrito entre 36.0 y 38.9) se asoció con un aumento de $10 \%$ en los eventos; esto se elevó a $52 \%$ más de riesgo con anemia más severa (hematocrito entre 18.0 y 20.9).

Al momento de decidir si realizamos la transfusión, hay que tener en cuenta los cambios fisiológicos del envejecimiento como la hipertrofia ventricular izquierda, menor respuesta beta-adrenérgica y menor reserva cardiaca, lo que aumenta el riesgo de falla cardiaca en caso de cardiopatías previas como fibrilación auricular; y a nivel pulmonar hay una reducción fisiológica del volumen pulmonar, disminución de la elasticidad, aumento del espacio muerto, disminución de los capilares que impacta en el recambio gaseoso, por lo que la respuesta al estrés es menor, más lenta y en general hay menos tolerancia a cambios súbitos de volumen; esto significa que las transfusiones deben llevarse a cabo más lentamente, valorando el uso de diuréticos; se debe trasfundir unidad por unidad y reevaluar la condición clínica después de cada una, con mayor razón si tiene una función cardiaca comprometida. ${ }^{8}$

La decisión final de transfundir debe incorporar el estado clínico, la comorbilidad y los deseos individuales del paciente, ${ }^{9}$ considerando los efectos adversos que pueden presentarse, Beyer y colaboradores evaluaron un grupo de adultos mayores hospitalizados durante un año, $11 \%$ de los pacientes (n40) presentó reacciones, siendo la fiebre la más frecuente $(72 \%)$, disnea $(10 \%)$, vómito y escalofríos ( $8 \%$ ) en último lugar. El porcentaje de personas con reacciones postransfusionales fue pequeño; $\sin$ embargo, se especula que hay cierto sesgo por el alto porcentaje de pacientes con trastorno neurocognitivo incapaces de comunicarse.

En pacientes frágiles los niveles de $\mathrm{Hb}$ por encima de $10 \mathrm{~g} / \mathrm{dL}$ o Hct por encima de $30 \%$ bien pueden ser beneficiosos en dos situaciones: infarto al miocardio y fractura de cadera, aunque no hay validez suficiente para establecerlo en las guías; el estado de fragilidad, más que la edad, contribuye a la mortalidad, complicaciones, resultados adversos al alta y estadías prolongadas en el hospital.

El paciente oncológico: dos ensayos pequeños (muestra n149) han comparado los umbrales de transfusión en pacientes sometidos a tratamiento contra el cáncer por neoplasias hematológicas, siendo diferente el contexto de los pacientes en quimioterapia o trasplante de médula ósea de aquéllos en etapas terminales o en agonía. En espera de ensayos con el poder estadístico adecuado, los pacientes que reciben tratamiento contra el cáncer con intención curativa deben recibir transfusiones de manera similar a otros pacientes médicos, con transfusión para los síntomas y consideración de la transfusión a un umbral de hemoglobina de 7 a $8 \mathrm{~g} / \mathrm{dL}$ en ausencia de síntomas.

Un metaanálisis de 1,839 publicaciones reporta que $89 \%$ de los pacientes presenta mejoría sintomática a corto plazo y $11 \%$ no tiene beneficio alguno, aun así no hay evidencia suficiente que respalde o no las transfusiones en este grupo. De los 3,473 pacientes incluidos, $29 \%$ recibió transfusión, las indicaciones para la misma incluían niveles bajos de hemoglobina, anemia sintomática definida por fatiga, debilidad, disnea, sangrado activo o beneficio previo demostrado al recibir la transfusión; esta mejoría se observa en los síntomas los dos primeros días con aumento de los días de vida en etapa terminal, lo cual es cuestionable desde el punto de vista ético al prolongar muy probablemente el sufrimiento. ${ }^{10}$

Podemos concluir que es necesario continuar con estudios que respalden la toma de decisiones en el paciente adulto mayor, ya que son un grupo etario cada vez más numeroso, con múltiples variables entre sí, por lo que es importante identificar tres puntos: primero recordar los cambios propios del envejecimiento, después reconocer al paciente frágil que amerita tratamiento meticuloso y por último, diferenciar si estamos ante un tratamiento curativo, paliativo o en el final de la vida, siempre respetando la decisión del paciente después haberle explicado detalladamente el procedimiento.

\section{Referencias}

1. Varela L, Tello T. Asambleas mundiales sobre el envejecimiento. En: Varela L. Principios de Geriatría y Gerontología. 2a ed. Lima: Universidad Peruana Cayetano Heredia; 2011. 19-24.

2. Envejecimiento y salud. Organización mundial de la salud. 2018. Disponible en: https://www.who.int/es/news-room/fact-sheets/detail/ envejecimiento-y-salud

3. Sánchez FP, Pérez ULE, Hernández MS, Rojo PN, Cabrera AEN, Fernández DND. La donación y la transfusión de sangre en función del envejecimiento poblacional de Cienfuegos, 2010-2016. Rev Cubana Hematol Inmunol Hemoter. 2019; 1: e931.

4. Urrutia A, Sacanellac E, Mascarod J, Formiga F. Anemia en el anciano. Rev Esp Geriatr Gerontol. 2010; 45 (5): 291-297.

5. Carson JL, Kleinman S. Indications and hemoglobin thresholds for red blood cell transfusion in the adult. UpToDate, Junio 2021. Revisado Julio 2021

6. Wu WC, Rathore SS, Wang Y, Radford MJ, Krumholz HM. Blood transfusion in elderly patients with acute myocardial infarction. N Engl J Med. 2001; 345: 1230-1236.

7. Foss NB, Kristensen MT, Kehlet H. Anaemia impedes functional mobility after hip fracture surgery. Age Ageing. 2008; 37 (2): 173-178. doi: 10.1093/ ageing/afm161. PMID: 18349013.

8. Lubart E, Segal R, Tryhub N, Sigler E, Leibovitz A. Blood Transfusion reactions in elderly patients hospitalized in a multilevel geriatric hospital. J Aging Res. 2014; 2014: 178298.

9. Carson JL, Guyatt G, Heddle NM, Grossman BJ, Cohn CS, Fung MK et al. Clinical practice guidelines from the AABB: red blood cell transfusion thresholds and storage. JAMA. 2016; 316 (19): 2025.

10. Chin-Yee N, Taylor J, Rourke K, Faig D, Davis A, Fergusson D et al. Red blood cell transfusion in adult palliative care: a systematic review. Transfusion. 2018; 58 (1): 233-241.

Tamizaje y diagnóstico para VIH. Opciones, eficacia y control de calidad

Sáez Alquezar Amadeo*

* Farmacéutico-Bioquímico.

El tamizaje y el diagnóstico para la infección por VIH siguen siendo temas de extrema importancia para poder dar continuidad a nivel internacional, identificar el mayor número posible de personas infectadas, disminuir el número de nuevos casos de infección y permitir que las personas infectadas puedan tener acceso al tratamiento. Datos recientes de la Organización Mundial de la Salud (OMS) muestran que en 2019, 1,700,000 personas contrajeron VIH. Aunque eso signifique el nivel más bajo 
observado desde 2010 (el número ha disminuido en $23 \%$ ), continúa muy por debajo del objetivo mundial de menos de 500,000 nuevas personas infectadas para 2020. Al mismo tiempo, los nuevos datos de la OMS muestran que las pruebas y los servicios para la prevención de VIH, así como la hepatitis B y C, se encuentran entre los servicios interrumpidos con mayor frecuencia a causa de la COVID-19.

Actualmente existen distintas opciones metodológicas y de logística para la aplicación del tamizaje para VIH. Al mismo tiempo disponemos de algoritmos que nos permiten la confirmación de los resultados iniciales de las muestras obtenidos en el tamizaje.

La asociación de pruebas serológicas (inmunoensayos) y pruebas moleculares (NAT, PCR) puede traer beneficios para acortar el periodo de la ventana inmunológica del $\mathrm{VIH}$ en el caso de individuos inmunosilenciosos, en quienes los niveles de anticuerpos son bajos o están ausentes o también en casos de cepas o variantes virales que no puedan ser detectadas por algunos inmunoensayos.

La eficacia de las pruebas diagnósticas para VIH es bastante elevada, pero se observan diferencias entre las metodologías, pruebas y algoritmos utilizados. Lejos de ser un inconveniente, significa que podemos adoptar estrategias diferentes en función de las necesidades, características y limitaciones de cada situación.

En donantes de sangre, el tamizaje serológico se ha mostrado bastante eficaz debido a la mejora de la sensibilidad y especificidad de los inmunoensayos para anti-VIH $1+2+O$ de tercera generación, y a las pruebas «combo» que detectan Ag y Ac del VIH. Aun así, existe un riesgo residual de transmisión que se puede disminuir realizando las pruebas NAT en paralelo con el screening serológico. En determinadas situaciones se admite la posibilidad de utilizar pruebas rápidas (en doble) para iniciar el cribado y después se utilizan pruebas serológicas complementarias o pruebas moleculares para confirmar el resultado obtenido inicialmente.

Los inmunoensayos más recientes muestran sensibilidad de $100 \%$ y especificidad $\geq 99.8 \%$. Eso aumenta la fiabilidad en los resultados. En donantes de sangre se obtienen pocos resultados falsos reactivos (RFR) y excluyendo los casos en que el donante está infectado en el periodo de ventana, los resultados reactivos son bastante confiables.

Entre las opciones de metodologías para inmunoensayos tenemos los ensayos inmunoenzimáticos: (ELISA), por quimioluminiscencia: ChLIA (CMIO), electroquimioluminiscencia: EChLIA de pruebas diagnósticas rápidas por inmunocromatografia (PDR). Cada día se van utilizando más las pruebas por ChLIA y EChLIA en sustitución de las pruebas tradicionales de ELISA.

Eso se debe a diversos motivos: las pruebas por ChLIA son capaces de detectar cantidades menores de Ac o Ag, las reacciones se procesan en menos tiempo y están a disposición equipamientos/plataformas apropiadas para rutinas diarias de pequeño, medio y gran porte.

Dentro de ese contexto de ofertas que incluye pruebas sensibles, distintas metodologías, algoritmos flexibles y equipamientos automatizados, no podemos olvidar el concepto fundamental: control de calidad.
Los laboratorios deben poseer procedimientos para asegurar la calidad: a) un sistema de gestión de la calidad; b) adoptar las buenas prácticas de laboratorio; c) implementar programas de control interno de la calidad (PCIC) para validar las corridas diarias y c) participar en programas de evaluación externa de la calidad (PEEC). Una recomendación importante relacionada con los kits comerciales utilizados es que deben ser evaluados antes de que entren en la rutina diaria. En los cambios de lotes de reactivos hemos de cerciorarnos de que el funcionamiento del lote inicial siga siendo el mismo.

También es importante que los laboratorios tengan certificaciones que indiquen que los procesos o servicios son ejecutados de acuerdo con los requisitos especificados, por ejemplo, por la norma ISO 15.189. Cuando tienen una certificación ( $p$. ej. AABB o CAP) pasan por una evaluación para verificar si todos los procedimientos están dentro de las normas establecidas.

Todas las pruebas usadas en el tamizaje serológico de bancos de sangre son cualitativas, con excepción del Ag p24 y el core del HCV, es decir, hemos de considerar que las únicas alternativas de resultados son: reactivo o no-reactivo.

Para implementar el control de calidad interno necesitamos de sueros control interno de baja reactividad (SCI) con valores del índice lectura/cutoff) dentro de un rango recomendado por las normas internacionales. Esos SCI en general se adquieren de proveedores confiables. Se usarán para cada parámetro y para cada metodología como referencial para aceptar o rechazar la corrida analítica.

Hoy en día la mayoría de los laboratorios utilizan equipamientos/plataformas de alimentación continua que poseen software internos que controlan las rutinas, incluso utilizando los gráficos de Levey-Jennings. Por supuesto que debemos respetar las indicaciones de los fabricantes.

Aun así, es importante que cada laboratorio aplique su propio control interno diariamente y verifique el comportamiento de sus SCI, estableciendo qué periodos son más favorables para la introducción de los mismos. Existen en el mercado SCI específicos para diversas plataformas que ya están ajustados para el rango de reactividad recomendado.

Los valores encontrados con los SCI son representados gráficamente y se deben analizar a diario dentro de los límites preestablecidos para que las corridas analíticas puedan ser aceptadas o rechazadas.

Para la participación en programas de evaluación externa de la calidad (PEEC) en serología existen algunas reglas que son importantes y deben seguirse.

a) La frecuencia de los programas debe ser lo mínimo mensual.

b) Lo paneles usados en la evaluación deben contener muestras reactivas para todos los parámetros del tamizaje y de preferencia de suero humano liofilizado.

c) Deben ser documentadas e investigadas las causas de las no conformidades observadas (RFR/RFNR).

d) Los proveedores de ensayos de aptitud deben ofrecer programas de educación continua. 
Visitas periódicas de inspección (externa o interna) deberán comprobar que se cumplen las normas establecidas.

\section{Programa manejo hemático del paciente patient blood management en México \\ Dr. Pérez Calatayud Ángel Augusto* \\ * Jefe de División Áreas Críticas Hospital General de México «Dr. Eduardo Liceaga». Asesor Científico de la International Patient Blood Management Foundation.}

En las últimas cuatro décadas, una mayor conciencia de los riesgos inherentes de la transfusión ha dado lugar a importantes iniciativas para mitigar esos riesgos a través de mejoras en la seguridad de los productos sanguíneos y avances en las prácticas clínicas de transfusión. Esto llevó al concepto de «uso óptimo de la sangre» que incluye el uso juicioso de las transfusiones en todos los entornos, pero también a las técnicas de conservación de la sangre, especialmente en cirugía ( $p$. ej. minimización de la pérdida de sangre, recuperación de sangre, hemodilución autóloga). Detrás de estos esfuerzos se encuentra el concepto más amplio de «manejo hemático del paciente» (PBM por sus siglas en inglés) que aborda la deficiencia de hierro, la anemia, la coagulopatía y la pérdida de sangre como factores de riesgo de resultados médicos adversos relacionados con hemorragias y transfusiones. Además, en el marco del PBM, la anemia y la deficiencia de hierro se reconocen como problemas de salud por derecho propio, que afectan a miles de millones en todo el mundo. Existen directrices de la OMS sobre el uso clínico de las transfusiones que están sujetas a actualizaciones periódicas. Sin embargo, existe una brecha a nivel mundial en el conocimiento y la implementación del PBM como un marco general para abordar los riesgos de deficiencia de hierro, anemia, pérdida de sangre y coagulopatía en un enfoque integral y multidisciplinario. ${ }^{1}$

En pacientes que enfrentan anemia, pérdida de sangre y/ o coagulopatía, la transfusión de componentes sanguíneos alogénicos sigue siendo la terapia predeterminada. Esto a pesar de la evidencia de que, en términos de eficacia y seguridad, las transfusiones son subóptimas en muchos entornos clínicos. El PBM permite reducciones significativas y la prevención de la transfusión de glóbulos rojos, plasma fresco congelado y plaquetas con resultados similares o mejorados. ${ }^{2}$

La anemia en la población general afecta a un estimado de 1.95 a 2.36 mil millones de personas en todo el mundo, con la mayor prevalencia en los países de ingresos bajos y medianos bajos. La anemia por deficiencia de hierro (IDA) por sí sola afecta a un estimado de 1.24 a 1.46 mil millones de individuos en el mundo. ${ }^{3}$ El doble, puede sufrir deficiencia de hierro (DI) sin anemia y otras deficiencias de micronutrientes que pueden conducir a anemia. La anemia de la inflamación es la segunda anemia más común en todo el mundo y a menudo coexiste con la AlF, particularmente en personas que viven en países de ingresos bajos y medianos con alta prevalencia de deficiencias nutricionales y enfermedades infecciosas. La prevalencia máxima de anemia se da en recién na- cidos y niños, mujeres en edad reproductiva, mujeres durante el embarazo y ancianos. La carga mundial de morbilidad de la anemia es enorme con:

- Mayor morbilidad y mortalidad infantil.

- Deterioro del desarrollo neurocognitivo de bebés, niños y adolescentes.

- Aumento significativo de la morbilidad y la mortalidad materna.

- Coste social y pérdida de productividad laboral.

- Reducción de la calidad de vida. ${ }^{4}$

La dimensión macroeconómica de la anemia en años vividos con discapacidad (AVD) representa $8.8 \%$ de todas las afecciones en todo el mundo y provoca pérdidas cognitivas y productivas del producto interno bruto (PIB) de hasta $4.05 \%$. Detección y manejo de anemia en la población general y particularmente en los subgrupos más vulnerables sigue siendo una necesidad insatisfecha. ${ }^{5}$ La anemia preoperatoria en pacientes quirúrgicos es más prevalente que en la población general y se relaciona con un aumento muy significativo de la morbilidad, la mortalidad y la duración promedio de la estadía hospitalaria en la mayoría de los tipos de cirugía. ${ }^{6-8}$

Anemia como comorbilidad en pacientes con enfermedades comunes no transmisibles. Con 700 millones de casos de enfermedad renal crónica en todo el mundo y estimaciones de prevalencia de anemia en esta población entre 14 y $64 \%$, es probable que 100 millones o más padezcan anemia. La anemia en estas poblaciones sigue siendo poco reconocida y tratada. ${ }^{7}$

La anemia en pacientes con neoplasias oncológicas o hematológicas tiene una prevalencia de entre 26 y $53 \%$ y hasta $75 \%$ en pacientes con tumores sólidos que reciben quimioterapia. Con más de 19 millones de nuevos pacientes con cáncer cada año, millones también padecen anemia concomitante. La evidencia sugiere que la anemia en estos pacientes se asocia con un aumento de la morbilidad y la mortalidad, un estado funcional más deficiente y una calidad de vida relacionada con la atención médica.

La anemia adquirida en el hospital en pacientes sin hemorragia o cirugía es muy prevalente. Entre 35 y $75 \%$ de los pacientes ingresados en el hospital desarrollan anemia durante su estancia hospitalaria (anemia adquirida en el hospital) y la prevalencia es de hasta $100 \%$ en pacientes con estancias en la unidad de cuidados intensivos de más de siete días. De los dados de alta del hospital anémicos, aproximadamente la mitad sigue anémica hasta 12 meses después.

La pérdida importante de sangre debido al embarazo, la cirugía y los traumatismos afecta a millones de pacientes. La incidencia global de hemorragia posparto (HPP) y HPP grave ocurre en $6 \%$ y $1.86 \%$ de todos los partos, es decir, aproximadamente seis millones de eventos por año. De 80 a $90 \%$ de las pacientes presentan anemia después de la cirugía.

Las coagulopatías adquiridas e inducidas por medicamentos son cada vez más prevalentes. La coagulopatía inducida por trauma temprano es común y ocurre en más de $15 \%$ de los pacientes con trauma admitidos. También 
se puede encontrar en hasta $11 \%$ de los pacientes con lesiones leves sin alteración fisiológica o administración de hemoderivados. Las coagulopatías adquiridas e inducidas por medicamentos se relacionan con un aumento de la mortalidad, morbilidad grave, incluido el accidente cerebrovascular hemorrágico, y un aumento del ingreso a terapia intensiva y de la duración general de la enfermedad. 5-10

\section{Bases científicas del programa}

El manejo hemático del paciente o Patient Blood Management se define como una estrategia de seguridad del paciente con un enfoque multimodal basado en evidencia disponible para mejorar los resultados clínicos de los pacientes, gestionando y conservando la propia sangre del paciente, al mismo tiempo que previene eventos adversos y promueve el empoderamiento de pacientes en su proceso de atención. ${ }^{1}$

Para esto se incluyen tres pilares como paquetes de atención centrados en:

Pilar 1: Optimización de la masa eritrocitaria.

Pilar 2: Minimizar la pérdida sanguínea.

Pilar 3: Incremento de la tolerancia a la anemia.

La implementación de este programa se lleva a cabo mediante las tres 'Es'.

Evidencia: manejo adecuado de la anemia no mediante medicina transfusional, sino atacando la causa de raíz. Manejo adecuado de la coagulopatía por hemorragia bajo el principio de «trata primero lo que mata primero». ${ }^{1}$ Ética: mejorar la seguridad y la calidad de atención del paciente mediante una mejora del proceso de la medicina transfusional con impacto en morbilidad, mortalidad infecciones nosocomiales, estancia hospitalaria e ingreso a terapia intensiva.

Economía: establecer un ahorro significativo en gastos directos e indirectos de la atención del paciente para ser utilizados en otras áreas que requieren atención.

La Organización Mundial de la Salud en el Foro Global de Seguridad Sanguínea en 2011 reconoció la importancia del PBM para garantizar la calidad y seguridad de la transfusión sanguínea y actualmente también pertenece al marco de acción para el avance del acceso universal seguro y de calidad de los hemocomponentes como parte de la estrategia objetivo 4 2020-2023.

\section{Beneficiarios}

- Dada la prevalencia combinada de anemia y etiologías que conducen a anemia, pérdida de sangre y coagulopatía con hemorragia, casi todas las personas pueden beneficiarse del PBM durante su vida. Éste es aún más el caso del envejecimiento de la sociedad y el aumento de enfermedades crónicas no transmisibles como la enfermedad renal crónica, la enfermedad cardiaca crónica y la diabetes. ${ }^{9-11}$

- Personas con anemia crónica o deficiencias de micronutrientes: mejor calidad de vida, productividad, desempeño y desarrollo cognitivos.
- Atención materno-infantil: disminución de los resultados adversos, incluida la mortalidad.

- Pacientes con enfermedades crónicas: mejor salud y calidad de vida relacionada con la salud.

- Pacientes, quirúrgicos, médicos y obstétricas: mejores resultados para los pacientes, incluida la morbilidad y la mortalidad.

- Pacientes en general debido a la educación, el empoderamiento y la toma de decisiones compartida, todos ellos fundamentales para PBM.

Impacto en la prestación de asistencia y la cobertura universal en salud.

PBM mejor: ${ }^{12}$

1. El estado de salud nacional a través de la protección de la salud, la promoción de la salud y la prevención de enfermedades, los servicios de salud pública más esenciales, el acceso a la atención médica debido a la reducción de la utilización de recursos y la reducción de la estadía hospitalaria promedio, siendo así una inversión para una sociedad participativa.

2. El desempeño cognitivo, productividad laboral y potencialmente el producto interno bruto. La salud y bienestar de la comunidad, incluso para las personas que de otro modo podrían necesitar una transfusión.

Implementar PBM puede reducir: ${ }^{13}$

1. Costos del sistema de salud al mejorar los resultados de salud, prevenir condiciones de salud secundarias e incurrir en menores costos relacionados con los ciudadanos y los cuidadores a corto y largo plazo, apoyando así específicamente la meta de cobertura universal de salud.

2. Dependencia transfusional institucional y nacional mediante el manejo preventivo de los pacientes de una manera que preserve la propia sangre del paciente.

3. Disminuir el papel de las transfusiones de sangre y los bancos de sangre, y la presión sobre la población de donantes.

4. El PBM reduce la dependencia de transfusiones nacionales e institucionales, mejorando también la respuesta a una pandemia cuando hay escasez de sangre, debido a enfermedades infecciosas emergentes o reemergentes en el grupo sanguíneo, derivaciones de donantes o distanciamiento social que conduce a la renuencia a donar.

\section{Referencias}

1. Manejo hemático del paciente. Guía de Práctica Clínica: Evidencias y Recomendaciones. México, CENETEC; 2020. Disponible en: http:// www.cenetec-difusion.com/CMGPC/GPC-SS-830-20/ER.pdf

2. Shander A, Goobie SM, Warner MA, Aapro M, Bisbe E, PerezCalatayud AA et al. International Foundation of Patient Blood Management (IFPBM) and Society for the Advancement of Blood Management (SABM) Work Group. Essential role of patient blood management in a pandemic: a call for action. Anesth Analg. 2020; 131 (1): 74-85.

3. Gorlinger K, Pérez-Ferrer A, Dirkmann D, Saner F, Maegele M, Calatayud ÁAP, Kim TY. The role of evidence-based algorithms for rotational 
thromboelastometry-guided bleeding management. Korean J Anesthesiol. 2019; 72 (4): 297-322.

4. Clínicas mexicanas de Anestesiología Vol. 38 Manejo hemático del paciente y monitoreo de la coagulación a la cabecera del enfermo ISBN: 978-607-741-268-7. 2020 enero abril 2020.

5. Bisbe E, Garcia-Casanovas A, Illa C, Varela J, Basora M, Barquero M et al. Maturity assessment model for patient blood management to assist hospitals in improving patients' safety and outcomes. The MAPBM project. Blood Transfus. 2021; 19 (3): 205-215.

6. Drabinski T, Zacharowski K, Meybohm P, Ruger AM, Ramirez de Arellano A. Estimating the epidemiological and economic impact of implementing preoperative anaemia measures in the German healthcare system: the health economic footprint of patient blood management. Advances in therapy. 2020; 37 (8): 3515-3536.

7. Morton J, Anastassopoulos KP, Patel ST, Lerner JH, Ryan KJ, Goss TF et al. Frequency and outcomes of blood products transfusion across procedures and clinical conditions warranting inpatient care: an analysis of the 2004 healthcare cost and utilization project nationwide inpatient sample database. Am J Med Qual. 2010; 25 (4): 289-296.

8. Trentino KM, Farmer SL, Swain SG, Burrows SA, Hofmann A, lenco R et al. Increased hospital costs associated with red blood cell transfusion. Transfusion. 2014

9. Freedman J, Luke K, Escobar M, Vernich L, Chiavetta JA. Experience of a network of transfusion coordinators for blood conservation (Ontario Transfusion Coordinators [ONTraC]). Transfusion. 2008; 48 (2): 237-250.

10. Klein HG, Hrouda JC, Epstein JS. Crisis in the sustainability of the U.S. blood system. N Engl J Med. 2017; 377 (15): 1485-1488.

11. Carson JL, Triulzi DJ, Ness PM. Indications for and adverse effects of red-cell transfusion. N Engl J Med. 2017; 377 (13): 1261-1272.

12. Ad N, Holmes SD, Patel J, Shuman DJ, Massimiano PS, Choi E et al. The impact of a multidisciplinary blood conservation protocol on patient outcomes and cost after cardiac surgery. J Thorac Cardiovasc Surg. 2017; 153 (3): 597-605 el.

13. Stein P, Kaserer A, Sprengel K, Wanner GA, Seifert B, Theusinger OM et al. Change of transfusion and treatment paradigm in major trauma patients. Anaesthesia. 2017; 72 (11): 1317-1326.

Precisión en el banco de sangre: aplicación de la genómica en la medicina transfusional

Montemayor Celina, MD PhD*

* Oficial Médica, Centro de Inovación, Canadian Blood Services, Ontario, Canadá.

La genómica es un elemento central en el movimiento de vanguardia que hoy conocemos como «medicina de precisión». Esta nueva rama de la medicina busca individualizar el diagnóstico, pronóstico y tratamiento médico de acuerdo a las variaciones genómicas y fisiológicas que caracterizan a cada ser humano. Los grupos sanguíneos constituyen un grupo de genes con mucha diversidad en las diferentes regiones del mundo y por lo tanto, representan una plataforma ideal y universal para la aplicación clínica de la genómica.

En nuestro campo ya se han establecido las ventajas clínicas de utilizar ensayos moleculares para predecir el fenotipo eritrocitario de donadores y pacientes. Por ejemplo, la genotipificación de antígenos eritrocitarios es una alternativa para tipificar pacientes que han sido transfundidos recientemente. También es útil para la identificación de fenotipos raros cuando no existen anticuerpos comerciales que se puedan utilizar en ensayos de aglutinación. La genotipificación también se ha convertido en un apoyo central para el soporte transfusional de pacientes que reciben ciertas terapias monoclonales, como anti-CD38 o anti-CD47, ya que estos anticuerpos interfieren con las pruebas tradicionales del banco de sangre. Finalmente, los ensayos moleculares tienen fuertes aplicaciones en la medicina prenatal, por ejemplo, en la determinación del riesgo de enfermedad hemolítica del recién nacido y/o trombocitopenia aloinmune neonatal. Los ensayos de genotipificación de antígenos eritrocitarios que se utilizan comúnmente en los bancos de sangre están basados en la detección dirigida de un número limitado y definido de variantes genómicas para grupos de sangre. La secuenciación de siguiente generación (NGS por sus siglas en inglés) ha surgido en los últimos años como una nueva tecnología que permite una detección más comprehensiva y precisa de antígenos eritrocitarios y plaquetarios.

En esta sesión se revisarán los principios de genotipificación en el banco de sangre, el mecanismo de las pruebas actualmente disponibles, y la aplicación de las nuevas plataformas de secuenciación de siguiente generación (NGS). Discutiremos el principio de NGS, incluyendo las ventajas y desventajas de plataformas de corta y larga lectura de ADN. Se revisará la literatura que ha documentado la precisión y el potencial de NGS en el banco de sangre. Por último, se aplicará el conocimiento adquirido en la discusión de casos clínicos en transfusión que han requerido NGS para su resolución. La sesión concluirá con una discusión del campo de genómica transfusional enfocado en las variantes específicas de América Latina.

\section{Referencias}

1. Montemayor C, Simone A, Long J, Montemayor O, Delvadia B, Rivera R et al. An open-source python library for detection of known and Novel Kell, Duffy, and Kidd variants from exome sequencing. Vox Sang. 2021; 116 (4): 451-463.

2. Montemayor C, Brunker PA, and Keller MA. Banking with Precision: Transfusion Medicine as a Potential Universal Application in Clinical Genomics. Current Opinion in Hematology. 2019; 26 (6): 480-487.

3. Montemayor-Garcia C, Karagianni P, Stiles DA, Reese EM, Smellie DA, Loy DA et al. Genomic coordinates and continental distribution of 120 blood group variants reported by the 1,000 genomes project. Transfusion. 2018; 58 (11): 2693-2704

4. Montemayor-Garcia C, Westhoff CM. The "next generation" reference laboratory? Transfusion. 2018; 58: 278.

5. Denomme GA, Anani WQ, Avent ND, Bein G, Briggs LB, Lapadat RC et al. Red cell genotyping 2015: precision medicine, conference summary. Therapeutic Advances in Hematology. 2017; 8 (10): 277-291.

6. Basu D, Datta SS, Montemayor C, Bhattacharya P, Mukherjee K, Flegel WA. ABO, Rhesus, and Kell antigens, alleles and haplotypes in West Bengal, India. Transfusion Medicine and Hemotherapy. 2017; 44: 1-5.

7. Montemayor-Garcia C, Coward R, Albitar M, Udani R, Jain P, Koklanaris $E$ et al. Acquired RhD mosaicisim in MPL-mutated post-essential thrombocythemia myelofibrosis: mechanism and transfusion management. Transfusion. 2017; 57 (9): 2136-2139.

Iniciativas internacionales para impulsar la medicina transfusional en Latinoamérica

Montemayor Celina, MD PhD*

* Oficial Médica, Centro de Inovación, Canadian Blood Services, Ontario, Canadá.

En esta sesión se discutirán las recientes iniciativas a nivel internacional para apoyar el desarrollo de la medicina transfusional y la terapia celular en países de habla hispana. 
Los objetivos de esta sesión incluyen:

1. Discutir el importante papel del Grupo Cooperativo Iberoamericano de Medicina Transfusional (GCIAMT), con énfasis en su Programa de Educación Continua.

2. Describir el crecimiento exponencial de actividades en idioma español por parte de la AABB (American Association of Blood Banks) y las oportunidades futuras de educación, capacitación y colaboración. Éstas incluyen:

- Congreso anual virtual con subtítulos en español en todas las ponencias, así como traducción durante la sesión de preguntas y respuestas.

- Actividades mensuales de educación y discusión en el campo de terapia celular.

- Traducción de material educativo en medicina transfusional.

- Acceso abierto y gratuito a los estándares fundamentales para bancos de sangre, en idioma español.

- Programas de capacitación en calidad basados en los estándares fundamentales.

- Un nuevo programa de certificado de calidad para organizaciones internacionales.

- Acreditación y consultoría.

- Grupo Hispano de Investigación en Medicina Transfusional.

- Preguntas sobre medicina transfusional del día en español.

- Nuevas propuestas.

3. Discutir otras actividades de apoyo por organizaciones internacionales:

- Global Blood Fund: donación de equipo y móviles de donación, material promocional.

- WIRhE: apoyo a esfuerzos locales de investigación sobre la prevalencia de enfermedad Rh, publicaciones traducidas al español, apoyo para investigación de implementación con el objetivo de erradicar la enfermedad Rh.

4. Invitación al público y discusión activa de ideas y propuestas.

Ligas y referencias de interés

Grupo Cooperativo Iberoamericano de Medicina Transfusional (GCIAMT). Disponible en: https://gciamt.org/

Congreso Anual AABB, página en Español. Disponible en: https://www. aabb.org/annual-meeting/learn/para-hispanohablantes

Subsección de Español de la AABB. Disponible en: https://www.aabb. org/get-involved/committees-sections/cellular-therapies-section/ subsections

- Estándares Fundamentales para Bancos de Sangre, en Español. Disponible en: https://www.aabb.org/aabb-store/product/ est\%C3\%Alndares-fundamentales-para-recolecci\%C3\%B3n-ytransfusi\%C3\%B3n-de-sangre---digital-15079861

- Pregunta de Medicina Transfusional del Día, en Español. Disponible en: https://transfusionnews.com/2019/09/03/transfusion-medicinequestion-of-the-day-now-available-in-spanish/

- WIRhE, Guía para prevenir la enfermedad Rh, en Español. Disponible en: https://wirhe.org/useful-links/

- Disponible en: https://wirhe.org/wp-content/uploads/2021/07/VasserES.pdf
Prueba cruzada linfocitaria

QFB. De Leo Cervantes Claudia J*

* Laboratorio de Histocompatibilidad Labstra S.C.

En 1966 Kissmeyer-Nielsen introdujo la prueba cruzada directa entre células del donante y suero del receptor, lo que permitió una disminución de los rechazos hiperagudos. A esto se suma lo demostrado en 1969 por Patel y Terasaki, el fracaso inmediato del injerto era el resultado de anticuerpos preformados citotóxicos presentes en el paciente (receptor) en contra de los antígenos HLA del donador. A partir del conocimiento de estos anticuerpos y de su posible impacto, la prueba cruzada se convirtió en un componente fundamental en los protocolos de trasplantes, principalmente en el ámbito renal.

La prueba cruzada linfocitaria (PCL) consiste en el análisis de la sensibilización de tipo humoral, específica del receptor contra el donador en estudio, derivado de la exposición a antígenos HLA extraños a los propios debido a: hemotransfusiones, embarazos / abortos y trasplantes previos. El resultado de una prueba cruzada positiva se considera una contraindicación para la realización del trasplante siempre y cuando se tenga la certeza de tratarse de anticuerpos clínicamente relevantes que puedan ocasionar un rechazo hiperagudo o pérdida temprana del injerto.

Con el avance tecnológico y un mejor conocimiento de las interacciones inmunitarias entre la pareja receptordonador se cuenta con diferentes tipos de pruebas cruzadas para detectar anticuerpos preformados en el receptor, entre las cuales tenemos las siguientes:

1. Prueba cruzada por el método citotoxicidad dependiente de complemento (CDC). Esta técnica serológica se ha utilizado ampliamente de manera rutinaria por décadas en los diversos laboratorios de histocompatibilidad en el mundo. En 1964 Terasaki y McClelland describieron una microtécnica basada en la activación del complemento donde los linfocitos del donador son primeramente incubados por 30' con suero del receptor, posteriormente se adiciona una fuente de complemento (suero de conejo) para continuar con una incubación de una hora, durante este tiempo de existir un complejo antígeno-anticuerpo se lleva la activación del complemento a través de la vía clásica, lo cual provoca daño en la membrana celular y al incorporar un colorante vital, éste penetra al interior de la célula. La tinción es visualizada mediante un microscopio invertido de contraste de fases, evaluando el porcentaje de lisis celular de la reacción y asignando una calificación con base en un sistema estandarizado.

Esta técnica permite detectar anticuerpos anti-HLA y no-HLA fijadores de complemento del tipo IgG e IgM. Para incrementar su sensibilidad se han realizado variaciones a la técnica CDC, entre las cuales se encuentran: incremento en los tiempos de incubación, la realización de lavados previamente a la adición del complemento, la incorporación de la antiglobulina humana (AHG) para detectar bajos niveles de anticuerpos y la utilización del agente 
reductor ditiotreitol (DTT) para descartar una falsa positividad en la prueba cruzada por presencia de autoanticuerpos del tipo IgM.

2. Prueba cruzada por citometría de flujo. Esta prueba surge en 1983 por Garavoy y colaboradores, es más sensible que CDC, no depende de la activación del complemento y es capaz de detectar bajos niveles de anticuerpos donador específico (ADEs) que no son identificados en una prueba por CDC-AHG, esto permite estudiar a pacientes de alto riesgo inmunológico y principalmente a los re-trasplantes.

La prueba se realiza incubando suero del receptor con células del donador, específicamente linfocitos T-B marcados con anticuerpos monoclonales con un fluorocromo diferente cada uno para diferenciar anticuerpos anti-HLA de clase I y II, posteriormente se incorpora un anticuerpo secundario anti-I gG conjugado con un fluorocromo, el cual se fija a todos los Acs IgG presentes en el suero del paciente que se hayan unido a los linfocitos del donador. La adquisición de la muestra se realiza en un citómetro de flujo y los resultados se expresan como negativo o positivo, de acuerdo al valor medio de fluorescencia obtenido. La intensidad de la fluorescencia emitida es proporcional a la cantidad de anticuerpos anti-HLA que se hayan unido a las células.

Los pacientes con una prueba cruzada negativa por CDC-AHG, pero positiva por citometría de flujo están en riesgo de presentar mayor número de episodios de rechazo y una posible falla temprana del injerto. Una limitante de esta prueba al igual que otras basadas en células es obtener resultados falsos positivos, como es el caso de pacientes tratados con inmunosupresores para terapia de inducción, entre ellos rituximab, daclizumab y globulina antitimocítica. Por lo anterior y con la finalidad de obtener resultados de las pruebas cruzadas en pacientes que reciban terapia de inducción como con rituximab, ahora se cuenta con una prueba conocida como FlowDSA-XM, la cual utiliza el método tradicional de la citometría de flujo combinada con la tecnología de microperlas recubiertas con anticuerpos anti-HLA de clase I y II para distinguir anticuerpos donante específico (ADEs) de manera selectiva.

3. Prueba cruzada virtual (PCV). No es una prueba física, es un análisis de los anticuerpos (Acs) antiHLA detectados en el suero de un paciente mediante una técnica de fase sólida (microperlas recubiertas con antígenos HLA purificados) para predecir si el suero analizado tiene la capacidad de reaccionar contra las células de un donador, específicamente contra los antígenos HLA del mismo. Conocer el perfil inmunológico de los anticuerpos permite establecer los antígenos HLA prohibidos y permisibles en cada paciente y por consiguiente, inferir el resultado de la prueba cruzada como negativa o positiva dependiendo si el donante posee o no los antígenos definidos. Para evaluar el riesgo pretrasplante es importante de manera previa contar con la información reciente de los Acs del paciente y la tipificación HLA clase I-II del receptor y del potencial donador.
La PCV es de gran utilidad en los programas de trasplantes para la asignación de órganos a partir de donadores fallecidos porque permite ganar tiempo en decidir qué pacientes en lista de espera pueden ser candidatos al trasplante, de igual manera el beneficio se extiende en los programas de donación renal cruzada.

$\mathrm{Si}$ el resultado de una prueba cruzada virtual es positivo, es probable que se produzca un rechazo agudo o crónico mediado por anticuerpos.

\section{Referencias}

1. Lenexa KS. ASHI laboratory manual. 4th ed. ASHI. 2000.

2. Gunawansa N, Rathore R, Sharma A, Halawa A. Crossmatch strategies in renal transplantation: a practical guide for the practicing clinician. J Transplant Surg. 2017; 1 (1): 8-15.

3. Jaramillo A, Ramon DS. The crossmatch assay in solid organ transplantation. Introduction to flow cytometry. Nova Science Publishers, Inc. 2019, 237-273.

4. Mahowald GK. The CDC crossmatch in the era of flow cytometric crossmatch and single antigen beads. J Bras Nefrol. 2021; 43 (3): 299300. doi: 10.1590/2175-8239-JBN-2021-0110.

5. Mulley WR, Kanellis J. Understanding crossmatch testing in organ transplantation: A case guide for the general nephrologist. Nephrology. 2011; 16 (2): 125-133

6. Patel R, Terasaki PI. Significance of the positive crossmatch test in kidney transplantation. N Engl J Med. 1969; 280: 735-739.

Recomendaciones del uso correcto de la sangre en el paciente pediátrico

Dr. Saucedo Montes Erick Eduardo*

* Hematólogo Pediatra, Jefe de Banco de Sangre Hospital Ángeles Tampico.

\section{II ntroducción}

La medicina transfusional es una de las disciplinas que interactúa con todas las especialidades, con mayor prescripción en el paciente hematoncológico, como tratamiento coadyuvante o paliativo y es piedra angular en el choque hemorrágico. ${ }^{1}$

En pediatría su principal uso en nuestro país está destinado a pacientes con trastornos hematoncológicos (leucemias, síndromes de falla medular, anemias hemolíticas congénitas con requerimiento transfusional, trasplante de células hematopoyéticas, cuidados paliativos), unidades de cuidados intensivos pediátricos y/o neonatales, así como las condiciones de urgencias que ponen en peligro la vida del menor (principalmente las relacionadas con accidentes automovilísticos), por ello la importancia de establecer recomendaciones de su uso correcto de hemocomponentes, ya que en la gran mayoría de unidades médicas de primer o segundo nivel, que tengan acceso a un banco de sangre y/o servicio de transfusión y cuenten con servicio de urgencias y/o unidades con área de hematoncología pediátrica, cuidados intensivos pediátricos $\mathrm{y} / \mathrm{o}$ neonatales $\mathrm{y} / \mathrm{o}$ cuidados paliativos de nuestro país, será de suma importancia establecer lineamientos de acuerdo a guías tanto nacionales como internacionales a fin de prescribir de forma correcta (dosis ponderal) dichos componentes sanguíneos con el beneficio de hacer acciones adecuadas que no afecten la calidad en la atención y seguridad del paciente en cuanto a transfusiones sanguíneas se refiera. 
Como recomendación inicial será individualizar cada prescripción de un acto transfusional, con base en el estado clínico del paciente, causa del déficit del componente sanguíneo y considerar alternativas a la transfusión (de acuerdo con valores y costumbres de los padres y/o tutores, ya que ellos son quienes son los responsables de otorgar la autorización del acto transfusional mediante el consentimiento informado).

Es importante poder disponer de bibliografía que cuente con niveles de evidencia y grados de recomendación debido a la gran heterogeneidad de recomendaciones, lo que hace complicado su comprensión así como su aplicación. El Grade Working Group (formado por los líderes basados en evidencia) ha tomado en consideración dichas dificultades, por lo cual se ha realizado unificación de criterios con base en consensos internacionales conocidos como el sistema GRADE para la valoración de grados de evidencia y recomendaciones en las guías de práctica clínica.

EI GRADE es un sistema de valoración de la calidad de la evidencia científica que permite simplificar la clasificación de las recomendaciones en fuertes o débiles (Tabla 1). Concluyendo de la siguiente manera:

Recomendaciones fuertes: evidencia de alta calidad metodológica (hacer lo de siempre y/o no hacerlo nunca).
Recomendaciones débiles: evidencia de regular o baja calidad metodológica (puedo hacerlo, pero hay que considerar otros factores).

Otra forma de poder optar por qué decisión tomar ante la realización del acto transfusional será con base en los grados de evidencia, tomando como indicación absoluta las condiciones clínicas que se cataloguen como una fuerte recomendación y que además presenten evidencia científica de alta calidad metodológica, como a continuación se describe en la Tabla 2.

\section{Objetivo}

La siguiente revisión documental tiene como objetivo especificar indicaciones de transfusión de hemocomponentes para uso en la edad pediátrica basadas en grados de recomendación y evidencia, de acuerdo a la literatura nacional e internacional.

\section{I ntroducción}

En todo el mundo se registran alrededor de 14 millones de transfusiones de concentrados eritrocitarios. En Estados Unidos se registran alrededor de 36,000 concentrados eritrocitarios transfundidos, 7,000 unida-

Tabla 1: Sistema GRADE para la valoración de grados de evidencia y recomendaciones en las guías de práctica clínica.

Calidad de la evidencia

Alta

Ensayos clínicos aleatorizados sin fallas de diseño o evidencia muy fuerte de estudios observacionales

Media

Ensayos clínicos aleatorizados con limitaciones importantes o evidencias consistentes de estudios observacionales

Baja

Estudios observacionales (cohorte, caso-control, serie temporal, antesdespués, o series de casos
Recomendaciones e implicancias

Fuertes

Beneficios superan riesgos y costos (o viceversa)

Aplicable a la mayoría de los pacientes sin reservas

Débiles

Beneficios en estrecho equilibrio con riesgos y costos, o bien inciertos Cualquier alternativa puede ser igualmente razonable

Decisión en cada caso individual según otros criterios (acceso, disponi-

bilidad, preferencias, riesgos o costos)

Tabla 2: Formulación de los grados de recomendación.

Grados de recomendación

Denominación
Descripción

Beneficios vs. riesgos

1A Fuerte recomendación

Evidencia científica de alta calidad metodológica

1B Fuerte recomendación

Evidencia científica de moderada calidad metodológica

1C Fuerte recomendación

Evidencia científica de baja calidad metodológica

2A

Débil recomendación

Evidencia científica de alta calidad metodológica

2B

Débil recomendación

Evidencia científica de moderada calidad metodológica

2C

Evidencia científica de baja calidad metodológica

Las ventajas o beneficios compensan claramente los riesgos o viceversa

Las ventajas o beneficios compensan claramente los riesgos, o viceversa

Las ventajas o beneficios compensan claramente los riesgos, o viceversa

Las ventajas o beneficios quedan balanceados con los riesgos

Las ventajas o beneficios quedan balanceados con los riesgos

Existe incertidumbre en la estimación de beneficios y riesgos. Las ventajas o beneficios podrían estar balanceados con los riesgos 
Tabla 3: Transfusión de componentes sanguíneos en niños.

\begin{tabular}{|c|c|c|c|}
\hline Hemocomponente & Objetivo & Dosis & Resultado esperado \\
\hline $\begin{array}{l}\text { Concentrado de } \\
\text { glóbulos rojos }\end{array}$ & $\begin{array}{l}\text { Aumentar la capacidad } \\
\text { de transporte de oxígeno }\end{array}$ & $10-15 \mathrm{~mL} / \mathrm{kg}$ & $\begin{array}{l}\text { Aumenta } 2-3 \mathrm{~g} / \mathrm{dL} \\
\text { de hemoglobina }\end{array}$ \\
\hline $\begin{array}{l}\text { Concentrado } \\
\text { de plaquetas }\end{array}$ & $\begin{array}{l}\text { Prevenir sangrado por } \\
\text { alteración cuantitativa o } \\
\text { cualitativa de plaquetas }\end{array}$ & $5-10 \mathrm{~mL} / \mathrm{kg}$ & $\begin{array}{l}\text { Aumenta } 50,000 \\
\text { plaquetas } / \mathrm{mm}^{3}\end{array}$ \\
\hline $\begin{array}{l}\text { Plasma fresco } \\
\text { congelado }\end{array}$ & $\begin{array}{l}\text { Reponer factores } \\
\text { de coagulación }\end{array}$ & $10-15 \mathrm{~mL} / \mathrm{kg}$ & $\begin{array}{l}\text { Aumento de } 15 \text { a } \\
20 \% \text { de los factores }\end{array}$ \\
\hline Crioprecipitado & $\begin{array}{l}\text { Tratamiento y profilaxis en } \\
\text { deficiencia de factores }\end{array}$ & $\begin{array}{l}1-2 \mathrm{U} / 10 \\
\mathrm{~kg} \text { de peso }\end{array}$ & $\begin{array}{l}\text { Aumento de } 60 \\
\text { a } 100 \mathrm{mg} / \mathrm{dL} \text { de } \\
\text { fibrinógeno }\end{array}$ \\
\hline
\end{tabular}
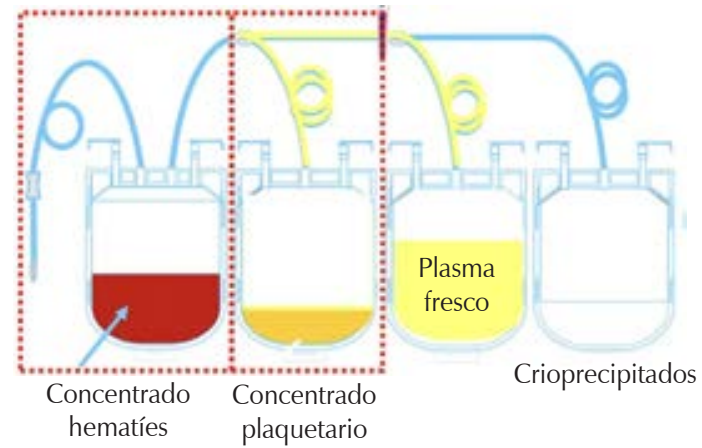

Tabla 4: Cuidados especiales en actos transfusionales.

Recién nacidos

En caso de transfusión masiva en recién nacido, ajustar la temperatura de la sangre para evitar una baja de 0.7 a $2.5^{\circ} \mathrm{C}$ El suero fisiológico acompañado de adenina, glucosa y manitol, que incluye el concentrado de eritrocitos, representa un riesgo por su alta toxicidad renal y puede causar alteración de la volemia flujo cerebral del recién nacido, pero la transfusión de pequeños volúmenes $(5-15 \mathrm{~mL} / \mathrm{kg})$ de concentrado de eritrocitos con glucosa y manitol son seguras

Leucorreducción

El uso de filtros leucocitarios ayuda a disminuir las reacciones inmunológicas: reacción febril no hemolítica, enfermedad de injerto contra huésped e inmunosupresión por efectos inmunoestimuladores Irradiación

Utilizada con la finalidad de evitar la proliferación de linfocitos del donante en el receptor y evadir que se genere reacción postransfusional

Transfusiones de glóbulos rojos frescos o almacenados En promedio se utilizan glóbulos rojos frescos con más menos siete días o unidades de máximo de 35 a 42 días de almacenamiento
En unidades de fototerapia tener precauciones porque la sangre puede hemolizarse dependiendo de la ubicación del equipo de transfusión

Las plaquetas no pueden calentarse porque se altera su función
Puede utilizarse filtro tanto para glóbulos rojos como para concentrados plaquetarios
La irradiación disminuye la supervivencia de los glóbulos rojos y plaquetas, aumenta el potasio extracelular, por esto el uso del componente debe tener irradiación reciente para limitar los efectos del potasio libre

Las unidades almacenadas de un mismo donante acumulan sustancias tóxicas como potasio, amoniaco, baja capacidad de descarga de oxígeno por la pérdida de 2.3 difosfoglicerato; a pesar de ello, estas desventajas no superan los riesgos de la exposición alogénica de los diferentes donantes des de plaquetas y 10,000 unidades de plasma fresco congelado anualmente (PFC). ${ }^{1}$ Estas prescripciones deben estar dirigidas a objetivos terapéuticos, por lo que en la actualidad la recomendación es individualizar la terapia, todo ello con el conocimiento de que el uso clínico de los hemocomponentes no carece de riesgos, es bien conocido para todos que la transfusión salva vidas, pero es necesario establecer que el mismo acto puede incrementar la morbilidad y mortalidad en el receptor. I niciando con el grupo de pacientes recién nacidos, es importante mencionar que hay diferencias en las que se efectúan a individuos de otros grupos etarios como mayor sensibilidad a los cambios de temperatura (termorregulación), mayor riesgo de hipoxia y cambios hematológicos propios del periodo neonatal. ${ }^{2}$ Además, las tasas de transfusión se incrementan conforme disminuye la edad gestacional o el peso al nacer. ${ }^{3}$

En pacientes pediátricos, e incluso en la población general, la tendencia actual es una actitud restrictiva a la indicación de hemocomponentes debido a los riesgos que este procedimiento representa. Debido a esto, se han intentado desarrollar nuevos protocolos como el de alicuotas de donante único (se anticipa si el recién nacido requiere más de una transfusión y se reservan las unidades de un solo donante para obtener los glóbulos rojos a transfundir en las diferentes ocasiones). . $^{4-6}$

Basado en recomendaciones y guías de carácter internacional así como nacional (AABB, ASCO 2018, NOM253-SSA1-2012, guías para el uso clínico de la sangre, etcétera), a continuación se establecen indicaciones 
Tabla 5: Indicaciones de transfusión de hemocomponentes en pediatría.

\begin{tabular}{llcl}
\hline Concentrado eritrocitario & Concentrado plaquetario & Plasma fresco congelado & Crioprecipitado \\
\hline - Anemia con trastorno & - Trombocitopenia $<20,000$ & - Deficiencia de factores & - Disfibrinogenemia \\
hemodinámico asociado & plaquetas con sangrado activo & de coagulación & - Hipofibrinogenemia \\
- Anemia hemolítica & Trombocitopenia inmune primaria $<$ & - Hepatopatía secundaria & - Deficiencia de factor XIII \\
- Angénita estadio & 10,000 plaquetas sin sangrado activo & \\
$\begin{array}{l}\text { Afección hemolítica aguda con } \\
\text { - Hemorragia aguda }\end{array}$ & Trastorno plaquetario cualitativo & \\
\hline
\end{tabular}

puntuales en cuanto a transfusión de hemocomponentes de acuerdo a dosis ponderal en pacientes pediátricos y un estimado de los parámetros a mejorar posterior a la transfusión (Tabla 3).

Durante el acto transfusional se deben considerar algunas cuestiones específicas, con la finalidad de que la transfusión sea lo más segura posible para el paciente, desde tomar en cuenta si se requiere algún producto, ya sea irradiado o leucodepletado ( pacientes inmunocomprometidos, hematoncológicos, postrasplantado de células hematopoyéticas, etc.) así como si es un recién nacido que se encuentre bajo fototerapia por hiperbilirrubinemia. ${ }^{7}$ En la tabla 4 se muestran algunas de las consideraciones especiales a tomar al momento de realizar el acto transfusional en pacientes pediátricos. ${ }^{7-9}$

Dentro de las principales causas en las que se requiere apoyo transfusional de algún hemocomponente en pacientes pediátricos, podemos encontrar en orden de frecuencia las siguientes causas (Tabla 5).

La Organización Mundial de la Salud reconoce la importancia de la hemovigilancia para detectar y prevenir la manifestación o la recurrencia de eventos indeseados relacionados con las transfusiones, incrementando así la seguridad, la eficacia y la eficiencia de la transfusión sanguínea. Con base en ello y debido a que el acto transfusional es responsabilidad de quien lo prescribe, debe racionalizarse su uso con base en el estado clínico del paciente y no en la corrección de cifras de estudios paraclínicos, bajo el sustento fisiopatológico por el que se desencadena el déficit del componente sanguíneo y tener presentes otras alternativas a la transfusión como hierro y otros hematínicos, eritropoyetina, trombopoyetina, factor estimulante de colonias de granulocito, liofilizados de factores de coagulación, antifibrinolíticos, etcétera. ${ }^{10}$

\section{Conclusiones}

El apego a las guías con base en grados de recomendación y evidencia, y sobre todo el contexto clínico del paciente, es lo que nos apoyará en la decisión de realizar el acto transfusional, siempre anteponiendo los beneficios sobre los riesgos de la misma así como tomando en cuenta valores, costumbres y creencias de los padres y en el caso de que existan alternativas al uso de hemocomponentes poder ofertarlo y de lo contrario, especificar tanto en expediente clínico la justificación de la transfusión como en el consentimiento informado el que no exista terapéutica opcional (ejemplo síndrome de falla de médula muy grave), dando cumplimiento a lo normativo de la NOM-004-SSA3-2012 y a su vez al proceso de hemovigilancia, Ilenado de consentimiento informado, nota pretransfusional, transfusional así como postransfusional según lo determina la NOM-253-SSA1-2012.

\section{Referencias}

1. Frazier K, Higgins J, Bugajski, Jones AR, Brown MR. Adverse reactions to transfusion of blood products and best practices for prevention. Crit Care Nurs Clin North Am. 2017; 29 (3): 271-290.

2. Oliveira E, Herdy V, Pereira D, Dallabela F, Vidal J, Linhares V. Nurses' knowledge of blood transfusion in neonate. Rev Gaúcha Enferm. 2017;38 (1): e63557. Available in: http://dx.doi. org/10.1590/1983-1447.2017.01.63557

3. Strauss RG. How I transfuse red blood cells and plate- lets to infants with the anemia and thrombocytopenia of prematurity. Transfusion. 2008; 48 (2): 209-217. doi: 10.1111/j.1537-2995.2007.01592.x.

4. Saldaña-Casas $\mathrm{O}$, De la Torre-Fernández A, Guzmán-García M, BlasMendiola C, Gómez-Gómez M, Saltigeral-Simental P. Transfusión de componentes sanguíneos en un hospital privado para niños. Rev Mex Pediatr. 2005; 72 (2): 65-69.

5. Arca G, Carbonell-Estrany X, López J, Figueras J, Fernández B, Blanco D et al. Anemia neonatal. En: Junta Directiva de la Sociedad Española de Neonatología (SEN). Protocolos de Neonatología. 2. ed. España: Asociación Española de Pediatría (AEP). 2003. 362-71.

6. Restrepo N. Manejo de componentes sanguíneos en recién nacidos. Programa de educación continua en pediatría. Sociedad Colombiana de Pediatría. 2013; 12 (2): 59-69.

7. New HV, Berryman J, Bolton-Maggs PH, Cantwell C, Chalmers EA, Davies T et al. Guidelines on transfusion for fetuses, neonates and older children. Br J Haematol. 2016; 175 (5): 784-828. doi: 10.1111/bjh.14233.

8. Rodrigues L, Barbosa A, Barbosa C, Basílio J, Novello R, Pessoa V et al. Transfusión de hemocomponentes en niños: ¿qué, cuándo y cómo usar? Resid Pediatr. 2015; 5 (1): 14-20.

9. Strauss RG. 2008 Emily Cooley Memorial Lecture: lessons learned from pediatric transfusion medicine clinical trials. A little child shall lead them. Transfusion. 2009; 49 (9): 1996-2004. doi: 10.1111/j.15372995.2009.02267. $x$

10. Schoettker P, Marcucci CE, CassoC, Heim C. Revisiting transfusion safety and alternatives to transfusion. La Presse Medicale. 2016; 45 (7-8Pt2): 331-340.

\section{Infección oculta por el virus B de la hepatitis} Aspectos vinculados a la medicina transfusional Dr. Rey Jorge Alberto*

* Bioquímico. Facultad de Farmacia y Bioquímica. Universidad de Buenos Aires, Argentina.

La infección oculta por el virus B de la hepatitis (IOB) es una entidad emergente en el área de la medicina transfusional. Su calificativo de «oculta» pone de manifiesto su característica principal que es la ausencia del 
HBsAg en el suero de los individuos portadores de la infección. La reunión de expertos en taormina ${ }^{1}$ define a la IOB como la presencia de ADN del HBV con capacidad de replicación (es decir, ADN circular covalentemente cerrado del HBV episómico [ADNccc]) en el hígado y/o ADN del HBV en la sangre de personas que dan negativo en las pruebas del antígeno de superficie de la hepatitis B (HBsAg) actualmente disponibles. De estar presente el ADN del HBV la carga viral del mismo no debe superar las $200 \mathrm{UI} / \mathrm{mL}$ para ser considerada una $\mathrm{IOB}$, puesto que cargas mayores implicarían la existencia de una mutante que no es reconocida por algunos equipos comerciales para la detección del HBsAg. Las IOBs se califican en serológicas, con presencia sérica de anti-HBC y/o anti-HBs, o no serológica o primaria cuando son negativos ambos anticuerpos. La IOB se detectó en $38 \%$ de los pacientes con hepatitis criptogénicas y en $25.6 \%$ de los pacientes con carcinoma hepatocelular. ${ }^{2}$ La transmisión de IOB por transfusión de sangre y hemocomponentes fue demostrada aun con donantes con cargas virales por debajo del límite de detección (LD) $(3.4 \mathrm{UI} / \mathrm{mL})$ de las pruebas NAT. La transmisión es dependiente del volumen de plasma transfundido y la seguridad transfusional se mejoraría mediante la selección con anti-HBc, el uso de NAT con LD de 0.8 copias $/ \mathrm{mL}$ o con inactivación de patógenos. ${ }^{3}$ Si bien los ensayos para HBsAg han mejorado sus LD y capacidad de detección de mutantes, existe una variabilidad de equipos con diferentes comportamientos. ${ }^{4}$ Por otra parte, el uso de anti- HBc ha demostrado su eficiencia, a punto de plantear que en países de baja endemicidad el uso de anti-HBc y una prueba NAT en testeo individual permitiría la no realización de HBsAg. ${ }^{5}$ Los dos principales inconvenientes para la implementación de la selección con anti-HBc son la frecuencia en países con alta endemicidad y su especificidad. Este último aspecto se ha mejorado notoriamente y su implementación en la selección de donantes no ha tenido impacto en los países con baja endemicidad para HBV. ${ }^{6}$ En los países de media a alta endemicidad, las tasas de anti-HBc superiores a $5 \%$ podrían hacer impracticable el uso en la selección de donantes. ${ }^{7}$ Respecto del uso de pruebas NAT en la selección de donantes, sabemos que tales pruebas han logrado disminuir ostensiblemente el riesgo residual de transmisión de enfermedades contagiosas, pero incluso en la época del NAT la transmisión transfusional de HBV sigue siendo la más frecuente de las infecciones virales. ${ }^{8}$ Probablemente, uno de los factores que más peso tiene en la detección de IOB entre los donantes es la estrategia de la selección. El testeo individual ha demostrado una eficiencia mayor que el testeo en mini pool. ${ }^{9}$ La emergencia de la IOB en la medicina transfusional obliga a un replanteo en la selección de donantes de sangre que tenga en cuenta la endemicidad y la factibilidad de cada región. ${ }^{10}$ Así, en países con baja endemicidad y alto ingreso económico la realización de HBsAg, de anti-HBC y NAT preferentemente en muestra individual sería el estándar superior, aunque hay suficientes pruebas para obviar la realización de HBsAg. En países con moderada y alta endemicidad, la anti-HBc no se puede implementar sin comprometer la disponibilidad de sangre. Por lo tanto, la prueba de HBsAg en combinación con NAT sería preferible cuando hay recursos disponibles. En países de alta endemia con recursos limitados, los test rápidos pueden ser una alternativa válida.

\section{Referencias}

1. Raimondo G, Locarnini S, Pollicino T et al. Update of the statements on biology and clinical impact of occult hepatitis B virus infection. J Hepatol. 2019; 71: 397-408.

2. Muto J, Sugiyama M, Shirabe K et al. Frequency and characteristics of occult hepatitis b infection among hepatocellular carcinoma patients in Japan. An Hepatol. 2018; 17 (4): 596-603.

3. Candotti D, Assennato SM, Laperche S et al. Multiple HBV transfusion transmissions from undetected occult infections: revising the minimal infectious dose. Gut. 2019; 68 (2): 313-321.

4. Scheiblauer H, El-Nageh M, Diaz S et al. Performance evaluation of 70 hepatitis B virus (HBV) surface antigen (HBsAg) assays from around the world by a geographically diverse panel with an array of HBV genotypes and HBsAg subtypes. Vox Sanguinis, 2010; 98: 403-414.

5. Dodd R, Nguyen ML, Krysztof DE et al. Blood donor testing for hepatitis $B$ virus in the United States: is there a case for continuation of hepatitis B surface antigen detection? Transfusion. 2018; 58: 2166-2170.

6. Van de Laar TJ, Marijt-van der Kreek T, Molenaar-de Backer MW, Hogema BM, Zaaijer HL: The yield of universal antibody to hepatitis B core antigen donor screening in the Netherlands, a hepatitis B virus low-endemic country. Transfusion. 2015; 55: 1206-1213.

7. Taira R, Satake M, Momose $S$ et al. Residual risk of transfusiontransmitted hepatitis B virus (HBV) infection caused by blood components derived from donors with occult HBV infection in Japan. Transfusion. 2013; 53: 1393-1404.

8. Calderón GM, González-Velázquez F, González-Bonilla CR et al. Prevalence and risk factors of hepatitis C virus, hepatitis B virus, and human immunodeficiency virus in multiply transfused recipients in Mexico. Transfusion. 2009; 49 (10): 2200-2207.

9. Weusten J, Vermeulen M, van Drimmelen H, Lelie N: Refinement of a viral transmission risk model for blood donations in seroconversion window phase screened by nucleic acid testing in different pool sizes and repeat test algorithms. Transfusion. 2011; 51: 203-215.

10. Candotti D, Laperche S. Hepatitis B virus blood screening: need for reappraisal of blood safety measures? Front Med. 2018. Available in: https://doi.org/10.3389/fmed.2018.00029

\section{El servicio de transfusión ante el paciente con} anemia hemolítica autoinmune

Dr. Muñiz Díaz Eduardo*

* División de Inmunohematología. Banc de Sang i Teixits. Barcelona. España.

El tratamiento de elección de la anemia hemolítica autoinmune (AHAI) no es la transfusión de hematíes; de hecho, no se recomienda la transfusión a menos que el estado clínico del paciente la haga necesaria. El tratamiento de elección consiste en la administración de esteroides, que a dosis de $1-2 \mathrm{mg} / \mathrm{kg} /$ día, resultan efectivos en la mayoría de pacientes. No es el temor a que la hemólisis del paciente se agrave como consecuencia de la transfusión, ya que es previsible que el grado de hemólisis no sea superior al que ya está aconteciendo con los propios hematíes del paciente. Tal como comentan los doctores Issitt y Anstee en su libro Applied Blood Group Serology, 1998, basándose en su larga experiencia, los pacientes transfundidos precozmente después del diagnóstico suelen tener un curso clínico menos favorable y un peor 
pronóstico que los pacientes tratados exclusivamente con esteroides. Al parecer este nuevo estímulo antigénico puede conllevar un incremento de la producción de autoanticuerpos y como resultado una respuesta más irregular al tratamiento inmunosupresor y remisiones menos prolongadas. No obstante, existen situaciones en las que el estado clínico del paciente justifica la transfusión. En general, cuando el síndrome anémico no es bien tolerado, o cuando aparecen signos de insuficiencia cardiaca o signos neurológicos de isquemia cerebral, la transfusión no sólo está indicada, sino que habrá que prepararla y administrarla con la mínima demora posible. Para proporcionar una transfusión segura y eficaz al paciente afectado de AHAl que inevitablemente ha de ser transfundido, debe tomarse una serie de precauciones tanto en el ámbito del laboratorio como de la clínica. Las pruebas de compatibilidad exigen una serie de técnicas adicionales que tienen como objetivo primordial descartar la presencia de un aloanticuerpo oculto por el autoanticuerpo en los pacientes con antecedente transfusionales u obstétricos. Una vez preparadas las unidades hay que intentar transfundir sólo la cantidad necesaria para mejorar la situación clínica del paciente, tan lentamente como permita el estado del paciente y bajo una estricta supervisión. A continuación se revisa la estrategia de trabajo que el servicio de transfusión debe realizar para asegurar la transfusión segura del paciente afecto de AHAI, especialmente en los casos en que ésta se debe a la acción de autoanticuerpos de clase IgG.

\section{Información clínica}

Es importante disponer de toda la información posible en torno a antecedentes del paciente y a su estado clínico. Interesa saber si ha estado transfundido previamente, número de gestaciones, antecedentes patológicos, fármacos, etc. Por otra parte, el estado del paciente nos orientará en torno al tiempo que disponemos para preparar las unidades de hematíes más óptimas.

\section{Determinación del grupo ABO y Rh}

La tipificación del grupo ABO no suele resultar problemática.

Para la determinación del grupo hemático, además de los sueros anti-A, anti-B (opcionalmente, también anti$A B$ y anti- $A 1$ ), idealmente debe emplearse un control negativo (albúmina bovina al $5 \%$ o, si se dispone de ello, la solución en la que va suspendido el anticuerpo monoclonal empleado).

Para el grupo sérico, además de los hematíes $A_{1}$ y $B$ (opcionalmente también hematíes $A 2, A B$ y $O$ ) deben emplearse los hematíes del propio paciente en suspensión salina al 3-5\%.

Respecto al sistema Rh es importante realizar una tipificación lo más completa posible, siempre que no existan transfusiones en los últimos tres meses, de los antígenos D, C, C, E, y e. Los reactivos monoclonales actualmente utilizados no suelen producir falsos resultados positivos, pero es recomendable un control de albúmina al $5 \%$, o bien el diluyente en el que están suspendidos los anticuerpos.
Estudio completo de la prueba directa de la antiglobulina (Coombs directo)

El diagnóstico de AHAl se habrá establecido con base en la concurrencia de anemia, signos biológicos de hemólisis y prueba directa de la antiglobulina (PDATG) positiva. Una vez obtenido el resultado positivo con la antiglobulina polivalente habrá que caracterizar la inmunoglobulina implicada con la ayuda de las antiglobulinas monovalentes, habitualmente anti-IgG y anti-C3b,d. En caso de que fuera necesario cabe el empleo de otras antiglobulinas monovalentes anti-IgM o anti-IgA.

Los autoanticuerpos calientes son mayoritariamente de clase IgG, aunque estudios recientes realizados con técnicas muy sensibles demuestran que hasta en $37 \%$ de casos suelen detectarse simultáneamente inmunoglobulinas de clase IgM o IgA, o ambas. No obstante, el perfil más común esperado en una AHAI caliente será el de anti-IgG positivo sólo o acompañado de C3b,d. Una buena antiglobulina IgG debe comenzar a dar resultados positivos en presencia de un mínimo de 150 moléculas de IgG por hematíe.

\section{Estudio del eluido}

La realización de un eluido y el estudio posterior del mismo nos permite confirmar la naturaleza autoinmune de las inmunoglobulinas IgG fijadas a la membrana del hematíe. Cuando el eluido contiene exclusivamente un autoanticuerpo, éste es reactivo con todas las células del panel, mostrando en ocasiones una especificidad relativa.

Una PDATG positiva, pero que cursa con un eluido no reactivo, puede sugerir la intervención de un fármaco. También es sugestivo de un proceso que comporta en el paciente la presencia de inmunocomplejos, de paraproteína o de una proporción superior a la habitual de inmunoglobulinas que de forma inespecífica se han fijado a los hematíes del paciente.

La presencia de un aloanticuerpo en el eluido es sugestiva de una reacción transfusional retardada, de una enfermedad hemolítica del recién nacido o, más raramente, de un autoanticuerpo «mimicking» o de un fenómeno de Matuhasi-Ogata.

Existen múltiples métodos de elución y cada uno de ellos posee ventajas e inconvenientes, si bien en los últimos años se han impuesto los reactivos comerciales de elución a pH ácido.

\section{Autoanticuerpos con especificidad}

Rh o especificidad relativa

En ocasiones, algunos autoanticuerpos reaccionan con todos los hematíes del panel, pero muestran una reactividad superior (aglutinación de intensidad superior o título superior) frente a hematíes de un determinado fenotipo Rh y, más concretamente, frente al antígeno e.

La actitud a adoptar en caso de que el paciente deba ser transfundido es controvertida. Algunos expertos abogan por no emplear los hematíes que contengan el antígeno 
e, excepto en el caso de que respetar esta regla implique transfundir sangre $R h(D)+$ a un individuo $R h(D)$-, especialmente si se trata de una mujer en edad fértil. I gualmente, si un paciente posee un autoanti-e más un aloanticuerpo (anti-e), debe respetarse esta incompatibilidad prioritariamente y prescindir de la especificidad relativa del autoanticuerpo.

Otros expertos, por el contrario, recomiendan ignorar las especificidades relativas apoyándose en las siguientes consideraciones. Primero, los estudios de supervivencia de los hematíes compatibles frente a los incompatibles no son concluyentes $y$, en muchos de ellos, el beneficio de respetar la especificidad relativa es mínimo. Y en segundo lugar, contemplar la especificidad relativa puede implicar utilizar hematíes en los que pueden estar presentes antígenos ausentes del fenotipo del paciente, con el consiguiente riesgo de inmunización.

\section{Estudio del suero/ plasma}

En más de $80 \%$ de los pacientes con AHAl IgG, el autoanticuerpo se encuentra libre en el suero, lo que determina que tanto el escrutinio como la identificación de anticuerpos irregulares y las pruebas de compatibilidad resulten positivos. En esta situación, si el paciente tiene antecedentes transfusionales y/o de gestación, no es posible asegurar que la reactividad observada se deba únicamente a la presencia de un autoanticuerpo. El objetivo fundamental al abordar el estudio del suero es detectar la presencia de aloanticuerpos que pudieran quedar ocultos por el autoanticuerpo libre.

Las técnicas de elección para investigar la presencia de aloanticuerpos ocultos por el autoanticuerpo son las de adsorción: autoadsorción y adsorción alogénica o diferencial.

\section{Autoadsorción}

La mejor técnica actualmente disponible para detectar un aloanticuerpo en presencia de un autoanticuerpo es la autoadsorción del suero del paciente a $37^{\circ} \mathrm{C}$ frente a sus propios hematíes después de haber realizado la elución de al menos una fracción del autoanticuerpo. Tras las adsorciones, el suero es nuevamente enfrentado al panel de hematíes, de manera que una vez eliminada la interferencia creada por el autoanticuerpo podremos determinar claramente la presencia de un aloanticuerpo y su especificidad.

La mayoría de autoanticuerpos poseen un título inferior a 16 en la PIATG, de forma que de dos a tres autoadsorciones resultan suficientes en la mayoría de casos. Si el título es superior pueden tratarse los hematíes con enzimas para incrementar la cantidad de autoanticuerpos adsorbidos. Por el contrario, si la PDATG es muy débil puede realizarse la autoadsorción sin elución previa de los hematíes.

El principal inconveniente técnico de este método es la hemólisis que, en ocasiones, implica la elución de los hematíes del paciente e impide la reutilización de los mismos.
La técnica de autoadsorción es tan útil que merece la pena conservar hematíes del paciente obtenidos con ocasión de la primera transfusión para poder realizar autoadsorciones en el caso de que en el futuro éste requiera más sangre. Los hematíes pueden conservarse en ACD, CPD, o congelados, si se dispone de los medios para efectuarlo.

\section{Adsorción diferencial}

Esta técnica constituye la alternativa ideal a la autoadsorción cuando el paciente ha sido transfundido recientemente. Consiste en la adsorción del autoanticuerpo empleando hematíes alogénicos de diferente fenotipo. Por ejemplo, la adsorción de un suero que contenga un autoanticuerpo más un aloanticuerpo de especificidad anti-Jk ${ }^{\mathrm{a}}$ con unos hematíes de fenotipo Jk(a-), resultará en la adsorción del autoanticuerpo, y no en la del aloanticuerpo, que podrá ser fácilmente detectado con el panel de hematíes.

Al igual que con la autoadsorción, el tratamiento enzimático de los hematíes mejora el rendimiento de cada adsorción, aunque no es absolutamente necesario.

Como la mayoría de las reacciones transfusionales hemolíticas son causadas por un número limitado de anticuerpos (ABO, Rh, Kell, Kiddy Duffy), la complejidad de disponer de hematíes de diferente fenotipo se simplifica, especialmente si se conoce el fenotipo Rh del paciente. Es más, si conocemos el fenotipo extendido del paciente bastará con seleccionar una sola célula idéntica para realizar las adsorciones diferenciales.

Cuando no se conoce el fenotipo Rh del paciente, y existe una transfusión reciente que no permite determinarlo de una manera objetiva, la selección de los hematíes para las adsorciones conlleva mayor complejidad. En esta situación se debe investigar escrupulosamente la posibilidad de que algún anticuerpo de especificidad Rh pueda quedar oculto por el autoanticuerpo y por ello, se requieren tres células de fenotipo $R_{1} R_{1}, R_{2} R_{2}$ y $r$, respectivamente. Las tres células serán Kell -, una de ellas Jk(a-), otra Jk(b-). Si se utilizan hematíes tratados con enzimas podemos ignorar el sistema Duffy, o de lo contrario, una célula deberá ser Fy(a-) y otra, como mínimo S- .

Fenotipo de los hematíes que permanecen en el suero

$\begin{array}{ll}\text { R1R1 kk ss Jk(a+b-) Fy }(a+b-) & \text { c, E, K, S, Jk } k^{b}, F y^{b} \\ \text { R2R2 kk SS Jk(a+b-) Fy(a+b-) } & \text { C, e, K, s, Jk } \text { Fy }^{b} \\ \text { rr kk ss Jk(a-b+) Fy(a-b+) } & \text { C, D, E, S, Jk , Fy }\end{array}$

La desventaja potencial de la adsorción diferencial obedece a la posibilidad de que un anticuerpo dirigido contra un antígeno de alta frecuencia pueda ser también adsorbido por las células empleadas, pero en la práctica estos anticuerpos son poco frecuentes.

Si los hematíes empleados en la adsorción son tratados enzimáticamente y el título del anticuerpo es inferior a 16 en la PIATG, dos o tres adsorciones pueden resultar suficientes para eliminar el autoanticuerpo.

Para disponer de los hematíes necesarios, cuando se plantee la necesidad de realizar adsorciones diferencia- 
les, puede resultar muy útil conservar estos hematíes en una solución de conservación a $4{ }^{\circ} \mathrm{C}$.

La autoadsorción o la adsorción diferencial del eluido también puede resultar útil para diferenciar si la reactividad observada obedece a la presencia de un autoanticuerpo o a la suma de éste más un aloanticuerpo, como podría suceder en el caso de una PDATG positiva como resultado de una reacción transfusional hemolítica.

\section{Adsorciones diferenciales} con polietilenglicol ( PEG)

EI PEG es un polímero soluble en agua que actúa como potenciador de la reacción antígeno-anticuerpo y que además, resulta muy útil para acortar los procedimientos de adsorción. La incorporación de PEG a la mezcla de suero y de hematíes nos ahorra el tratamiento enzimático de los hematíes y nos permite reducir el tiempo de incubación de cada adsorción a un máximo de 15 minutos. Para minimizar el riesgo de dilución de la muestra problema se aconseja emplear una proporción volumen a volumen de cada uno de los tres elementos.

Al realizar la prueba cruzada se empleará una mayor proporción del suero adsorbido del orden de dos a tres veces para compensar el efecto diluidor del PEG, y la lectura se efectuará con antiglobulina anti-IgG.

\section{Recomendaciones finales}

Procurar transfundir sólo la cantidad necesaria para compensar el estado hemodinámico del paciente a ritmo lento y con una vigilancia estricta, especialmente en los primeros minutos.

\section{Referencias}

1. Garratty G. Drug-induced immune hemolytic anemia. Hematology Am Soc Hematol Educ Program. 2009; 1: 73-79.

2. Petz L. "Least incompatible" units for transfusion in autoimmune hemolytic anemia: should we eliminate this meaningless term? A commentary for clinicians and transfusion medicine professionals. Transfusion. 2003; 43: 1503-1507.

3. Petz L. Review: evaluation of patients with immune hemolysis. Immunohematology. 2004; 20: 167-176.

4. Petz L. Cold antibody autoimmune haemolytic anemias. Blood Rev. 2007; 22: 1-15.

5. Petz L. Diagnostic complexities in autoimmune haemolytic anemias. Transfusion. 2009; 49: 202-203.

6. Sachs U, Roder L, Santoso S, Bein G Does a negative direct antiglobulin test exclude warm autoimmune haemolytic anaemia? A prospective study of 504 cases. Br J Haematol. 2006; 132: 651-666.

7. Yazer MH, Triulzi DJ. The role of the elution in antibody investigations. Transfusion. 2009; 49: 2395-2399.

8. Packman $\mathrm{CH}$. Hemolytic anemia due to warm autoantibodies. Blood reviews. 2008; 22: 17-31.

Panaglutinación: un reto para los servicios de transfusión y laboratorios de inmunohematología Dr. Muñiz Díaz Eduardo*

* División de Inmunohematología. Banc de Sang i Teixits. Barcelona. España.

Uno de los problemas más complejos en un servicio de transfusión, si no el que más, es el hallazgo de una pana- glutinación en el curso de las pruebas de compatibilidad transfusional. El escrutinio de anticuerpos irregulares y la identificación muestran la presencia de un panaglutinina y las pruebas cruzadas resultan incompatibles con todas las unidades seleccionadas. Las posibles causas de la panaglutinación pueden ser: un autoanticuerpo (no se excluye que uno o más aloanticuerpos puedan estar ocultos en pacientes con antecedentes obstétricos y/o transfusionales), una mezcla de aloanticuerpos, un anticuerpo contra un antígeno de alta incidencia (también pueden estar ocultos uno o más aloanticuerpos contra antígenos comunes en pacientes previamente estimulados), una reactividad dirigida contra algún elemento presente en la solución de conservación de los hematíes comerciales y/o en la propia tarjeta y, finalmente, un medicamento (anticuerpo monoclonal) que interfiere en las pruebas de compatibilidad.

Al problema de identificar la causa de la panaglutinación se suma, en algunos casos, la dificultad de seleccionar los hematíes de fenotipo más adecuado cuando la panaglutinación es debida a la presencia de un anticuerpo dirigido contra un antígeno de alta incidencia y/o a una mezcla de aloanticuerpos. La percepción del grado de complejidad del problema y la capacidad para resolverlo puede ser variable entre los diferentes servicios de transfusión, pero a menudo este tipo de problema ha de derivarse a un laboratorio de inmunohematología de referencia. No obstante, todos los servicios de transfusión pueden realizar un estudio clínico y serológico más completo que permita orientar la causa de la panaglutinación y realizar la transfusión, si fuera necesario, con la máxima seguridad posible para el paciente.

La información clínica es fundamental comenzando por el diagnóstico, el motivo de la transfusión, el grado de urgencia, los antecedentes obstétricos y/o transfusionales, la fecha de la última transfusión, la medicación y la raza o etnia.

Para orientar la posible causa de la panaglutinación desde el punto de vista serológico es fundamental disponer del resultado del autocontrol.

Cuando el autocontrol es positivo debe examinarse la prueba directa de la antiglobulina (PDA). Un autocontrol positivo con PDA positiva nos orienta hacia un autoanticuerpo libre que suele estar presente en la mayoría de pacientes con PDA positiva. En este caso, en los pacientes con antecedentes transfusionales u obstétricos es fundamental excluir la presencia de aloanticuerpos ocultos con técnicas de adsorción. Un autocontrol positivo con PDA negativa no excluye la posible presencia de un autoanticuerpo libre residual en un paciente, tal vez en tratamiento con esteroides, en el que la PDA ya se ha hecho negativa, o bien puede indicar la presencia de un autoanticuerpo de tan baja afinidad que se pierde con los lavados de los hematíes previos a la realización de la prueba. Una alternativa es la presencia de una reactividad ligada a algún elemento (aditivo, conservante) presente en la solución de conservación de los hematíes comerciales y/o en la propia tarjeta.

Cuando el autocontrol es negativo puede resultar útil la valoración del patrón de reacción de la panaglutinina (homogéneo, heterogéneo). Un patrón homogéneo es 
más indicativo de la presencia de un anticuerpo dirigido contra un antígeno de alta incidencia; por el contrario, un patrón heterogéneo se asocia más frecuentemente a la presencia de una mezcla de aloanticuerpos, pero no excluye la posible presencia de un anticuerpo contra un antígeno de alta incidencia que se expresa de forma variable en los hematíes, o incluso, a la combinación de ambas posibilidades. En cualquiera de estas situaciones suele ser necesaria la intervención de un laboratorio de referencia, con los recursos adecuados (muestras de hematíes de fenotipo escogido, antisueros con especificidades poco comunes) para identificar la naturaleza del/los anticuerpos presentes en la muestra problema. En estos casos es importante que el servicio de transfusión excluya con adsorción la presencia de aloanticuerpos ocultos por el anticuerpo de alta incidencia y que determine el fenotipo eritrocitario que abarca a los antígenos más comunes (siempre que el paciente no haya sido transfundido en los tres últimos meses) por si la transfusión fuera necesaria. En casos extremos en los que la transfusión es necesaria y urgente, cabe administrar un tratamiento inmunosupresor previo a la transfusión que pueda minimizar una posible reacción hemolítica.

Es fundamental mantener una comunicación fluida y estrecha con los servicios clínicos que deben conocer la naturaleza y gravedad del problema. $Y$ hay que medir muy bien los tiempos para diseñar, en cada caso, el mejor plan posible de trabajo y el más seguro para el paciente.

A las causas más comunes de panaglutinación hay que añadir las debidas a los anticuerpos monoclonales que, de manera cada vez más frecuente, se prescriben para el tratamiento de neoplasias y hemopatías malignas. En estos casos las interferencias pueden ser muy diversas y sólo sabiendo que el paciente está recibiendo el fármaco, podemos sospechar el problema y resolverlo de la forma más adecuada.

\section{Referencias}

1. Nance ST, Arndt PA. Review: what to do when all RBCs are incompatible. Serologic aspects. Immunohematology. 2004; 20 (3): 147-160.

2. Poole J. Problem-solving in antibody identification. Vox Sanguinis. 2004; 87 (Suppl. 1): S67-S69.

3. Poole J, Daniels G. Blood group antibodies and their significance in transfusion medicine. Transfu Med Rev. 2007; 21 (1): 58-71.

4. Muñiz-Díaz E. Interferencias creadas por los anticuerpos monoclonales en las pruebas de compatibilidad transfusional. Blood Tranfusion. 2018; 16 (Suppl. 2); S281-S282.

Fenotipos eritrocitarios en población mexicana Dr. Baptista González Héctor A*

* Director de Medicina Transfusional y Banco de Sangre Fundación Clínica Médica Sur. Ciudad de México.

\section{Introducción}

Los grupos sanguíneos son una herramienta tradicional en el ámbito antropológico, al ser considerados como marcadores de identidad poblacional o genética. La composición de la población actual mexicana tiene un componente híbrido: indígena, europeo, africano y oriental.

El mestizaje mesoamericano se interpreta en los conceptos geopolíticos, culturales y biológicos como la fusión principal de cuatro grupos étnicos: el europeo, el africano y el oriental con el indígena que genera la identidad cultural denominada mestizo-mexicano. En México, la migración europea, principalmente de España, continuó hasta principios de siglo XIX. En todas estas migraciones debe considerarse la existencia de un componente negro-africano que ha prevalecido desde el siglo XVI. Hasta el siglo pasado, los grupos indígenas nativos de México mantenían muchas de sus características etnográficas y su variación genética puede atribuirse a la carga genética, adaptación, selección natural y posiblemente, a la mezcla interétnica en ciertas áreas. En México se han realizado investigaciones acerca de la composición genética en poblaciones aisladas con el objetivo de compararlas con otras poblaciones mesoamericanas, africanas y asiáticas.

\section{El sistema eritrocitario $\mathrm{Rh}$}

Es el más complejo y polimórfico de todos sistemas de antígenos eritrocitarios reconocidos; está compuesto por al menos 55 antígenos, de los cuales cinco de ellos tienen la mayor relevancia en el campo clínico después del sistema $A B O$ y son $R h D, R h C$, Rhc, RhE y Rhe, siendo los más frecuentemente implicados en la aloinmunización eritrocitaria seguidos del sistema Kell, entre otros más. Las proteínas RhD y RhCE son producto de los genes RHD y RHCE, respectivamente; se expresan en diferentes combinaciones fenotípicas de forma homocigota, heterocigota o hemicigota. En los sujetos RhD positivo se representan en nueve combinaciones fenotípicas: CcDEe, CcDee, ccDEe, ccDee, CCDee, CCDEE, CCDEE, CCDEE y CCDEe e igual número para los sujetos RhD negativo CcdEe, Ccdee, ccdEe, ccdee, CCdee, CCdEE, CcdEE, ccdEE y CcdEe.

Cada tripleta o haplotipo de la combinación RhD/RhCE deriva de distintos eventos genéticos en el camino evolucionario del género Homo. El haplotipo originario parece haber sido cDe (Ro), que es altamente prevalente en población de origen negro-africano. Mediante un evento de mutación puntual se dio origen al haplotipo CDe (R1) y por otro lado a CDE (R2); mediante recombinación de ambos haplotipos se generó el haplotipo $\mathrm{CDE}(\mathrm{Rz})$ de más reciente aparición evolutiva. En algún momento evolutivo como especie, el haplotipo cDe, como consecuencia de la deleción del gen RhD, se perdió la expresión del RhD y se generó la población de sujetos RhD negativo con el haplotipo cde.

El reporte que se ha considerado como referente nacional de la frecuencia fenotípica de los grupos sanguíneos en la población residente del Valle de México, es el de Grunbaum y Héctor Rodríguez Moyado que incluyeron a donantes de sangre del Centro Médico Nacional del IMSS. A pesar del sesgo de selección al que puede conducir, es una práctica común utilizar a sujetos de una población específica, como es el caso de los donantes de sangre, para efectuar estudios sobre 
la frecuencia fenotípica de los grupos sanguíneos y a partir de aquí generalizar la distribución de frecuencias al resto de la población de sujetos.

En el estudio fenotípico de donantes de la Ciudad de México, en los donantes RhD positivo fueron identificadas las nueve variantes fenotípicas del sistema $\mathrm{Rh}$, en orden de frecuencia: CCDee $>$ CcDEe $>$ CcDee $>$ ccDEe $>c$ CDEE >CCDEe>ccDee >CCDEE >CCDEE. En los donantes RhD negativo se identificaron sólo siete variantes fenotípicas, en orden de frecuencia ccdee $>$ Ccdee $>$ ccdEe $>$ CcdEe $>$ ccdEE $>$ CCdee y CCdEE (Tabla 1).

Para establecer las posibles diferencias en las frecuencias fenotípicas del reporte actual, en comparación con los reportes seleccionados de la literatura, en los sujetos RhD positivo en el fenotipo CcDee se observó en $27.2 \%$ de los casos menor frecuencia en los indígenas reportados por Lisker, ${ }^{1,2}$ pero menor que lo reportado por Heiken $(40.4 \%)$. En los ocho restantes fenotipos de los sujetos RhD positivo no hay diferencias significativas entre las frecuencias observadas con las señaladas en otros reportes. Estas diferencias tienen dos posibles explicaciones que pueden coexistir: el mestizaje europeo con el haplotipo $\mathrm{CDe} / \mathrm{cde}(\mathrm{R} 1 / \mathrm{r})$, que explicaría la elevada prevalencia del fenotipo CcDee por aporte del haplotipo cde en la población de nuestro reporte, junto con la Heiken y Grunbaum. Por otro lado, la baja prevalencia del fenotipo CcDee en población indígena o con menor mestizaje podría deberse a la presencia del haplotipo $\mathrm{CDe} / \mathrm{CDe}(\mathrm{R} 1 / \mathrm{Ro})$, que es más común en población con antecedente negro-africano. Estimaciones iniciales de nuestro grupo, $57.1 \%$ aproximadamente de los sujetos CcDee poseen el haplotipo CDe/cDe. Se observan dos grupos con diferencias en las frecuencias del fenotipo CcDee: en población indígena o con menor mestizaje su frecuencia es menor de $12 \%$, mientras que en población con mayor mestizaje se observa mayor de $18 \%$. Estas frecuencias no tienen relevancia desde el punto de vista transfusional, pero son de importancia para predecir la cigocidad al RhD del varón RhD positivo con pareja RhD negativo en la probabilidad de tener descendencia RhD negativo (Tabla 2).

Para los sujetos RhD negativo hubo diferencias significativas en la frecuencia en el fenotipo ccdee. Se observó mayor frecuencia en el reporte de indígenas, con $100 \%$ de frecuencia contra $89.8 \%$ de nuestro grupo. Las diferencias parecen deberse a los tamaños muestrales con bajo número de sujetos RhD negativo incluidos.

La ausencia de la diferencia en el resto de los fenotipos evaluados se puede explicar debido a que en los sujetos RhD positivo, los fenotipos CCDee, CCDEe y CCDee ocupan $77.7,72.3,73.1$ y $79.6 \%$ de los sujetos evaluados en nuestro estudio, en los indígenas de la compilación de Lisker, y en los reportes de referencia descritos por Grunbaum y Heiken, es decir, en su conjunto los restantes cinco fenotipos son de baja prevalencia en todas las poblaciones, siendo el de menor prevalencia $C D E(R z)$, que es más frecuente en grupos indígenas americanos cuya aparición es la más reciente en el proceso evolutivo del género Homo.

Considerando la baja prevalencia del fenotipo cDe, se apoya la evidencia de la baja contribución de los ante- cesores africanos en la población del Valle de México. Para otros centros urbanos del país, como es el caso de la ciudad de León en el estado de Guanajuato, Mérida, Yucatán, Oaxaca, Oaxaca y de Saltillo, Coahuila, las frecuencias génicas de los grupos sanguíneos describen un patrón trihíbrido de ascendencia negra, india y blanca con las siguientes proporciones: $0.084,0.513$ y 0.403 en León: $0.059,0.512$ y 0.429 en Mérida; $0.018,0.676$ y 0.306 en Oaxaca; y $0.073,0.547$ y 0.380 en Saltillo. El patrón general tiene alta ascendencia india seguida de la ascendencia blanca y negra. Este patrón es congruente con la mayoría de otros estudios realizados en México, incluyendo la costa este, donde predomina la ascendencia indígena y europea, con menor contribución de ancestros africanos a partir de la baja prevalencia del fenotipo $\mathrm{cDe}$, que es menor de $2 \%$.

\section{Sistema Kell}

El gen Kell se localiza en el brazo largo del cromosoma 7, entre la posición 7q 32y. Este gen codifica una proteína glicosilada de $93 \mathrm{kD}$, la cual tiene áreas específicas donde se expresan varios antígenos Kell de una manera similar a la de los antígenos del sistema Rh. Ésta es una proteína transmembrana de Tipo II, de un solo paso y con la terminal $\mathrm{COOH}$ extramembrana. Los alelos de este sistema son codominantes y se rigen por la herencia mendeliana. Los genes Kell y Cellano codifican para los antígenos $\mathrm{K}$ y k: Fenotipos $\mathrm{K}+\mathrm{k}-, \mathrm{K}+\mathrm{k}+\mathrm{y} \mathrm{K}-\mathrm{k}+$. Igualmente, los genes $\mathrm{Kpa}$, Kpb y Kpc cuyos antígenos son antitéticos.

El antígeno Kell es altamente inmunogénico, lo conforman 36 antígenos. Cada uno de ellos viene dado por la presencia de determinados antígenos en la superficie del hematíe. El antígeno Kell, al igual que el resto que conforman su sistema, se desnaturaliza en presencia del DTT. El fenotipo Kell nulo, también llamado Ko, consiste en la nula expresión antigénica de los antígenos Kell en la membrana del hematíe. Por ende, la glicoproteína que conforma el antígeno Kell no se puede detectar en dicha membrana. El fenotipo McLeod es aquél en el que los antígenos Kell están débilmente expresados y en el que $\mathrm{Km}$ y $\mathrm{Kx}$ están ausentes. $\mathrm{Km}$ es un antígeno propio del sistema (KEL20) y Kx es un antígeno que conforma el sistema $K x$, del que es el único integrante.

La frecuencia de los fenotipos Kell en donantes en México es de $96.8,3.1$ y $0.1 \%$ para las combinaciones kk, Kk y $\mathrm{KK}$, respectivamente.

\section{Sistema Diego}

El sistema de grupos sanguíneos de Diego fue el primer marcador genético que señaló la descendencia de los amerindios con Siberia. Fue descubierto en 1953 en una mujer venezolana que sufrió tres accidentes obstétricos. Este anticuerpo, junto con el antígeno dirigido previamente desconocido, fue designado como el sistema Diego. A la fecha se han identificado 22 antígenos de Diego que han sido descubiertos dispersos en 16 sitios antigénicos en la banda 3. Se ha establecido que el Dia/ Dib en el último bucle extramembrana indicó que el 
fenotipo nulo de Diego no ha sido reportado. Una sola sustitución define dos alelos DI*B y DI*A responsable de los antígenos Dib y Dia. La sustitución ocurre en el gen SLC4A1 (cromosoma 17) que codifica la banda 3 de glicoproteína de la membrana del eritrocito. Si bien la ausencia total de la banda 3 es incompatible con la vida, una forma alterada que involucra a otro alelo: una deleción de 27 pares de bases da como resultado la ovalocitosis del sudeste asiático que confiere cierto grado de protección contra la malaria cerebral debido a Plasmodium falciparum y vivax.

La frecuencia de las combinaciones son de 92.0, 8.0 y $0 \%$ para los fenotipos Dia-Dib+, Dia+Dib+ y Dia+Dib-, respectivamente. El antígeno Dia es exclusivo de las poblaciones de ascendencia mongol de Polonia a Sudamérica y totalmente ausente en África aborigen y poblaciones europeas. Otro dato es la falta de Dia en algunos nativos americanos. La alta y baja frecuencia de Dia refleja dos eventos migratorios distintos en América del Sur, es decir, una ola sin Dia seguida de una con Dia. Sin embargo, esta teoría no pudo explicar la ausencia

Tabla 1: Distribución de los fenotipos del sistema Rh.

\begin{tabular}{|c|c|}
\hline RhD positivo (\%) & RhD negativo (\%) \\
\hline CCDee (27.2) & ccddee (92.3) \\
\hline CcDEe (26.0) & Ccdee (5.1) \\
\hline CcDee (24.0) & ccddEe (2.0) \\
\hline ccDEe (0.03) & CcdEE (0.4) \\
\hline ccDEE (16.1) & CcdEe (0.0) \\
\hline CCDEe (2.5) & CCdee (0.02) \\
\hline ccDee (2.8) & ccdEE (0.06) \\
\hline CcDEE (1.2) & CCdEE $(0.1)$ \\
\hline CCDEE (0.1) & CCdEe (0.02) \\
\hline
\end{tabular}

de Dia en los pueblos nativos americanos que viven en las regiones árticas que en principio se asentaron más recientemente. En comparación con las poblaciones euroasiática y africana, los nativos americanos actuales muestran menor diversidad genética y polimorfismos ubicuos. Estas características pueden deberse a los efectos fundados en serie durante la migración desde África al cono sur de América como resultado del pequeño tamaño de poblaciones que cruzaron el estrecho de Bering y pasaron el istmo de Panamá.

\section{Sistema Duffy (Tabla 3)}

El gen DARC se ubica en el brazo largo del cromosoma 1, banda 23 sub-banda 2 (1q23.2), posee dos exones

\section{Tabla 3: Fenotipos eritrocitarios en donantes.}

\begin{tabular}{|c|c|c|c|c|c|}
\hline Sistema & & & Fenotipos & & \\
\hline 002 & MM & $M N$ & $\mathrm{NN}$ & $S$ & s \\
\hline MNS & 41.5 & 47.9 & 10.6 & 59.8 & 40.2 \\
\hline 003 & $\mathrm{P} 1+$ & P- & & & \\
\hline$P$ & 78.8 & 21.2 & & & \\
\hline 006 & kk & $\mathrm{Kk}$ & KK & & \\
\hline KELL & 96.8 & 3.1 & 0.1 & & \\
\hline $\begin{array}{l}007 \\
\text { Lewis }\end{array}$ & $\begin{array}{c}\text { Lea+b- } \\
11.1\end{array}$ & $\begin{array}{c}\text { Lea-b+ } \\
71.5\end{array}$ & $\begin{array}{c}\text { Lea-b- } \\
17.2\end{array}$ & $\begin{array}{c}\text { Lea }+b+ \\
0.2\end{array}$ & \\
\hline 008 & Fya+b- & Fya $+b+$ & Fya-b+ & Fya-b- & \\
\hline Duffy & 30.5 & 44.8 & 24.0 & 0.7 & \\
\hline 009 & $\mathrm{Jka}+\mathrm{b}-$ & Jka $+b+$ & Jka $+b+$ & Jka $+b+$ & \\
\hline KIDD & 25.3 & 47.7 & 26.8 & 0.2 & \\
\hline 010 & Dia-b+ & $\mathrm{Dia}+\mathrm{b}+$ & Dia+b- & & \\
\hline Diego & 92.0 & 8.0 & 0 & & \\
\hline
\end{tabular}

Tabla 2: Comparación en las frecuencias fenotípicas compiladas de los haplotipos RhD/RhCE en sujetos RhD positivo y RhD negativo.

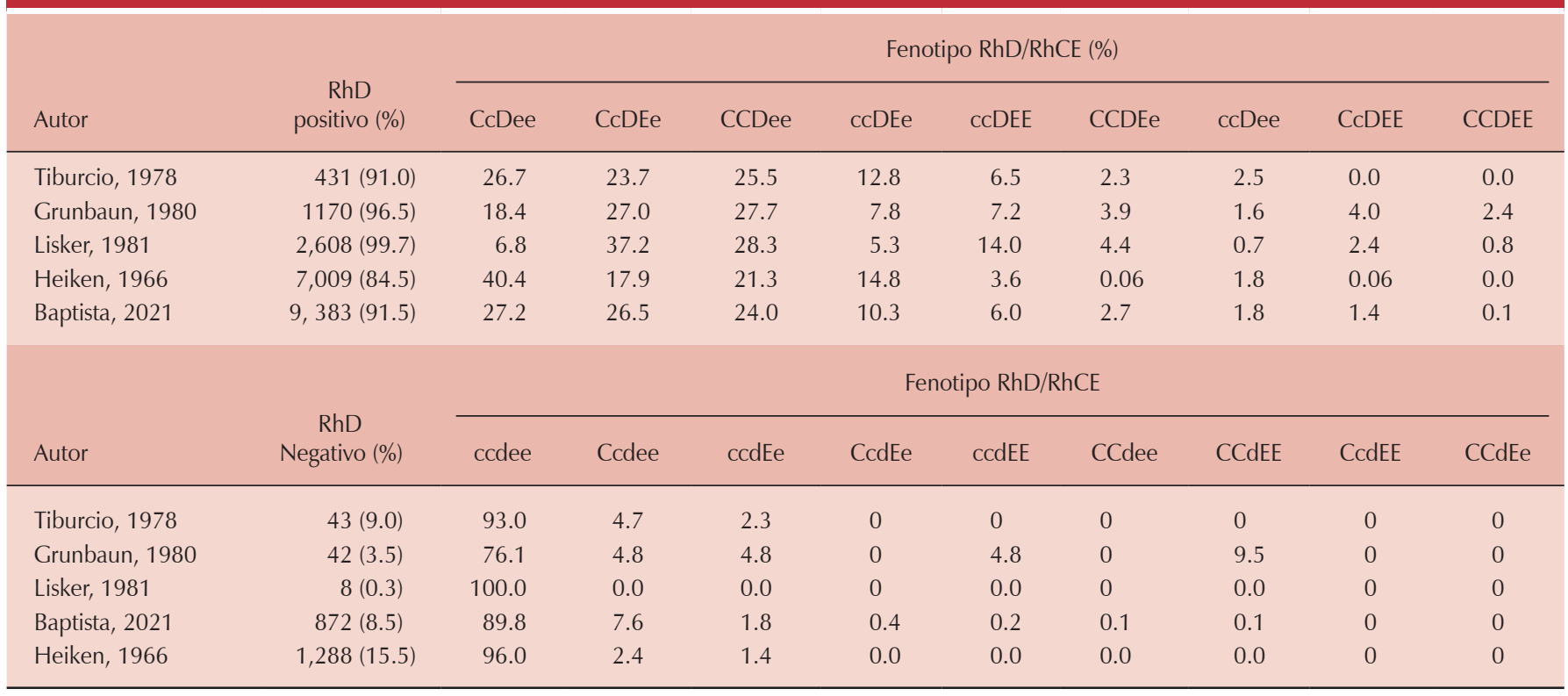


que codifican para la glicoproteína Duffy receptor de quimiocinas, que porta los cinco antígenos del sistema sanguíneo Duffy, el exón 1 codifica para los primeros siete aminoácidos de la glicoproteína y el resto de los residuos están codificados en el exón 2 .

Los antígenos Fya y Fyb son codificados por el gen bialélico, $\mathrm{FY}^{*} \mathrm{~A}$ y $\mathrm{FY} \mathrm{F}^{*} \mathrm{~B}$ que dan lugar a los cuatro fenotipos sanguíneos más frecuentes: Fy $(a+b-)$, Fy $(a-b+)$, Fy $(a+b+)$ y $F y(a-b-)$. Estos antígenos se consideran también como antígenos menores de histocompatibilidad y queda la posibilidad de su participación en el rechazo del trasplante. En el feto, los antígenos Fy pueden ser detectados a partir de la séptima semana de gestación y están bien expresados al nacimiento. Sin embargo, la enfermedad hemolítica del recién nacido por incompatibilidad de grupo sanguíneo Duffy no es usual y puede no ser detectada rutinariamente. Esto se debe a la inmunogenicidad moderada de los antígenos Fy.

El mecanismo principal del fenotipo Fya-b- es resultado de una mutación en la caja GATA-1 del promotor del gen $\mathrm{T}-67 \mathrm{C}$, en el alelo $\mathrm{FY} * \mathrm{~B}$ en población de origen negro-africana y en el alelo $\mathrm{FY}^{*} \mathrm{~A}$ en individuos de Nueva Guinea, lo cual produce la ausencia de la proteína en los eritrocitos. La base molecular de la variación entre los alelos FY*A y FY*B es el cambio de una sola base en la posición 125; guanina en $\mathrm{FY*} A$ y adenina en $\mathrm{FY} * \mathrm{~B}$ (G125A).

El alelo $\mathrm{FY}^{*} \mathrm{X}$, provoca la detección débil del antígeno Fyb producido por el cambio C286T que resulta en el cambio de una arginina por una cisteína en el aminoácido 89 de la proteína. Cinco son los grupos sanguíneos que conforman este sistema. Cada uno de ellos viene por la presencia de determinados antígenos en la superficie del hematíe. Tanto Fya y Fyb son muy sensibles a enzimas proteolíticas como la papaína, la ficina o la bromelina, aunque son resistentes a la tripsina. Son antígenos que desaparecen cuando se utiliza alguna de estas enzimas para su diferenciación.

Las frecuencias fenotípicas los antígenos Duffy en México son de $30.5,44.8,24.0$ y $0.7 \%$, para Fya+b-, Fya+b+, Fya-b+ y Fya-b-, respectivamente.

\section{Sistema Kidd}

Son proteínas que se encuentran en el grupo sanguíneo de Kidd, que actúan como antígenos, es decir, tienen la capacidad de producir anticuerpos en ciertas circunstancias. El antígeno Jk se encuentra en una proteína responsable del transporte de urea en los glóbulos rojos y el riñón.

Las frecuencias fenotípicas los antígenos Kidd en México son de $25.3,47.7,26.8$ y $0.2 \%$, para Jka+b-, $\mathrm{Jka}+\mathrm{b}+, \mathrm{Jka}+\mathrm{b}+\mathrm{y} \mathrm{Jka}+\mathrm{b}+$, respectivamente.

\section{Referencias}

1. Heiken AR, Rasmuson M. Genetical studies on the Rh blood group system. Hereditas. 1966; 55 (15): 192-212.

2. Murillo J, González A, Correa LR, Torchon EM, Vañerio AL, Sierra ME. Frecuencia del fenotipo Rh en la población donante del Valle de
Zamora, Michoacán México. Revista de la Asociación Mexicana de Medicina Transfusional, AC. 2017; 10 (Sup 1 (Trabajos libres del XV congreso de la AMMTAC, Guadalajara, Jalisco)): S32-S33.

3. Coronado EM, Sosa GM, Zavala-Cervantes DNS. Frecuencia de fenotipos del sistema Rh en donantes del Centro Estatal de la Transfusión Sanguínea de Yucatán. Revista de la Asociación Mexicana de Medicina Transfusional, AC. 2010; 3 (Suplemento 1): S100.

4. Cruz MRC, Iglesias AFG, Béjar RIL. Frecuencia de fenotipos del sistema Rh en los donadores del Instituto Nacional de Rehabilitación de la Ciudad de México, D.F. Rev Mex Med Tran. 2009; 2 (Suplemento 1): S117-118.

5. Grootkerk-Tax MG, Maaskant-van Wijk PA, van Drunen J, van der Schoot CE. The highly variable RH locus in nonwhite persons hampers RHD zygosity determination but yields more insight into $\mathrm{RH}$-related evolutionary events. Transfusion. 2005; 45 (3): 327-337.

6. Grunbaum BW, Selvin S, Myhre BA, Pace N. Distribution of gene frequencies and discrimination probabilities for 22 human blood genetic systems in four racial groups. J Forensic Sci. 1980; 25 (2): 428444 .

7. Guzmán-Reyes FAE, Escamilla-Guerrero DV, Ramírez-Quiróz G, Bretón V, Nava DME. Prevalencia del fenotipo Rh y SABO en donantes del Banco de Sangre del Instituto Nacional de Pediatría. Revista de la Asociación Mexicana de Medicina Transfusional, AC. 2010; 3 (Suplemento 1): S101.

8. Lisker R. Estructura genética de la población mexicana. Aspectos médicos y antropológicos, Editorial Salvat, 1981.

9. Rojas-García MMM, Rolero-López MCG, Aguilar-Lapale D. Frecuencia de grupos sanguíneo ABO y fenotipo Rh en donadores de sangre de la Centro Estatal de la Transfusión Sanguínea Tlaxcala, México durante el año 2008. Revista de la Asociación Mexicana de Medicina Transfusional, AC. 2010; 3 (Suplemento 1): S102.

Acciones de los Bancos de Sangre ante COVI D-19 Macedo Reynada JD*

* Encargado del Banco de Células Troncales Hematopoyéticas, BCS, Centro Médico Nacional «La Raza».

\section{Antecedentes}

Dentro de los tres meses posteriores al primer caso diagnosticado, el brote de la enfermedad respiratoria aguda causado por el nuevo coronavirus (SARS-CoV-2), COVID-19, rápidamente se convirtió en una pandemia mundial. La rápida propagación de este virus fue vinculada a un mercado de mariscos y vida silvestre en Wuhan, provincia de Hubei, China. A pesar de los extraordinarios intentos universales de limitar la propagación de este virus, inclusive ya con la disponibilidad de múltiples vacunas, se diagnostican diariamente nuevos casos y emergen nuevas preocupaciones como el surgimiento de la variante delta, todo ello afectando drásticamente a la salud asistencial, donde destacan el Banco de Sangre y la Medicina Transfusional.

Debido al crecimiento, prevalencia y naturaleza altamente infecciosa de COVID-19, nuevas políticas y pautas han comenzado a desarrollarse en las prácticas de la medicina transfusional. La COVID-19 ha impactado en la seguridad tanto de los donantes de sangre como de los receptores de hemocomponentes, obligando a un cambio en el enfoque del manejo y distribución de los productos sanguíneos y haciendo también al Banco de Sangre un partícipe activo en la propuesta de estrategias terapéuticas contra el SARS-CoV-2 como el plasma convaleciente. 


\section{Donación de sangre y sus componentes}

A nivel de legislatura internacional la Administración Federal de Drogas (FDA) y en el contexto nacional la COFEPRIS, a través de lo estipulado en la NOM-253SSA1-2012, establecen criterios que debe cumplir un donante de sangre antes de donar un hemocomponente. Cualquier criterio de exclusión detectado durante el proceso de entrevista y el examen físico podría diferir temporal o permanentemente al donante.

Tras el inicio del brote de COVID-19 en los Estados Unidos, se implementaron preguntas y requisitos de selección adicionales. Aunque no estandarizado en todas las organizaciones de recolección de sangre, la Cruz Roja Americana puso en vigor nuevas políticas de aplazamiento en febrero de 2020 antes del cierre regional y nacional. Todos los donantes con un historial de viajes reciente a China, Hong Kong, Macao, Irán, Italia y Corea del Sur fueron aplazados durante 28 días.

A nivel nacional se emitieron criterios de diferimiento a través del Centro Nacional para la Transfusión Sanguínea y el «Lineamiento técnico para la selección y diferimiento de donantes en México, en relación con COVID-19 y otras infecciones respiratorias agudas», cuya última actualización fue publicada en abril de 2021. En dicho documento destaca la adición de lineamientos basados en recomendaciones internacionales en el contexto de la pandemia y transmisión comunitaria, actualización de definiciones de casos de acuerdo con los criterios de la OMS y actualización de periodos de diferimiento.

La evidencia disponible a la fecha demuestra que el virus no es transmisible a través de componentes sanguíneos.

\section{Donantes sospechosos de COVI D-19 y estrategias de mitigamiento}

Todos los centros y campañas de donación de sangre adoptaron varias medidas para prevenir la transmisión del SARS-CoV-2. Las medidas incluyeron detección de temperatura para todos los donantes y el personal antes de la entrada a los centros de donación, distanciamiento social ( $>2$ metros) cuando sea posible, sanitización de máquinas y superficies entre donaciones, uso obligatorio de cubrebocas para donantes y personal, uso de desinfectante para manos antes y durante la donación, entre otras.

Estas prácticas preventivas se hicieron eco de las pautas de los Centros de Control de Enfermedades (CDC) y se implementaron de manera similar en todo el mundo. A la par que se implementaron estas políticas, las donaciones de sangre comenzaron a disminuir a medida que la pandemia de COVID-19 creció y la cancelación de la donación de sangre aumentó.

El Banco Central de Sangre del Centro Médico Nacional «La Raza» y sus centros de colecta registraron una afluencia de 72,798 predonantes con un total de 34,657 donaciones efectivas en 2019, esta cifra disminuyó a 45,794 y 22,079 , respectivamente en 2020 , representando un decremento de $36.29 \%$ de las donaciones efectivas.

Como resultado, los hospitales desarrollaron estrategias para adaptarse a este suministro de sangre en escasez (criterios adicionales para las órdenes de transfusión se revisan con pautas más estrictas, fraccionamiento de unidades de aféresis plaquetas en dos dosis y establecimiento de comités para la racionalización del uso clínico de la sangre).

A nivel global se optó por reprogramar cirugías electivas y cambiar los procedimientos quirúrgicos a entornos ambulatorios en la medida de lo posible. Con ello, se logró amortizar la demanda y la oferta de componentes sanguíneos. La semana del 23 de marzo de 2020, la mayoría de los hospitales de Estados Unidos informaron que ya no realizaban cirugías electivas, reportando sólo $10.6 \%$ de nosocomios con cirugías en esta modalidad.

El manejo transfusional del paciente (Patient Blood Management [PBM]) cobró especial relevancia en el contexto de escasez de componentes sanguíneos; ésta es una estrategia basada en la gestión de éstos con la finalidad de proporcionar mejores resultados para los pacientes y una administración adecuada de un recurso limitado mientras se optimiza la atención médica y se reducen los costos en salud. Además, esta estrategia echa mano del uso de agentes farmacológicos como desmopresina, antifibrinolíticos, concentrado de complejo protrombínico y vitamina K, suplementos de hierro en preparaciones orales o intravenosas, y los agentes estimulantes de la eritropoyesis. Los programas de PBM y de medicina sin sangre son ahora una prioridad en todos los sistemas de salud nacionales e internacionales.

\section{Plasma convaleciente}

El plasma convaleciente se obtiene de individuos recuperados de COVID-19 y que han generado una respuesta inmunológica. En Estados Unidos han administrado más de 250,000 a través de un programa de acceso ampliado, autorizaciones de uso de emergencia y ensayos clínicos. Esta modalidad terapéutica parece ser ineficaz si se administra al final de la evolución de la enfermedad. Es más probable que sea eficaz en la fase temprana (idealmente, dentro de los tres días posteriores al inicio de los síntomas), aunque se necesitan ensayos adicionales para determinar el momento óptimo. Se debe usar plasma de alto título, generalmente administrado como una dosis única de una o dos unidades, siempre en el contexto de investigación clínica.

\section{Conclusiones}

Estar preparado para enfrentar una pandemia asegura que los hemoderivados estén disponibles para aquellos pacientes que requieren apoyo transfusional, y un plan sólido ayuda a proteger la seguridad y salud de los profesionales en medicina transfusional.

Enfoques clave observados durante la presente pandemia fueron la educación del personal para impulsar la motivación y prevenir la infección del capital humano y de los donantes, detonando campañas de sensibilización con la intención de mantener el reclutamiento de donadores ante esta situación sin precedentes. 


\section{Referencias}

1. Actualización del lineamiento técnico para la selección y diferimiento de donantes en México, en relación al COVID-19 y otras infecciones respiratorias agudas. CNTS, SS. México. Abril 2021.

2. Pandey HC, Coshic P, C S C, Arcot PJ, Kumar K. Blood supply management in times of SARS-CoV-2 pandemic-challenges, strategies adopted, and the lessons learned from the experience of a hospitalbased blood centre. Vox Sang. 2021; 116 (5): 497-503.

3. Tolich D, Auron M, McCoy K, Dargis M, Quraishy N. Blood management during the COVID-19 pandemic. Clevel Clin J Med. 2020.

4. Sahu KK, Raturi M, Siddiqui AD, Cerny J. Because every drop counts: blood donation during the COVID-19 pandemic. Transfus Clin Biol. 2020; 27 (3): 105-108.

5. Pagano MB, Rajbhandary S, Nunes E, Cohn CS. Transfusion services operations during the COVID-19 pandemic: Results from AABB survey. Transfusion. 2020; 60 (11): 2760-2762.

I ntegración de pruebas serológicas y moleculares en inmunohematología

Dra. Castilho Lilian*

* Investigadora y directora del Laboratorio de Inmunohematología Molecular en Hemocentro-UNICAMPCampinas, Brasil.

La International Society of Blood Transfusion (ISBT) reconoce actualmente 43 sistemas de grupos sanguíneos con 343 antígenos y tres categorías (serie 901 , serie 700 y colecciones) con 34 antígenos. Los antígenos de eritrocitos se heredan genéticamente y cada sistema tiene un solo gen o un conjunto de dos o tres genes homólogos y estrechamente relacionados. Hasta ahora, los 43 sistemas son determinados por 48 genes ( 15 autosomas y 1 cromosoma X). La edad de la genómica ha permitido la aplicación de métodos moleculares basados en el ADN a la medicina transfusional. La tecnología del ADN permitió comprender las bases moleculares de todos los antígenos de grupos sanguíneos comunes y ahora los genes que gobiernan los sistemas de grupos sanguíneos han sido clonados y secuenciados. La gran diversidad de antígenos eritrocitarios se origina a partir de cambios a nivel genético que van desde variación de un solo nucleótido (SNV) hasta intercambios de genes, inversiones, deleciones, inserciones, splicing alternativo, entre otros mecanismos. La técnica de hemaglutinación ha sido considerada el estándar de oro para la determinación de antígenos eritrocitarios desde su descubrimiento por Landsteiner en 1900. Sin embargo, esta técnica tiene limitaciones que muchas veces nos impiden resolver un problema de inmunohematología. A partir del conocimiento de las bases moleculares responsables de la expresión de los antígenos de los grupos sanguíneos fue posible utilizar ensayos basados en ADN que pueden ser utilizados para superar las limitaciones de los ensayos de hemaglutinación. La genotipificación ofrece muchas ventajas sobre las pruebas serológicas, con el beneficio principal de predecir el fenotipo del grupo sanguíneo en situaciones que no se pueden realizar serológicamente. Así, se han desarrollado varios ensayos para la genotipificación de grupos sanguíneos para predecir el perfil de antígenos de grupos sanguíneos de un individuo.
Incluyen PCR-RFLP, PCR alelo específica, PCR-multiplex, ensayos basados en secuencias, PCR en tiempo real y microarrays.

Las pruebas moleculares son un campo que avanza rápidamente y ofrece un enorme potencial en medicina transfusional, se ha implementado con éxito en laboratorios de inmunohematología para ayudar a resolver casos complejos y está demostrando ser una herramienta poderosa, con posibles ventajas para identificar sangre rara y encontrar mejores combinaciones de antígenos para pacientes con transfusión crónica.

Se ha demostrado que aunque las pruebas de hemaglutinación se consideran más rápidas y económicas que las pruebas moleculares, para pacientes con diagnósticos específicos, pueden ser limitadas, costosas y consumir mucho tiempo. El análisis de costo-beneficio es un desafío, pero los costos de un paciente aloinmunizado y una reacción a la transfusión deben tenerse en cuenta al analizar si la tipificación molecular en el diagnóstico es rentable. La posibilidad de realizar genotipificación junto con la hemaglutinación cambia el rango de posibilidades en los procedimientos de transfusión, lo que aumenta la seguridad de los pacientes transfundidos con bajos costos adicionales.

La integración de pruebas serológicas y moleculares permite resolver casos clínicos de manera más eficiente, en menos tiempo y a menor costo, especialmente en pacientes con transfusiones recientes, con anticuerpos raros y con anemia hemolítica autoinmune.

\section{Referencias}

1. ISBT-Working party on red cell immunogenetics and blood group terminology. Available in: http://www.isbtweb.org/working-parties/ red-cell-immunogenetics-and-blood-group-terminology/bloodgroup-terminology/

2. Denomme GA. Molecular basis of blood group expression. Transfus Apher Sci. 2011; 44: 53-63.

3. Denomme GA, Flegel WA. Applying molecular immunohematology discoveries to standards of practice in blood banks: now is the time. Transfusion. 2008; 48: 2461-2475.

4. Hillyer $C D$, Shaz BH, Winkler AM et al. Integrating molecular technologies for red blood cell typing and compatibility testing into blood centers and transfusion services. Transfusion Medicine Reviews. 2008; 22: 117-132.

5. Reid M, Denomme GA. DNA-based methods in the immunohematology reference laboratory. Transfus Apher Sci. 2011; 44: 65-72.

6. Castilho L. Molecular typing of blood group genes in diagnostics. Annals of Blood. 2021; 6: 20.

\section{Resolviendo problemas de inmunohematología} desde la serología a las pruebas moleculares

Dra. Castilho Lilian*

* Investigadora y directora del Laboratorio de Inmunohematología Molecular en Hemocentro-UNICAMPCampinas, Brasil.

El uso de la información genética proporcionada por el proyecto del genoma humano agregó una nueva fase en inmunohematología. Se demostró que no necesitamos glóbulos rojos para la genotipificación de glóbulos rojos, ya que el ADN genómico puede obtenerse de diferentes fuentes de células y que las células transfundidas no 
interfieren y, por lo tanto, podríamos tipificar pacientes que han sido recientemente transfundidos. También se demostró que las pruebas moleculares podrían usarse para tipificar pacientes con autoanticuerpos calientes, tipificar antígenos de baja y alta frecuencia, ayudar en la identificación de antígenos variantes y en la diferenciación entre $D$ débil y $D$ parcial.

Se recomienda la tipificación molecular para pacientes dependientes de transfusiones, como parte del proceso de identificación de anticuerpos, ya que la identificación del fenotipo predicho del paciente permite al laboratorio determinar a qué antígenos el paciente puede y no puede responder para producir aloanticuerpos. Además, la tipificación molecular proporciona más información sobre el perfil antigénico de los pacientes, especialmente aquellos en los que no se dispone de reactivos serológicos como, por ejemplo, los antígenos DO y los tipos de sangre raros.

Los pacientes con anemia falciforme se encuentran entre los que más se benefician de la tipificación molecular, ya que permite una compatibilidad de antígenos más extendida, identifica a los pacientes que carecen de antígenos de alta prevalencia y ayuda a diferenciar entre autoanticuerpos y aloanticuerpos. Además, la discriminación entre $D$ débil y $D$ parcial en pacientes con anemia falciforme puede ser de importancia clínica porque los portadores del antígeno D parcial pueden desarrollar anti-D cuando se transfunden con unidades de glóbulos rojos D-positivos, con raras excepciones.

La hemaglutinación ha identificado muchas variantes fenotípicas codificadas por RHD, RHCE o híbridos de los dos y el análisis molecular ha revelado una variación notable dentro de las variantes. Se han definido numerosos fenotipos $D$ parciales y $D$ débiles a nivel molecular y esta información, junto con los datos clínicos y serológicos, se ha utilizado para orientar la política de transfusión para los pacientes.

Los pacientes con autoanticuerpos calientes o con interferencia de anticuerpos monoclonales como anti-CD38 y anti-CD47 también se han beneficiado de un genotipo extendido con la posibilidad de recibir transfusiones de unidades de glóbulos rojos más compatibles con antígenos clínicamente significativos. Este enfoque reduce el riesgo de reacciones transfusionales hemolíticas, previene una mayor aloinmunización y mejora la atención del paciente al reducir el tiempo de trabajo y el número de pruebas realizadas para eliminar la interferencia de los autoanticuerpos.

Sin embargo, la serología sigue siendo muy importante para identificar el problema e identificar los anticuerpos con la utilización de diferentes herramientas. Las pruebas moleculares son un complemento de las pruebas de hemaglutinación y tienen aplicaciones precisas en la resolución de los problemas. El uso de técnicas serológicas y moleculares ha ayudado a resolver casos clínicos complejos en inmunohematología que antes eran difíciles de resolver. En la actualidad, esta asociación de técnicas es utilizada por los laboratorios de referencia para solucionar problemas y asegurar una transfusión más eficaz.

\section{Referencias}

1. Reid ME, Rios M, Powell D et al. DNA from blood samples can be used to genotype patients who have recently received a transfusion. Transfusion. 2000; 40: 48-53.

2. Westhoff C. Blood group genotyping. Blood. 2019; 133: 1814-1820.

3. Da Costa DC, Pellegrino J, Guelsin GAS et al. Molecular matching of red blood cells is superior to serological matching in sickle cell disease patients. Rev Bras Hematol Hemoter. 2013; 35: 35-38.

4. El Kenz H, Efira A, Quoc Le P et al. Transfusion support of autoimmune hemolytic anemia: how could the blood group genotyping help? Transl Res. 2014; 163: 36-42.

5. Reid M, Lomas-Francis C. Molecular approaches to blood group identification. Curr Opin Hematol. 2002; 9: 152-159.

\section{La enfermera en la medicina transfusional}

LE Zamudio Godínez Lucía*

* Especialista en Aferesis y Medicina Transfusional.

La creciente demanda de los servicios de atención a la salud, los avances en los tratamientos médicos, las nuevas tecnologías que se van desarrollando de acuerdo con los estándares internacionales han hecho que sea fundamental la participación del personal de enfermería en los diferentes niveles de atención de promoción a la salud, prevención de enfermedades, tratamiento y cuidado del individuo en sus diferentes etapas de la vida, contribuyendo a mejorar la calidad de vida de la población.

El objetivo del cuidado enfermero es la atención del paciente para contribuir a mejorar su calidad de vida, recuperar la salud y favorecer el bienestar de la población, limitando los daños y riesgos inherentes a los tratamientos médicos y las estancias hospitalarias.

Con la aparición de la NOM 019 para la práctica de enfermería en nuestro país, la responsabilidad del ejercicio profesional cobra aún mayor importancia el desempeño en cualquier nivel de atención de los servicios de salud. ${ }^{1}$ La Organización Mundial de la Salud (OMS) y la Organización Panamericana de la Salud (OPS) establecen el abastecimiento de sangre segura y una atención de calidad a la población. Por lo que, de acuerdo con las recomendaciones, el proceso de obtención de la sangre del donador hasta que el paciente es transfundido debe ser controlado y vigilado con el fin de incrementar la seguridad transfusional. ${ }^{2}$

La OPS nos describe lo siguiente: «La hemovigilancia consiste en un conjunto de procedimientos de vigilancia que abarca toda la cadena transfusional, desde la donación y el procesamiento de la sangre y sus componentes, hasta su suministro y transfusión a los pacientes y su seguimiento. La hemovigilancia comprende el seguimiento, la notificación, la investigación y el análisis de los eventos adversos asociados con la donación, el procesamiento y la transfusión de la sangre, y la adopción de medidas encaminadas a prevenir la presentación o la recurrencia de estos eventos». ${ }^{2}$

De igual manera, el Centro Nacional de la Transfusión Sanguínea y la NOM-253-SSA1-2012 para la disposición de sangre humana y sus componentes con fines terapéuticos, establecen que los Bancos de Sangre, los servicios de transfusión y los establecimientos de atención médica que en sus instalaciones apliquen transfusiones, 
deberán establecer un sistema de hemovigilancia y el personal de enfermería debe formar parte del Comité de Medicina Transfusional. ${ }^{3-5}$

De acuerdo con estos conceptos, el trabajo del personal de enfermería es fundamental en todo el proceso de la cadena transfusional, desde la atención al donador, el proceso de análisis, estudio, separación, almacenamiento de los hemocomponentes y posteriormente la transfusión y el cuidado del paciente..$^{5-7}$

La formación académica del profesional de enfermería cubre el perfil para el desempeño de la atención directa al donador y el paciente en cualquier ámbito hospitalario. ${ }^{1,8}$

\section{Responsabilidades de enfermería}

Las actividades en las cuales interviene el personal de enfermería pueden ser diversas y de acuerdo a cada institución la responsabilidad en cada parte del proceso puede ser de menor o mayor grado.

- Atención de donadores: somatometría, revisión general.

- Toma de muestras de sangre en donadores.

- Flebotomía.

- Vigilancia y atención de reacciones adversas a la donación.

- Recolección de hemocomponentes por aféresis, cuidado, vigilancia y tratamiento de reacciones adversas.

- Procesamiento de la sangre.

- Control de calidad de productos sanguíneos.

- Almacenamiento y distribución de productos.

- Solicitud y recepción de productos sanguíneos.

- Toma de muestras de sangre en pacientes.

- Manejo y conservación de productos sanguíneos.

- Transfusión de hemocomponentes.

- Vigilancia y atención de reacciones adversas a la transfusión.

- Procedimientos de aféresis terapéutica.

- Atención de pacientes de trasplante de médula ósea.

\section{Donación}

El donador es un individuo en buenas condiciones de salud, que no presenta datos patológicos, por lo que el cuidado de enfermería debe enfocarse en intervenciones de educación, fomento a la salud y actividades de cuidado para mantener al donador estable, que pueda terminar el proceso de donación con signos vitales normales y sin datos de lesiones por las punciones venosas. De ahí la importancia de que el personal de enfermería tenga la habilidad de realizar venopunciones de primera intención, sin causar lesiones por una mala técnica. Mantener al donante en observación posterior a la flebotomía para evitar contusiones por lipotimias, mareos o caídas. El donador sano debe continuar así después de la donación de sangre.

\section{Aféresis}

El donador de aféresis representa un proceso adicional, la valoración, selección y aceptación del donante lo realiza el médico responsable, el resto de las actividades para llevar a cabo el procedimiento son total responsabilidad del personal de enfermería; la valoración del acceso venoso, la preparación de la máquina, los insumos, toma de muestras de sangre, la programación del procedimiento, venopunción, cuidado y control del funcionamiento de la máquina y sobre todo, y lo más importante, la vigilancia y el cuidado del donador durante todo el proceso: atender las reacciones adversas en caso de que se presenten, administrar los tratamientos que el médico indique y mantener la vigilancia hasta que el donador se retire en las mejores condiciones de salud.

\section{Procesamiento de la sangre, control de calidad}

En algunas instituciones, el personal de enfermería participa en procesos del fraccionamiento de la sangre $y / 0$ actividades del control de calidad de los productos y el almacenamiento de los hemocomponentes.

\section{Transfusión}

La terapia transfusional es una actividad terapéutica coadyuvante a un sin número de patologías de diver-

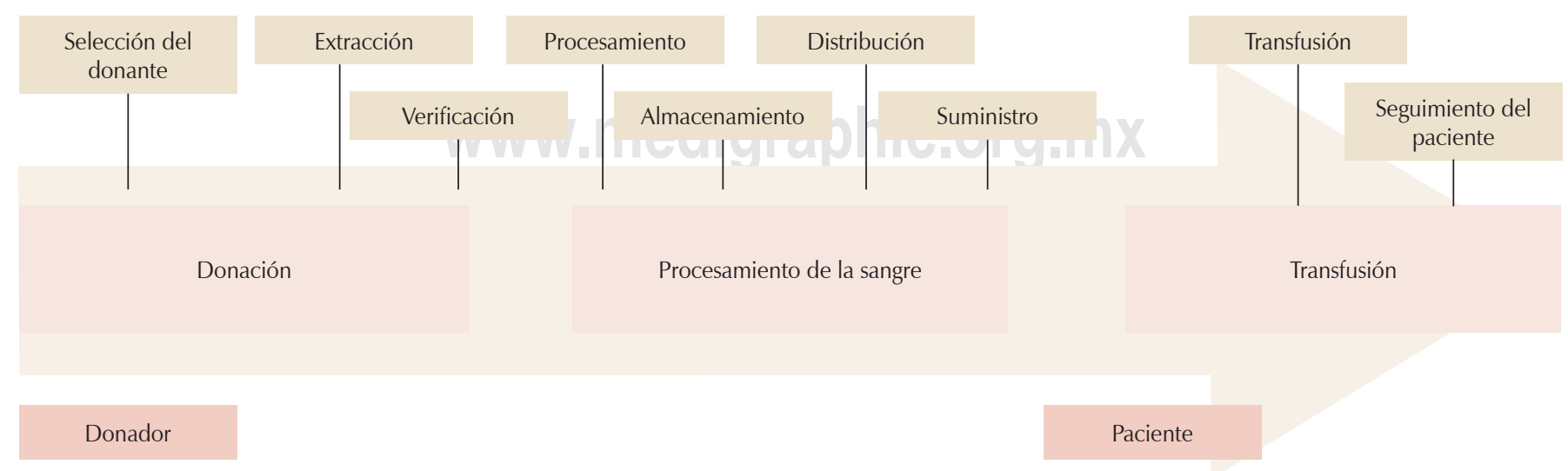

Figura 1: Cadena transfusional. ${ }^{6}$ 
sas especialidades, actos quirúrgicos y emergencias médicas en todo el mundo; ha permitido disminuir la mortalidad y mejorar la calidad de vida de la población; aunque también sabemos que el riesgo transfusional es inherente, a pesar de la evolución de las técnicas de laboratorio para el estudio de la sangre, los métodos de leucorreducción e inactivación de patógenos con el objetivo de incrementar la seguridad del paciente. ${ }^{6,8}$

Las acciones de enfermería con los pacientes que necesitan apoyo transfusional requieren doble esfuerzo en sus cuidados, ya que el acto transfusional en sí es un proceso de alta responsabilidad que demanda extremo cuidado, adicional a las intervenciones propias de su patología. ${ }^{9}$ El acto transfusional es un proceso de total responsabilidad de enfermería, la gestión y aplicación de los cuidados para la transfusión deben ser unificados y específicos para que el procedimiento se ejecute de forma eficiente y con calidad para reducir el riesgo en el receptor. El personal debe estar capacitado, contar con manuales de procedimiento y protocolos de acción ante la presencia de reacciones transfusionales, sin olvidar la protección legal del profesional al ser parte activa de este proceso. ${ }^{10}$ Las actividades en general deben realizarse con conocimiento y siguiendo técnicas de asepsia en todo momento:

- Revisión de indicación médica escrita en el expediente.

- Preparación del paciente.

- Toma y rotulado correcto de muestras sanguíneas para las pruebas de compatibilidad.

- Recepción del producto sanguíneo verificando la temperatura, color, aspecto general, sin presencia de coágulos.

- Descongelar a baño María de $37^{\circ} \mathrm{C}$ en caso de plasma o crioprecipitados.

- Instalar equipo de transfusión con filtro estándar, teniendo cuidado de no perforar la bolsa del producto.

- Explicar al paciente el procedimiento, verificar la identidad correctamente en forma verbal y con los registros del paciente.

- Seleccionar el acceso venoso de mejor calibre e instalar la transfusión indicada, sin mezclar con soluciones y medicamentos.

- Mantener un goteo lento los primeros 15 minutos y vigilar al paciente.

- Toma de signos vitales antes, durante y después de la transfusión.

- Regular el goteo de la transfusión de acuerdo al tiempo indicado.

- Mantener en vigilancia continua al paciente.

- Registrar en el expediente los datos del producto transfundido, signos vitales y las observaciones generales.

\section{Reacción transfusional}

La presencia de efectos adversos a la transfusión en forma inmediata, mediata o tardía son un riesgo inherente a la terapia que pueden ocurrir por diversas causas; la importancia del cuidado de enfermería es mantener al paciente sometido a transfusión en observación continua para identificar y atender oportunamente al paciente que presenta reacción transfusional de acuerdo con los protocolos de la institución.

\section{Otras responsabilidades}

La función de la enfermera juega un papel importante en las buenas prácticas transfusionales, la observación del paciente, estar capacitado en los objetivos de una buena indicación de la transfusión contribuye a retroalimentar junto con el médico tratante para el uso racional de los productos sanguíneos.

En los servicios de trasplante hematológico (médula ósea, células progenitoras hematopoyéticas de sangre periférica) también es indispensable la participación de enfermería, el acondicionamiento del paciente previo al trasplante, el apoyo transfusional, los procedimientos de aféresis y el cuidado de aislamiento protector posterior al trasplante son algunas de las actividades de gran responsabilidad para ellos.

De igual importancia es el registro de todos los procesos que se realizan, las observaciones del donador y el paciente, los tratamientos administrados, llevar bitácoras de transfusión en los servicios y mantener la información correctamente registrada que permita la verificación y trazabilidad de las actividades. ${ }^{2-7}$

\section{Conclusiones}

El papel de enfermería dentro del campo de la medicina transfusional es fundamental, la gestión del cuidado en todas las partes del proceso de la cadena transfusional son una gran responsabilidad, que obliga al profesional de la salud a estar capacitado, actualizarse continuamente y ofrecer una calidad de atención al donador y al paciente con el objetivo de minimizar los riesgos y ofrecer la seguridad de los procesos en todo momento.

\section{Referencias}

1. Norma Oficial Mexicana NOM-019-SSA3-2013, Para la práctica de enfermería en el Sistema Nacional de Salud.

2. Organización Panamericana de la Salud. Guía para establecer un sistema nacional de hemovigilancia. Washington, D.C.: OPS, 2017

3. CNTS. Recomendaciones para la Conformación, Estructura y Funcionamiento del Comité de Medicina Transfusional en los Servicios de Salud. México, 2020

4. Norma Oficial Mexicana NOM-253-SSA1-2012, Para la disposición de sangre humana y sus componentes con fines terapéuticos.

5. EDQM, European Directorate for the Quality of Medicines \& HealthCare, Guide to the preparation, use and quality assurance of blood components. 20th ed. 2020, Council of Europe.

6. Muñiz-Diaz E, León GG, Torres OW. Manual Iberoamericano de hemovigilancia. Banc de Sang i Teixit. GCIAMT, OPS, Barcelona 2015.

7. ISBT Science Series, 15, 277-291, Section 14. Transfusion risks and haemovigilance, 2020, Blackwell Publishing Ltd.

8. Intervenciones de Enfermería para la Seguridad en el Manejo de la Terapia Transfusional. México: Secretaría de Salud; 2 de julio de 2015.

9. Zamudio GL, Marmolejo GM, Téllez MM. Medicina transfusional para enfermeras. Rev Mex Med Transfus. 2014; 7 (2): 18-25.

10. Vargas BZ. Guía de cuidados de enfermería para la administración de la sangre y sus componentes. REV ENF. Edición Semestral Nº. 37, Julio 2019-diciembre 2019 
Acercándonos al estándar global de atención con inactivación de patógenos para la seguridad de la sangre: ¿cómo llegamos allí en América Latina? Marcelo Pedraza R*

* Gerente Médico Centro Nacional de Sangre CENASA Programa Nacional de Sangre Cruz Roja Hondureña.

\section{I ntroducción}

Desde 1978 el Programa Nacional de Sangre (PNS) de la Cruz Roja Hondureña (CRH) es la referencia para la calidad de la sangre en el país, logrando así establecerse con base en la ley para inicios del año 2000 según el Artículo Número 6 de la Ley de Honduras. Con la capacidad de hacer pruebas de análisis especiales de: VIH, VHB, VHC, sífilis, HTLV I y II, Hbcore y Chagas, y pruebas de biología molecular NAT para VHC, VHB, HIV, asesoramiento para los hospitales públicos y privados del país en medicina transfusional e inmunohematología.

A inicios del año 1998 el PNS trabajó en la implementación de un programa de calidad, en la cual le permitió dar cumplimiento a la norma técnica de la Asociación Americana de Bancos de Sangre (AABB) logrando así su acreditación para los bancos en la ciudad de Tegucigalpa y en la ciudad de San Pedro Sula. EI PNS promueve la donación voluntaria altruista y no remunerada (DVANR), a fin de proporcionar a los hondureños hemoderivados seguros y de calidad en la red hospitalaria en el país; sin embargo, el tipo de donación predominante es por reposición. Por lo tanto, son muchos los esfuerzos que la CRH y el PNS realiza en la promoción de la DVANS.

EI PNS colecta y procesa anualmente un promedio de 45, 000 unidades (antes de la situación de emergencia en salud) de las cuales $8 \%$ son voluntarios y se distribuye aproximadamente $80 \%$ de los hemocomponentes a los servicios de salud a nivel nacional; esto se hace a través del Centro Nacional de Sangre (CENASA) ubicado en Tegucigalpa, el Centro Regional de Sangre en San Pedro Sula (CERESA) y CESAAT en La Ceiba. Para el año 2020, debido a la emergencia mundial en salud, se redujo la colección anual a 33,340 unidades de sangre.

\section{¿Por qué la necesidad de implementar I ntercept en} Honduras?

La contaminación plaquetaria es la segunda causa de muerte en aquellos pacientes que son transfundidos, llegando en algunos casos a sepsis. ${ }^{1}$ En Honduras las estadísticas de reacciones a la transfusión de plaquetas no han sido claramente determinadas, además que se presenta una limitación en la determinación de una aloinmunización contra HLA, que es una complicación a largo plazo de pacientes que tienen altos requerimientos de transfusión plaquetaria entre otros. ${ }^{2}$ Un problema de alto impacto es el control de las enfermedades por arbovirus, debido a la vigilancia y prevención que involucra la vigilancia de sus vectores, por ejemplo, lo que hace difícil su control y casi imposible evitar su expansión en los países tropicales. ${ }^{3}$ Como uno de los requisitos para dar cabalidad a la acreditación de la AABB en el estándar 5.1.5.2 se establece que el Banco de Sangre deberá tener métodos para la detección de bacterias o tecnología de inactivación de patógenos en todos los componentes plaquetarios. ${ }^{4}$ Ello motivó al PNS a estudiar alternativas que pudieran dar cumplimiento.

Se realizó una investigación bibliográfica en estudios publicados en Francia y Suiza, se encontró que la técnica de inactivación de patógenos posee un impacto en las infecciones transmitidas por transfusión de plaquetas versus mortalidad, después de transfundir PLT inactivados fue de cero casos. ${ }^{5,6}$

Los retos en la implementación de esta técnica se basaron en dos ejes: el primero, los permisos de importación y conformación de registros sanitarios para esta técnica, y segundo, la crisis política en el país en el año 2017, logrando finalmente en el mes de marzo de 2018 la instalación de los equipos. Se desarrolló un plan de implementación que incluía determinar los costos de análisis para la implementación de la técnica, realizar un estudio sobre los costos de recuperación de los productos suministrados en los sectores públicos y privados, capacitación de personal, definir tiempos de procesamiento de componentes, así como de las validaciones de operación y controles de calidad, entre otros, esta técnica es implementada en los bancos de sangre de CENASA y CERESA.

\section{Metodología}

En este proceso se evaluaron 30 componentes combinados de plaquetas de donantes aleatorios (RDP) antes y después de ser sometidos al tratamiento de INTERCEPT Blood System para plaquetas. Se prepararon unidades individuales de plaquetas suspendidas en plasma al $100 \%$ mediante el método de plasma rico en plaquetas (PRP) a partir de unidades de sangre de $450 \mathrm{~mL}$. Para cada réplica experimental se seleccionaron seis RDP al azar, se combinaron componentes de plaquetas idénticas $A B O$ en uno de los contenedores de almacenamiento, con un volumen medio superior a $255 \mathrm{~mL}$. Las unidades individuales se dejaron en reposo durante un mínimo de 90 minutos seguido de una agitación de cuatro a siete horas en condiciones estables en el Banco de Sangre. Las unidades sin agregados se agruparon entre las 00:00 y 01:00 horas (9-16 horas después de la recolección) teniendo la disponibilidad del pool inactivado desde el día uno a las 18:00 horas. Uno de los resultados relevantes en la implementación es la disponibilidad del pool. ${ }^{7}$ Además de los 30 primeros pools de plaquetas presentaron una dosis media de plaquetas de $3.8 \pm 0.6 \times 10^{11}$ y un volumen promedio de $308 \pm 8 \mathrm{~mL}$, determinando de esta manera una dosis «estándar de concentrados plaquetarios» (Tabla 1) que son transfundidos a los pacientes mayores y en pacientes pediátricos, bajo los criterios de calidad establecidos por el estándar de la AABB.

\section{Conclusiones}

La producción de RDP, la conformación del pool de concentrados plaquetarios y el método con INTERCEP son 


\begin{tabular}{lcccc}
\multicolumn{5}{c}{$\begin{array}{c}\text { Tabla 1: Control de calidad de inactivación de } \\
\text { patógenos en componentes plaquetarios. }\end{array}$} \\
\hline $\begin{array}{l}\text { Producción } \\
\text { de rutina }\end{array}$ & $\begin{array}{c}\text { Volumen } \\
(\mathrm{mL})\end{array}$ & PLT conc. $\times 10^{9} / \mathrm{L}$ & Plt dosis $\times 10^{11}$ & $\mathrm{pH}$ \\
\hline Promedio & 304 & 1,245 & 3.8 & 7.3 \\
Media & 304 & 1,188 & 3.6 & 7.0 \\
DE & 8 & 207 & 0.6 & 0.4 \\
Mínimo & 280 & 1,020 & 3.1 & 7.0 \\
Máximo & 320 & 1,690 & 5.1 & 8.0 \\
\hline
\end{tabular}

factibles siguiendo una planificación de la implementación, obteniendo como resultado que los productos son liberados desde el día uno, al mismo tiempo que la producción actual. Esto significa que los productos de plaquetas INTERCEPT están dos días más disponibles para la transfusión. Esto llevó a trabajar más de cerca con los Bancos de Sangre de los hospitales para que lograran conocer el producto y pudieran mejorar el manejo de su reserva de los componentes para que sean transfundidos eficientemente.

En el Banco de Sangre ha mejorado la producción del componente y en los últimos tres años el CENASA ha tenido una producción de 3,145 pools de plaquetas con un porcentaje de descarte de $0.8 \%$ desde los inicios en la producción, y en CERESA se han producido 3,537 pools, con un porcentaje de descarte de $0.11 \%$, lo cual demuestra que la comunicación con los Bancos de Sangre de los hospitales, la educación sobre el hemocomponente y la planificación de producción de componentes ayuda a los hospitales a dar un uso adecuado de sus reservas de hemocomponentes y en el Banco de Sangre se reduce el impacto sobre los costos de inversión en la técnica.

Al presente durante la emergencia mundial de salud, el PNS a través de la Federación Internacional de la Cruz Roja y Media Luna Roja (IFRC) logró iniciar el proceso de inactivación de plasma convaleciente de SARS-CoV-2 y ser transfundido a aquellos pacientes que han sido diagnosticados con esta enfermedad, gracias a la aprobación de la investigación sobre el uso de este hemocomponente, en la actualidad, se está recopilando la información para posteriormente publicar los resultados obtenidos.

\section{Referencias}

1. Hong H, Xiao W, Lazarus HM, Good CE, Maitta RW, Jacobs MR. Detection of septic transfusion reactions to platelet transfusions by active and passive surveillance. Blood. 2016; 127 (4): 496-502.

2. Gil-García E. Indicaciones de transfusión de hemocomponentes. Rev Hematol Mex. 2018; 19 (2): 83-90.

3. Arredondo-García JL, Méndez-Herrera A, Medica Cortina H. Arbovirus en Latinoamérica. Acta Pediatr Mex. 2016; 37 (2): 111-131.

4. AABB Standard 32ed.

5. French HV data: 2006-2011: Sweeney J, Lozano M. Platelet transfusion therapy. Bethesda: AABB Press, 2013. 2012-2013: French National Agency for Medicine and Health Product Safety/ANSM, Hemovigilance Activity Reports.
6. Swiss HV data: SwissMedic Haemovigilance Annual Reports, 2010-2013.

7. Dumont LJ, Dumont DF, Unger ZM et al. A randomized controlled trial comparing autologous radiolabeled in vivo platelet (PLT) recoveries and survivals of 7-day-stored PLT-rich plasma and buffy coat PLTs from the same subjects. Transfusion. 2011; 51 (6): 1241-1248.

\section{El impacto de la biología molecular en Banco de Sangre (NAT)}

QB Martínez Pablo Gladys*

* Química en el Banco de Sangre y Medicina Transfusional en el Instituto Nacional de Pediatría.

El objetivo principal del Banco de Sangre es ofrecer productos sanguíneos. El riesgo de transmisión de los virus (VIH, VHB y VHC) a través de la sangre ha disminuido, debido a que actualmente se cuenta con reactivos serológicos de tercera y cuarta generación y el uso de la inactivación de patógenos en los diferentes productos sanguíneos. Sin embargo, la tecnología de ácidos nucleicos (NAT) nos permite detectar la presencia del material genético del virus en la sangre antes que los ensayos serológicos sean positivos; logrando con esta tecnología el acortar el periodo de ventana.

Las pruebas de NAT parten del principio de la reacción en cadena de la polimerasa (PCR), obteniendo resultados altamente específicos y sensibles para la determinación de los virus de VIH, VHC y VHB. En la actualidad, contamos con pruebas comerciales: a) PCR, es la amplificación basada en la reacción en cadena de la polimerasa en donde se producen gran número de copias de ADN virales que serán detectadas colorimétricamente y b) TMA, es la amplificación basada en la transcripción en donde se generan millones de copias de ARN y que serán detectadas por las unidades relativas de luz generadas.

La decisión de implementar una tecnología depende de la incidencia de la enfermedad, forma de transmisión y la valoración del costo/beneficio. La implementación de NAT en el instituto de tercer nivel se basa en aumentar la seguridad transfusional de nuestros pacientes pediátricos reduciendo el periodo de ventana serológico e identificando a los virus en etapas tempranas de cero conversión. Considerando a nuestra población pediátrica, en el año 2008 se empezó a trabajar NAT en minipooles de seis y en 2018 se migra a la técnica de TMA en muestras individuales (Tabla 1 ).

La tecnología NAT en minipool se realizó en el analizador COBAS $^{\circledR}$ AMPLICOR, en donde el proceso era semiautomatizado; hubo una mejora en la tecnología COBAS, migrando al nuevo instrumento $\mathrm{COBAS}^{\circledR} \mathrm{Am}$ pliPrep, el cual automatizó la purificación del ADN y el ARN mediante una tecnología de perlas magnéticas, una vez obtenida la extracción, el material genético se pasa al termociclador para terminar el proceso de amplificación y detección. Para tener una integración completa del proceso sin manipulación de los purificados de ADN y ARN se cambió a la nueva tecnología el sistema COBAS 201, esta nueva tecnología es una PCR en tiempo real automatizada, con tecnología de multimarcadores fluorescentes y diseño modular, es 


\begin{tabular}{lcccc} 
Tabla 1: Comparación de los periodos de ventana. \\
\begin{tabular}{l} 
Días \\
\hline Virus
\end{tabular} & Serología & NAT (pool) & NAT individual & TMA \\
\hline HIV & 16 & 10 & 7 & 4 \\
VHC & 70 & 9 & 7 & 3 \\
VHB & 59 & 49 & 38 & 16 \\
\hline
\end{tabular}

\begin{tabular}{lrrr} 
& Tabla 2: Total de donadores estudiados. \\
\hline Marcador & Hombre & Mujeres & Todas \\
\hline HIV & 42,833 & 21,981 & 64,814 \\
Positivos & $\mathbf{1 3}$ & $\mathbf{5}$ & $\mathbf{1 8}$ \\
VHC & 42,851 & 21,980 & 64,831 \\
Positivos & $\mathbf{1 2}$ & $\mathbf{1 0}$ & $\mathbf{2 2}$ \\
VHC & 42,847 & 22,135 & 64,982 \\
Positivo & $\mathbf{6}$ & $\mathbf{1}$ & $\mathbf{7}$ \\
& & Total & $\mathbf{1 9 4 , 6 7 2}$ \\
\hline
\end{tabular}

NAT $=$ 2008-2018. TMA $=$ 2018-Julio de 2021.

decir, se integra todo el proceso: extracción, amplificación y detección.

Todos estos cambios tecnológicos ayudaron en el proceso de análisis y la confiabilidad de los resultados. Pero se seguía trabajando en minipooles de seis y si algún pool era reactivo se tenían que resguardar seis unidades de sangre para su posterior apertura y saber hacia qué virus era reactivo. En 2018 se realiza un cambio en el procesamiento de las muestras por la tecnología NAT y se migra de manera contundente al análisis por la tecnología TMA. Se instala en un instituto de tercer nivel el primer equipo Procleix ${ }^{\circledR}$ Panther $^{\circledR}$ System con tecnología completamente automatizada, trabaja con muestras individuales y se obtienen resultados en un corto tiempo. Necesitó de poco espacio debido a que es un equipo integrado, disminuye el error humano al no manipular las muestras y requerir de un mínimo de manipulación en todo el proceso, se trabaja con el tubo primario de la donación y es de flujo continuo (Tabla 2). Durante el tiempo que se ha estudiado a los donadores de sangre por las técnicas moleculares, no se ha identificado ningún caso con infección viral (VHB, VHC y $\mathrm{VIH}$ ) en periodo de ventana serológica; únicamente se demostró NAT positivo en donadores con pruebas serológicas positivas. Con los resultados obtenidos en el Instituto Nacional de Pediatría (INP), se demostró en donadores de sangre la ausencia de infecciones virales (VHB, VHC y VIH) en periodo de ventana serológica con la prueba de NAT. Es importante seguir trabajando con las pruebas de ácidos nucleicos en pro de la seguridad transfusional.

\section{Referencias}

1. González-Diez R. NAT y seguridad de la transfusión sanguínea. Gac Med Mex. 2004; 140 (Supl. 3):

2. Mtz-Álvarez JC. La biología Molecular y su aplicación en el Banco de Sangre. Una herramienta a nuestro alcance. Gac Med Mex. 2007; 143 (Supl 2):

3. Villanueva M. Experiencia de las pruebas de NAT en el Banco de Sangre del Instituto Nacional de Pediatría. Rev Mex Med Tran. 2009; 2 (Supl. 1): s69-s71

Requisito o discriminación del rechazo de donadores pertenecientes a grupos claves

Palomino Morales $\mathrm{R}^{*}$

* UMAE Hospital de Especialidades, Centro Médico Nacional «Siglo XXI», IMSS. Coordinación de los Servicios Auxiliares para Dx y Tx del Hospital General «Xoco», SEDESA.

\section{I ntroducción}

Los criterios de exclusión, desde un punto de vista metodológico, se basan en el principio de que no toda la población se sitúa en torno a características de contenido, de lugar y de tiempo, adecuadas para el objetivo que se pretende, y que por ende se les debe discriminar de la población muestral. En este sentido y en respuesta a la propagación del VIH/SIDA en la década de los 80 en ciertos grupos poblacionales, los departamentos de salud de todo el mundo determinaron quiénes serían aquellas personas a las que se les prohibiría, de manera temporal o permanente, la donación de sangre, por considerarlas «donantes de alto riesgo».

\section{Criterios de diferimiento en los sistemas de sangre}

En muchos países desarrollados, el VIH es más prevalente entre hombres que tienen sexo con hombres (HSH) que entre la población general.

\section{Estados Unidos}

En Estados Unidos, en 2005, los HSH, los afroestadounidenses y las personas que participan en comportamientos heterosexuales de alto riesgo representaron 49 y $32 \%$ de los nuevos diagnósticos de $\mathrm{VIH}$, respectivamente.

La agencia estadounidense Administración de Alimentos y Medicamentos (FDA, por sus siglas en inglés), sostiene que la ventana de postergación de un año está «respaldada por la mejor evidencia científica que hay disponible». Las mujeres que han sido parejas sexuales de HSH tienen una postergación de un año desde su última exposición. Esta es la misma política que se usa para las parejas sexuales de personas en grupos de alto riesgo. El 27 de mayo de 2016, la FDA aprobó un nuevo cuestionario sobre el historial de los donantes de sangre de uso general en los servicios de sangre, el cual es compatible con el diferimiento de 12 meses.

\section{Unión Europea}

Italia, Letonia, Polonia, Rusia y España son los únicos países europeos que no tienen medidas de diferimiento 
hacia HSH. Se permite la donación si el donante no ha tenido ninguna relación sexual de riesgo, pero no depende de la orientación sexual del donante.

El Reino Unido ha implementado, a partir de noviembre de 2017, una política de diferimiento de tres meses en todos los hombres gais o bisexuales que quieran donar sangre. Sin embargo, esta política no afecta a Irlanda del Norte, que todavía tiene un periodo de postergación de 12 meses.

El Comité de Asesoramiento sobre la Seguridad de la Sangre, Tejidos y Órganos recomendó el cambio de política después de que un estudio concluyera que una restricción total podría violar la legislación sobre igualdad y que el riesgo de que el $\mathrm{VIH}$ alcance el suministro de sangre sólo aumentaría aproximadamente $2 \%$.

En Irlanda, los HSH pueden donar sangre si no han participado en sexo oral o anal con otro hombre desde al menos 12 meses antes de la donación. Esta política entró en vigor a partir del 16 de enero de 2017.

En 2014 el Banco de Sangre de Nueva Zelanda cambió el periodo de diferimiento de cinco años a un año por recomendación de Medsafe. Esta decisión se tomó en gran medida debido a los datos obtenidos recientemente de la transmisión de VIH en Australia, país que ya tenía un diferimiento de un año.

México

Siguiendo esta línea argumentativa, la Norma Oficial Mexicana NOM-253-SAA1-2012, para la disposición de la sangre humana y sus componentes con fines terapéuticos; no hace distinción alguna sobre las preferencias sexuales del candidato a donar. Las consideraciones que más se le acercan tienen que ver con las siguientes cuestiones: prácticas sexuales de riesgo; hábitos de consumo (estupefacientes); y número de parejas sexuales.

En el numeral 6.10.4.7 menciona que se excluirán las personas que tienen mayor probabilidad de infectarse por el virus de la inmunodeficiencia humana, por los virus $\mathrm{B}$ o $\mathrm{C}$ de la hepatitis u otros agentes transmisibles sexualmente y por transfusión, mientras persista el factor de riesgo: a) quienes mantienen prácticas sexuales de riesgo, $y b$ ) los compañeros sexuales de personas infectadas por el virus de la inmunodeficiencia humana, virus $B$ o virus $C$ de la hepatitis o de cualquiera de las personas que indica este apartado.

Por su parte, en el apartado $\mathbf{3 . 2 . 5}$ define «prácticas sexuales de riesgo» como aquella en la que ocurre contacto o traspaso de sangre, secreciones sexuales u otros líquidos corporales de personas que pudieran tener infecciones transmisibles, con sitios del cuerpo de otra persona a través de los cuales el agente infeccioso pudiese penetrar.

\section{Razonamiento tras restricciones}

En 1985 las primeras pruebas que usaban el método ELISA buscaban anticuerpos, es decir, la respuesta del sistema inmunológico al virus. Sin embargo, cuando se usa este método hay un periodo de ventana durante el cual una persona que está infectada de VIH es capaz de propagar la enfermedad a pesar de dar negativo en la prueba del virus. Este periodo de ventana puede durar de tres a seis meses, con una media de 22 días. Todavía se usan análisis basados en métodos ELISA en países desarrollados debido a ser altamente sensibles. En países en desarrollo, estos análisis son a menudo el único método disponible para detectar el VIH en la sangre donada. Para hacer frente al periodo de ventana inherente al uso de estos análisis, se evalúa también si los donantes tienen comportamientos de alto riesgo, uno de los cuales es un historial de actividad sexual con parejas del mismo sexo, entre los donantes potenciales que sean hombres. Entre otros grupos con restricciones similares se encuentran los trabajadores sexuales, los consumidores de drogas por inyección y la gente que vive en países con una prevalencia de VI H elevada (como los del África subsahariana).

Hay pruebas más modernas que buscan el virus directamente, como la prueba del antígeno p24, que busca una parte de la superficie del virus, y las pruebas de amplificación de ácidos nucleicos (NAT) que buscan el material genético del virus. Con estos análisis, el periodo de ventana es más corto, de una duración media de 12 días. Las pruebas combinadas de cuarta generación de $\mathrm{VIH}$ son concluyentes tras tres meses y las pruebas de hepatitis B son concluyentes tras seis meses.

También hay riesgos asociados con los donantes que no son HSH y que dan positivo en la prueba del VIH, lo que puede tener consecuencias muy importantes, ya que la última donación del donante podría haberse producido dentro del periodo de ventana de las pruebas y podría haber entrado en el suministro de sangre, con la posibilidad de infectar a los que reciben los hemoderivados.

La medida de restringir la donación sanguínea a ciertos grupos poblacionales, por considerar que éste es un medio adecuado para conseguir el fin de tener un suministro seguro de sangre para la población, es un camino muy cuestionable, pues aunque el deseo es en cierta medida consistente y racional, la creencia, aun al ser consistente, no es óptima. El creer que las políticas restrictivas a la población clave de alto riesgo, por ser la comunidad más afectada por enfermedades como el VIH/SIDA, logrará dar seguridad al suministro de sangre es tan correcto como aventar una moneda al aire, pues efectivamente la certidumbre es de casi $50 \%$.

Claro está que aunque este tipo de medidas pueden llegar a ser complementadas para mejorar su certidumbre, existen otros medios, como el análisis previo de la sangre donada, que tienen una incertidumbre mínima, por lo que es inevitable notar que las restricciones de los llamados «grupos de alto riesgo» no son el camino más óptimo, ni tampoco el más racional para la consecución de los fines buscados.

\section{Referencias}

1. OMS, "Día Mundial del Donante de Sangre 2005", Organización Mundial de la Salud. Centro de Prensa, 24 de mayo de 2005, Centro de 
Prensa, 24 de mayo de 2005, http://www.who.int/mediacentre/news/ notes/2005/np_wha03/es/index.html

2. 1992 Recommendations for the prevention of Human Immunodeficiency Virus Transmission by Blood and Blood Products Archivado el 29 de junio de 2007 en Wayback Machine.

3. Simon Mallory, "Gran Bretaña permitirá que los hombres homosexuales donen sangre", CNN México, 8 de septiembre de 2011, Simon Mallory, "Gran Bretaña permitirá que los hombres homosexuales donen sangre", CNN México, 8 de septiembre de 2011, http://mexico.cnn. $\mathrm{com} / \mathrm{salud} / 2011 / 09 / 08 / g r a n-b r e t a n a-p e r m i t i r a q u e-l o s-h o m b r e s-$ homosexuales-donen-sangre

4. Sabrina Tavernise ( 23 de diciembre de 2014). [Consultado el 26 de diciembre de 2014] "F.D.A. Easing Ban on Gays, to Let Some Give Blood". New York Times.

5. Lise M. Steven. "Donación de sangre". En: The Journal of the American Medical Association 287, 15, 2002.

6. "LGBTQ+ Donors". Cruz Roja estadounidense. [Consultado el 5 de julio de 2017].

7. Landau E. CNN.com, Banon Gay Men Donating Blood Up held. 14 de junio de 2010. [Último acceso: 17 de junio de 2012] Available in: http:// thechart.blogs.cnn.com/2010/06/14/ban-on-gay-men-donating-bloodupheld/

8. «Criteria for blood donor selection». Comité Libanés de Transfusión de Sangre. Archivado desde el original el 2 de abril de 2019.

9. CDC, "Departamento de Salud y Servicios Humanos. Centros para el Control y la Prevención de Enfermedades", EI VIH en hombres homosexuales (gay), bisexuales y otros hombres que tienen relaciones sexuales con hombres (HSH), 16 de diciembre de 2010. [Último acceso: 17 de junio de 2012] Disponible en: http://www.cdc.gov/hiv/spanish/ $\mathrm{msm} /$ index.htm.

10. "Detailed Eligibility Criteria". Servicio Sanguíneo de Nueva Zelanda. [Consultado el 21 de abril de 2015].

FACT, importancia y experiencia del impacto de la acreditación

Salazar Riojas R*

* Jefe en el Laboratorio de Hematología. Universidad Autónoma de Nuevo León.

La acreditación es un procedimiento mediante el cual un organismo autorizado reconoce formalmente que una organización es competente para llevar a cabo tareas específicas. A medida que continúan los esfuerzos por ampliar los servicios, es fundamental prestar más atención a la calidad, la eficiencia y la eficacia en función de los costos.

La Norma Internacional ISO 15189 aborda los requisitos de calidad y competencia en los laboratorios médicos. Tiene sus orígenes en los requisitos de competencia de la Organización Internacional de Normalización/Comisión Electrotécnica Internacional (ISO/IEC) 17025 y los requisitos del sistema de gestión de calidad (SGC) de la NORMA ISO 9001. El cumplimiento de esos requisitos es una prueba objetiva de que el laboratorio cumple tanto con la competencia técnica como con los requisitos del sistema de gestión que son necesarios para entregar de manera consistente resultados técnicamente válidos.

Fundada en 1996, FACT establece estándares para la práctica médica y de laboratorio de alta calidad en terapias celulares. FACT es una corporación sin fines de lucro cofundada por la Sociedad Internacional de Terapia Celular (ISCT) y la Sociedad Americana de Trasplante de Sangre y Médula (ASBMT) con el propósito de la inspección y acreditación voluntaria en el campo de la terapia celular. La acreditación FACT es el umbral para la excelencia en la terapia celular, incluyendo la médula ósea o el trasplante de sangre del cordón umbilical (TMO). FACT incluye requisitos tanto clínicos como de laboratorio. Recibir una unidad de sangre del cordón umbilical, médula ósea o sangre periférica estimulada de una organización de terapia celular dentro de esta prestigiosa comunidad de organizaciones acreditadas por FACT asegurará a los clientes que están en buenas manos. Las pruebas de diagnóstico suelen implicar procesos complejos de varios pasos sujetos a múltiples fuentes de error. Estudios realizados en los Estados Unidos y Europa han demostrado que se producen errores a lo largo del proceso de ensayo, incluida la etapa preanalítica (recogida, etiquetado y transporte de muestras); etapa analítica (pruebas en el laboratorio); y etapa postanalítica (gestión de datos y presentación de informes sobre los resultados). La mayoría de los errores ocurren fuera del laboratorio en el preanalítico (46-68\%) y etapas postanalíticas (18-47\%). Esto no incluye los errores basados en la clínica que ocurren al decidir qué pruebas ordenar y en la interpretación de los resultados de las pruebas, ambas áreas de alto riesgo de error. La frecuencia de errores durante la etapa analítica es menor pero sigue siendo significativa, se estima entre el 7 y $12 \%$, a pesar de años de regulación de la gestión de la calidad. En los Estados Unidos, se estima que de 6 a 12\% de los errores de laboratorio ponen a los pacientes en riesgo de atención inadecuada y potencialmente de eventos adversos, mientras que de 26 a $30 \%$ de los errores tienen un impacto negativo en otros aspectos de la atención.

Las fuentes de errores incluyen: falta de competencia del operador o incumplimiento de los procedimientos de prueba estándar; almacenamiento o caducidad incorrecta del reactivo e inexactitud del instrumento. También se pueden introducir errores durante la recogida, el etiquetado y el transporte de las muestras, el registro en el laboratorio o la transcripción y entrega de los resultados. Combinados, estos errores pueden llevar a la variación significativa en la exactitud del resultado divulgado, llevando en algunos casos a la diagnosis incorrecta, al tratamiento inadecuado, o a la retención de la terapia salvavidas.

El impacto de la acreditación de laboratorio en la atención al paciente:

El último informe del Instituto de Medicina (IOM) titulado «Improving Diagnostics in Health Care» se centra enteramente en los errores de diagnóstico y está destinado a mejorar el diagnóstico en la atención médica. Tres de los ocho objetivos proporcionados por el comité que crea el informe tienen vínculos directos con la acreditación de laboratorios, a saber, el objetivo número 2, mejorar la educación y capacitación de los profesionales de la salud en el proceso de diagnóstico; objetivo número 4, desarrollar e implementar enfoques para identificar, aprender y reducir los errores de diagnóstico y los cuasi accidentes en la práctica clínica; y la meta número 5, establecer un sistema de trabajo y una cultura que apoye el proceso de diagnóstico y las mejoras en el rendimiento diagnóstico. La acreditación proporciona los medios perfectos para abordar estos objetivos. 
La variabilidad de los resultados de las pruebas y la frecuencia de errores pueden reducirse mediante la implementación y supervisión de un sistema integral de gestión de la calidad de laboratorio. Esto ha incluido la participación en pruebas de aptitud regulares (PT), que es un requisito previo para cualquier sistema de acreditación para laboratorios clínicos. La acreditación proporciona la verificación de que los laboratorios se adhieren a los estándares de calidad y competencia establecidos que se consideran necesarios para las pruebas precisas y confiables del paciente y la seguridad del personal y el medio ambiente.

El impacto de la acreditación en la atención al paciente es primordial. Como tal, estos incluyen: 1) aumentar la confianza del paciente y la confianza en el sistema de atención médica; 2) disminución en el número de casos que viajan al extranjero para buscar tratamiento médico y diagnóstico preciso; 3) aumento del rigor en la concesión de licencias, competencias, formación y educación de los profesionales de laboratorio; y 4) estimulación de la innovación, la investigación y los nuevos descubrimientos. Con base en lo anterior, las autoridades sanitarias de los Emiratos Árabes Unidos insisten ahora en la acreditación como medio para mejorar la atención al paciente. Con la introducción de la acreditación hay más demandas para contratar tecnólogos bien capacitados y calificados, invertir en una infraestructura sólida y empujar el listón a un nivel más alto.

La adhesión a los estándares de calidad y la participación en programas de acreditación que certifican esta adhesión pueden mejorar la eficiencia operativa y el servicio al cliente y reducir las tasas de errores de laboratorio. Tener un punto de referencia internacional es otra gran ventaja de la acreditación que puede afectar la atención al paciente. Tomemos por ejemplo una métrica de calidad simple, como el rechazo de muestras y cómo el seguimiento y la direccionamiento de esta métrica única pueden afectar la atención oportuna y efectiva. Muchos otros indicadores que se utilizan para medir objetivamente la eficacia del programa de gestión de la calidad tendrán efectos similares, si no más significativos, en la atención al paciente. El examen citológico de los frotis cervicales es otro ejemplo en el que la mejora de la calidad de la notificación está muy relacionada con mejores resultados para los pacientes y los beneficios de la detección temprana del cáncer de cuello uterino.

La acreditación promueve la confianza en los laboratorios y la confianza entre las autoridades, los proveedores de atención médica y los pacientes de que los laboratorios y los resultados que producen son precisos y confiables. Los laboratorios exitosos pueden justificar los recursos que necesitan para mantener la calidad. EI aumento de los recursos, a su vez, ayuda a mejorar la capacidad del laboratorio y puede aumentar el rendimiento. El reto para muchas redes de laboratorios hoy en día es mejorar visiblemente su rendimiento a un nivel en el que este tipo de refuerzo positivo comience a surtir efecto.

Por último, cultivar una cultura de calidad en cualquier organización requiere tiempo. La ventaja de la acreditación radica en su utilidad como herramienta transformadora para cualquier laboratorio u organización que busque la excelencia en el desempeño. La mejora continua sigue como una progresión natural que conduce a una mejora gradual y constante en la calidad, el rendimiento y los resultados. Trevor Peter y colaboradores afirmaron que es probable que la acreditación tenga efectos indirectos en el desempeño de otras áreas del sistema de salud. Las mejoras impulsadas por el laboratorio pueden ayudar a mejorar la gestión de la atención médica de manera más amplia. Por ejemplo, la mejora de la cadena de suministro requiere mejores habilidades de previsión y mejores sistemas de gestión de inventario y seguimiento del consumo. El proceso de actualización de estos sistemas en el ámbito nacional también podría beneficiar a los sistemas de la cadena de suministro de medicamentos. Además, el ejemplo de la acreditación de laboratorios, con sus procesos establecidos y estructurados, normas definidas y organismos de acreditación, puede demostrar los beneficios de la evaluación sistemática del desempeño y la mejora continua de la calidad, así como catalizar el impulso para mejorar la atención al paciente en todo el sistema de atención médica.

Las organizaciones acreditadas por FACT voluntariamente buscan y mantienen la acreditación a través de un proceso riguroso, demostrando su creencia de que las necesidades del paciente son primordiales. Recibir atención de una organización de terapia celular dentro de la prestigiosa comunidad de organizaciones acreditadas por FACT puede hacer que confíe en que está en buenas manos. La acreditación proporciona medios perfectos para construir laboratorios médicos de calidad, y ayuda a mejorar el diagnóstico en la atención médica y la seguridad del paciente. Se alienta a las autoridades sanitarias a considerar la acreditación como uno de los medios para mejorar la seguridad y la atención. Además pueden ayudar a impulsar mejoras en la gestión de laboratorios individuales y redes de laboratorios, asimismo pueden tener efectos indirectos positivos en el rendimiento de otros sectores del sistema sanitario.

Como paciente, la acreditación FACT puede garantizar que la organización de atención médica que elija está comprometida con la atención de calidad.

\section{Referencias}

. Marmor S, Begun JW, Abraham J, Virnig BA. The impact of center accreditation on hematopoietic cell transplantation (HCT). Bone Marrow Transplant. 2015; 50 (1): 87-94. doi: 10.1038/bmt.2014.219.

2. Anthias C, O'Donnell PV, Kiefer DM, Yared J, Norkin M, Anderlini P et al. European Group for Blood and Marrow Transplantation Centers with FACT-JACIE accreditation have significantly better compliance with related donor care standards. Biol Blood Marrow Transplant. 2016; 22 (3): 514-519. doi: 10.1016/j.bbmt.2015.11.009.

3. Anthias C, Ethell ME, Potter MN, Madrigal A, Shaw BE. The impact of improved JACIE standards on the care of related BM and PBSC donors. Bone Marrow Transplant. 2015; 50 (2): 244-247. doi: 10.1038/ bmt.2014.260.

4. http://www.factwebsite.org/Standards/ 
Donación altruista: estrategias de difusión en el CETS Veracruz

TS Ramírez Ortiz S,* Dr. Santiesteban González $\mathrm{S}^{\ddagger}$

* Centro Estatal de la Transfusión Sanguínea de Veracruz. ‡ Director del Centro Estatal de la Transfusión Sanguínea de Veracruz.

Como parte de su programa estratégico para promover la cultura de la donación de sangre, la Organización Mundial de la Salud (OMS) llegó a considerar que en el año 2020 todos los países deberían obtener suministro de sangre de donaciones voluntarias. Sin embargo, en países como México aún prevalece la donación por reposición.

Es justo en el contexto mexicano que el Centro Nacional de la Transfusión Sanguínea, en conjunto con los Centros Estatales, trabajan con estrategias diversas para incrementar los niveles de donación altruista y con ello llegar a consolidar una cultura de la donación.

El caso particular del Centro Estatal de la Transfusión Sanguínea en Veracruz (CETS) ha encontrado en las redes sociales los medios o canales de difusión de contenidos para sensibilizar a una sociedad acostumbrada a la donación por reposición.

El objetivo de esta ponencia es reflexionar y compartir parte de las experiencias que en el uso de redes sociales se ha tenido para ir consolidando una cultura de la donación altruista. Si bien es cierto que es un trabajo en ciernes, también se puede reconocer la utilidad de las redes sociales para difundir y vincularse con la sociedad civil en general, pero también con las empresas, el sector educativo, grupos religiosos y la Defensa Nacional.

\section{I ntroducción}

Remitirse a la historia de la transfusión sanguínea es reconocer que existen antecedentes que nos remontan al año 1628, cuando William Harvey por primera vez habla de la circulación y las propiedades de la sangre; primer paso que conduciría a los trabajos de Baptiste Denys en Francia y Richard Lower en Inglaterra, quienes realizan las primeras transfusiones de animales a humanos, con resultados poco significativos que llevaron a su prohibición.

Aquellos cimientos permitieron que ya en el siglo XIX se tuvieran experiencias vinculadas a las primeras transfusiones exitosas, particularmente para atender hemorragias postparto. Sería en la segunda parte de aquel siglo cuando el cirujano Joseph Lister emplea antisépticos para controlar las infecciones que provocaban las transfusiones.

A inicios del siglo XX, Karl Landsteiner descubre que las personas tienen distintos grupos sanguíneos y logra describir el sistema ABO. Es en 1914 durante la primera guerra mundial cuando se logra la conservación de la sangre, para que en 1921 corresponda a la Cruz Roja crear la primera entidad de donantes de sangre del mundo.

Sería en la primera mitad del siglo XX cuando en México se vive una serie de experiencias importantes en la historia de la transfusión sanguínea y la creación de los bancos de sangre. Se reconoce como los padres de la transfusión sanguínea en el país a los médicos Matías D
Beistegui, Francisco Javier Vértiz, Narciso Cosío y José Aguilar Álvarez. Sería después de aquellas experiencias cuando se crean los primeros bancos de sangre de los Centros Médicos Nacionales. ${ }^{1}$

A partir de aquellas experiencias, es el 24 de noviembre de 1982 cuando se crea el Centro Nacional de la Transfusión Sanguínea, cuyo objetivo es realizar las funciones de control y vigilancia sanitaria de los actos de disposición de sangre y sus componentes, conforme a la Ley General de Salud, formar recursos humanos en el campo de la transfusión sanguínea y desarrollar e impulsar las investigaciones en el campo de la medicina transfusional. ${ }^{2}$ Es en el año 2004 cuando la Organización Mundial de la Salud (OMS), en honor a Karl Landsteiner, designa el 14 de junio como el Día Mundial del Donante de Sangre, para reconocer y agradecer a los donantes de sangre de todo el mundo, ya que con este gesto solidario y comprometido, contribuyen a salvar vidas y mejorar la salud del semejante.

En ese contexto, la donación altruista se ha concebido como una práctica que garantiza sangre segura; en México corresponde al Centro Nacional de la Transfusión Sanguínea (CNTS) y a los Centros Estatales definir políticas y estrategias que sensibilicen y faciliten este tipo de donaciones en sus entidades.

\section{Desarrollo}

El Centro Estatal de la Transfusión Sanguínea (CETS) de Veracruz, a partir de las políticas implementadas por el CNTS y de los compromisos institucionales que el gobierno federal ha suscrito con la OMS, ha implementado diferentes estrategias para promover la cultura de la donación altruista.

En tal sentido, para continuar con el trabajo que se ha realizado en el Departamento de Promoción de la Donación Altruista de Sangre del CETS, a finales del año 2019 y a partir de la exploración que se hiciera para saber qué tanta información y conocimiento la sociedad veracruzana tenía sobre la donación de sangre, se consideró la importancia de educar a la sociedad en materia de donación altruista de sangre. Se apostó por el fomento de la cultura de la donación altruista desde una perspectiva del conocimiento.

Con otras palabras, se diría que para el CETS un donante informado es aquel que sabe de la importancia de la donación, distingue entre donación altruista y, por reposición, reconoce que la donación altruista garantiza la calidad de la sangre y con ello se contribuye a salvar vidas, por lo que es un ciudadano comprometido con la donación recurrente. En virtud de lo anterior, el diseño e implementación de una campaña de divulgación y difusión sobre la donación altruista partió de reconocer el papel que están jugando hoy día las redes sociales en distribución de contenidos, especialmente en el caso de Facebook, Instagram y Twitter, donde fue necesario el establecimiento de objetivos, metas y tipo de contenido que se iban a compartir a través de las redes sociales. Justo en este sentido, sin duda ha sido la creación de la fan page del CETS la decisión que reorientó el trabajo de difusión del centro. 
Si en la vida cotidiana de las personas las redes sociales han reinventado los procesos de socialización y reconocimiento, se juzgó oportuno y pertinente el empleo de estas redes digitales, siempre procurando un manejo institucional de la información que en ellas se comparte.

\section{Las estrategias}

Consistieron en reconocer el tipo de público usuario en cada una de las redes. En donde puede destacarse el tipo de soporte o formato a través del cual se inició la divulgación de conocimiento:

Infografías: informar sobre qué es la transfusión sanguínea, qué es la donación de sangre, los diferentes tipos de donación, etcétera.

Carteles: manejo de información básica que a través de lo visual y su texto favoreciera la comprensión del tema que en cada uno de ellos se maneja.

Vídeos: manejo de contenido a través de la imagen y el audio, lo que facilitará a los usuarios de las redes sociales el acercamiento a un tema que por el formato permite mayor profundidad en el manejo de la información, pero más fácil para su comprensión.

Quiz: su objetivo en primera instancia es promover la participación de los usuarios de las redes para responder a preguntas relacionadas con la donación; en segunda instancia, acercar conocimiento a quienes no saben las respuestas.

Influencers: su objetivo fue llegar a su público con información de la donación de sangre y la invitación abierta a donar.

Club Por Mis Venas Corre Vida: se pretende que las personas se inscriban para convertirse en donadores de repetición e indiquen cuantas veces al año desean donar, de esa manera, poder contactarlos y recordarles que les toca donar.

Los personajes del CEST: se busca crear cuatro personajes con identidad propia: Plaqui (plaquetas), Plasmi (plasma) Eri (eritrocitos) y Criolín (Crios), que suelen ser empleados en cada uno de los eventos que se organizan, además de ser elementos que acompañan y hacen más amigable el proceso de donación al utilizarse como mascotas o juguetes.

\section{Las campañas}

Te Reto a Donar \#BloodChallenge: su objetivo fue que nuestros donadores altruistas retaran a cinco amigos en sus diferentes redes sociales a realizar una donación. Este reto, además de ser un elemento para invitar a donar, también ampliaba nuestro alcance hacia usuarios que desconocían del tema

Celebra tu cumpleaños donando vida: nuestros donadores en el mes de su cumpleaños acuden a realizar una donación de sangre (esta campaña es permanente por su naturaleza).

Soy Donador Altruista: esta campaña es la que se encuentra en curso actualmente y se ha lanzado a nivel estatal con apoyo de la Dirección de Comunicación Social de los Servicios de Salud de Veracruz y busca captar donadores en todo el estado.

\section{EI reconocimiento a nuestros donadores}

- Publicación y reconocimiento de su donación a través de las redes sociales.

- Entrega de un souvenir alusivo a la donación.

- Participación de algunos donadores en videos promocionales realizados en el CETS.

\section{Vínculos con los sectores sociales}

La vinculación es otra de las estrategias que se han implementado en el CETS para promover la cultura de la donación altruista, donde es posible destacar las pláticas de fomento a la cultura de la donación altruista de sangre que se han dado para algunas organizaciones ciudadanas, empresariales, religiosas y militares y en donde se busca también la formación de promotores comunitarios de la donación altruista de sangre, pues sólo con el compromiso de la sociedad podremos avanzar en este camino.

\section{Reflexiones finales}

Como se espera haber compartido, la donación tiene una larga historia en el mundo. Sin duda, es una de las innovaciones en salud más importantes por la contribución que hacen en la preservación de la salud.

Ha correspondido a las organizaciones del sector salud, tanto internacionales como nacionales, implementar políticas que contribuyan a la cultura de la donación. No obstante, en países como México hay mucho por hacer, ya que no se han alcanzado los índices que la OMS recomienda para garantizar sangre segura para todos.

EI CETS Veracruz, a partir de estos compromisos, ha implementado estrategias de comunicación con un impacto significativo en el aumento de donadores altruistas, que si bien podemos reconocer hemos dado pasos firmes, aún queda mucho por andar, pero creemos que estamos en el camino correcto.

\section{Referencias}

1. Marrón PM. Historia de la transfusión sanguínea. Revista Mexicana de Anestesiología. 2017; 40 (3): 233-238. Disponible en: https://www. medigraphic.com/pdfs/rma/cma-2017/cma173m.pdf.

Secretaría de Salud. Programa de Acción Efectivo. Seguridad de la sangre y de las células Troncales. [Consultado: 27/07/2021]. transfusionsanguineaversion5.pdf (salud.gob.mx). 2013.

Cómo seleccionar donantes de sangre en poblaciones de bajo riesgo basadas en la evidencia científica

Kuperman Silvina Laura*

* Coordinadora de Bancos Asistenciales (Banco de Sangre, Banco Público de Referencia Nacional de Sangre de Cordón Umbilcal y Banco de Tejidos) del Hospitalde Pediatría Garrahan. Buenos Aires, Argentina. 
Los Bancos de Sangre tienen la responsabilidad de recolectar sangre sólo de los donantes denominados de bajo riesgo para cualquier infección que podría ser transmitida a través de la transfusión. Por lo tanto, es esencial un proceso riguroso para evaluar la idoneidad de los donantes potenciales para proteger la seguridad y la suficiencia del suministro de sangre y salvaguardar la salud de los receptores de la transfusión y los donantes de sangre, asegurando que los donantes adecuados no se difieran innecesariamente. Por tal motivo, se debe realizar una adecuada selección de donantes de sangre a través de una historia clínica predonación combinada con estudios de laboratorio altamente sensibles, que disminuya la probabilidad de infecciones en periodo de ventana inmunológica. Esto último sumado al riesgo potencial de que ocurra algún error durante el procesamiento de la muestra, hace indispensable poner en marcha acciones que incluyen la eliminación de la donación de reposición, la información y educación a la comunidad, el diseño de la entrevista predonación basada en: 1) normas y regulaciones vigentes locales; 2) la evidencia científica disponible; y 3 ) datos epidemiológicos locales. Sin embargo, reconocemos que la evidencia de alta calidad sobre la cual basamos las decisiones sobre la idoneidad de los posibles donantes resulta en ocasiones limitada y poco robusta para establecer causalidad entre conductas de riesgo del donante y la transmisión de infecciones por la sangre. En condiciones en las que la evidencia emergente sugiere que los criterios de diferimiento podrían ser más flexibles, se recomienda la aplicación de un enfoque de precaución hasta que se disponga de evidencia científica de mejor calidad metodológica. Aun con el riesgo de diferir a personas innecesariamente y que de esta manera se sientan vulneradas respecto a cumplir el deseo de donar sangre, la decisión se inclina a promover el derecho del paciente a recibir sangre lo más segura posible. El virus de la inmunodeficiencia humana adquirida y las hepatitis virales B y C pueden ser transmitidas mediante las relaciones sexuales entre varón y mujer, así como en las relaciones entre varones. Estos virus pueden transmitirse durante el periodo de ventana y durante la fase asintomática de la infección. Pagar o recibir dinero o drogas para tener sexo, tener múltiples parejas sexuales, practicar sexo sin protección, sexo anal, hombres que tienen sexo con hombres (HSH), y mujeres que tienen relaciones sexuales con HSH. Según Programa Conjunto de las Naciones Unidas sobre el VIH/SIDA ONUSIDA, 2019, denomina poblaciones clave a: 1 ) profesionales del sexo; 2) hombres que tienen relaciones sexuales con hombres; 3 ) personas que usan drogas inyectables; 4) personas transgénero; 5) presos. La planificación de programas para grupos de población clave puede ser más eficaz si se estiman de forma precisa las dimensiones de esos grupos de población. Esas cifras permiten a los programas nacionales sobre sida, a los diferentes ministerios de sanidad, donantes y a las organizaciones establecer criterios sobre la selección del donador. Si bien los datos de vigilancia epidemiológica han demostrado que ciertos comportamientos sexuales están asociados con un mayor riesgo de transmisión del VIH, VHB y VHC, el grado de riesgo varía y puede estar influenciado por factores socioeconómicos nacionales y regionales, específicamente en lo relacionado con estándares de cuidado de la salud, higiene y educación. En lo que se refiere a la seguridad de la sangre, el riesgo también está asociado al tipo de donante, la eficacia del proceso de elegibilidad y de la detección de las infecciones. La implementación del tamizaje molecular, además del serológico, proporciona una alta sensibilidad que reduce significativamente el riesgo de que una donación que contenga el agente infeccioso para el cual se aplica la prueba molecular. A modo de ejemplo, sólo se hará referencia al riesgo relacionado con la conducta de riesgo $\mathrm{HSH}$.

\section{Diferimiento basado en el tiempo}

Tras la aparición de la infección por HIV, en la década de 1980 muchos países introdujeron el diferimiento permanente para los hombres que tienen relaciones sexuales con hombres y desde entonces todos los países han ido cambiando hacia una política basada en un periodo desde la última relación sexual de HSH. En los años 2000 se comenzó a introducir el diferimiento por 12 meses, hasta que en 2017 Reino Unido redujo el diferimiento a tres meses, luego de lo cual otros países fueron tomando la misma política.

El diferimiento permanente de los $\mathrm{HSH}$ por muchos países ha sido criticado por ser selectivamente discriminatorio y carente de rigor científico. Esta política se ha sometido a revisión en algunos países a la luz de tecnologías cada vez más sensibles y fiables para el tamizaje de la sangre donada y la puesta en marcha de la vigilancia epidemiológica de donantes y poblaciones consideradas de «riesgo». Los estudios que utilizan modelos matemáticos para predecir el impacto de la reducción de los intervalos de diferimiento han sugerido que el aumento del riesgo de que una donación que presenta VIH ingrese al suministro de sangre es pequeño, pero no nulo, con poca ganancia en la seguridad de la sangre y con impacto en la cantidad de personas disponibles para donar.

\section{Diferimiento basado en el riesgo individual}

Algunos países tienen políticas basadas en comportamientos sexuales considerados de mayor riesgo independientemente del género de la pareja. Estos incluyen relaciones sexuales con una nueva pareja o varias parejas y el reconocimiento de un comportamiento de riesgo de la pareja.

Los donantes son entrevistados cara a cara por un profesional capacitado, para facilitar una entrevista más detallada y en general las políticas fueron introducidas por decretos o leyes gubernamentales sin una evaluación formal del riesgo o un análisis del impacto.

En 2001, I talia cambió del diferimiento permanente para $\mathrm{HSH}$ al diferimiento por conductas sexuales independientemente del sexo de la pareja. Tanto los hombres como las mujeres son diferidos durante cuatro meses desde 
que tienen relaciones sexuales con una pareja nueva u ocasional, o indefinidamente para las personas que regularmente tienen relaciones sexuales con múltiples parejas nuevas. No se demostraron diferencias significativas cuando compararon las tasas de VIH antes y después del cambio, pero fueron altas en donantes tanto por primera vez como repetidos (12.3 por 100,000 y 3.8 por 100,000 en 2010) en comparación con muchos países del norte de Europa.

En 2018, la tasa de VIH entre los donantes por primera vez en Italia fue de 14.2 cada 100,000 donaciones en comparación con el Reino Unido, en donde la prevalencia del VIH fue de 1.5 cada 100,000 donantes de primera vez.

En España, los donantes se difieren 12 meses a personas que tienen relaciones sexuales con más de una pareja concurrente, o con una pareja ocasional. Los datos publicados hasta 2014 encontraron una prevalencia del VIH de alrededor de 7.7 por 100,000 donaciones, con niveles sólo ligeramente más bajos en donantes repetidos. Los autores informaron tasas similares a las de la población general, lo que sugiere una política de selección ineficaz.

Hay que tener en cuenta que ambos modelos se basan en estudios cuyos resultados sólo son aplicables a las poblaciones estudiadas y a un cálculo de riesgo residual determinado, que se relaciona con condiciones propias tales como: un modelo de donación de sangre basado en donantes $100 \%$ voluntarios y frecuentes, la disponibilidad de prueba de biología molecular para el tamizaje de la sangre donada, implementación de sistemas de calidad supervisados por la autoridad competente, prevalencia en la población general de la infección en cuestión y el alcance de detección de la infección en la población en general.

Si bien es esencial que los Servicios de Sangre identifiquen y difieran a los donantes potenciales cuyo comportamiento sexual los ponga en alto riesgo de contraer enfermedades infecciosas que puedan transmitirse a través de una transfusión, es fundamental que existan políticas públicas enfocadas a identificar y medir conductas que conllevan a aumentar la probabilidad de infecciones, a promover estrategias de educación a la población para su prevención y control del daño, acompañando a los sistemas de hemovigilancia, los cuales son imprescindibles para generar datos de calidad que sean el sustento para la toma de decisiones en los criterios de elegibilidad.

Los criterios de aplazamiento deben ser de fácil comprensión por el personal (el cual debe estar capacitado para tal fin) y los posibles donantes, y acompañado de material informativo, debería facilitar la autoexclusión predonación. Las preguntas de criterios de selección deben ser sometidas a un proceso de validación que asegure la efectividad de la entrevista. Se recomienda la aplicación de un enfoque de precaución, dado que la decisión se inclina a promover el derecho del paciente a recibir sangre lo más segura posible.

Los Servicios de Sangre deben elaborar criterios para definir comportamientos de riesgo y desarrollar las pautas apropiadas para la selección de donantes.
Cada país tiene visiones diferentes sobre lo que son comportamientos aceptables en los donantes y niveles de riesgo, por lo que puede haber diferencias significativas en las pautas de diferimiento entre países. Los criterios deben revisarse con frecuencia, considerando los cambios en la epidemiología de la enfermedad, las mejoras en las tecnologías disponibles para el tamizaje de la donación, el cambio en las conductas en la comunidad, los datos de vigilancia y de la evidencia científica disponible. Mientras que algunos países podrían decidir revisar sus criterios y políticas con la intención de reducir periodos de diferimiento, a otros se les puede requerir que mantengan un enfoque más restrictivo. Una alternativa para definir la elegibilidad basada en conductas sexuales de riesgo, sin tener en cuenta el género del donante, pone el foco en una nueva pareja sexual en un periodo determinado.

El potencial donante no debe donar durante al menos seis meses (podría ser tres meses) si se realizan pruebas moleculares como parte del tamizaje para infecciones transmisibles por transfusión desde la última vez que:

1. Recibió u otorgó dinero o drogas a cambio de sexo.

2. Ha tenido más de una pareja sexual y ha tenido sexo anal con alguna de sus parejas.

3. Ha tenido sexo anal con una nueva pareja sexual (a los efectos de la selección del donante, una nueva pareja es alguien con quien no ha tenido relaciones sexuales antes o una pareja anterior con la que ha reiniciado una relación sexual).

4. Si tiene una relación sexual con una sola pareja, puede donar una vez que hayan transcurrido tres meses desde la fecha del primer contacto sexual, incluso si continúa teniendo sexo anal.

No debe donar durante al menos seis meses (podría ser tres meses si se realizan pruebas moleculares como parte del tamizaje para infecciones transmisibles por transfusión) después del último contacto sexual con una pareja que es, o cree que puede ser:

1. VIH o HTLV positivo.

2. Portador de hepatitis B o C.

3. Una pareja que alguna vez ha recibido dinero o drogas por sexo.

4. Una pareja que alguna vez ha sido usuario de drogas inyectables, incluso hace mucho tiempo o sólo una vez. Esto incluye esteroides y toda droga no prescripta por un médico.

No debe donar durante al menos seis meses (podría ser tres meses si se realizan pruebas moleculares como parte del tamizaje para infecciones transmisibles por transfusión) si:

1. Ha tomado profilaxis previa a la exposición (PrEP) para la prevención del VIH.

2. Ha tomado o le han recetado profilaxis postexposición (PEP) para la prevención del VIH. 
Referencias

1. Revised Recommendations for Reducing the Risk of Human Immunodeficiency Virus Transmission by Blood and Blood Products, Guidance for Industry, U.S. Department of Health and Human Services, Food and Drug Administration, Center for Biologics Evaluation and Research, 2020. [Accessed 11 August 2021] Available in: https://www. fda.gov/regulatory-information/search-fda-guidance-documents/ revised-recommendations-reducing-risk-human-immunodeficiencyvirus-transmission-blood-and-blood

2. Goldman M, Shih Y, O'Brien SF et al. Donor deferral policies for men who have sex with men: past, present and future. Vox Sang. 2018; 113: 95-103.

3. Tiberghien P, Pillonel J, Toujas F et al. Changes in France's deferral of blood donation by men who have sex with men. N Engl J Med. 2017; 376: 1485-1486.

4. Liumbruno GM, Pupella S, Regine $V$ et al. A new questionnaire to improve the effectiveness of pre-donation screening for sexual risk behaviors of HIV infection among blood donors in Italy. Transfusion. 2015; 55: 91A.

5. Bes $\mathrm{M}$, Piron $\mathrm{M}$, Casamitjana $\mathrm{N}$ et al. Epidemiological trends of HIV-1 infection in blood donors from Catalonia, Spain (2005-2014). Transfusion. 2017; 57: 2164-2173.

\section{Plasma convaleciente contra COVID-19}

Dra. Ventura Enríquez Y,* Dra. en C. Fernández Sánchez $\mathrm{V}, \neq$ QFB De la Rosa Cortina $\mathrm{E}^{\S}$

* J efe de Hematología y Hemoterapia. ${ }^{\ddagger}$ Coordinador de Terapia Celular del Banco de Sangre. ${ }^{\S}$ Coordinador del Laboratorio de Hemostasia y Trombosis del Banco de Sangre. Centro Medico Naval, Cd. de México.

\section{SARS-COV-2}

El 07 de enero de 2020, las autoridades chinas identificaron como agente causante del brote un nuevo tipo de virus de la familia Coronaviridae. Los coronavirus son una familia amplia de virus, pero se sabe que sólo siete infectan al humano. El virus tiene una forma pleomórfica redonda con envoltura y espículas en su superficie externa, contiene una estructura simple de RNA. El virus se adhiere a los receptores de las células blanco por medio de las espículas de glucoproteínas. ${ }^{7}$

\section{Enfermedad del Coronavirus SARS-CoV-2}

El periodo de incubación estimado para la COVID-19 es de hasta 14 días desde el momento de la exposición, con un periodo de incubación de cuatro a cinco días. ${ }^{2,3}$ La tasa de mortalidad reportada es de 3.8\%, con mayor riesgo en pacientes mayores de 70 años, independientemente de las condiciones médicas crónicas. ${ }^{4}$ El espectro de la enfermedad puede variar desde una infección asintomática hasta una neumonía con síndrome de dificultad respiratoria aguda (SDRA) y muerte. ${ }^{5}$ Los hallazgos de laboratorio comunes incluyen leucopenia, linfopenia, niveles elevados de aminotransferasas (TGO y TGP), proteína C reactiva, dímero $D$, ferritina y deshidrogenasa láctica. Si bien la COVID-19 es principalmente una enfermedad pulmonar, los datos emergentes sugieren que también conduce a problemas cardiacos, dermatológicos, hematológicos, hepáticos, neurológicos, renales y otras complicaciones. Los eventos tromboembólicos también ocurren en pa- cientes con COVID-19, con mayor riesgo en pacientes críticamente enfermos. ${ }^{6}$

\section{Plasma convaleciente (PC)}

La inmunoterapia con PC es una estrategia de inmunización pasiva que se ha utilizado en la prevención y el manejo de enfermedades infecciosas desde principios del siglo XX. EI PC fue empleado eficazmente contra infecciones virales similares como SARS-CoV y MERS-CoV. El tratamiento con plasma convaleciente se basa en la transferencia exógena de anticuerpos neutralizantes que pueden proporcionar protección a un individuo mientras crea su propia respuesta inmunológica. La terapia con PC es intrínsecamente heterogénea, los diferentes fenotipos de anticuerpos en una respuesta inmune podrían tener diferentes efectos sobre la progresión de la enfermedad. ${ }^{7}$ Un beneficio terapéutico del plasma convaleciente es la activación del complemento o fagocitosis dependiente de anticuerpos, también es una fuente rica en citocinas antiinflamatorias, factores de coagulación, anticuerpos naturales, defensinas, pentraxinas y otras proteínas inmunomoduladoras que podrían controlar el síndrome de respuesta inflamatoria sistémica. ${ }^{8,9} \mathrm{En}$ el caso específico de la enfermedad COVID-19, se presenta una sobreactivación del sistema inmunológico que puede desencadenar hiperinflamación sistémica o «tormenta de citosinas», que ocasionan daño pulmonar (fibrosis y reducción de la capacidad pulmonar), por lo que los mecanismos inmunológicos que proporciona el PC pudieran tener además otros aspectos benéficos. ${ }^{10} \mathrm{EI}$ PC se obtiene mediante aféresis de personas sobrevivientes de infecciones previas provocadas por patógenos de interés en los que se producen anticuerpos contra el agente causal de la enfermedad. ${ }^{9}$

El 23 de agosto de 2020, la Administración de Alimentos y Medicamentos (FDA) emitió la autorización del uso emergente del plasma convaleciente en investigación para el tratamiento de la COVID-19 en pacientes hospitalizados como un tratamiento seguro para el control de la enfermedad. ${ }^{11}$ Existen diferentes estudios controversiales sobre la experiencia que se ha tenido con el uso del PC en la COVID-19, la mayoría se basan en evaluar la eficacia y seguridad del PC, así como encontrar una correlación con la mejoría en pacientes con neumonía por SARS-CoV-2.9 En la actualidad, se encuentran registrados en ClinicalTrials.gov de la NIH 169 ensayos clínicos con PC como tratamiento, de los cuales nueve se llevaron a cabo en México por diferentes instituciones de salud pública y privadas.

\section{Experiencia del uso de plasma convaleciente en el CEMENAV}

En México, la Comisión Federal para la Protección de Riesgos Sanitarios (COFEPRIS) es la institución encargada de autorizar el uso clínico del PC. La autorización indica que se debe hacer la trazabilidad del componente, registro del receptor y resultados en sus variables de laboratorio, signos vitales, variables clínicas y radiográficas. En marzo de 2020, el Centro Médico Naval (CEMENAV), en colaboración con el Hospital General de 
México y el Instituto Nacional de Enfermedades Respiratorias (INER), sometieron a sus respectivos Comités de Investigación, Ética en investigación y de Bioseguridad su primer ensayo clínico aleatorizado, doble ciego de asignación paralela usando PC. Su objetivo fue evaluar la eficacia en la reducción de la tasa de mortalidad en enfermos con COVID-19 en estadio II (moderado) y III (grave) (registro en el Clinical Trials.gov identifier: NCT04405310). La selección, obtención y preparación de los PC se llevó a cabo en el Banco de Sangre de ambas Instituciones. Para este estudio, se incluyeron 39 pacientes que cubrieron los criterios de inclusión, 19 con enfermedad moderada y 20 con enfermedad grave; $16 / 19$ moderados y 13/20 graves recibieron plasma convaleciente. La relación final tratamiento: control fue de 3:1. La mediana de los títulos de anticuerpos IgG antiSARS-CoV-2 en los plasmas convalecientes fue de 1:32. En nuestros resultados encontramos que la mortalidad general en el grupo de plasma fue significativamente menor con respecto al grupo control, sin importar el estadio de la enfermedad, aunque sólo fue significativa en el caso de los pacientes en estado grave (datos en proceso de publicación).

En el grupo de plasma, la media de sobrevida fue significativamente mayor respecto al grupo tratado con albumina. No se presentaron eventos adversos relacionados a la transfusión del plasma o placebo a los participantes del ensayo.

\section{Conclusión}

A pesar de los estudios controversiales con el uso de PC, en nuestra experiencia obtuvimos resultados favorables con su aplicación; sin embargo, reconocemos las limitaciones de este estudio, relacionadas principalmente con el número reducido de pacientes incluidos en ambos grupos, lo que no permitió relacionar significativamente la contribución de diferentes factores de riesgo conocidos con el desenlace. El uso del plasma convaleciente en pacientes con COVID-19 sigue siendo una herramienta emergente que todavía requiere esfuerzos en la investigación de su aplicación, así como de la estandarización de los diferentes procesos que intervienen en las fases de obtención hasta su aplicación.

\section{Referencias}

1. Hopkins J. Coronavirus resource center. Available in: https://coronavirus. jhu.edu/map.html

2. Guan WJ, Ni ZY, Hu Y et al. Clinical characteristics of coronavirus disease 2019 in China. N Engl J Med. 2020; 382 (18): 1708-1720. Available in: https://www.ncbi.nlm.nih.gov/pubmed/32109013

3. Lauer SA, Grantz $\mathrm{KH}, \mathrm{Bi}$ Q et al. The incubation period of coronavirus disease 2019 (COVID-19) from publicly reported confirmed cases: estimation and application. Ann Intern Med. 2020; 172 (9): 577-582. Available in: https://www.ncbi.nlm.nih.gov/pubmed/32150748

4. Hozhabri H, Piceci Sparascio F. The Global Emergency of Novel Coronavirus (SARS-CoV-2): an update of the current status and forecasting. Int J Environ Res Public Health 2020; 17: 5648.

5. Stokes EK, Zambrano LD, Anderson KN et al. Coronavirus disease 2019 case surveillance-United States, January 22-May 30, 2020. MMWR Morb Mortal Wkly Rep. 2020; 69. Available in: https://www.cdc.gov/ mmwr/volumes/69/wr/pdfs/mm6924e2-H.pdf

6. Lauer SA, Grantz KH, Bi Q, et al. The incubation period of coronavirus disease 2019 (COVID-19) from publicly reported confirmed cases: estimation and application. Ann Intern Med. 2020;172(9):577-582. Available in: https://www.ncbi.nlm.nih.gov/pubmed/32150748.

7. Ventura AS, Burgos LD, Scibona $P$ et al. A randomized trial of convalescent plasma in Covid-19 severe pneumonia. NEJM. doi: 10.1056/ NEJMoa2031304

8. Rojas M, Rodríguez Y, Monsalve DM, Acosta-Ampudia Y. Convalescent plasma in Covid-19: Possible mechanisms of action. Autoinmunity reviews. 2020; 19 (7): 102554. doi: 10.1016/j.autrev.2020.102554.

9. Agarwal A, Mukherjee A, Kumar $\mathrm{G}$ et al. Convalescent plasma in the management of moderate covid-19 in adults in India: open-label phase II multicenter randomized controlled trial (PLACID Trial). BMJ. 2020; 371: $\mathrm{m} 3939$.

10. McGonagle D, Sharif K, O'Regan A et al. The role of cytokines including interleukin-6 in COVID-19 induced pneumonia and macrophage activation syndrome-like disease. Autoimmun Rev. 2020; 10.1016/j. autrev.2020.102537. In press:102537

11. Joyner MJ, Senefeld JW, Klassen SA et al. Effect of convalescent plasma on mortality among hospitalized patients with COVID-19: initial three-month experience. medRxiv. Available in: https://oi. org/10.1101/2020.08.12.20169359 